UNIVERSIDADE DE SÃO PAULO

ESCOLA DE EDUCAÇÃO FÍSICA E ESPORTE

\title{
COMPARAÇÃO ENTRE DOIS PROTOCOLOS DE REABILITAÇÃO APÓS RECONSTRUÇÃO DO LIGAMENTO CRUZADO ANTERIOR ATRAVÉS DE ANÁLISE BIOMECÂNICA
}

\author{
Cláudia Silveira Lima
}




\title{
COMPARAÇÃO ENTRE DOIS PROTOCOLOS DE REABILITAÇÃO APÓS RECONSTRUÇÃO DO LIGAMENTO CRUZADO ANTERIOR ATRAVÉS DE ANÁLISE BIOMECÂNICA
}

\author{
CLÁUDIA SILVEIRA LIMA
}

Tese apresentada à Escola de Educação Física e Esporte da Universidade de São Paulo, como requisito parcial para obtenção do grau de Doutor em Educação Física. 


\section{Lima, Cláudia Silveira}

Comparação entre dois protocolos de reabilitação após reconstrução do ligamento cruzado anterior através de análise biomecânica / Cláudia Silveira Lima. - São Paulo : [s.n.], 2006.

xxii, 172p.

Tese (Doutorado) - Escola de Educação Física e Esporte da Universidade de São Paulo.

Orientador: Prof. Dr. Alberto Carlos Amadio

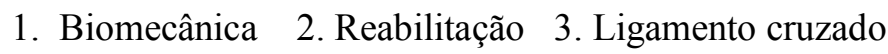
anterior I. Título. 


\section{AGRADECIMENTOS}

Esta chegando ao fim uma longa jornada que começou há seis anos atrás com uma conversa tímida com uma pessoa indescritível, Professor Alberto Carlos Amadio. Durante esta jornada muitas pessoas apoiaram este trabalho de diferentes maneiras e a elas quero deixar registrado meu agradecimento.

Ao meu orientador, Professor Alberto Carlos Amadio, pela oportunidade, pelos conhecimentos transmitidos, pelas inúmeras discussões científicas, pela incansável disponibilidade e pelas colocações imprescindíveis para realização do trabalho. Mas acima de tudo pela amizade, pela compreensão e apoio que sempre estiveram presentes no nosso convívio. Aprendi muito neste tempo e tenho a certeza de ter convivido com uma referência na área da biomecânica e um exemplo de vida.

Ao amigo e colega Professor Antônio Carlos S. Guimarães, por ter sido coresponsável pelo caminho que escolhi em termos profissionais, pelos ensinamentos, pela inspiração, pelas contribuições a este projeto e pela amizade. De alguma forma tu participaste de todos os momentos das minhas conquistas profissionais e concluir este doutorado sem a tua presença não será fácil. Você faz muita falta.

Ao Doutor Arnaldo José Hernandez, por ter confiado no meu trabalho e permitido que os pacientes do grupo do joelho do HC fossem contatados para participar da pesquisa, pela sua atenção e pelas suas contribuições para elaboração do projeto.

Ao Professor Júlio Cerca Serrão, pelo apoio junto ao laboratório propiciando as condições necessárias para que o trabalho fosse desenvolvido e pelas colocações oportunas durante a elaboração do projeto e realização da pesquisa.

Aos médicos do grupo do joelho do $\mathrm{HC}$ por terem me recebido e ajudado no contato com os pacientes durante o período de seleção da amostra.

Aos voluntários da pesquisa, principalmente aos pacientes, pela dedicação e o esforço para cumprir as exigências do protocolo de tratamento. E pela cumplicidade durante os quatro meses de convivência. 
Aos amigos Renato e Alex Sandra, por todo o respaldo no atendimento aos pacientes. Vocês foram essenciais durante o período de tratamento dos pacientes.

Ao amigo Luis Mochizuki por todos os momentos dedicados para me assessorar na resolução de problemas, dos mais simples aos mais complexos.

A todos os colegas e amigos do laboratório que fizeram os momentos de trabalho intenso serem amenizados pelo auto-astral do convívio com vocês.

À Márcia Regina de Sá e a Jaqueline E. Albuquerque por toda a assessoria no desenvolvimento da pesquisa.

À Ilza B. Santos, Maria de Lourdes Silva, Márcio A. do Nascimento, Célia Yamaoka e Maria Lúcia V. Franco pela eficiência nas orientações e o pronto atendimento as solicitações realizadas.

À Capes e à Universidade Federal do Rio Grande do Sul, em especial à Escola de Educação Física, pelo apoio financeiro e administrativo durante este período.

Aos pesquisadores Carlo De Luca, Serge Roy, Alexander Adam e Itzik Melzer, do NeuroMuscular Research Center, pela acolhida e pela oportunidade de aprendizado durante a minha permanência nesta instituição.

Aos amigos Renato, Alex Sandra, Luis, Roberto, Márcia e Kátia por terem sido a minha família em São Paulo. Vocês se tornaram grandes amigos e pessoas especiais para mim.

Aos verdadeiros amigos, Fernando e família e Moacir e família, pelo apoio, pelo companherismo e pela amizade. Obrigado por dividirem comigo os momentos bons e me ampararem nos mais difíceis. Ter vocês ao meu lado em São Paulo foi essencial.

Aos meus pais, Carlos e Yara, por terem me mostrado que o amor e a determinação fazem alcançar os nossos sonhos. O apoio, a confiança e o amor de vocês foram imprescindíveis. Vocês são os maiores exemplos da minha vida.

Aos meus irmãos, Mauro e Daniela, e suas famílias por poder sempre contar com o apoio, o carinho e o amor de vocês.

Em especial, ao meu marido, Jorge Juchem Zanette, por mais uma vez ter me apoiado e, desta vez, transformado a sua vida para enfrentar ao meu lado esta jornada. A tua presença, o teu apoio, a tua dedicação e o teu amor foram indispensáveis para a conclusão da tese. Tu és único, obrigado por fazer parte da minha vida.

E a minha filha, Amanda, que chegou no finalzinho desta jornada para completar a minha vida. 


\section{SUMÁRIO}

Página

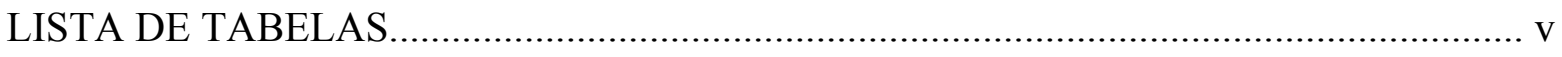

LISTA DE FIGURAS ......................................................................................... vii

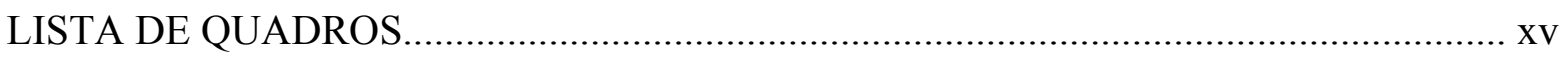

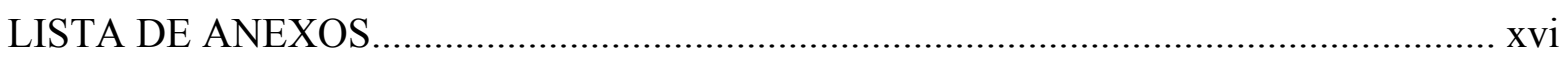

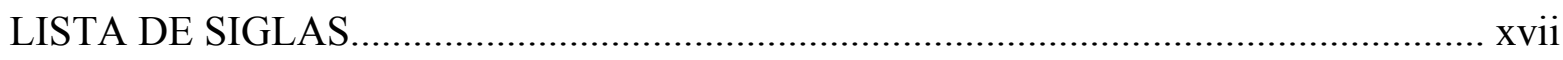

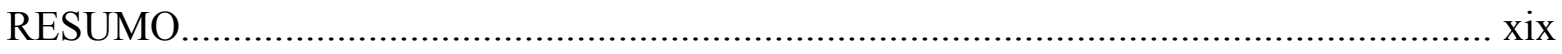

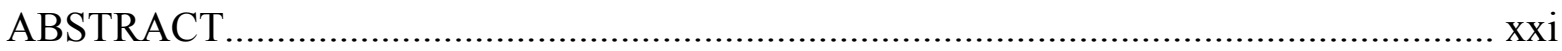

1 INTRODUÇÃO

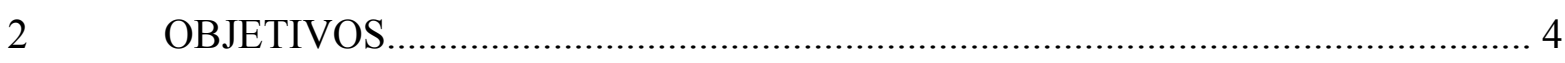

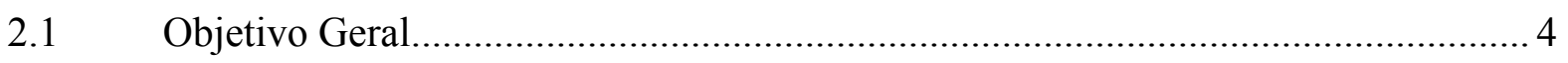

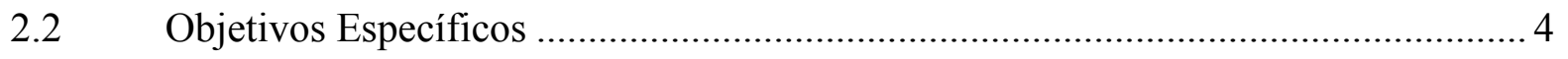

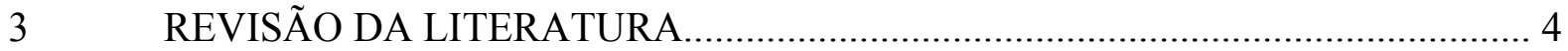

3.1 Efeito dos exercícios em Cadeia Cinética Aberta e Cadeia Cinética Fechada na biomecânica da articulação do joelho ..................................................................... 5

3.2 Marcha e suas relações com o comprometimento do LCA .................................... 19

3.3 Marcha em piso fixo e na esteira rolante .......................................................... 29

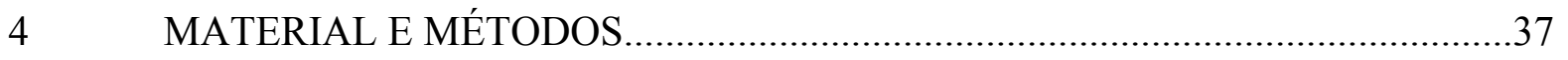

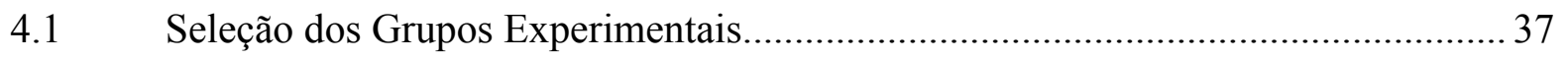

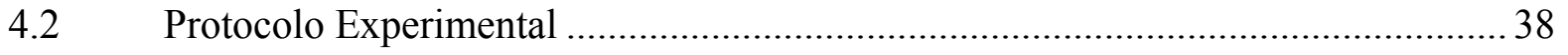

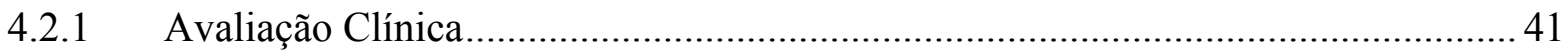

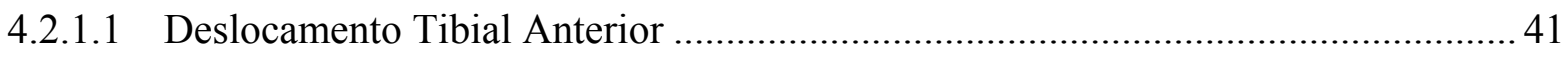

4.2.1.2 Escore de Lysholm - Escala de Avaliação Funcional do Joelho ............................ 42

4.2.2 Avaliação dinâmica, cinemática e eletromiográfica da marcha ............................. 42

4.2.2.1 Determinação das variáveis dinâmicas e cinemáticas: força reação do solo, parâmetros temporais e espaciais do ciclo da marcha.............................................. 43

4.2.2.2 Determinação de variáveis cinemáticas: Variações angulares do joelho ................. 48 
4.2.2.3 Determinação das variáveis eletromiográficas no ciclo da marcha........................ 49

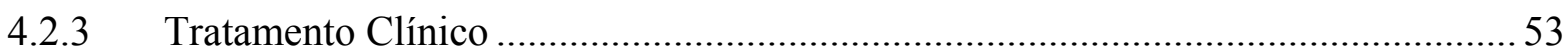

4.3 Tratamento Matemático e Análise Estatística dos Resultados ...............................60

4.4 Controle do Erro Experimental e Limitações Metodológicas ................................. 61

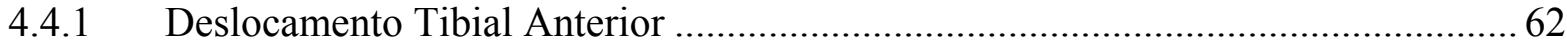

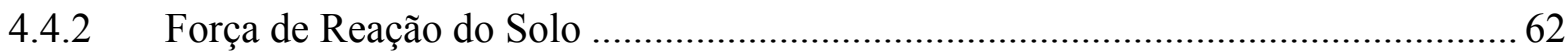

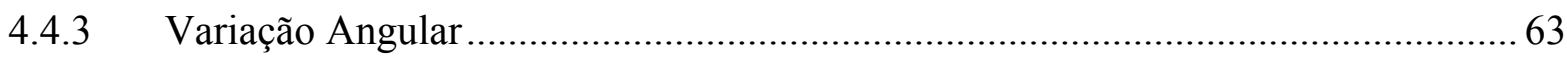

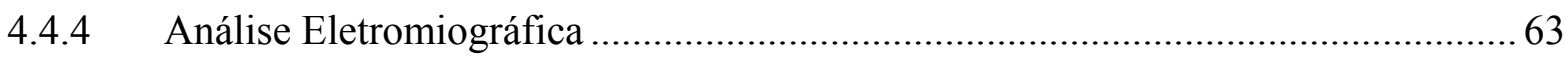

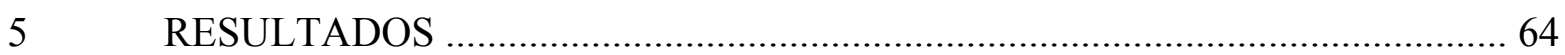

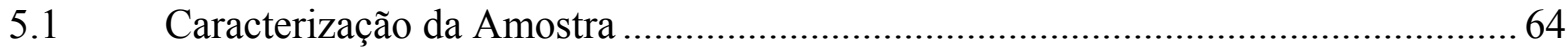

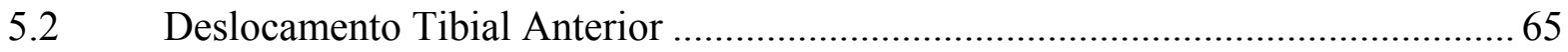

5.3 Escore de Lysholm - Escala de Avaliação Funcional do Joelho ............................. 66

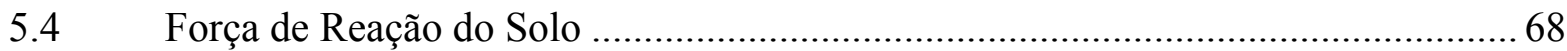

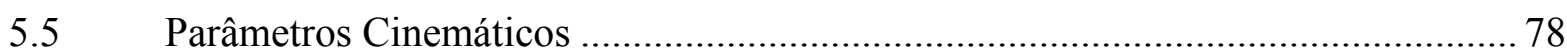

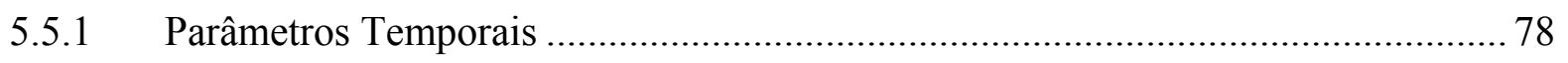

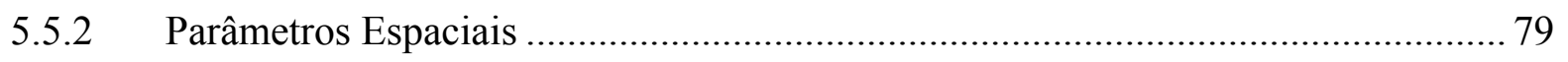

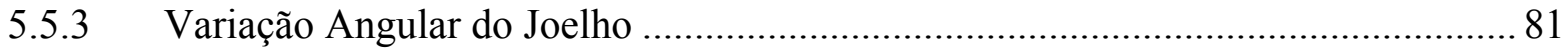

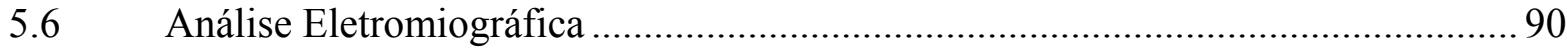

5.7 Simetria em função da lateralidade do acometimento da lesão .............................. 100

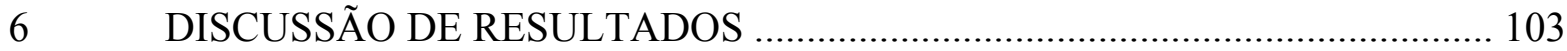

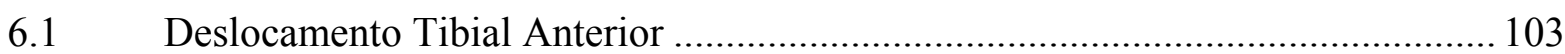

6.2 Escore de Lysholm - Escala de Avaliação Funcional do Joelho ............................ 105

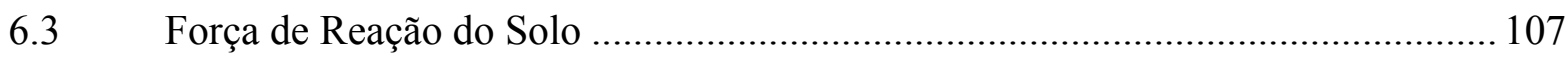

6.4 Parâmetros Cinemáticos ................................................................................... 111

6.4.1 Parâmetros Temporais e Espaciais ...................................................................... 111

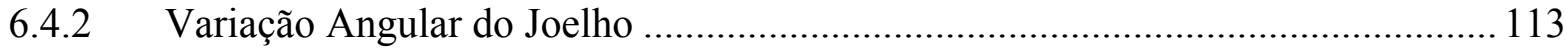

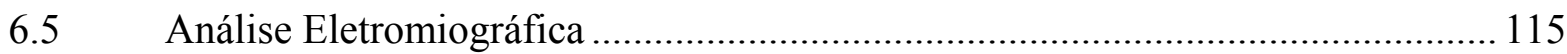

6.6 Simetria em função da lateralidade do acometimento da lesão ............................. 117

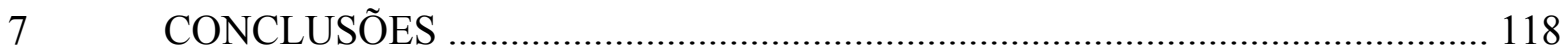

REFERÊNCIAS ................................................. 120

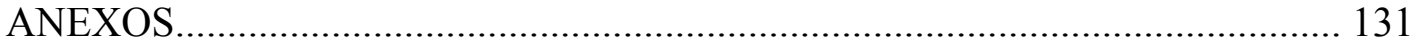




\section{LISTA DE TABELAS}

Página

TABELA 1 - Análise descritiva e distribuição de freqüência das características dos grupos amostrais: controle (CON), cadeia cinética aberta (CCA) e cadeia cinética fechada (CCF) separados por teste: testes 1 (Pré), 2 (1PO) e 3 (4PO), quando necessário

TABELA 2 - Média e desvio padrão das variáveis da força de reação do solo, apresentadas por teste: testes 1 (Pré), 2 (1PO) e 3 (4PO) em cada grupo: controle $(\mathrm{CON})$, cadeia cinética aberta $(\mathrm{CCA})$ e cadeia cinética fechada $(\mathrm{CCF})(\mathrm{n}=10$ em cada grupo $)$

TABELA 3 - Composição dos componentes principais das variáveis relativas à força de reação do solo e seus percentuais acumulados, para os testes 1 (Pré), 2 (1PO) e 3 (4PO).

TABELA 4 - Comparação entre os grupos controle (CON), cadeia cinética aberta (CCA) e cadeia cinética fechada (CCF) $(n=10$ em cada grupo) dos componentes principais das variáveis da força de reação do solo nos testes 1 (Pré), 2 (1PO) e 3 (4PO)......

TABELA 5 - Composição dos componentes principais das variáveis relativas à força de reação do solo e os percentuais acumulados, para os grupos cadeia cinética fechada (CCF) e aberta (CCA) $(\mathrm{n}=10$ em cada grupo).

TABELA 6 - Comparação dos componentes principais das variáveis relativas à força de reação do solo entre testes: 1 (Pré), 2 (1PO) e 3 (4PO) nos grupos controle $(\mathrm{CON})$, cadeia cinética aberta (CCA) e cadeia cinética fechada(CCF) ( $\mathrm{n}=10$ em cada grupo).

TABELA 7 - Média e desvio padrão dos parâmetros temporais da marcha da perna operada (OP) e não-operada (NOP), apresentados por grupo: controle $(\mathrm{CON})$, cadeia cinética aberta (CCA) e cadeia cinética fechada (CCF) (n = 10 em cada grupo) nos testes 1 (Pré), 2 (1PO) e 3 (4PO). 
TABELA 8 - Média e desvio padrão dos parâmetros espaciais da marcha da perna operada (OP) e não-operada (NOP), apresentados por grupo: controle $(\mathrm{CON})$, cadeia cinética aberta (CCA) e cadeia cinética fechada (CCF) (n $=10$ em cada grupo) nos testes 1 (Pré), 2 (1PO) e 3 (4PO).

TABELA 9 - Média dos coeficientes de variação dos envoltórios lineares do sinal eletromiográfico da perna operada (OP) e não-operada (NOP), apresentados por grupo: controle (CON), cadeia cinética aberta (CCA) e cadeia cinética fechada (CCF) $(\mathrm{n}=10$ em cada grupo) nos testes 1 (Pré), 2 (1PO) e 3 (4PO).

TABELA 10 - Média e desvio padrão das simetrias relativas à força de reação do solo, apresentados por grupo: controle (CON), cadeia cinética aberta (CCA) e cadeia cinética fechada (CCF) $(\mathrm{n}=10$ em cada grupo) nos testes 1 (Pré), 2 (1PO) e 3 (4PO).

TABELA 11 - Média e desvio padrão das simetrias relativas as variáveis cinemáticas: parâmetros temporais, parâmetros espaciais e variação angular, apresentados por grupo: controle (CON), cadeia cinética aberta (CCA) e cadeia cinética fechada (CCF) $(\mathrm{n}=10$ em cada grupo) nos testes 1 (Pré), 2 (1PO) e 3 (4PO). 


\section{LISTA DE FIGURAS}

Página

FIGURA 1 - Desenho ilustrativo do direcionamento do vetor de ação do M.quadríceps femoral (Q) e seus componentes vetoriais de deslocamento anteroposterior $\left(\mathrm{Q}_{\mathrm{a}}\right)$ e de compressão $\left(\mathrm{Q}_{\mathrm{b}}\right)$ em exercícios de (a) CCA e (b) CCF (BODOR, 2001).

FIGURA 2 - Média do strain (deformação) do LCA (a) flexo-extensão ativa, (b) contração isométrica do M.quadríceps femoral, (c) contração isométrica dos isquiostibiais e (d) contração simultânea do M.quadríceps femoral e isquiostibiais (BEYNNON et al., 1995)....

FIGURA 3 - Desenho esquemático do modelo proposto, demonstrando a orientação das forças musculares com a mudança do ângulo de flexão $(0,60$ e 120 graus) e com variação no deslocamento tibial anterior $(0,4$ e $8 \mathrm{~mm})$ (IMRAN \& O’CONNOR, 1998)

FIGURA 4 - Efeito da co-contração dos isquiostibiais $(\mathrm{ON}, 125 \mathrm{~N}, 250 \mathrm{~N}$ e $375 \mathrm{~N}$ de força) na translação tibial em (a) $0^{\circ}$ de flexão, (b) $30^{\circ}$ de flexão, (c) $45^{\circ}$ de flexão e (d) $60^{\circ}$ de flexão (IMRAN \& O’CONNOR, 1998)......

FIGURA 5 - Valores médios do strain do LCA produzido pelo agachamento (CCF) e pela flexo-extensão ativa do joelho (CCA) (adaptado de BEYNNON et al., 1997).....

FIGURA 6 - Translação da tíbia de acordo com a variação angular do joelho em diferentes exercícios: extensão do joelho (círculo preenchido), agachamento com centro de gravidade sobre os pés (quadrado), agachamento com centro de gravidade na frente dos pés (círculo sem preenchimento) e agachamento com centro de gravidade atrás dos pés (cruz), (KVIST \& GILLQUIST, 2001). 
FIGURA 7 - Percentual de ativação dos diferentes músculos em ângulos diferentes de flexo-extensão do joelho nos exercícios de extensão do joelho (EJ) e agachamento (AG) (adaptado de KVIST \& GILLQUIST, 2001).............

FIGURA 8 - Foto ilustrativa da forma de execução do teste de Lachman (ACL STUDY GROUP, 2003).

FIGURA 9 - Gráfico da componente vertical da FRS da perna envolvida com lesão e a perna não envolvida de dois grupos de pacientes de LCA: Coper (sem instabilidade no joelho) e Não-Coper (com instabilidade no joelho) (RUDOLPH et al., 1998).

FIGURA 10 - Gráfico da variação angular do joelho da perna envolvida com lesão e a perna não envolvida de dois grupos de pacientes de LCA: Coper (sem instabilidade no joelho) e Não-Coper (com instabilidade no joelho) (RUDOLPH et al., 1998).

FIGURA 11 - Gráfico da componente vertical da FRS da perna envolvida com lesão de pacientes de LCA e de sujeitos sem lesão do LCA (MOTA et al., 2002)..

FIGURA 12 - Gráfico da variação angular do joelho da perna envolvida com lesão de pacientes de LCA e de sujeitos sem lesão do LCA (MOTA et al., 2002)..

FIGURA 13 - Gráfico da variação angular do joelho de sujeitos sem lesão do LCA, com lesão do LCA, com LCA reconstruído fraco e com LCA reconstruído forte (LEWEK et al., 2002).

FIGURA 14 - Gráfico da variação angular do joelho de sujeitos com lesão do LCA e sujeitos saudáveis (DEVITA et al.,1997)

FIGURA 15 - Gráficos da variação angular do joelho de sujeitos com três e cinco semanas de pós-operatório de LCA e sujeitos saudáveis (DEVITA et al., 1997).

FIGURA 16 - Gráficos da variação angular do joelho de sujeitos com três semanas e seis meses de pós-operatório de LCA e sujeitos saudáveis (DEVITA, HORTOBAGYI \& BARRIER, 1998)...

FIGURA 17 - Média do ângulo do joelho nas diferentes cadências em relação à fase da passada (WINTER, 1983a). 
FIGURA 18 - Envelope linear do sinal EMG de cinco músculos em três diferentes cadências (WINTER, 1983a).

FIGURA 19 - Ângulo, momento de força e potência do joelho em relação a fase da passada (WINTER \& ENG, 1983).

FIGURA 20 - Média das componentes da força de reação do solo para perna direita e esquerda, durante a caminhada. (a) componente vertical, (b) componente ântero-posterior e (c) componente médio-lateral (HAMILL, BATES \& KNUTZEN, 1984)......

FIGURA 21 - Média do ângulo de flexão do joelho no momento do contato inicial da fase de apoio para a caminhada em piso fixo e aos 0,2, 4 e 14 minutos da caminhada na esteira (MATSAS, TAYLOR \& MCBURNEY, 2000)..

FIGURA 22 - Diagrama de blocos representando o fluxograma das etapas metodológicas segundo protocolo experimental. Siglas utilizadas: DTA - deslocamento tibial anterior e PO - pós-operatório.

FIGURA 23 - Ilustração do posicionamento do equipamento KT1000.

FIGURA 24 - Fotos ilustrativas dos equipamentos utilizados para avaliação da marcha: esteira rolante com plataformas de força acopladas, eletrogoniômetro e eletromiógrafo

FIGURA 25 - Sistema Gaitway da Kistler: esteira rolante com duas plataformas de força embutidas. (adaptado de GAITWAY, 1996).

FIGURA 26 - Curva esquemática da força reação do solo representando algumas variáveis estudadas: (1) pico de força vertical máxima 1, (2) pico de força vertical máxima 2, (3) força vertical mínima, (4) taxa de crescimento 1, (5) taxa de crescimento 2, (6) deflexão da força. E representação esquemática do que corresponde a passada, o passo, o apoio duplo e o apoio simples. (Adaptado de SACCO, 2001)

FIGURA 27 - Curva esquemática da força reação do solo com representação esquemática do intervalo de tempo que corresponde o tempo de apoio duplo, tempo de apoio simples, tempo do passo e tempo da passada. 
FIGURA 28 - Ilustração do posicionamento do eletrogoniômetro.....

FIGURA 29 - Sistema Bagnoli-8 com oito canais da Delsys (adaptado de WINTER, 1979)

FIGURA 30 - Etapas do tratamento matemático do sinal eletromiográfico do músculo vasto lateral direito para a elaboração dos envoltórios lineares. (A) Sinal EMG bruto. (B) Sinal EMG retificado e retirado o off-set. (C) Sinal EMG retificado (cinza) e sinal filtrado com freqüência de corte de $5 \mathrm{~Hz}$ (preto). (D) Envoltórios lineares.

FIGURA 31 - Ilustração do posicionamento dos eletrodos nos músculos avaliados: (a) vasto lateral e (b) bíceps femoral (cabeça longa).

FIGURA 32 - Fotos ilustrativas do exercício de extensão do joelho. Posição 1: posição inicial e final de execução. Posição 2: posição final da fase ascendente do exercício

FIGURA 33 - Fotos ilustrativas do exercício de extensão do quadril. Posição 1: posição inicial e final de execução. Posição 2: posição final da fase ascendente do exercício.

FIGURA 34 - Fotos ilustrativas do exercício de agachamento. Posição 1: posição inicial e final de execução. Posição 2: posição final da fase descendente do exercício

FIGURA 35 - Gráfico do deslocamento tibial anterior na comparação entre os grupos controle $(\mathrm{CON})$, cadeia cinética aberta (CCA) e cadeia cinética fechada (CCF) $(\mathrm{n}=10$ em cada grupo) nos testes 1 (Pré) e 3 (4PO).

FIGURA 36 - Gráfico do deslocamento tibial anterior na comparação entre testes: testes 1 (Pré) e 3 (4PO) por grupo: controle (CON), cadeia cinética aberta (CCA) e cadeia cinética fechada (CCF) $(\mathrm{n}=10$ em cada grupo).

FIGURA 37 - Gráfico do valor do escore de Lysholm na comparação entre os grupos controle $(\mathrm{CON})$, cadeia cinética aberta $(\mathrm{CCA})$ e cadeia cinética fechada $(\mathrm{CCF})(\mathrm{n}=10$ em cada grupo) nos testes 1 (Pré) e 3 (4PO) 
FIGURA 38 - Gráfico do valor do escore de Lysholm na comparação entre os testes 1 (Pré) e 3 (4PO)em cada grupo: controle $(\mathrm{CON})$, cadeia cinética aberta (CCA) e cadeia cinética fechada $(\mathrm{CCF})(\mathrm{n}=10 \mathrm{em}$ cada grupo).

FIGURA 39 - Gráficos da componente vertical da força de reação do solo da perna operada ou direita (OP/D) e da perna não-operada ou esquerda (NOP/E) durante a fase de apoio da marcha na comparação entre grupos: controle $(\mathrm{CON})$, cadeia cinética aberta (CCA) e cadeia cinética fechada (CCF) (n = 10 em cada grupo) no Teste 1 (Pré).

FIGURA 40 - Gráficos da componente vertical da força de reação do solo da perna operada ou direita (OP/D) e da perna não-operada ou esquerda (NOP/E) durante a fase de apoio da marcha na comparação entre grupos: controle $(\mathrm{CON})$, cadeia cinética aberta (CCA) e cadeia cinética fechada (CCF) (n $=10$ em cada grupo) no Teste 2 (1PO)

FIGURA 41 - Gráficos da componente vertical da força de reação do solo da perna operada ou direita (OP/D) e da perna não-operada ou esquerda (NOP/E) durante a fase de apoio da marcha na comparação entre grupos: controle $(\mathrm{CON})$, cadeia cinética aberta (CCA) e cadeia cinética fechada (CCF) (n $=10$ em cada grupo) no Teste 3 (4PO).

FIGURA 42 - Gráficos da componente vertical da força de reação do solo da perna operada ou direita (OP/D) e da perna não-operada ou esquerda (NOP/E) durante a fase de apoio da marcha na comparação entre os testes 1 (Pré), 2 (1PO) e 3 (4PO), do grupo cadeia cinética fechada (CCF) $(n=10)$. A curva do grupo controle aparece como referência.

FIGURA 43 - Gráficos da componente vertical da força de reação do solo da perna operada ou direita (OP/D) e da perna não-operada ou esquerda (NOP/E) durante a fase de apoio da marcha na comparação entre os testes 1 (Pré), 2 (1PO) e 3 (4PO), do grupo cadeia cinética aberta (CCA) $(n=10)$. A curva do grupo controle aparece como referência 
FIGURA 44 - Gráficos da variação angular do joelho da perna operada ou direita (OP/D) e da perna não-operada ou esquerda (NOP/E) durante a fase de apoio da marcha na comparação entre grupos: controle $(\mathrm{CON})$, cadeia cinética aberta $(\mathrm{CCA})$ e cadeia cinética fechada $(\mathrm{CCF})(\mathrm{n}=10$ em cada grupo) no Teste 1 (Pré)

FIGURA 45 - Gráficos da variação angular do joelho da perna operada ou direita (OP/D) e da perna não-operada ou esquerda (NOP/E) durante a fase de apoio da marcha na comparação entre grupos: controle $(\mathrm{CON})$, cadeia cinética aberta $(\mathrm{CCA})$ e cadeia cinética fechada $(\mathrm{CCF})(\mathrm{n}=10$ em cada grupo) no Teste 2 (1PO)

FIGURA 46 - Gráficos da variação angular do joelho da perna operada ou direita (OP/D) e da perna não-operada ou esquerda (NOP/E) durante a fase de apoio da marcha na comparação entre grupos: controle $(\mathrm{CON})$, cadeia cinética aberta (CCA) e cadeia cinética fechada $(\mathrm{CCF})(\mathrm{n}=10$ em cada grupo) no Teste 3 (4PO)

FIGURA 47 - Gráficos da variação angular do joelho da perna operada ou direita (OP/D) e da perna não-operada ou esquerda $(\mathrm{NOP} / \mathrm{E})$ durante a fase de apoio da marcha na comparação entre os testes 1 (Pré), 2 (1PO) e 3 (4PO), do grupo cadeia cinética fechada $(\mathrm{CCF})(\mathrm{n}=10)$. A curva do grupo controle aparece como referência

FIGURA 48 - Gráficos da variação angular do joelho da perna operada ou direita (OP/D) e da perna não-operada ou esquerda (NOP/E) durante a fase de apoio da marcha na comparação entre os testes 1 (Pré), 2 (1PO) e 3 (4PO), do grupo cadeia cinética aberta $(\mathrm{CCA})(\mathrm{n}=10)$. A curva do grupo controle aparece como referência

FIGURA 49 - Gráfico da diferença pico a pico do movimento articular do joelho da perna operada (OP) e não-operada (NOP) durante as fases de apoio e balanço da marcha nos grupos controle $(\mathrm{CON})$, cadeia cinética aberta (CCA) e cadeia cinética fechada(CCF) $(\mathrm{n}=10$ em cada grupo) no Teste 1 (Pré).... 
FIGURA 50 - Gráfico da diferença pico a pico do movimento articular do joelho da perna operada (OP) e não-operada (NOP) durante as fases de apoio e balanço da marcha nos grupos controle (CON), cadeia cinética aberta (CCA) e cadeia cinética fechada(CCF) $(\mathrm{n}=10$ em cada grupo)no Teste $2(1 \mathrm{PO}) \ldots$

FIGURA 51 - Gráfico da diferença pico a pico do movimento articular do joelho da perna operada (OP) e não-operada (NOP) durante as fases de apoio e balanço da marcha nos grupos controle $(\mathrm{CON})$, cadeia cinética aberta $(\mathrm{CCA})$ e cadeia cinética fechada(CCF) $(n=10$ em cada grupo) no Teste 3 (4PO)..

FIGURA 52 - Gráfico da diferença pico a pico do movimento articular do joelho da perna operada (OP) e não-operada (NOP) durante as fases de apoio e balanço da marcha na comparação entre os testes 1 (Pré), 2 (1PO) e 3 (4PO), do grupo cadeia cinética fechada $(\mathrm{CCF})(\mathrm{n}=10)$.

FIGURA 53 - Gráfico da diferença pico a pico do movimento articular do joelho da perna operada (OP) e não-operada (NOP) durante as fases de apoio e balanço da marcha na comparação entre os testes 1 (Pré), 2 (1PO) e 3 (4PO), do grupo cadeia cinética aberta $(\mathrm{CCA})(\mathrm{n}=10)$.

FIGURA 54 - Gráficos dos envoltórios lineares do sinal eletromiográfico dos músculos M.vasto lateral e M.bíceps femoral da perna operada ou direita (OP/D) e da perna não-operada ou esquerda (NOP/E) na comparação entre grupos: controle $(\mathrm{CON})$, cadeia cinética aberta (CCA) e cadeia cinética fechada (CCF) $(\mathrm{n}=10$ em cada grupo) no Teste 1 (Pré), registrada no ciclo da marcha voluntária.

FIGURA 55 - Gráficos dos envoltórios lineares do sinal eletromiográfico dos músculos M.vasto lateral e M.bíceps femoral da perna operada ou direita (OP/D) e da perna não-operada ou esquerda (NOP/E) durante a fase de apoio da marcha na comparação entre grupos: controle $(\mathrm{CON})$, cadeia cinética aberta (CCA) e cadeia cinética fechada (CCF) $(\mathrm{n}=10$ em cada grupo) no Teste 2 (1PO), registrada no ciclo da marcha voluntária 
FIGURA 56 - Gráficos dos envoltórios lineares do sinal eletromiográfico dos músculos M.vasto lateral e M.bíceps femoral da perna operada ou direita (OP/D) e da perna não-operada ou esquerda (NOP/E) durante a fase de apoio da marcha na comparação entre grupos: controle $(\mathrm{CON})$, cadeia cinética aberta (CCA) e cadeia cinética fechada $(\mathrm{CCF})(\mathrm{n}=10$ em cada grupo) no Teste 3 (4PO), registrada no ciclo da marcha voluntária

FIGURA 57 - Gráficos dos envoltórios lineares do sinal eletromiográfico dos músculos M.vasto lateral e M.bíceps femoral da perna operada ou direita (OP/D) e da perna não-operada ou esquerda (NOP/E) na comparação entre os testes 1 (Pré), 2 (1PO) e 3 (4PO), do grupo cadeia cinética fechada $(\mathrm{CCF})(\mathrm{n}=10)$, registrada no ciclo da marcha voluntária. A curva do grupo controle aparece como referência

FIGURA 58 - Gráficos dos envoltórios lineares do sinal eletromiográfico dos músculos M.vasto lateral e M.bíceps femoral da perna operada ou direita (OP/D) e da perna não-operada ou esquerda (NOP/E) na comparação entre os testes 1 (Pré), 2 (1PO) e 3 (4PO), do grupo cadeia cinética aberta (CCA) $(\mathrm{n}=10)$, registrada no ciclo da marcha voluntária. A curva do grupo controle aparece como referência. 


\section{LISTA DE QUADROS}

Página

QUADRO 1 - Descrição dos exercícios realizados no primeiro mês pós-cirúrgico, conforme orientação que foi entregue aos

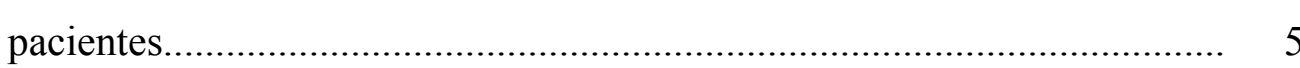

QUADRO 2 - Descrição dos exercícios realizados nos protocolos de reabilitação do ligamento cruzado anterior entre a quinta e a décima sexta semana de pós-operatório

QUADRO 3 - Programação do treinamento de resistência dos protocolos de exercícios em cadeia cinética aberta e fechada, em relação ao número de séries e repetições, e à carga utilizada no período pós-operatório (PO) 


\section{LISTA DE ANEXOS}

Página

ANEXO I - $\quad$ Termo de Consentimento Pós-informação.............................................131

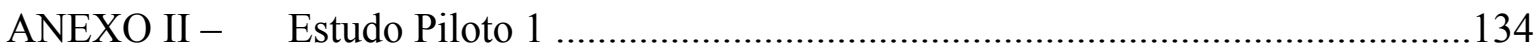

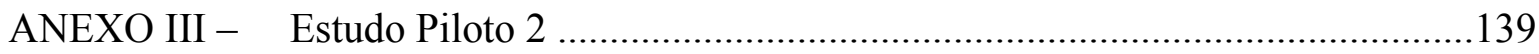

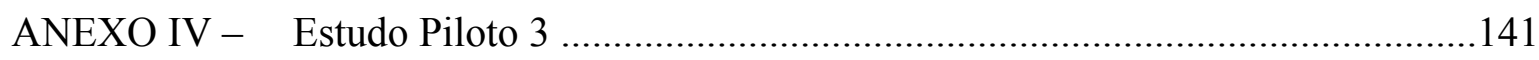

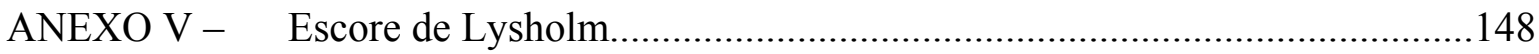

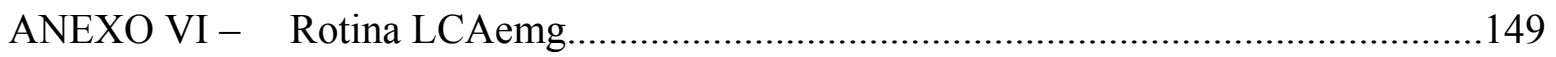

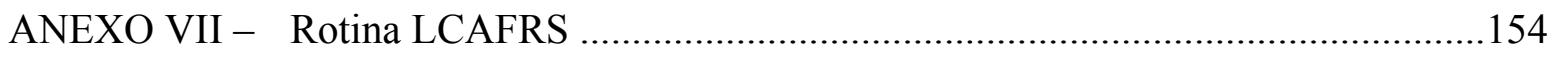

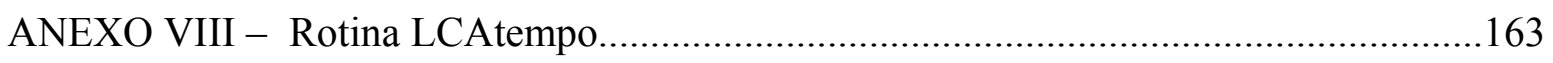

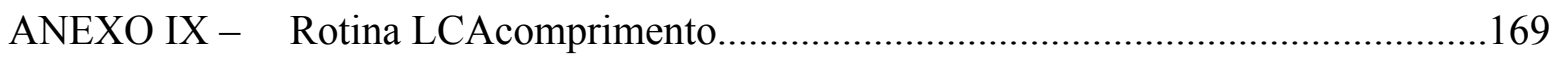




\section{LISTA DE SIGLAS}

LCA: Ligamento cruzado anterior

CCA: Cadeia cinética aberta

CCF: $\quad$ Cadeia cinética fechada

CON: $\quad$ Controle

DTA: Deslocamento tibial anterior

EMG: $\quad$ Eletromiografia

FRS: $\quad$ Força de reação do solo

PO: $\quad$ Pós-operatório

OP: $\quad$ Operada (sujeitos com lesão) ou direita (sujeitos saudáveis)

NOP: Não-operada (sujeitos com lesão) ou esquerda (sujeitos saudáveis)

1PO: $\quad$ Um mês de pós-operatório

4PO: $\quad$ Quatro meses de pós-operatório

ADM: $\quad$ Amplitude de movimento

1RM: Uma repetição máxima (carga máxima)

CV: $\quad$ Coeficiente de variação

VL: $\quad$ M.vasto lateral

BF: $\quad$ M.bíceps femoral

Fy1: $\quad$ Primeiro pico da força vertical de reação do solo

Fy2: $\quad$ Segundo pico da força vertical de reação do solo

Fymin: $\quad$ Força vertical mínima

txcFy1: Taxa de crescimento para o primeiro pico da força vertical de reação do solo

txcFy2: Taxa de crescimento para o segundo pico da força vertical de reação do solo

dFymin: Deflexão da força vertical de reação do solo

tFy1: $\quad$ Tempo para o primeiro pico da força vertical de reação do solo

tFy2: $\quad$ Tempo para o segundo pico da força vertical de reação do solo

tFymin: $\quad$ Tempo para a força vertical mínima

simeFy1: Simetria do primeiro pico da força vertical de reação do solo 
simeFy2: $\quad$ Simetria do segundo pico da força vertical de reação do solo simeFymin: Simetria da força vertical mínima

simetFy1: Simetria para o tempo do primeiro pico da força vertical de reação do solo simetFy2: Simetria para o tempo do segundo pico da força vertical de reação do solo simetFymin: Simetria para o tempo da força vertical mínima 


\title{
RESUMO
}

\section{COMPARAÇÃO ENTRE DOIS PROTOCOLOS DE REABILITAÇÃO APÓS RECONSTRUÇÃO DO LIGAMENTO CRUZADO ANTERIOR ATRAVÉS DE ANÁLISE BIOMECÂNICA}

\author{
Autor: CLÁUDIA SILVEIRA LIMA \\ Orientador: PROF. DR. ALBERTO CARLOS AMADIO
}

Exercícios em cadeia cinética aberta e fechada tem sido propostos para a reabilitação no pós operatório de reconstrução do ligamento cruzado anterior. Não há consenso na literatura sobre qual o tipo de exercício é mais apropriado e ao mesmo tempo seguro, não pondo em risco o procedimento cirúrgico. O propósito deste estudo foi verificar os efeitos da utilização de protocolos de reabilitação em cadeia cinética aberta e fechada de indivíduos em pós operatório de reconstrução do ligamento cruzado anterior, através de respostas comportamentais verificadas por indicadores biomecânicos. A amostra experimental foi constituída de trinta indivíduos, divididos em três grupos amostrais independentes: $(\mathrm{CON})$ dez indivíduos normais que não sofreram nenhum tipo de intervenção; (CCF) dez pacientes submetidos ao programa de reabilitação em cadeia cinética fechada e (CCA) dez pacientes submetidos ao programa de reabilitação em cadeia cinética aberta. Os testes para avaliar os parâmetros biomecânicos selecionados foram realizados em duas etapas: avaliação clínica (deslocamento tibial anterior e escore de Lysholm) e avaliação da marcha (análise dinâmica, cinemática e eletromiográfica). O tratamento foi realizados três vezes por semana, durante doze semanas. Os pacientes foram submetidos a três testes; o primeiro no pré-operatório; o segundo após quatro semanas da cirurgia e o terceiro após quatro meses de cirurgia. $\mathrm{O}$ grupo controle realizou apenas um teste e não foi submetido a nenhum tipo de tratamento. Para a 
análise do deslocamento tibial anterior foi utilizado o aparelho KT1000. A análise da marcha foi realizada através da esteira rolante Gaitway Kistler, a análise da atividade eletromiográfica através do sistema Bagnoli 8, composta de eletrodos de superfície e a análise da variação angular do joelho através do eletrogoniômetro Elgon-Burns. Os dados foram registrados, armazenados, processados e analisados estatisticamente, levando-se em consideração o nível de significância de 0,05 . As variáveis relativas à força de reação do solo foram analisadas através da determinação de componentes principais. O deslocamento tibial anterior diminuiu ao final do tratamento e o escore de Lysholm aumentou em ambos os grupos, sem diferença significativa entre eles. Das variáveis analisadas relativas à marcha o tempo de apoio simples, as taxas de crescimento para os picos da força vertical, a deflexão da força mínima, a força mínima e o segundo pico parecem-nos serem as variáveis mais sensíveis para identificar diferenças na forma de andar em função do protocolo de reabilitação. Ao analisar a amplitude de movimento percebe-se que esta variável é sensível a mudanças expressivas na variação angular do joelho, como ocorreram no teste após quatro semanas de pós-operatório. Pela análise descritiva, diferenças angulares menores devem ser analisadas através dos ângulos em momentos específicos da marcha. Em relação à atividade elétrica muscular o M.bíceps femoral foi o que apresentou maior variação na sua atividade. E os valores de simetria demonstram que o grupo cadeia cinética aberta foi o que apresentou maiores diferenças entre as pernas no teste após quatro semanas de cirurgia, o que demonstra maior instabilidade no andar. O presente estudo permite concluir que as alterações da marcha são mais expressivas um mês após a cirurgia do que no período pré-operatório. O escore de Lysholm, os componentes principais das variáveis relativas a força de reação do solo e a variação angular do joelho indicam que os exercícios em cadeia cinética fechada são mais eficientes para a recuperação da marcha do que os de cadeia cinética aberta. No entanto, os dois tipos de exercícios propiciam melhora dos parâmetros da marcha e parecem ser eficientes na recuperação da marcha dos pacientes submetidos à reconstrução do ligamento cruzado anterior. $\mathrm{O}$ período de quatro meses de reabilitação assegura uma marcha sem riscos para o paciente, mas ainda distinta da característica da marcha de indivíduos não acometidos pela lesão.

PALAVRAS CHAVES: Biomecânica, Marcha, Reabilitação, Ligamento Cruzado Anterior, Cadeia Cinética. 


\begin{abstract}
COMPARISON BETWEEN TWO REHABILITATION PROTOCOLS AFTER ANTERIOR

CRUCIATE LIGAMENT RECONSTRUCTION USING BIOMECHANICS ANALYSIS
\end{abstract}

\author{
Author: CLÁUDIA SILVEIRA LIMA \\ Adviser: PROF. DR. ALBERTO CARLOS AMADIO
}

Open kinetic chain and closed kinetic chain exercises have been proposed for rehabilitation protocol in the reconstruction of the anterior cruciate ligament. There is no consensus in the literature regarding which exercise is more appropriate and at the same time safe without putting in risk the surgical procedure. The purpose of this study was to evaluate the results of the open kinetic chain and closed kinetic chain protocols in the rehabilitation of those individuals that were subject to the reconstruction of the anterior cruciate ligament based on biomechanical indicatives. The sample was made of thirty individuals, divided in three independent groups: $(\mathrm{CON})$ ten normal individuals that were not submitted to the surgical intervention; (CCF) ten patients submitted to the closed kinetic chain rehabilitation program, and (CCA) ten patients submitted to the open kinetic chain rehabilitation program. Tests to evaluate the desired biomechanical parameters had been carried out through two stages: clinical evaluation (anterior tibial displacement and Lysholm`s score) as well as gait evaluation (dynamic, kinematic and electromyografic analysis). The treatment was carried out three times per week, during twelve weeks. Each patient had been evaluated in three occasions: before the surgery; four weeks after the surgery; and four months after the surgery. The group control was submitted to only one evaluation test and no treatment at all. KT1000 equipament was used for evaluating the tibial displacement. The gait analysis was carried out through the Gaitway Kistler treadmill; the electromyography analysis was evaluated through 
the System Bagnoli 8 composed of surface electrodes and the analysis of the angular variation of the knee through Elgon-Burns electrogoniometer. Data had been collected and analyzed considering the 0,05 significance level. The ground reaction force variable had been analyzed through of the determination of main components. The anterior tibial displacement diminished at the end of the treatment and the Lysholm's score increased in both groups without significant difference between them. From the analyzed variables regarding gait, the time of simple support, the taxes of growth for peaks of the vertical force, the deflection of the minimum force, the minimum force and as the peak, seem to be the most sensible variables to identify gait differences due to the rehabilitation protocol. Upon analyzing the amplitude of movement it was noticed that this variable was sensible to huge changes in the angular variation, as those observed after four weeks from the surgery. By the descriptive analysis, lesser angular differences must be analyzed through the angles at specific moments of the gait. Regarding the muscular activity the femoral biceps femoris (long head) presented greater variation in its activity. And, the symmetry values demonstrate that the open kinetic chain group presented greater differences between both legs in the test four weeks after the surgery, demonstrating greater instability in walking. The current study permit to conclude that the variations in the gait are higher in one month after the surgery than in the pre-surgery period. The Lysholm`s score, the ground reaction force, variable the main components and the angular variation of the knee indicates that the exercises in closed kinetic chain are more efficient than opened kinetic chain for recovering the gait. However, the two exercises improved the parameters of gait and seem to be efficient in recovering the gait pattern of patients submitted to the anterior cruciate ligament reconstruction. Although the four months period of rehabilitation is enough to reinstate a harmless gait pattern to patients, it is still not sufficient to return the patients`gait standards to those of individuals without injury.

KEYWORDS: Biomechanics, Gait, Rehabilitation, Anterior Cruciate Ligament, Kinetic Chain. 


\section{INTRODUÇÃO}

A lesão do ligamento cruzado anterior (LCA) é uma lesão freqüente, principalmente em indivíduos que praticam atividades esportivas. Os movimentos que exigem freadas bruscas, mudanças de direções, comuns em determinados esportes, provocam uma maior exigência deste ligamento e são considerados os principais mecanismos de lesão do LCA (KIRKLEY, MOHTADI \& OGILVIE, 2001).

A maioria dos pacientes com este tipo de lesão é submetido à cirurgia de reconstrução ligamentar (LEWEK, RUDOLPH, AXE \& SNYDER-MACKLER, 2002; RUDOLPH, EASTLACK, AXE \& SNYDER-MACKLER, 1998), principalmente aqueles que pretendem manter uma vida ativa em termos de exercício físico. Isto se deve, em parte, pela percepção das alterações e limitações nas suas atividades de vida diária e, também, pela dificuldade de se estabilizar o joelho com ruptura do LCA através do reforço muscular. Apesar de os músculos serem protetores articulares secundários, o papel do LCA na estabilização anterior da tíbia não consegue ser eficientemente substituído pela musculatura.

O sucesso cirúrgico e do programa de reabilitação culminará com o retorno do paciente tanto as suas atividades de vida diária como as práticas de exercícios físicos, o que na maioria das vezes acontece quando a amplitude de movimento e a força muscular parecem estar recuperadas (BEYNNON, FLEMING, JOHNSON, NICHOLS, RENSTROM \& POPE, 1995; DEVITA, HORTOBAGYI \& BARRIER, 1998; KEAYS, BULLOCK-SAXTON \& KEAYS, 2000). A avaliação para a alta do paciente costuma ser realizada por parâmetros subjetivos tanto pelo fisioterapeuta quanto pelo médico e pode acontecer dos pacientes ainda apresentarem alterações nos padrões funcionais de movimento, como a marcha ${ }^{1}$, depois de completado o período de reabilitação (CARTER \& EDINGER, 1999; DEVITA, HORTOBAGYI \& BARRIER, 1998).

A análise da marcha de pacientes com reconstrução do LCA tem sido realizada antes e após o procedimento cirúrgico (BULGHERONI, BULGHERONI, ANDRINI, GUFFANTI \& GIUGHELLO, 1997; DEVITA, HORTOBAGYI \& BARRIER， 1998; DEVITA, HORTOBAGYI, BARRIER, TORRY, GLOVER, SPERONI, MONEY \& MAHAR, 1997; LEWEK et al. 2002; RUDOLPH, AXE \& SNYDER-MACKLER, 2002; RUDOLPH et al., 1998; SNYDER-MACKLER, DELITO \& STRALKA, 1995). 
Estudos descrevendo a marcha de pacientes com lesão do LCA, sem intervenção cirúrgica, permitem inferir que quando os pacientes se submetem à cirurgia podem já apresentar alterações nos padrões da marcha (DEVITA et al., 1997; LEWEK et al., 2002; RUDOLPH, AXE \& SNYDER-MACKLER, 2002; RUDOLPH et al., 1998).

Os estudos que procuraram avaliar, entre outros aspectos, a marcha dos pacientes após a cirurgia demonstram que as alterações dessa se acentuam logo após a cirurgia e parecem permanecer mesmo após longo período pós-cirúrgico. Estudo de LEWEK et al. (2002) demonstra que mesmo após um período de três meses pós-cirúrgico é possível encontrar alterações na marcha dos pacientes. E os estudos de DEVITA, HORTOBAGYI e BARRIER (1998) demonstram alterações com até seis meses de cirurgia.

Nas pesquisas citadas envolvendo a análise da marcha de pacientes após a cirurgia de reconstrução do LCA o tipo de reabilitação utilizado não foi controlado. Não era objetivo de nenhum destes trabalhos analisar que tipo de exercícios foi utilizado durante a reabilitação. A utilização de exercícios em cadeia cinética aberta (CCA) ou em cadeia cinética fechada (CCF) para reabilitação de pacientes com lesão do LCA é uma das maiores discussões na literatura.

As pesquisas relacionadas aos exercícios em CCF e em CCA na reabilitação de pacientes com lesão do LCA têm buscado esclarecer vários aspectos importantes do tratamento, porém, muitas questões ainda não foram suficientemente pesquisadas e outras ainda nem entraram em discussão.

No trabalho de LIMA e GUIMARÃES (2001) a recuperação da força muscular dos isquiostibiais $^{2}$ e do M.quadríceps femoral ${ }^{3}$ foi mais rápida nos sujeitos que realizaram reabilitação em CCA quando comparada à reabilitação em CCF. Os estudos de LEWEK et al. (2002) e RUDOLPH et al. (1998) sugerem que o reforço do M.quadríceps femoral e o conseqüente aumento da estabilidade articular do joelho são fatores importantes para o retorno dos padrões normais da marcha dos pacientes de com lesão do LCA. Estes fatos sugerem que a

\footnotetext{
${ }^{1}$ As terminologias marcha e andar serăo utilizadas ao longo do texto como sinônimos.

${ }^{2}$ Os músculos citados neste projeto seguem a Terminologia Anatômica Internacional traduzida para o português pela Sociedade Brasileira de Anatomia (2001). Com exceçăo do grupo muscular isquiostibiais, que neste projeto sempre que utilizada será referente aos músculos M. bíceps femoral (cabeça longa), M. semitendíneo e M. semimembranáceo.

3 O grupo muscular M.quadríceps femoral será utilizado neste projeto. E, pela Terminologia Anatômica Internacional, refere-se aos músculos M.reto da coxa, M.vasto lateral, M.vasto intermédio e M.vasto medial.
} 
reabilitação em CCA poderia recuperar melhor a marcha do que a reabilitação em CCF. Porém, os exercícios em CCF são considerados mais funcionais que os de CCA, os que melhor reproduziriam atividades do dia a dia. Neste caso, como a marcha é considerada um parâmetro funcional, os exercícios em CCF poderiam ter maior influência na recuperação da marcha de pacientes de com lesão do LCA.

De acordo com a literatura, o tipo de exercício utilizado na reabilitação pode ter influência nas alterações encontradas na marcha destes pacientes. Alguns aspectos favorecidos pelos exercícios em CCF e outros pelos exercícios em CCA.

A comparação da recuperação da marcha em relação aos dois tipos de programas de reabilitação, CCA e CCF, controversos na literatura, foi estudada apenas por HOOPER, MORRISEY, DRECHSLER, MORRISSEY e KING (2001) e não encontraram diferença entre os dois programas. $\mathrm{O}$ seu estudo foi realizado apenas na fase inicial pós cirúrgica. Nenhum estudo foi encontrado comparando os dois programas de reabilitação até o final do período de reabilitação.

Quanto mais informações forem possíveis de serem obtidas em relação à prescrição de protocolos de exercícios em CCA ou em CCF, melhores condições terão os profissionais que atuam na área da reabilitação, de fazer uma análise crítica quanto à eficácia destes exercícios, e desta forma, selecionar o seu programa de tratamento com maior segurança. A opção pelas melhores técnicas de reabilitação poderá garantir os melhores resultados ao final do tratamento.

A marcha alterada pode trazer conseqüências importantes às estruturas articulares e até musculares, ainda mais ao pensar na freqüência com que este tipo de movimento é realizado no dia a dia. Caso um dos protocolos, CCA ou CCF, recupere de forma mais adequada os padrões da marcha, pode ser esta a melhor opção de trabalho na reabilitação de cirurgia de reconstrução do LCA.

Desta forma, este projeto se propõe a verificar os efeitos de programas de exercícios em CCA e CCF na recuperação de padrões normais da marcha após cirurgia de reconstrução do LCA, com a intenção de buscar maiores subsídios para selecionar os exercícios de um programa de reabilitação de pacientes com lesão do LCA.

Com este intuito serão analisados os efeitos da utilização de protocolos de reabilitação em CCA e CCF nas variáveis dinâmicas, cinemáticas e eletromiográficas da 
marcha, além de variáveis clínicas como o deslocamento tibial anterior e o escore de Lysholm de indivíduos em pós-operatório de reconstrução de LCA.

2

OBJETIVOS

\subsection{Objetivo Geral}

Verificar os efeitos da utilização de protocolos de reabilitação em CCA e CCF de indivíduos em pós-operatório de reconstrução de LCA, através de respostas comportamentais por indicadores biomecânicos.

\section{$2.2 \quad$ Objetivos Específicos}

- Determinar os efeitos da reabilitação através de exercícios em CCA e CCF na avaliação clínica de indivíduos em pós-operatório de reconstrução de LCA.

- Determinar os efeitos da reabilitação através de exercícios em CCA e CCF nas variáveis cinemáticas da marcha de indivíduos em pós-operatório de reconstrução de LCA.

- Determinar os efeitos da reabilitação através de exercícios em CCA e CCF nos aspectos relacionados à força de reação do solo durante a marcha de indivíduos em pós-operatório de reconstrução de LCA.

- Determinar os efeitos da reabilitação através de exercícios em CCA e CCF nos padrões eletromiográficos da marcha de indivíduos em pós-operatório de reconstrução de LCA.

\section{REVISÃO DA LITERATURA}

Esta revisão será dividida em três tópicos principais: o primeiro relacionado ao efeito dos exercícios em CCA e CCF na biomecânica da articulação do joelho, mais especificamente sobre o LCA; o segundo tópico retratará a marcha e suas relações com o comprometimento do LCA e o terceiro abordará a marcha em piso fixo e na esteira. 


\section{biomecânica da articulação do joelho}

A melhor compreensão dos exercícios em CCA e CCF tem sido objetivo de muitos estudos. Várias abordagens são feitas no que diz respeito a este tema. A articulação do joelho é a mais estudada em relação aos efeitos destes exercícios, em aspectos como a translação tibial, a compressão articular, a atividade muscular, entre outros. Estes estudos envolvem sujeitos saudáveis e, principalmente, sujeitos com lesão do LCA, que se submeteram ou não a cirurgia.

Os trabalhos onde a biomecânica do joelho é analisada são estudados com a intenção de poder entender como a articulação e seus componentes reagem aos exercícios em CCA e CCF. Estas informações têm permitido entender melhor que tipo de comprometimento articular pode ser ocasionado e como preveni-lo. E, dentro da reabilitação, selecionar mais adequadamente o melhor tipo de exercício para diferentes lesões, como lesões ligamentares específicas ou lesões de cartilagem.

A análise da biomecânica do exercício em situação normal, ou seja, com sujeitos saudáveis ou por modelos que reproduzem a articulação normal, permite conhecer os "padrões" do movimento e a partir deles entender o que se diferencia em outras situações, como na lesão do LCA. Dentro desta perspectiva será feita uma abordagem inicial direcionada a estudos com referenciais da situação normal e na seqüência estudos envolvendo lesões de LCA sem e com tratamento cirúrgico.

McGINTY, IRRGANG e PEZZULLO (2000) preocupados com esta questão realizaram uma revisão da biomecânica das articulações do joelho mostrando a importância deste tema para o sucesso da reabilitação. Em suas conclusões salientam que o entendimento da biomecânica articular permite maximizar as funções do paciente ao mesmo tempo em que minimiza os riscos de lesão.

Em um estudo de BODOR (2001), ele selecionou um sujeito com a articulação do joelho normal e realizou a análise vetorial da ação do M.quadríceps femoral. A análise vetorial foi baseada em uma radiografia lateral realizada em $35^{\circ}$ de flexão do joelho e na realização do ultra-som muscular para determinar o sentido de contração do músculo durante o movimento de flexo-extensão do joelho, que ocorre na execução dos exercícios de extensão do joelho (CCA) e agachamento (CCF). Em seus resultados encontrou que a ação vetorial do M.quadríceps femoral no exercício de CCA é originada na tíbia e direcionada superior e 
anteriormente; e no exercício de CCF a ação vetorial é originada no fêmur e direcionada inferior e anteriormente (FIGURA 1). Segundo o autor, este posicionamento inferior do vetor de ação do M.quadríceps femoral produz componente vetorial anterior fêmoro-tibial ou posterior tíbio-femoral $\left(\mathrm{Q}_{\mathrm{a}}\right)$ que protege o LCA do deslocamento tibial anterior, independente da ação dos isquiostibiais. Em suas conclusões salientam que a fraqueza do M.quadríceps femoral é um fator de risco para lesões do LCA, que a força do M.quadríceps femoral é importante para prevenir e proteger o LCA e que a preservação da força do M.quadríceps femoral é um importante objetivo cirúrgico.

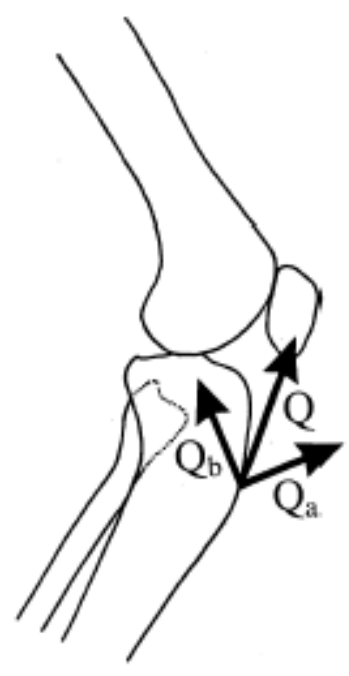

(a)

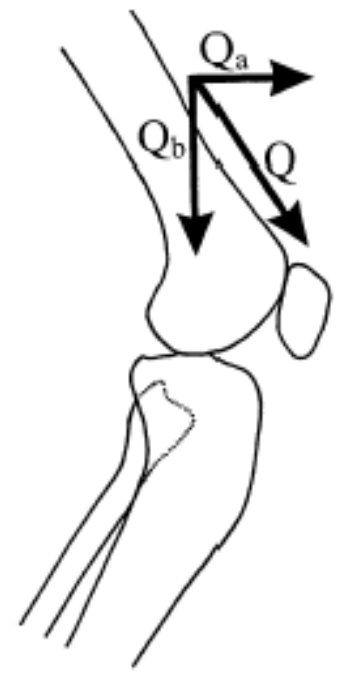

(b)

FIGURA 1 - Desenho ilustrativo do direcionamento do vetor de ação do M.quadríceps femoral (Q) e seus componentes vetoriais de deslocamento antero-posterior $\left(\mathrm{Q}_{a}\right)$ e de compressão $\left(\mathrm{Q}_{\underline{b}}\right)$ em exercícios de (a) CCA e (b) CCF (BODOR, 2001).

Um aspecto importante a ser salientado em relação ao trabalho de BODOR (2001) é que em uma análise teórica de composição de forças, a medida que o joelho é flexionado durante o agachamento a direção do vetor de ação do M.quadríceps femoral altera e isto faz com que o componente de ação $\mathrm{Q}_{\mathrm{b}}$ passe a ter uma ação posterior fêmoro-tibial. Isto ocorre 
quando a necessidade de produção de força do M.quadríceps femoral aumenta pelo aumento do braço de alavanca (Kvist e Gillquist, 2001). Talvez o posicionamento do vetor de ação do M.quadríceps femoral precise ser estimado em outros ângulos durante o movimento e não apenas em $35^{\circ}$ como foi realizado no estudo citado.

RENSTRÖM, ARMS, STANWYCK, JOHNSON e POPE (1986) mediram a deformação do LCA em cadáveres através de contrações geradas por estímulo elétrico dos isquios-tibiais isoladamente, do M.quadríceps femoral sozinho e em atividade simultânea do M.quadríceps femoral e isquios-tibiais, comparando a contração isométrica com o movimento passivo. Em suas conclusões citam que a contração isométrica do M.quadríceps femoral aumenta a deformação do LCA entre $0^{\circ}$ e $45^{\circ}$, quando comparado ao movimento passivo; que a contração isométrica dos isquios-tibiais diminui a deformação do LCA em todos os ângulos de movimento e que a contração dos isquios-tibiais simultânea a do M.quadríceps femoral não é suficiente para dissimular a deformação do LCA causado pela contração do M.quadríceps femoral dos $0^{0}$ aos $30^{\circ}$ de flexão.

DRAGANICH, JAEGER e KRALJ (1989) investigaram através de eletromiografia a co-ativação dos isquios-tibiais e do M.quadríceps femoral no exercício de extensão do joelho sentado e de extensão do joelho em decúbito ventral. Além disto estes autores analisaram a atividade dos isquios-tibiais durante a extensão monoarticular lenta do joelho, com os indivíduos na posição sentada. Nos resultados obtidos foi verificada uma ativação dos isquiostibiais durante a extensão do joelho, sendo mais acentuada na fase terminal da extensão, com percentuais acima do ruído e do máximo possível em crosstalk, ficando caracterizado a coativação dos isquios-tibiais com o M.quadríceps femoral.

Corroborando com os estudos de BODOR (2001); DRAGANICH, JAEGER e KRALJ (1989) e RENSTRÖM et al. (1986) encontra-se ainda outro trabalho de GRAHAM, GEHLSEN e EDWARDS (1993) que estudaram a atividade elétrica do M.quadríceps femoral e isquios-tibiais em alguns exercícios. Apesar de em suas conclusões considerarem os exercícios de CCF mais seguros para reabilitação do joelho, os resultados demonstram que o tempo de co-ativação dos isquios-tibiais com o M.quadríceps femoral na extensão do joelho é maior que o tempo de co-contração no agachamento.

Um estudo in vivo envolvendo sujeitos que não apresentavam comprometimento do LCA foi realizado por BEYNNON et al. (1995). Este estudo tinha por objetivo determinar as diferenças no strain do LCA entre diferentes atividades de reabilitação: durante o movimento 
de flexo-extensão do joelho, na contração isométrica do M.quadríceps femoral, na contração isométrica de isquiostibiais e na contração isométrica simultânea do M.quadríceps femoral e isquiostibiais. Os exercícios analisados eram de CCA, apesar desta classificação não ser mencionada pelos autores. Os seus resultados demonstraram que os exercícios que produzem baixo ou insignificante deformação do LCA e não seriam perigosos para o enxerto incluem contrações isométricas de isquiostibiais, atividades musculares do M.quadríceps femoral com o joelho flexionado em $60^{\circ}$ ou mais (contração isométrica isolada do M.quadríceps femoral, ou contração simultânea do M.quadríceps femoral e isquiostibiais), ou atividades que movimentem o joelho entre $35^{\circ}$ e $90^{\circ}$ de flexão (FIGURA 2).

(a)

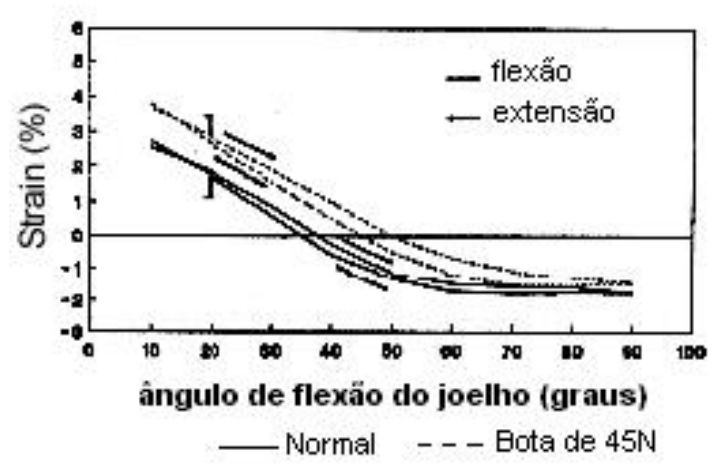

(c)

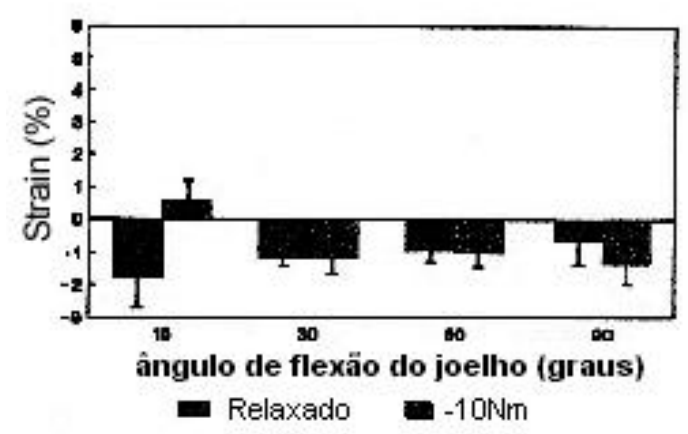

(b)

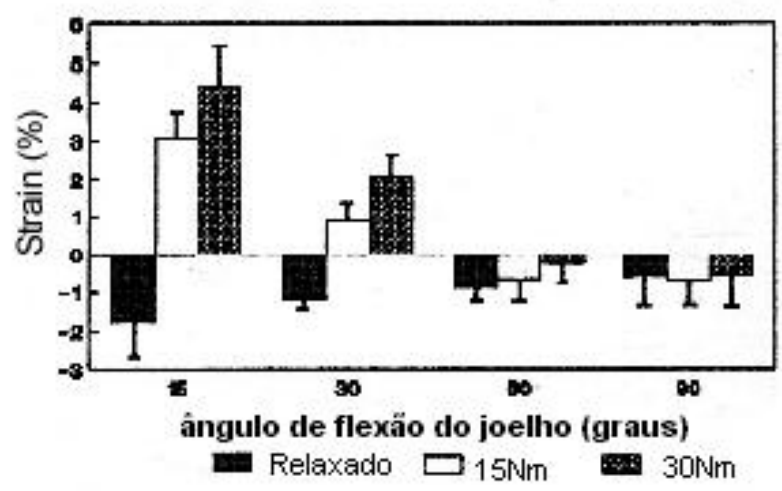

(d)

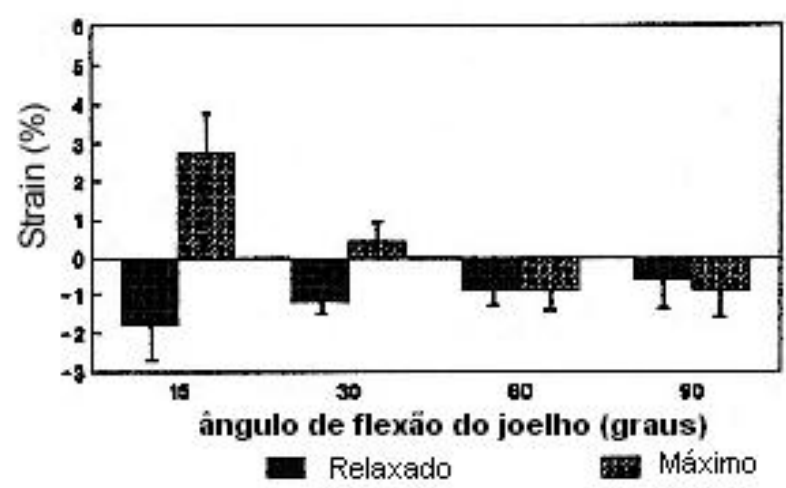

FIGURA 2 - Média do strain (deformação) do LCA (a) flexo-extensão ativa, (b) contração isométrica do M.quadríceps femoral, (c) contração isométrica dos isquiostibiais e (d) contração simultânea do M.quadríceps femoral e isquiostibiais (BEYNNON et al., 1995). 
IMRAN e O’CONNOR (1998) criaram um modelo matemático com o objetivo de investigar a ação dos isquiostibiais em relação à translação tibial anterior e conseqüente força nos ligamentos cruzados durante contração isométrica do M.quadríceps femoral (CCA). De acordo com o modelo proposto a direção das forças mudam com o aumento da flexão e a direção das forças dos isquiostibiais só conseguem atuar como protetoras do LCA em ângulos maiores que $15^{0}$ de flexão (FIGURA 3).

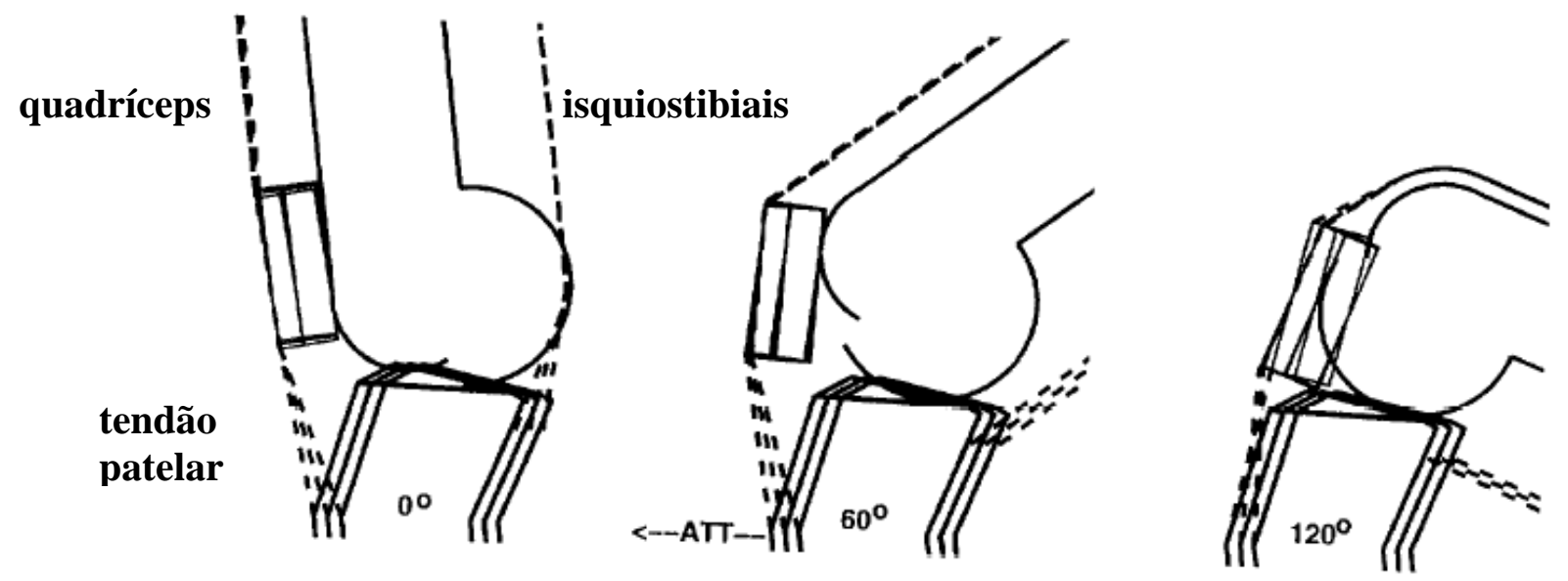

FIGURA 3 - Desenho esquemático do modelo proposto, demonstrando a orientação das forças musculares com a mudança do ângulo de flexão $(0,60$ e 120 graus $)$ e com variação no deslocamento tibial anterior $(0,4$ e $8 \mathrm{~mm}$ ) (IMRAN \& O’CONNOR, 1998).

Em suas conclusões salientam que a contração isométrica do M.quadríceps femoral provocam cargas importantes sobre o LCA da extensão completa até cerca de $85^{\circ}$ de flexão do joelho. A ação sinérgica dos isquiostibiais reduz esta carga, exceto em ângulos próximos da extensão completa. Os autores ainda reforçam que forças modestas de isquiostibiais (comparadas com as forças do M.quadríceps femoral) podem ajudar a proteger o LCA por ter um grande efeito na diminuição da translação tibial anterior, conforme demonstrado na FIGURA 4. 
(a) $0^{\circ}$ flexão

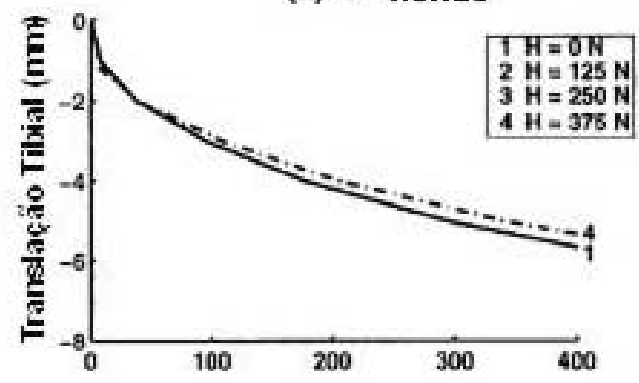

(b) $30^{\circ}$ flexão

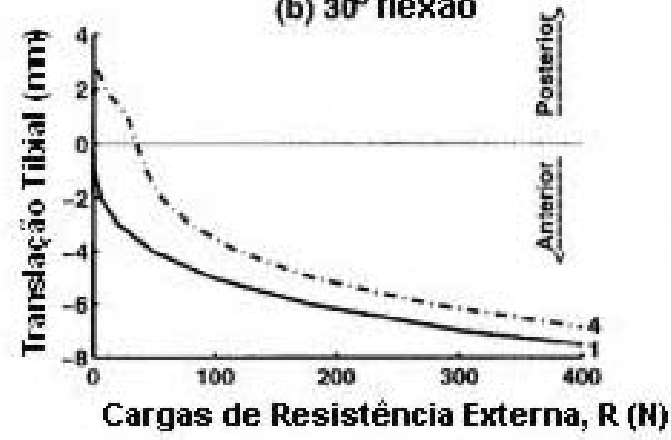

(c) $45^{\circ}$ flexão

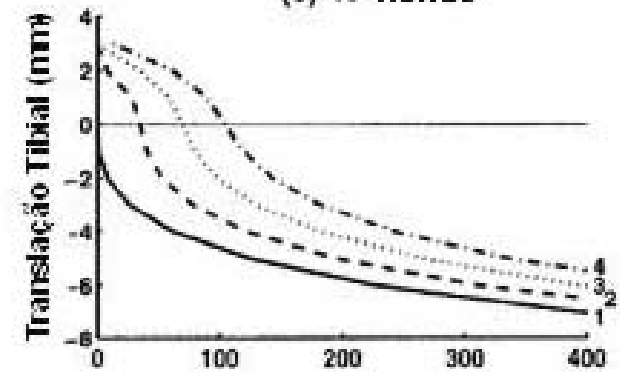

(d) $60^{\circ}$ flexão

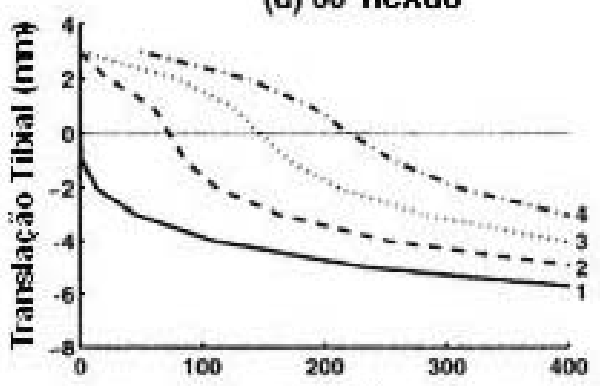

Cargas de Resistência Externa, R ( $\mathrm{H}$ )

FIGURA 4 - Efeito da co-contração dos isquiostibiais (ON, 125N, 250N e 375N de força) na translação tibial em (a) $0^{\circ}$ de flexão, (b) $30^{\circ}$ de flexão, (c) $45^{\circ}$ de flexão e (d) $60^{\circ}$ de flexão (IMRAN \& O’CONNOR, 1998).

SHELBURNE e PANDY (1998) utilizaram um modelo matemático para determinar o efeito da co-contração dos isquiostibiais nas cargas sobre o LCA durante o agachamento. Seus resultados mostram que a co-contração dos isquiostibiais é a maior responsável pelas cargas baixas sobre o LCA no agachamento. E que este tipo de exercícios é seguro para fortalecer os músculos da coxa em pacientes que realizaram a reconstrução do LCA.

Os estudos de BEYNNON et al. (1995), IMRAN e O'CONNOR (1998) e SHELBURNE e PANDY (1998), ao contrário dos estudos de BODOR (2001); DRAGANICH, JAEGER e KRALJ (1989), GRAHAM, GEHLSEN e EDWARDS (1993) e RENSTRÖM et al. (1986), consideram a co-contração dos isquiostibiais com o M.quadríceps femoral fator importante para diminuição da translação anterior da tíbia e conseqüente proteção do LCA.

O estudo de WILK, ESCAMILLA, FLEISIG, BARRENTINE, ANDREWS e BOYD (1996) comparou as forças compressivas e de deslocamento antero-posterior na articulação tibiofemoral e a atividade eletromiográfica durante exercícios de CCA (extensão do joelho) e CCF (agachamento e leg-press). Os seus resultados demonstraram maiores forças 
de deslocamento anterior da tíbia no exercício de extensão do joelho dos quarenta graus até a extensão completa enquanto nos exercícios de CCF não foram encontradas forças de deslocamento anterior. $\mathrm{O}$ interessante deste estudo é que foi encontrado maior co-contração entre o M.quadríceps femoral e os isquiostibiais apenas no agachamento. No leg-press, outro exercício em CCF, a co-ativação foi comparável à extensão do joelho, exercício em CCA. Este estudo demonstra que não podem ser generalizados os exercícios em CCF como os que apresentam maior co-contração entre o M.quadríceps femoral e os isquiostibiais, porque existe diferença entre os próprios exercícios em CCF.

Os estudos que seguem comparam diferentes exercícios e a sua sobrecarga no LCA, sem discutir a co-contração muscular e a sua influência no deslocamento tibial anterior.

BEYNNON, JOHNSON, FLEMING, STANKEWICH, RENSTRÖM e NICHOLS (1997) compararam exercícios em CCF e CCA em relação à deformação do LCA através da implantação de um transdutor em ligamentos normais. Os seus resultados não demonstraram diferença entre a deformação provocada pelo agachamento e a provocada pela flexo-extensão ativa do joelho (FIGURA 5). Eles salientam que o agachamento tem maiores forças compressivas e não necessariamente protege mais o LCA do que a flexo-extensão ativa do joelho.
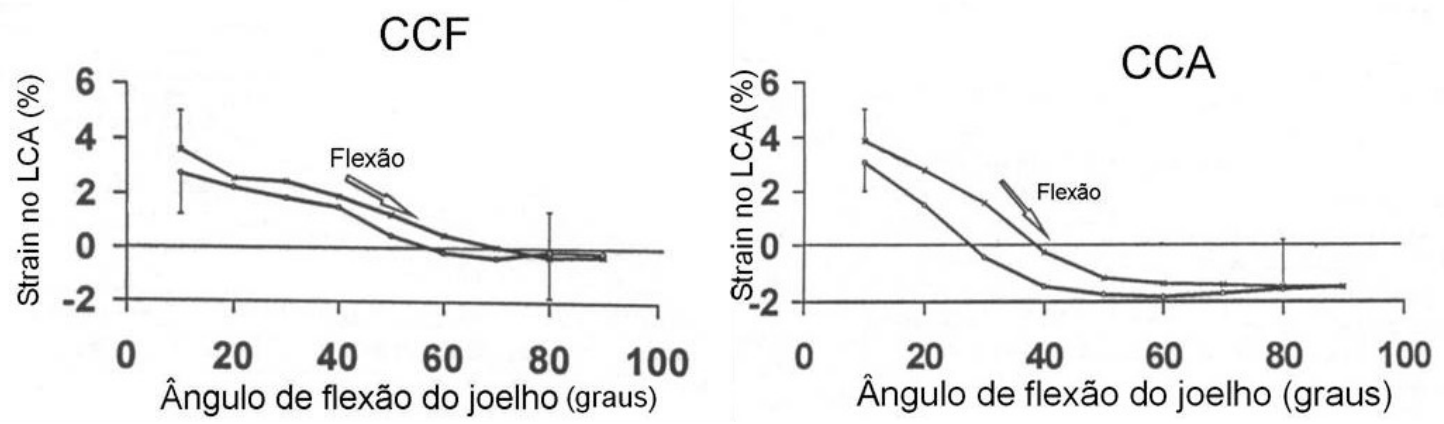

FIGURA 5 - Valores médios do strain do LCA produzido pelo agachamento (CCF) e pela flexo-extensão ativa do joelho (CCA) (adaptado de BEYNNON et al., 1997).

TOUTOUNGI, LU, LEARDINI, CATANI e O'CONNOR (2000) criaram um modelo matemático para determinar as forças do LCA durante exercícios isométricos (CCA), isocinéticos (CCA) e de agachamento (CCF) típicos de reabilitação. Nos exercícios de 
extensão isométrica/isocinética a maior força em LCA ocorreu nos ângulos entre $35^{\circ}$ e $40^{0}$ de flexão. Na flexão isométrica/isocinética o LCA não sofreu sobrecarga. Em relação ao agachamento o LCA apresentou pequenas forças em ângulos menores que $50^{\circ}$. Em suas conclusões salientam que o agachamento seria mais seguro para reabilitação do LCA do que a extensão do joelho isométrica/isocinética e que a flexão do joelho isométrica/isocinética pode ser seguramente utilizada para reforço dos isquiostibiais.

ESCAMILLA (2001) fez uma revisão sobre a biomecânica do agachamento um exercício típico de CCF. Vários aspectos foram examinados entre eles forças compressivas articulares, forças de tensão ligamentar, atividade muscular e estabilidade articular. Ele constatou que o agachamento apresenta pequenas para moderadas forças de deslocamento posterior, limitadas pelo ligamento cruzado posterior e, pequenas forças de deslocamento anterior, limitadas pelo LCA. A revisão levou-o a concluir que tanto as forças compressivas como as de tensão aumentam com o aumento da flexão. Desta forma, o agachamento entre os ângulos de $0^{0}$ e $50^{\circ}$ de flexão do joelho foi considerado adequado para reabilitação de pacientes com lesão do LCA.

Mais tarde, o agachamento e o leg-press, exercícios em CCF, foram estudados por ESCAMILLA, FLEISIG, ZHENG, LANDER, BARRENTINE, ANDREWS, BERGEMANN e MOORMAN (2001) com objetivo de quantificar as forças do joelho e a atividade muscular enquanto realizavam esses exercícios em diferentes técnicas. Entre seus resultados alguns são de maior interesse para esse trabalho. $\mathrm{O}$ agachamento apresentou maior atividade muscular do M.quadríceps femoral e dos isquiostibiais do que o leg-press. As forças compressivas tibiofemoral e patelofemoral e a tensão no ligamento cruzado posterior foram maiores no agachamento do que no leg-press. Em nenhum dos tipos de exercícios e nem em suas variações de técnicas foram encontradas forças no LCA. Em suas conclusões salientam que estes exercícios podem ser efetivos durante a reabilitação de pacientes com lesão do LCA.

Os estudos citados até agora são relacionados à compreensão dos exercícios em CCA e/ou CCF para sujeitos saudáveis ou modelos matemáticos baseados na situação normal. Estes estudos criam a possibilidade ou não de utilização destes exercícios para reabilitação de pacientes com lesão do LCA. Muitos estudos começaram a avaliar a eficácia destes exercícios em pacientes com comprometimento do LCA.

A avaliação dos exercícios em CCA e CCF na reabilitação de pacientes com lesão do LCA faz parte do processo de evolução que os exercícios terapêuticos sofrem ao longo dos 
anos. A evolução ocorre tanto nos seus conceitos quanto nas suas aplicações (NOYES, MANGINE \& BARBER, 1987; SHELBOURNE \& NITZ, 1990). O propósito da reabilitação é tornar as atividades o mais próximas da função normal do movimento humano, respeitando os cuidados decorrentes da cirurgia.

Um dos cuidados no pós-cirúrgico do LCA é a menor produção possível de DTA, para evitar a deformação do enxerto. Além desse cuidado o ganho de amplitude articular, o aumento da força muscular e a melhor qualidade dos movimentos diários do paciente fazem parte das metas da reabilitação (BEYNNON et al., 1995).

O DTA é sem dúvida um dos maiores interesses nas pesquisas relacionadas ao LCA, no entanto, percebem-se diferenças nos resultados das pesquisas relacionadas a este tema.

HENNING, LYNCH e GLICK (1985) realizaram um estudo in vivo com pacientes com ruptura parcial do LCA. Eles colocaram transdutores de força para avaliar a deformação do LCA. Os resultados mostraram que pedalar e realizar o meio agachamento com uma perna (exercícios em CCF) produzem uma deformação no LCA muito menor do que a produzida pela extensão do joelho contra um peso de aproximadamente $10 \mathrm{~kg}$ (exercício em CCA).

Uma comparação entre os exercícios de CCA e CCF em joelhos com LCA deficiente foi realizada por YACK, COLLINS e WHIELDON (1993) com o propósito de quantificar o DTA que ocorre em cada tipo de exercício. O agachamento paralelo (CCF) produziu DTA significativamente menor quando comparado com a extensão do joelho resistida $(\mathrm{CCA})$.

KVIST e GILLQUIST (2001), também compararam o DTA e incluíram a atividade eletromiográfica, entre exercícios em CCA e CCF, em sujeitos com LCA deficiente e em um grupo controle (FIGURA 6). 


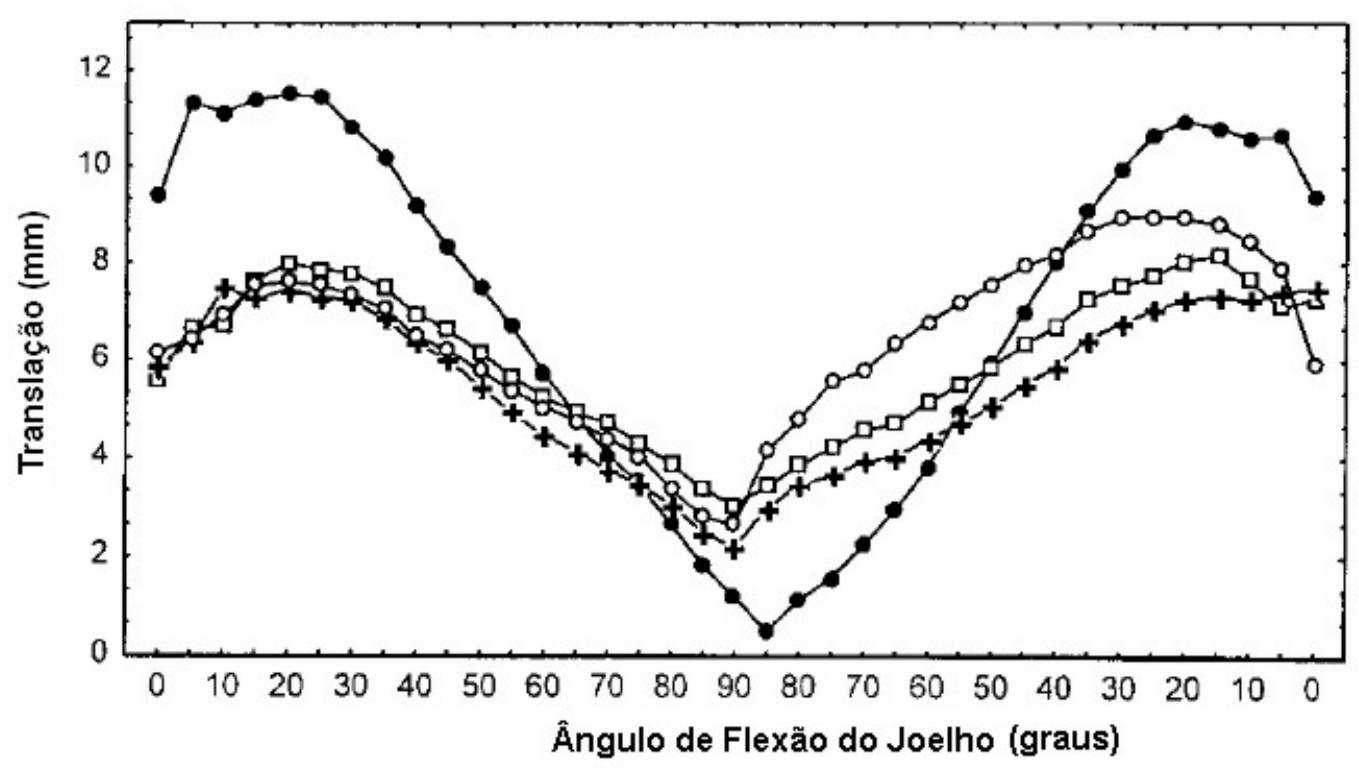

FIGURA 6 - Translação da tíbia de acordo com a variação angular do joelho em diferentes exercícios: extensão do joelho (círculo preenchido), agachamento com centro de gravidade sobre os pés (quadrado), agachamento com centro de gravidade na frente dos pés (círculo sem preenchimento) e agachamento com centro de gravidade atrás dos pés (cruz), (KVIST \& GILLQUIST, 2001).

Os seus resultados levaram a concluir que a CCF é melhor para minimizar a translação sagital da tíbia que ocorre com o LCA deficiente. E o interessante do estudo é que ao invés de atribuírem este resultado à co-ativação do M.quadríceps femoral com os isquiostibiais, que é o proposto pela literatura, eles atribuíram a co-ativação do M.quadríceps femoral com os gastrocnêmios, baseados nos seus resultados eletromiográficos (FIGURA 7). 


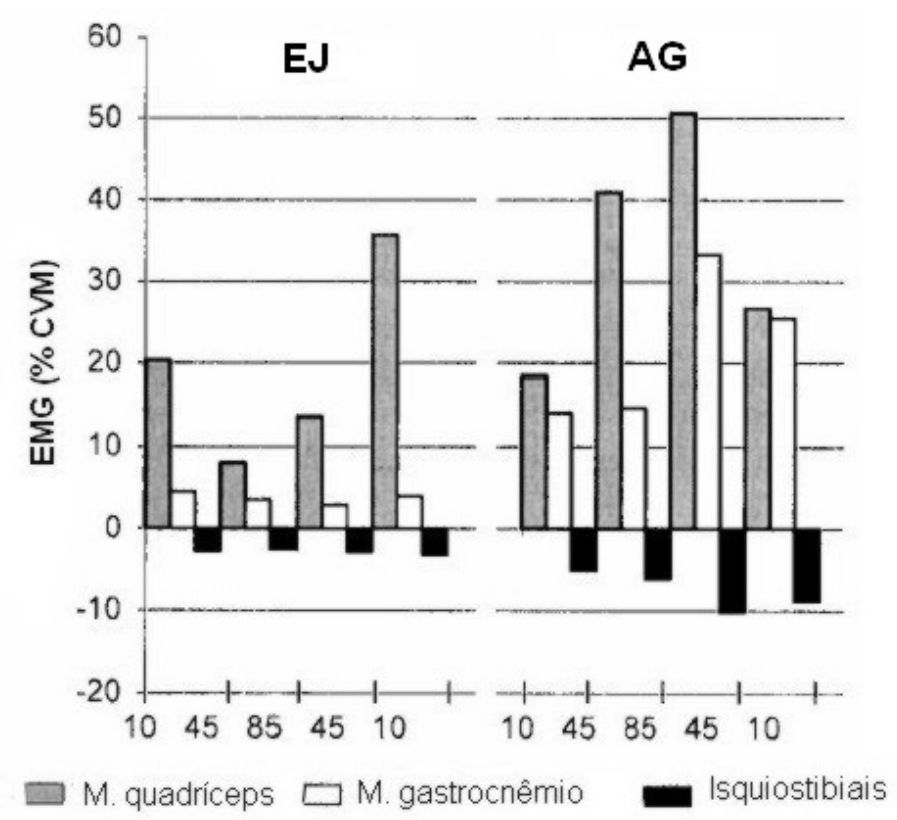

FIGURA 7 - Percentual de ativação dos diferentes músculos em ângulos diferentes de flexoextensão do joelho nos exercícios de extensão do joelho (EJ) e agachamento (AG) (adaptado de KVIST \& GILLQUIST, 2001).

BYNUM, BARRACK e ALEXANDER (1995) compararam exercícios em CCA e CCF após a reconstrução do LCA com a intenção de estabelecer se as atividades em CCF são as mais seguras e se elas oferecem vantagens em relação à reabilitação convencional. Dois grupos de pós-operados foram utilizados, onde um realizava as atividades em CCA e o outro em CCF. Eles avaliaram o deslocamento tibial anterior e os seus resultados demonstraram um maior deslocamento tibial anterior em CCA apenas quando o teste é realizado com a força máxima do equipamento. Em suas conclusões estes autores consideram os exercícios em CCF seguros e efetivos para serem utilizados nos estágios iniciais de tratamento e ainda lhes atribuem vantagens como menor dor patelo-femoral e menor estresse na maturação do enxerto.

No trabalho de LIMA e GUIMARÃES (1999), após três meses de reabilitação de pós-operatório de LCA, o DTA produzido no grupo de exercícios em CCA não apresentou diferença significativa em relação ao grupo de exercícios em CCF, sendo os valores do DTA em ambos os grupos insuficientes para prejudicar o enxerto. 
Outros autores como HOWELL (1993) e WHITE (1993), também salientam que o DTA produzido pelo exercício em CCA não é suficiente para prejudicar o procedimento cirúrgico, podendo ser inclusive menor que o provocado pelo próprio teste de Lachman (FIGURA 8). O teste de Lachman é um teste utilizado para diagnosticar ruptura do LCA, ele é realizado com o paciente em decúbito dorsal e o joelho posicionado entre $20^{\circ}$ e $30^{\circ}$ de flexão. O fêmur é estabilizado com uma mão enquanto a outra mão aplica uma firme pressão na região proximal da tíbia, da região posterior para a anterior, com o objetivo de transladar a tíbia anteriormente. O teste é positivo, indicando ruptura do LCA, quando existe o deslocamento anterior da tíbia e a finalização do movimento ocorre de forma suave (MALANGA, ANDRUS, NADLER \& MCLEAN, 2003).

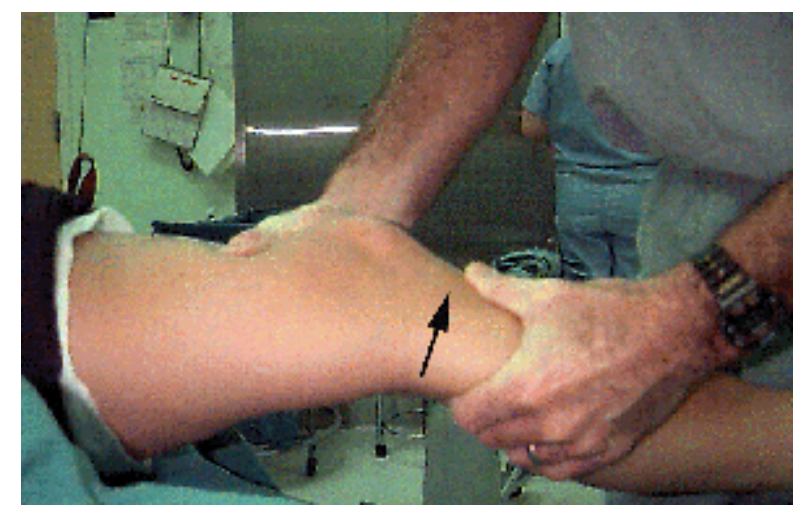

FIGURA 8 - Foto ilustrativa da forma de execução do teste de Lachman (ACL STUDY GROUP, 2003).

FLEMING, OKSENDAHL e BEYNNON (2005) realizaram uma revisão sobre o uso dos exercícios em CCA e CCF após a reconstrução do LCA. Em recentes trabalhos revisados por eles o pico de deformação produzido no enxerto ligamentar é similar entre os exercícios em CCA e CCF. Ainda mencionam que estudos clínicos sugerem que os dois tipos de exercícios são benéficos na fase inicial da reabilitação de pacientes com lesão do LCA reconstruído.

O retorno da força do M.quadríceps femoral e dos isquiostibiais aos níveis pré-lesão é outro objetivo de um programa de reabilitação (PERRIN, 1994). Trabalhos têm sido realizados com o objetivo de analisar o efeito dos exercícios de CCF e CCA na recuperação da 
força muscular. Este conhecimento pode ajudar na seleção do melhor protocolo de reabilitação a ser utilizado.

BUNTON, PITNEY, KANE e CAPPAERT (1993) realizaram um estudo de revisão e já nesta época referem-se aos exercícios em CCA como mais indicados para desenvolver a força muscular.

SNYDER-MACKLER, DELITTO e STRALKA (1995) avaliaram diferentes programas de reabilitação na recuperação da força muscular de pacientes com LCA reconstruído. Segundo seus estudos os exercícios em CCA recuperam melhor a força muscular e isto tem influência na cinemática do joelho e nos parâmetros da marcha porque estes melhoram com o aumento da força do M.quadríceps femoral.

O trabalho de LIMA e GUIMARÃES (2001) vai ao encontro do estudo de SNYDER-MACKLER, DELITTO e STRALKA (1995). Eles avaliaram a evolução do torque muscular dos extensores e flexores do joelho ao longo de três meses de reabilitação. Os seus resultados mostram que os exercícios em CCA recuperam mais rápido o torque muscular do que os exercícios em CCF. Porém, após doze semanas de tratamento a recuperação da força do M.quadríceps femoral não apresenta diferença significativa entre os grupos.

Os estudos relativos aos exercícios de CCA e CCF revisados até aqui tendem a defender os exercícios em CCF para diminuir o DTA e os exercícios em CCA para aumentar a força muscular.

A defesa maior a favor dos exercícios em CCF é devido à co-contração do M.quadríceps femoral e dos isquios-tibiais durante este tipo de exercício que protegeria o ligamento cruzado anterior por diminuir o deslocamento tibial anterior provocado pela contração do M.quadríceps femoral e, também, por serem exercícios mais funcionais.

Com os estudos apresentados, tanto a co-contração dos isquiostibiais como o deslocamento tibial anterior provocados pelos exercícios em CCA e CCF, são possíveis de serem questionados.

A co-contração dos isquiostibiais com o M.quadríceps femoral que ocorre no agachamento pode não ser o fator responsável pela diminuição da deformação do LCA. Os estudos mostraram que esta co-contração também pode estar presente na extensão do joelho isolada e não fica esclarecido se a sua intensidade é suficiente para minimizar o DTA provocado no movimento. 
Em relação ao deslocamento tibial anterior também existe divergência entre os estudos não sendo conclusivo se os exercícios em CCA provocam maior deslocamento tibial anterior do que os em CCF.

A recuperação da força muscular parece ser a única que não apresenta maiores discussões. Os estudos demonstram que os exercícios em CCA são mais eficazes e recuperam mais rápido a força muscular.

Outro objetivo importante da reabilitação é a recuperação funcional do paciente para que ele volte a realizar suas atividades de vida diária e esportiva. A literatura tende a defender os exercícios em CCF como mais funcionais do que os em CCA. Vários estudos de revisão bibliográfica abordam e defendem a maior funcionalidade dos exercícios em CCF, porém faltam estudos experimentais que comprovem esta hipótese.

O estudo de PERRIN (1994) apesar de ser favorável aos exercícios isocinéticos (CCA) para recuperação da força muscular defende a inclusão de exercícios em CCF para recuperação funcional dos pacientes.

RIVERA (1994) procurou justificar o uso de exercícios de reabilitação funcional através de considerações biomecânicas. $\mathrm{O}$ autor coloca que o sistema músculo-esquelético é composto por segmentos articulados e seus movimentos ocorrem pela ação de forças combinadas. Esta característica de movimento está presente nos exercícios em CCF e por isso estes exercícios são considerados mais funcionais. Mudanças significantes ocorrem na função dos grupos musculares e articulares dos membros inferiores quando são ativados em condições não funcionais, como ocorre durante a realização de exercícios em CCA. Ainda segundo Rivera, as alterações biomecânicas e estresse anormal provocados pelos movimentos em CCA tornam os exercícios em CCF essenciais no início do programa de reabilitação para a funcionalidade do atleta.

PANARIELLO (1991) também aborda sobre a funcionalidade dos exercícios em $\mathrm{CCF}$, acreditando ser esta a forma ideal de treinamento de força de membros inferiores porque estes exercícios são baseados na função corporal, não ocorrendo trabalho de grupos musculares isolados.

Este aspecto tem uma grande importância na reabilitação, pois se a maior funcionalidade do exercício permitir uma melhor qualidade dos movimentos utilizados no dia a dia, os exercícios que promovem este aspecto devem receber maior atenção. A aquisição dos movimentos dentro do padrão mais fisiológico poderá produzir ganhos mais equilibrados de 
força e amplitude, evitando com isso, outras lesões que poderiam ocorrer por sobrecargas articulares ou musculares.

Neste trabalho tem-se como objetivo avaliar o aspecto funcional da reabilitação de pacientes com lesão do LCA. E a análise da marcha foi escolhida para representar este aspecto. Dessa forma, o tópico que segue procura abordar estudos que já possuem algum tipo de informação sobre a marcha de pacientes com comprometimento do LCA e o tópico subseqüente estudos relativos à marcha normal em piso fixo e na esteira rolante.

\subsection{Marcha e suas relações com o comprometimento do LCA}

A análise da marcha na atualidade é muito utilizada para avaliar o comprometimento e a recuperação de pacientes com diferentes tipos de acometimento em termos de saúde (SAAD \& BATISTELLA, 1997). E, este tipo de avaliação também está sendo utilizado para pacientes com comprometimento do LCA.

Os pacientes com lesão do LCA antes de se submeterem à cirurgia costumam desenvolver mecanismos compensatórios nas suas atividades de vida diária, onde a marcha se inclui. A hipótese é de que estes mecanismos são causados por um aprendizado subconsciente e adaptações neuromusculares. O desenvolvimento destes mecanismos é benéfico para os sujeitos com lesão ou reconstrução do LCA porque diminuem o DTA provocado pela lesão do LCA (BERCHUCK, ANDRIACCHI, BACH \& REIDER, 1990).

Alguns estudos têm demonstrado as alterações que ocorrem durante a marcha nestes pacientes com lesão do LCA, antes de realizarem a cirurgia de reconstrução.

RUDOLPH et al.(1998) estudaram a marcha, entre outras atividades de dois grupos de indivíduos com ruptura total do LCA: um que apresentava instabilidade nas atividades de vida diária (não-coper) e o outro que não apresentava limitação nas atividades que realizava pré-lesão (coper). Ambos os grupos diminuíam a força com que eles entravam em contato com o solo e o grupo com instabilidade ainda mostrava menor flexão do joelho (FIGURAS 9 e 10). 


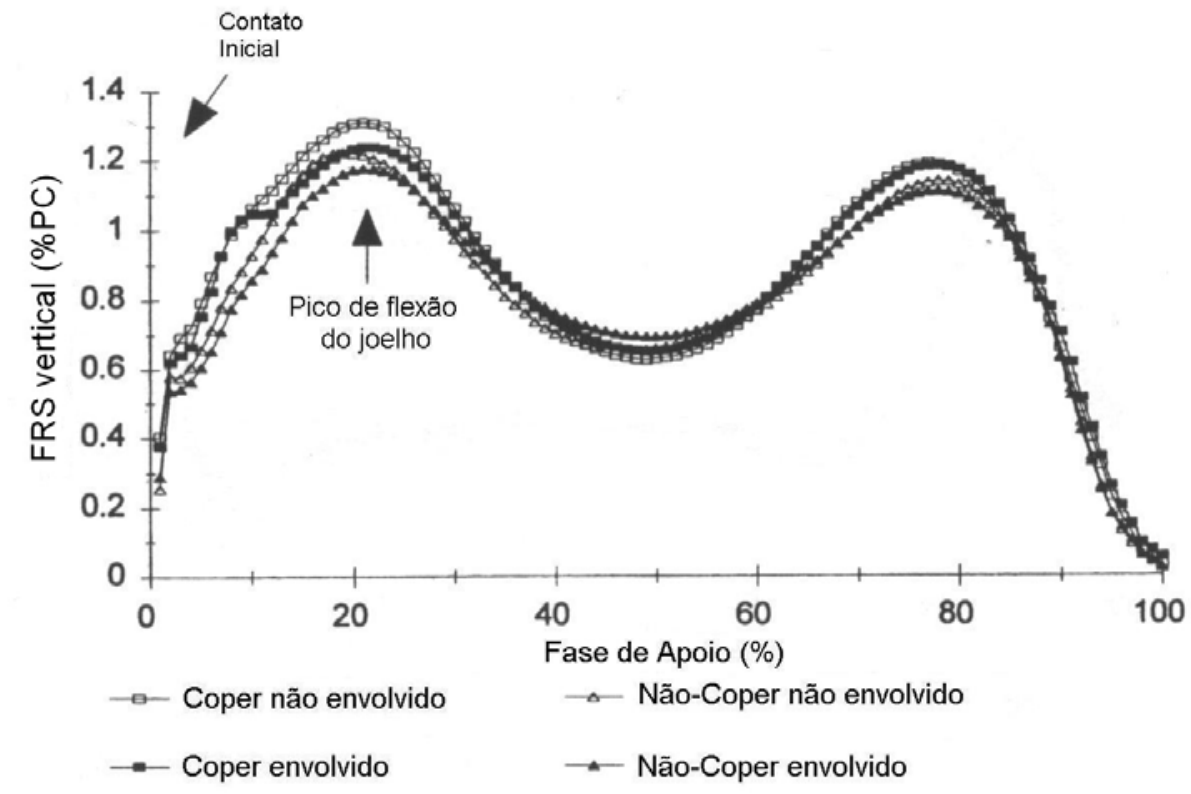

FIGURA 9 - Gráfico da componente vertical da FRS da perna envolvida com lesão e a perna $\underline{\text { não envolvida de dois grupos de pacientes de LCA: Coper (sem instabilidade no }}$ joelho) e Não-Coper (com instabilidade no joelho) (RUDOLPH et al., 1998). 


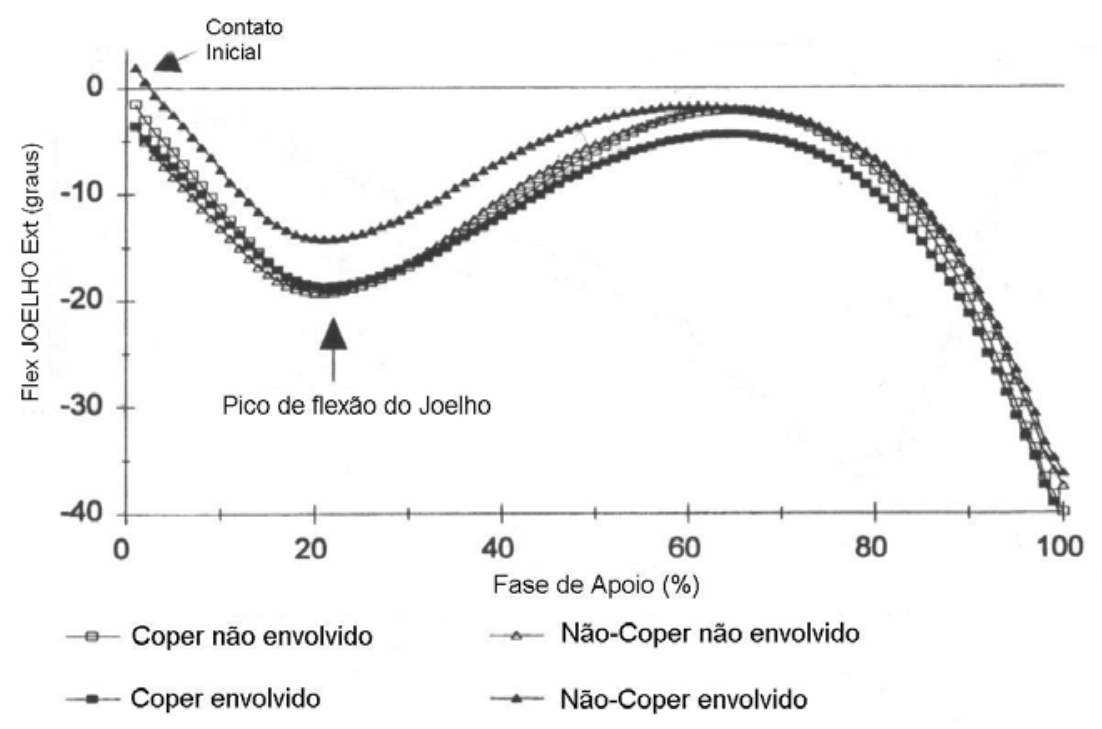

FIGURA 10 - Gráfico da variação angular do joelho da perna envolvida com lesão e a perna não envolvida de dois grupos de pacientes de LCA: Coper (sem instabilidade no joelho) e Não-Coper (com instabilidade no joelho) (RUDOLPH et al., 1998).

MOTA, AMADIO, HERNANDEZ e DUARTE (2002) também avaliaram a marcha de um paciente com lesão do LCA e compararam com um sujeito sem lesão. Os seus resultados mostraram um menor segundo pico da componente vertical da FRS e um valor maior da força vertical mínima (FIGURA 11). 


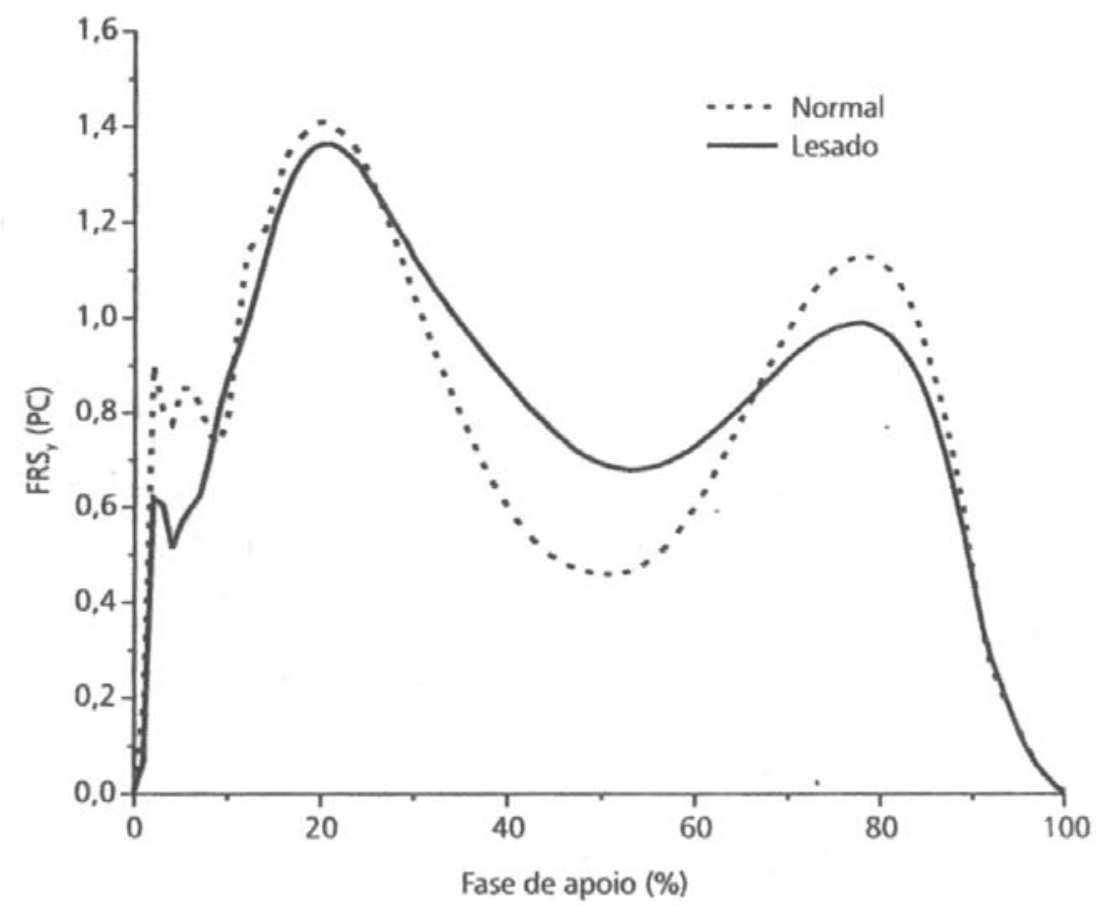

FIGURA 11 - Gráfico da componente vertical da FRS da perna envolvida com lesão de pacientes de LCA e de sujeitos sem lesão do LCA (MOTA et al., 2002).

Em relação às variações no ângulo do joelho, MOTA et al. (2002) encontraram um menor pico de flexão na fase inicial do apoio do sujeito com lesão do LCA quando comparado ao sujeito sem lesão (FIGURA 12). 


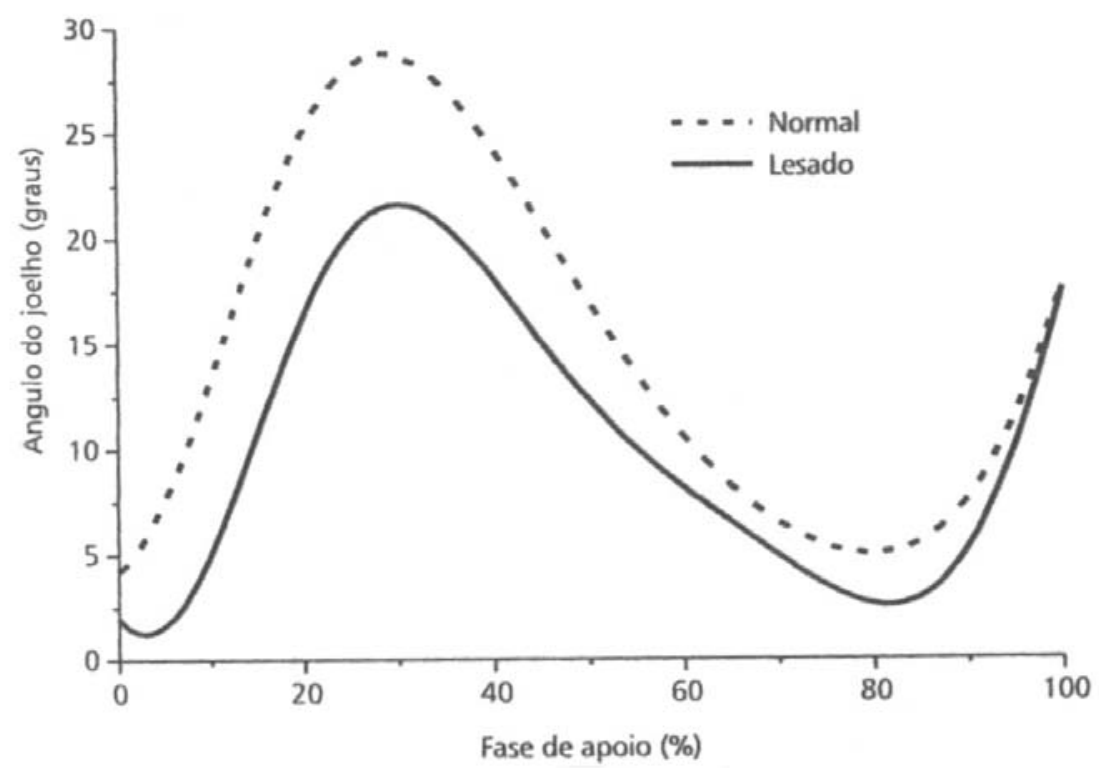

FIGURA 12 - Gráfico da variação angular do joelho da perna envolvida com lesão de pacientes de LCA e de sujeitos sem lesão do LCA (MOTA et al., 2002).

LEWEK et al. (2002) estudaram sujeitos com LCA deficiente e após a cirurgia de reconstrução. Os pacientes com LCA deficiente apresentaram diminuição no ângulo (FIGURA 13) e momento do joelho durante a caminhada. 


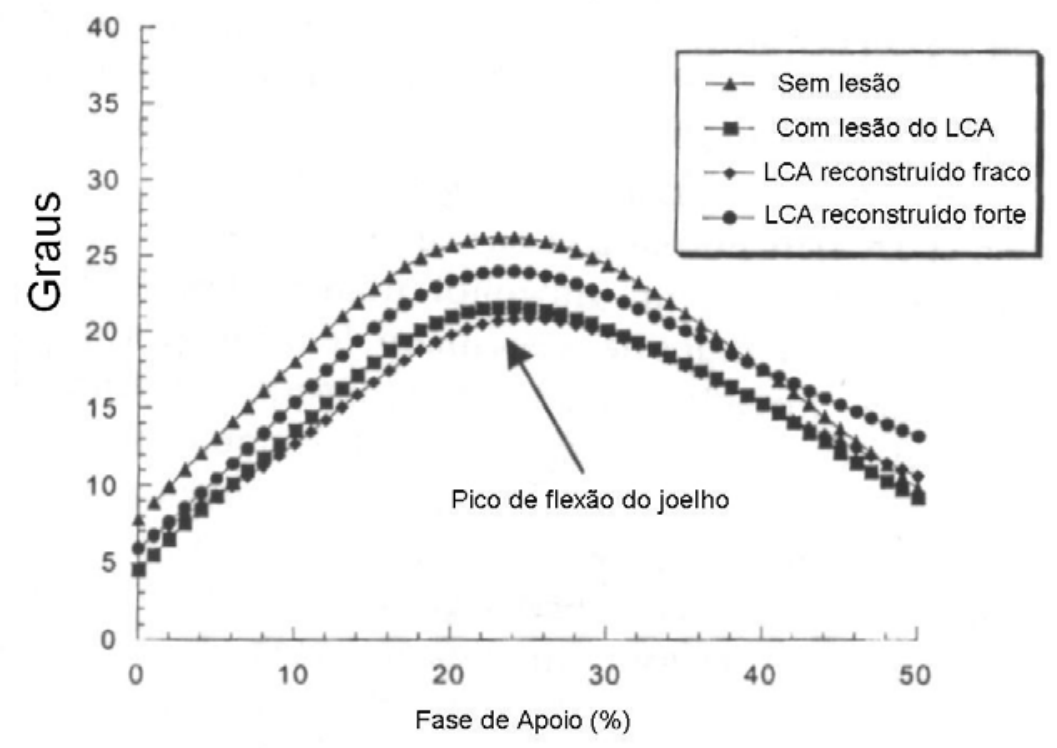

FIGURA 13 - Gráfico da variação angular do joelho de sujeitos sem lesão do LCA, com lesão do LCA, com LCA reconstruído fraco e com LCA reconstruído forte (LEWEK et al., 2002).

SHELBURNE, TORRY e PANDY (2005) utilizaram um modelo matemático para predizer a quantidade de força que o M.quadríceps e os isquiostibiais necessitam para restaurar a estabilidade dos joelhos com LCA deficiente durante a marcha. Eles concluem que o aumento da força dos isquiostibiais foi suficiente para estabilizar o joelho com LCA deficiente durante a marcha, e o mesmo não ocorreu com a diminuição da força do M.quadríceps femoral, esta foi insuficiente para restaurar a translação tibial anterior como nos joelhos com LCA normal.

DEVITA et al. (1997) procuraram identificar os efeitos iniciais da lesão do LCA e da cirurgia de reconstrução do ligamento avaliando a cinemática articular, cinética e energia durante a marcha. Antes de realizar a cirurgia os pacientes com lesão do LCA apresentaram maior flexão do joelho na segunda metade da fase de apoio (FIGURA 14). Eles também encontraram um prolongado torque extensor duas semanas após a lesão e para eles isto indicou que o processo de adaptação da deficiência do LCA é prolongado, requerendo maior tempo para o aprendizado das adaptações. 


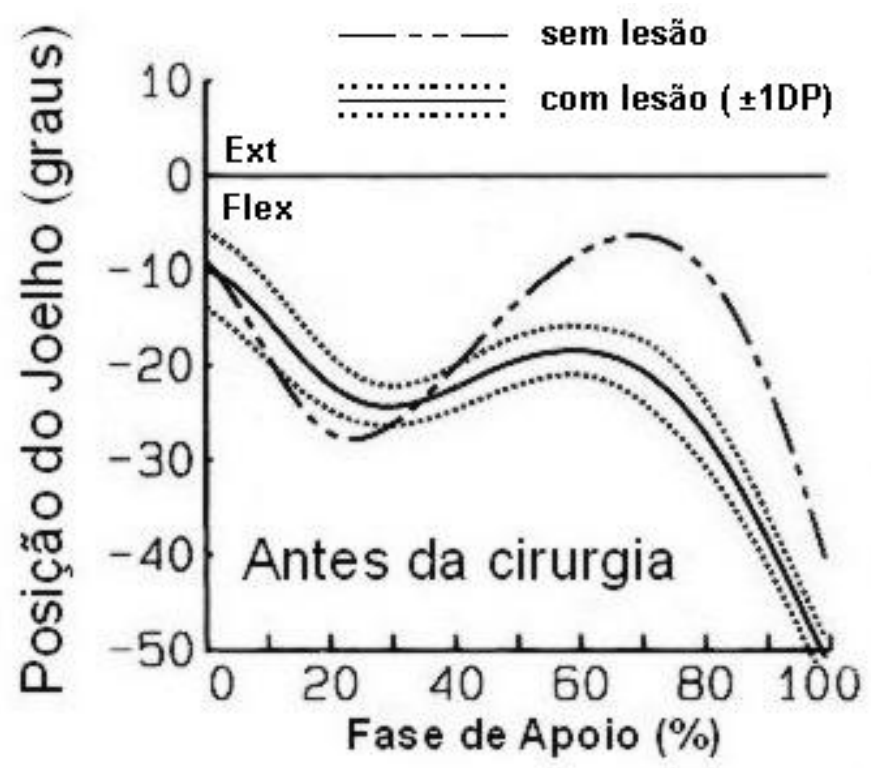

FIGURA 14 - Gráfico da variação angular do joelho de sujeitos com lesão do LCA e sujeitos saudáveis (DEVITA et al.,1997).

A maioria dos pacientes com LCA deficiente acaba submetendo-se à cirurgia de reconstrução, principalmente aqueles que pretendem manter uma vida ativa em termos de exercício físico. Isto se deve, em parte, pela percepção das alterações e limitações nas suas atividades de vida diária e, também, por alguns pesquisadores acreditarem que a permanência com o LCA deficiente levará a um maior comprometimento das estruturas do joelho com o passar do tempo (CARBON \& JOHNSON, 1993; MCDANIEL \& DAMERON, 1983). Apesar de os músculos serem protetores articulares secundários, o papel do LCA na estabilização anterior da tíbia não consegue ser eficientemente substituído pela musculatura.

Baseado nos trabalhos mencionados, os pacientes que se submetem à cirurgia podem já apresentar alterações nos padrões da marcha. Porém, o estudo de KNOLL, KOCSIS e KISS (2004) acompanhou pacientes com lesão do LCA desde antes da cirurgia até doze meses de pós-operatório. Em relação aos pacientes antes da cirurgia não encontraram diferença entre os padrões da marcha comparada a sujeitos sem lesão do LCA. Este estudo se contrapõe aos trabalhos anteriormente citados, colocando em dúvida se os sujeitos com o LCA deficiente utiliza compensações ou não durante a marcha. As alterações nos padrões da marcha podem aparecer ou ser acentuadas após a cirurgia. 
O sucesso cirúrgico e do programa de reabilitação culminará com o retorno do paciente tanto as suas atividades de vida diária como as práticas de exercícios físicos, o que na maioria das vezes acontece quando a amplitude de movimento e a força muscular parecem estar recuperadas (DEVITA, HORTOBAGYI \& BARRIER, 1998). A avaliação para a alta do paciente costuma ser realizada por parâmetros subjetivos tanto pelo fisioterapeuta quanto pelo médico e pode acontecer dos pacientes ainda apresentarem alterações nos padrões normais de movimento.

Os estudos que procuraram avaliar, entre outros aspectos, a marcha dos pacientes após a cirurgia demonstram que as alterações dessa se acentuam logo após a cirurgia e parecem permanecer mesmo após longo período pós-cirúrgico.

No estudo de DEVITA et al. (1997), ao avaliar os sujeitos após três e cinco semanas de cirurgia de reconstrução do LCA, encontraram uma maior flexão do joelho no contato do calcanhar e no médio apoio quando comparado aos sujeitos saudáveis, sendo que com três semanas estes valores são maiores do que com cinco semanas de pós-operatório (FIGURA 15). O comprimento do passo diminui com três semanas de pós-operatório e normaliza após cinco semanas. O tempo de apoio não altera nem com três nem com cinco semanas de pósoperatório. Eles salientam em suas conclusões que existe uma significante mudança na posição do quadril e do joelho, no trabalho positivo realizado no quadril e no impulso angular extensor do quadril em pacientes com três e cinco semanas de cirurgia de reconstrução do LCA quando comparado a sujeitos saudáveis. 

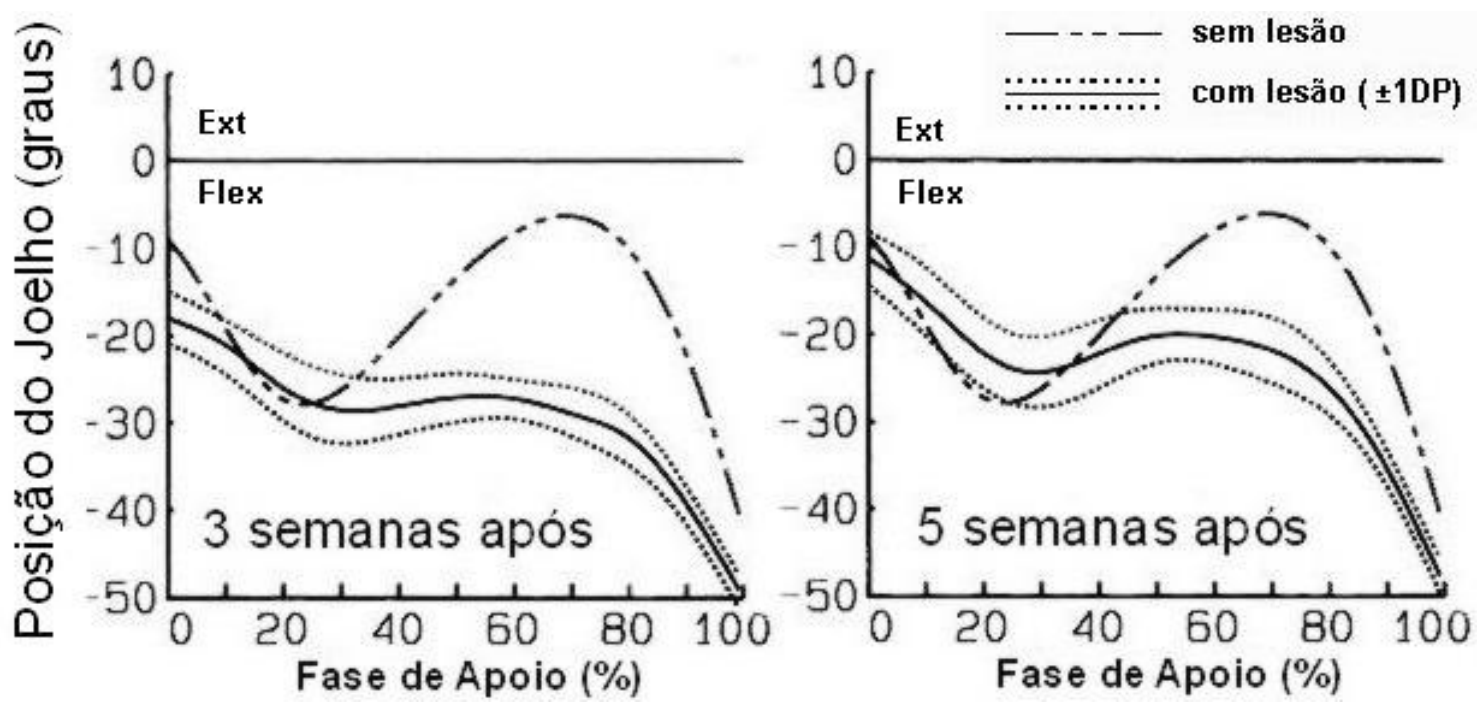

FIGURA 15 - Gráficos da variação angular do joelho de sujeitos com três e cinco semanas de pós-operatório de LCA e sujeitos saudáveis (DEVITA et al., 1997).

No estudo de LEWEK et al. (2002) os pacientes que foram submetidos à cirurgia de reconstrução do LCA há pelo menos três meses foram divididos em dois grupos: um grupo que apresentava menos de $80 \%$ de força do M.quadríceps femoral em relação ao lado não acometido e o outro que apresentava mais de $90 \%$ dessa força. O grupo com a musculatura do M.quadríceps femoral fraca apresentou menor pico de flexão do joelho na fase de apoio da marcha (FIGURA 13) As alterações nos ângulos e nos momentos do joelho na fase inicial da marcha e da corrida do grupo com M.quadríceps femoral fraco foram semelhantes ao grupo dos pacientes com LCA deficiente que não foram submetidos à cirurgia. Enquanto, o grupo com a musculatura do M.quadríceps femoral forte apresentou os mesmos padrões do grupo sem lesão do LCA. Os autores ainda salientam que a força do M.quadríceps femoral inadequada contribui para padrões alterados de marcha após a reconstrução do LCA.

Além desses estudos demonstrando que mesmo após um período de três meses póscirúrgico é possível encontrar alterações na marcha dos pacientes, existem estudos demonstrando alterações com até seis meses de cirurgia.

No estudo de DEVITA, HORTOBAGYI e BARRIER (1998) eles compararam a biomecânica do membro inferior durante a marcha entre indivíduos com reconstrução do LCA e que realizaram protocolo acelerado de reabilitação e sujeitos saudáveis. Os indivíduos com lesão do LCA foram testados três semanas e seis meses após a cirurgia. Os resultados relativos 
ao ângulo do joelho mostram uma maior flexão do joelho com três semanas de pós-operatório do que com seis meses e, após seis meses de cirurgia os ângulos do joelho são semelhantes aos sujeitos saudáveis (FIGURA 16). Segundo suas conclusões, os seus dados indicam que os pacientes caminham com padrões cinemáticos normais, mas continuam a usar torque articular e padrões de potência alterados após os seis meses de cirurgia.

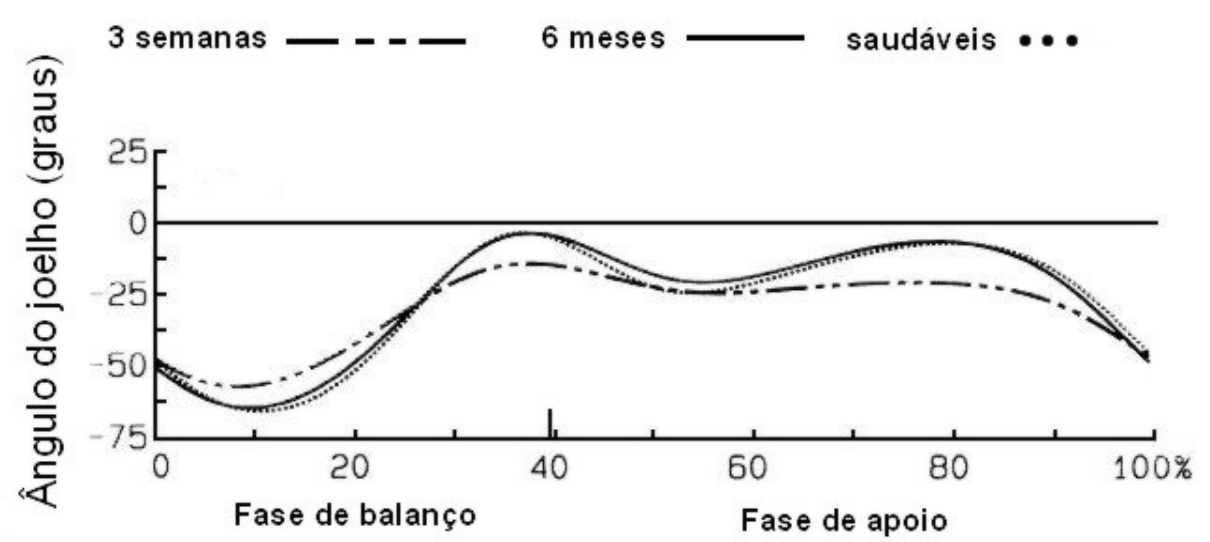

FIGURA 16 - Gráficos da variação angular do joelho de sujeitos com três semanas e seis meses de pós-operatório de LCA e sujeitos saudáveis (DEVITA, HORTOBAGYI \& BARRIER, 1998).

No trabalho de KNOLL, KOCSIS e KISS (2004) os pacientes operados recuperaram os parâmetros espaços-temporais e as alterações nos ângulos do joelho após quatro meses de cirurgia. Porém, a atividade eletromiográfica só foi comparável aos parâmetros da marcha dos sujeitos normais após oito meses de cirurgia.

Não era objetivo de nenhum dos trabalhos citados analisar que tipo de exercícios foi utilizado durante a reabilitação pós-cirúrgica do LCA. O tipo de exercício utilizado pode ter influenciado nas alterações encontradas na marcha, podendo a recuperação ser mais adequada se o tipo de exercício utilizado na reabilitação for bem selecionado.

O estudo de HOOPER et al. (2001) foi o único encontrado com o objetivo de comparar protocolos de reabilitação em CCF e CCA no pós-operatório de LCA na recuperação da marcha. Este estudo acompanhou os pacientes somente na fase inicial da reabilitação, com duas e seis semanas de pós-operatório. Os resultados não mostraram diferença entre os protocolos de reabilitação em CCF e CCA na recuperação funcional dos pacientes. Julgamos, 
entretanto que o período de seis semanas pode não ter sido suficiente para a percepção de diferenças entre os tipos de protocolo de reabilitação utilizado, sendo importante avaliar estas diferenças até o término do período de reabilitação.

\subsection{Marcha em piso fixo e na esteira rolante}

Uma abordagem prévia da marcha normal, tida aqui como a marcha de sujeitos saudáveis, é necessária para poder compreender as possíveis alterações decorrentes da lesão do LCA.

Em estudos datados da década de 80 encontram-se informações importantes sobre a marcha. Em diferentes trabalhos, WINTER (1983a), WINTER e ENG (1983) e WINTER e YACK (1987), entre outros de WINTER e colaboradores, procuraram analisar a atividade eletromiográfica durante a marcha e a partir destas informações formar uma base de referência.

WINTER (1983a) analisou as alterações que ocorrem no padrão da marcha com a variação da cadência, foram consideradas as cadências natural, lenta e rápida. Dois aspectos analisados pelo autor serão abordados por terem maior relação com as variáveis que serão analisadas neste projeto. $\mathrm{O}$ ângulo do joelho apresentou um padrão semelhante nas diferentes cadências, apresentando a maior variabilidade na fase inicial do apoio. $\mathrm{O}$ autor atribui esta maior variabilidade a uma relação direta com a quantidade de energia absorvida durante a contração excêntrica do M.quadríceps femoral na fase inicial do apoio onde o peso é absorvido, existe um aumento do ângulo de flexão com o aumento da cadência (FIGURA 17). 


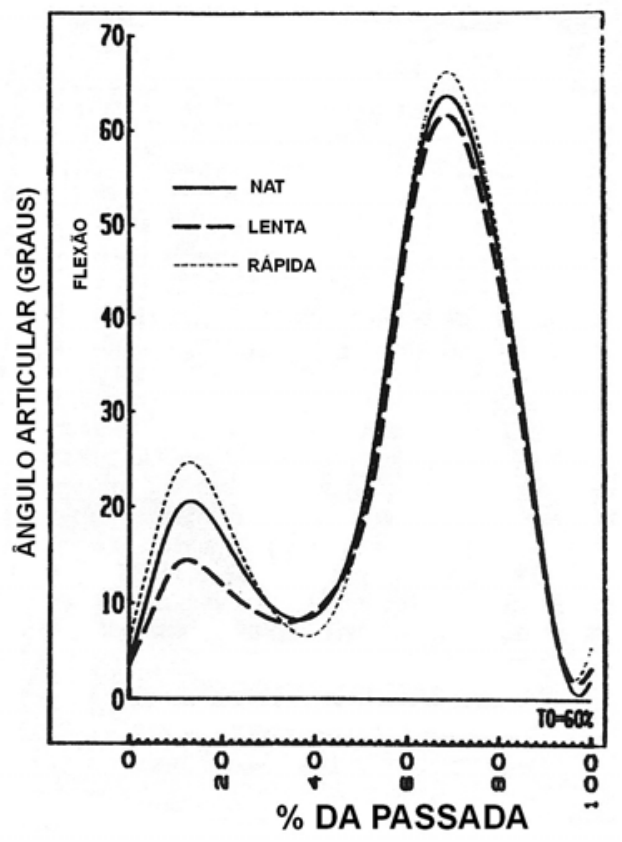

FIGURA 17 - Média do ângulo do joelho nas diferentes cadências em relação à fase da passada (WINTER, 1983a).

Outro aspecto que demonstrou ser consistente foi o padrão de ativação muscular. Em relação à ativação muscular o que modificou com as mudanças nas cadências foram as intensidades de ativação dos músculos (FIGURA 18). 


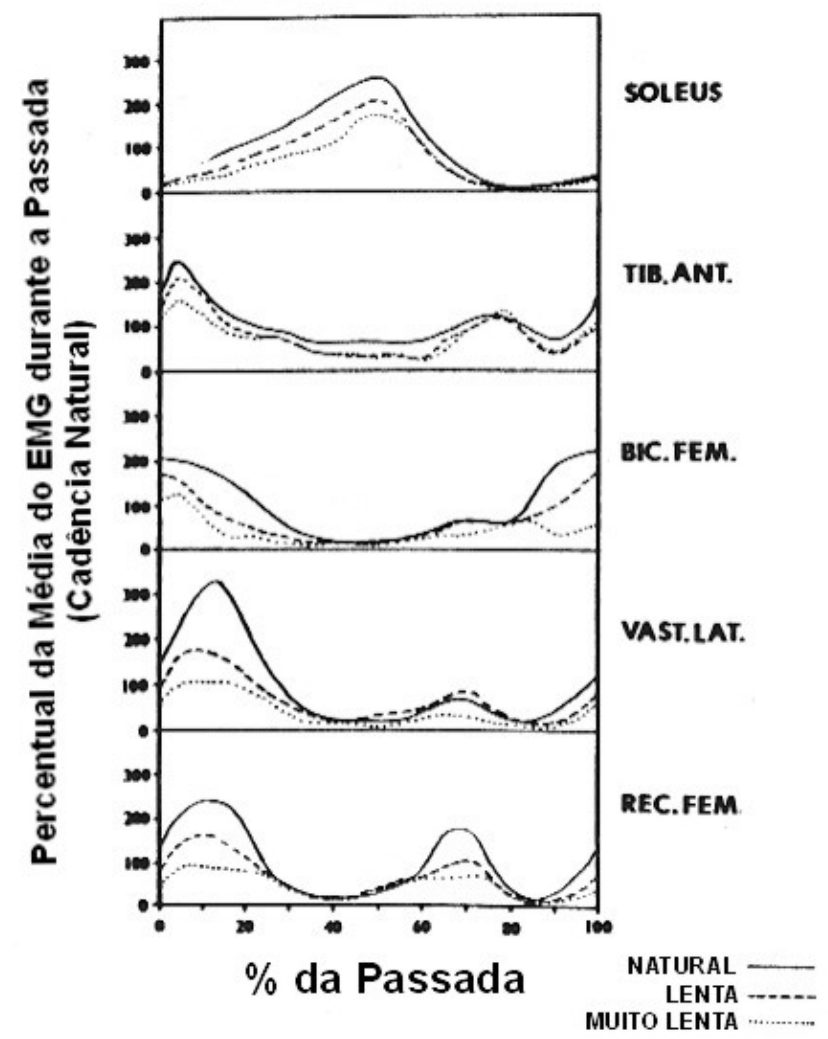

FIGURA 18 - Envelope linear do sinal EMG de cinco músculos em três diferentes cadências (WINTER, 1983a).

Entre as demais variáveis estudadas a que apresentou maior variabilidade com as mudanças na cadência foram os momentos articulares do joelho e do quadril.

WINTER e ENG (1983) tiveram como objetivo analisar a produção e absorção de energia nas articulações do joelho e do tornozelo, novamente considerando as cadências natural, lenta e rápida. A articulação do joelho apresentou quatro fases de potência mecânica (produto do torque articular pela velocidade angular da articulação): uma fase de trabalho negativo no momento da aceitação do peso; uma pequena fase de trabalho positivo durante o médio apoio; uma fase de trabalho negativo maior durante a propulsão e o início do balanço e uma fase final de absorção de energia no final do balanço que os autores atribuíram a contração excêntrica dos flexores do joelho (FIGURA 19). 


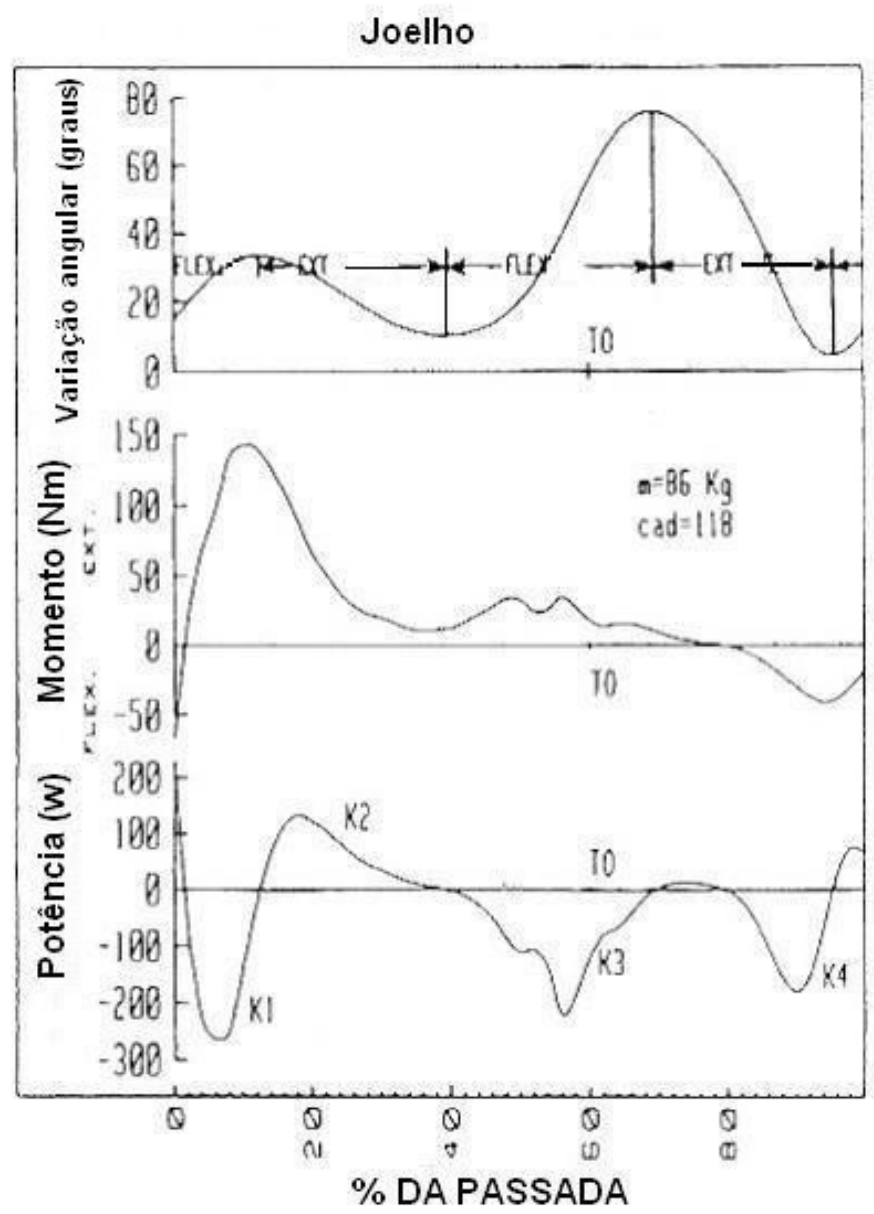

FIGURA 19 - $\underline{\text { Ângulo, momento de força e potência do joelho em relação a fase da passada }}$ (WINTER \& ENG, 1983).

O joelho foi considerado o principal responsável por absorção de energia e o tornozelo o principal gerador de energia. As principais mudanças encontradas com a variação da cadência foram uma diminuição do trabalho positivo do tornozelo e joelho com a diminuição da velocidade e uma diminuição na absorção de energia pelo M.quadríceps femoral na fase de aceitação do peso também com a diminuição da velocidade.

WINTER e YACK (1987) realizaram um estudo procurando identificar o padrão eletromiográfico da marcha com objetivo de ter uma base de referência para posteriores comparações. Os autores encontraram maior atividade dos músculos distais (perna) do que dos músculos proximais (coxa). A maior variabilidade nos padrões EMG ocorreram nos músculos 
proximais em relação aos distais. E cada músculo apresentou um mecanismo diferente de ativação durante o ciclo da marcha.

Em outro estudo envolvendo EMG ARSENAULT, WINTER e MARTENIUK (1986) realizaram uma comparação bilateral da EMG durante a marcha. Músculos homólogos apresentaram alta correlação entre si e uma forma de ativação quase idêntica. No entanto, diferenças na amplitude do sinal EMG foram encontradas.

WINTER (1983b) analisou a relação da flexão do joelho durante a fase de apoio com a ineficiência da caminhada. De acordo com seus resultados quanto maior a máxima flexão do joelho durante a fase de apoio maior o gasto energético durante a caminhada.

Outro aspecto que passou a ser de interesse foi estabelecer critérios para serem seguidos no protocolo de testes que procurassem garantir que as informações desejadas fossem adquiridas. ARSENAULT, WINTER e MARTENIUK (1986) procuraram analisar a quantidade de passadas requeridas para analisar os dados EMG da marcha. Os músculos M.reto da coxa, M.vasto medial, M.bíceps femoral, M.sóleo e M.tibial anterior foram estudados. Todos os músculos apresentaram alta estabilidade no sinal. De acordo com os autores, três passadas provém informações suficientes relativas aos dados EMG e tão confiáveis quanto os dados obtidos com doze passadas.

Após obterem-se informações de algumas características da marcha os estudos passaram a se preocupar com a simetria entre as pernas em relação a algumas variáveis da marcha. HAMILL, BATES e KNUTZEN (1984) estudaram a simetria da força de reação do solo durante a caminhada e a corrida. Os dados mostraram um alto grau de simetria entre as pernas nas forças de reação do solo, tanto para caminhada quanto para corrida (FIGURA 20). E esta simetria se manteve mesmo levando em consideração o lado dominante. 


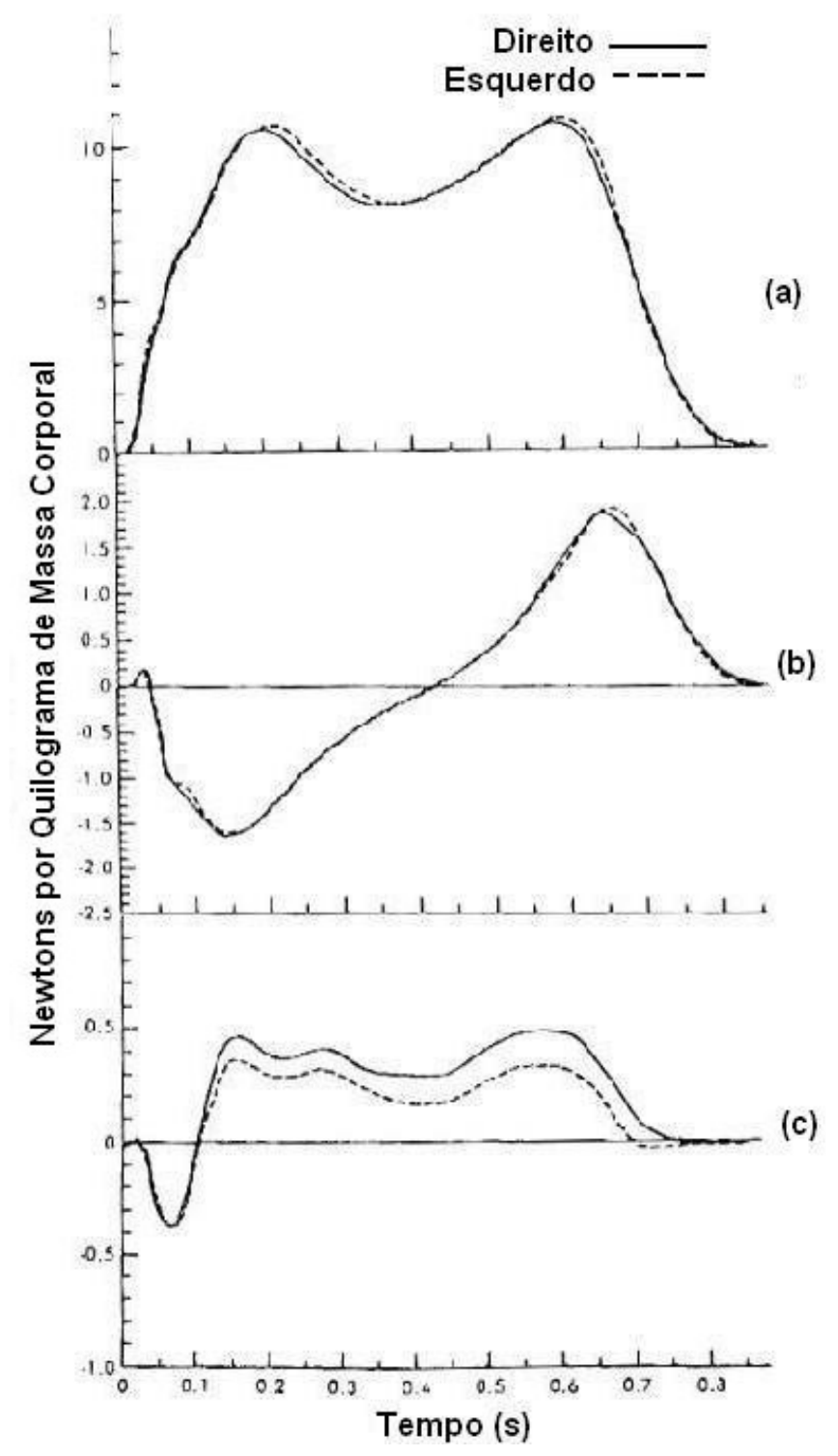

FIGURA 20 - Média das componentes da força de reação do solo para perna direita e esquerda, durante a caminhada. (a) componente vertical, (b) componente ântero-posterior e (c) componente médio-lateral (HAMILL, BATES \& KNUTZEN, 1984). 
Outro estudo abordando a simetria entre as pernas foi o de MAUPAS, PAYSANT, DATIE, MARTINET e ANDRÉ (2002) onde eles compararam a variação angular do joelho direito e esquerdo durante a caminhada. Uma diferença igual ou superior a cinco graus na flexão máxima do joelho foi encontrada entre os lados e esta diferença não apresentou correlação com a lateralidade do sujeito.

Com a difusão do uso das esteiras para realizar caminhadas e corridas começou-se a realizar estudos da marcha utilizando a esteira por ser mais fácil a análise de laboratório nestas condições. Muitos autores discutem que a marcha na esteira não reproduz a marcha em piso fixo. Com o intuito de procurar esclarecer esta questão muitos trabalhos comparando a marcha em piso fixo com a marcha na esteira têm sido realizados.

ALTON, BALDEY, CAPLAN e MORRISSEY (1998) procuraram comparar variáveis temporais do passo e variáveis cinemáticas das articulações do membro inferior entre marcha na esteira e marcha em piso fixo. Para mulheres somente o ângulo máximo de flexão do quadril apresentou diferença estatística, sendo maior na esteira. Para os homens a cadência e o ângulo máximo de flexão do joelho foram maiores na esteira. O tempo de apoio foi menor na esteira quando todos os sujeitos foram comparados juntos. Os autores concluem que existem diferenças nas variáveis temporais e cinemáticas da marcha na esteira em relação à marcha em piso fixo.

STOLZE，KUHTZ-BUSCHBECK，MONDWURF，BOCZEK-FUNCKE，JOHN, DEUSCHL e ILLERT (1997) com o objetivo de investigar diferenças entre a marcha na esteira e a marcha em piso fixo analisou comparativamente crianças e adultos. Os resultados mostraram algumas alterações como aumento da freqüência de passos, diminuição no comprimento da passada e diminuição da fase de apoio, tanto para adultos como para crianças, quando a marcha foi realizada na esteira.

WHITE, YACK, TUCKER e LIN (1998) compararam a força de reação do solo vertical da marcha em piso fixo com a marcha na esteira. Três velocidades de deslocamento foram analisadas. O padrão da força de reação do solo foi similar para todas as situações. No entanto, diferenças na magnitude da força foram evidenciadas entre os dois tipos de marcha durante o médio apoio e a última fase de apoio. Eles chamam a atenção de que se deve ter cuidado ao comparar a marcha na esteira com a marcha em piso fixo durante estas fases do apoio. 
MATSAS, TAYLOR e MCBURNEY (2000) tinham por objetivo avaliar em quanto tempo de familiarização na esteira os dados cinemáticos do joelho e os parâmetros temporais e espaciais da marcha eram representativos da marcha em piso fixo. Os seus resultados demonstram que a partir de seis minutos de familiarização existe uma alta-correlação dos dados da esteira com os dados do piso fixo sendo possível, a partir deste tempo, generalizar as informações da marcha na esteira para a marcha em piso fixo (FIGURA 21).

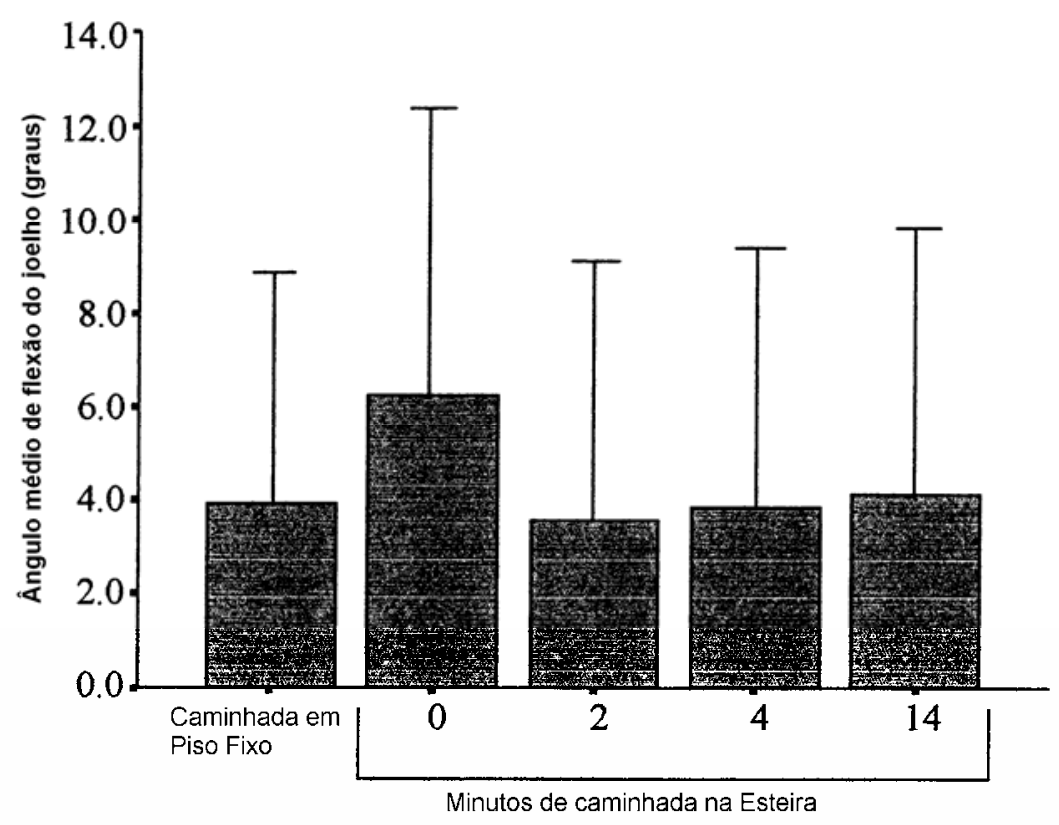

FIGURA 21 - Média do ângulo de flexão do joelho no momento do contato inicial da fase de apoio para a caminhada em piso fixo e aos $0,2,4$ e 14 minutos da caminhada na esteira (MATSAS, TAYLOR \& MCBURNEY, 2000).

Apesar das diferenças encontradas entre a marcha na esteira e a marcha em piso fixo, com este estudo abre-se a possibilidade de uma maior aceitação da análise da marcha na esteira, no momento em que se percebe que os valores de algumas variáveis se aproximam com as obtidas em piso fixo após um tempo de pelo menos seis minutos de familiarização na esteira. 
Esta pesquisa consistiu em um estudo de acompanhamento longitudinal, empírico com intervenção no real. A análise foi através da observação de comportamentos e a coleta de dados limitada a um período de tempo. Nesta pesquisa foi realizada uma avaliação biomecânica complexa da marcha, além de aspectos clínicos relevantes, em indivíduos com reconstrução do LCA submetidos a diferentes programas de reabilitação e indivíduos sem lesão. O principal objetivo deste trabalho foi avaliar a recuperação funcional do paciente.

\subsection{Seleção dos Grupos Experimentais}

A amostra foi intencional, constituída de trinta indivíduos. Os indivíduos foram divididos em três grupos de amostras independentes: (Grupo 1 - CON) dez indivíduos saudáveis que não sofreram nenhum tipo de intervenção; (Grupo 2 - CCF) dez indivíduos que após intervenção cirúrgica foram submetidos ao programa de reabilitação em CCF e (Grupo 3 - CCA) dez indivíduos que após intervenção cirúrgica foram submetidos ao programa de reabilitação em CCA. Para dividir os indivíduos com lesão do LCA nos dois grupos foi realizado um sorteio com o primeiro paciente para estabelecer o grupo que ele pertenceria, o paciente seguinte foi encaminhado para o outro grupo e assim sucessivamente os pacientes foram automaticamente intercalados entre os grupos.

Os pacientes com lesão de LCA que tinham indicação cirúrgica foram voluntários recrutados entre os pacientes do grupo de ortopedia adulto do Instituto de Ortopedia e Traumatologia da Faculdade de Medicina do Hospital das Clínicas da Universidade de São Paulo. O grupo controle foi formado por sujeitos voluntários interessados em participar da pesquisa.

Os critérios de inclusão comuns aos três grupos foram: idade entre 21 e 45 anos e indivíduos do sexo masculino. Para os pacientes a cirurgia de reconstrução do LCA devia ser realizada através da mesma técnica cirúrgica, utilizando o tendão patelar como enxerto ligamentar. Os critérios de exclusão para os pacientes foram: apresentar outra lesão ligamentar no joelho acometido, ser atleta e precisar de reabilitação diferenciada e apresentar alteração nos membros inferiores que pudesse comprometer a marcha. O critério de exclusão dos 
indivíduos do grupo controle foi apresentar algum acometimento de membros inferiores que pudesse comprometer a marcha.

Por se tratar de uma pesquisa envolvendo seres humanos o projeto necessitou de aprovação junto ao Comitê de Ética. Os procedimentos necessários para esta aprovação tiveram início com o encaminhamento do projeto, do termo de consentimento pós-informação e as demais documentações solicitadas à Comissão Científica do Departamento de Ortopedia e Traumatologia da Faculdade de Medicina da Universidade de São Paulo. Depois de aprovado por essa Comissão a documentação foi encaminhado para aprovação pela Comissão de Ética para Análise de Projetos de Pesquisa (CAPPesq) do Hospital das Clínicas da Faculdade de Medicina da Universidade de São Paulo. E por fim, foi encaminhado para a Comissão Nacional de Ética em Pesquisa (CONEP) para aprovação final.

Os pacientes que, após atendimento no ambulatório do Instituo de Ortopedia e Traumatologia da Faculdade de Medicina do Hospital das Clínicas, apresentaram indicação cirúrgica de reconstrução do LCA foram consultados a respeito da sua participação nessa pesquisa. O contato foi feito pela pesquisadora executante que explicou todo o envolvimento do paciente e mostrou o termo de consentimento pós-informação (ANEXO I), que ele teria que assinar. Com os pacientes que concordaram em participar da pesquisa foi marcada a data para realização do teste pré-cirúrgico. Só no dia do teste, depois do paciente ter tido tempo de refletir sobre o assunto, é que foi assinado o termo de consentimento pós-informação.

\subsection{Protocolo Experimental}

O protocolo experimental foi constituído de avaliações e tratamento. Os testes para avaliar os parâmetros biomecânicos desejados foram realizados em duas etapas: avaliação clínica (avaliação do DTA e escore de Lysholm) e avaliação da marcha (análise dinâmica, cinemática e eletromiográfica). O tratamento consistiu de dois protocolos de exercícios distintos, CCA e CCF, com progressão da carga ao longo do tempo. As medições foram realizadas em ambiente de laboratório e o tratamento foi desenvolvido em ambiente clínico apropriado.

O protocolo experimental ocorreu da seguinte forma: os pacientes receberam uma orientação inicial de exercícios para serem realizados todos os dias em casa, a partir da alta 
hospitalar, durante o primeiro mês pós-cirúrgico (orientações especificadas no QUADRO 1). Estes exercícios iniciais foram realizados de forma idêntica pelos dois grupos (CCF e CCA) até que eles pudessem realizar a avaliação da marcha na esteira sem o uso de muletas. Essa foi a forma utilizada para que a primeira avaliação da marcha após a cirurgia ainda não tivesse influência dos diferentes exercícios usados para reabilitação. E essa avaliação serviu de parâmetro para comparação com a avaliação ao final do tratamento onde os resultados seriam influenciados pelos diferentes tipos de reabilitação.

O tratamento propriamente dito iniciou com quatro semanas após a cirurgia (um mês pós-cirúrgico) e seguiu por doze semanas, ou seja, até completar quatro meses póscirúrgico, quando o período de reabilitação foi encerrado. Durante a pesquisa os pacientes foram submetidos a três testes: (Teste 1 - Pré) antes da cirurgia; (Teste 2 - 1PO) com quatro semanas pós-cirúrgico, ou seja, um mês pós-cirúrgico e (Teste 3 - 4PO) após dezesseis semanas da cirurgia, ou seja, quatro meses pós-cirúrgico (final do tratamento).

Para a elaboração deste protocolo experimental foi necessário a realização de três estudos pilotos com o objetivo de avaliar algumas variáveis. O primeiro estudo piloto foi realizado para solucionar o problema da equivalência das cargas a serem utilizadas nos dois tipos de protocolos de reabilitação propostos, CCF e CCA (ANEXO II). O segundo estudo piloto teve por objetivo avaliar se o sujeito com lesão do LCA seria capaz de realizar o teste de carga máxima antes da cirurgia (ANEXO III). E o terceiro estudo piloto teve como objetivos testar o protocolo de teste na esteira e avaliar se quatro semanas de pós-operatório seriam suficientes para o paciente conseguir caminhar na esteira sem apoio (ANEXO IV). A partir dos resultados dos estudos pilotos foi possível ajustar os aspectos relacionados ao protocolo experimental e garantir a viabilidade da metodologia proposta.

A FIGURA 22 apresenta um fluxograma ilustrativo dos procedimentos e instrumentos metodológicos utilizados, representando as etapas do protocolo experimental, definidas de acordo com a literatura especializada e os objetivos da presente pesquisa. 


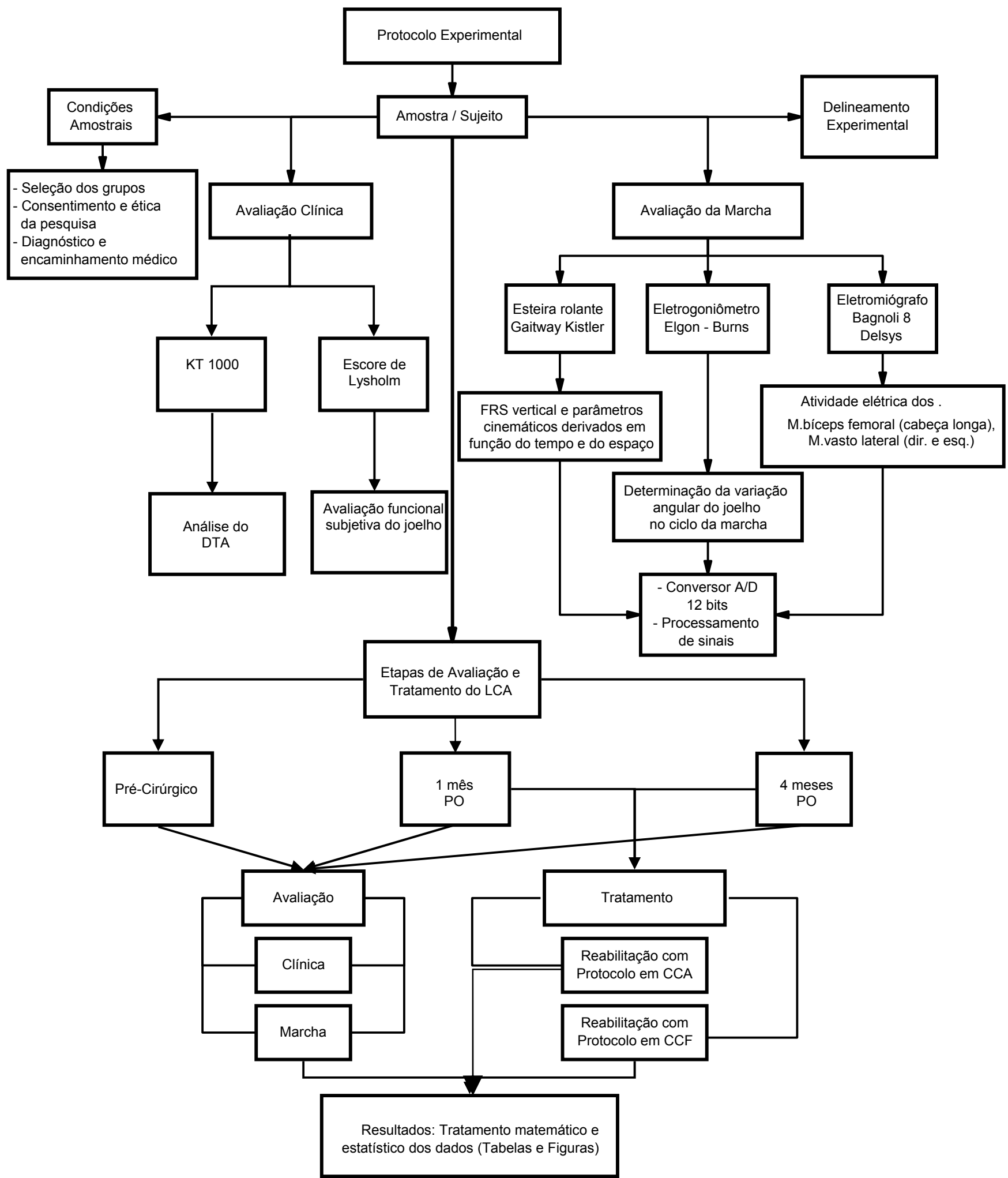

FIGURA 22 - Diagrama de blocos representando o fluxograma das etapas metodológicas segundo protocolo experimental. Siglas utilizadas: DTA - deslocamento tibial anterior e PO - pós-operatório. 


\subsubsection{Avaliação Clínica}

\subsubsection{Deslocamento Tibial Anterior}

Para análise do deslocamento tibial anterior foi utilizado o equipamento KT1000 (MEDmetric Corporation). O equipamento possui um sensor para ser posicionado na patela e outro para ser posicionado na tíbia e um dinamômetro que informa a força aplicada pelo sujeito que realiza o teste. Durante a aplicação da força o equipamento emite dois sons: o primeiro indica que a força aplicada é de $67 \mathrm{~N}$ (15 pounds) e o segundo indica uma força de 89N (20 pounds) que é a máxima do equipamento (WOJTYS \& CARPENTER, 1994). Através desse equipamento a tíbia é tracionada anterior ou posteriormente conforme o ligamento cruzado a ser testado, e o deslocamento da tíbia é medido em milímetros pelo sistema de escala existente no equipamento.

Para a avaliação do DTA o equipamento foi cuidadosamente posicionado no indivíduo que se encontrava em decúbito dorsal com o joelho em flexão de $20^{\circ}$. Para avaliar o LCA a força de tração na tíbia foi anterior e a força aplicada foi a máxima do equipamento (FIGURA 23). Três medições foram realizadas em cada joelho e o valor médio das três medidas foi utilizado para calcular a diferença do DTA entre os membros inferiores. O valor utilizado para avaliar o DTA foi o da diferença entre os membros inferiores.

FIGURA 23 - Ilustração do posicionamento do equipamento KT1000. 


\subsubsection{Escore de Lysholm - Escala de Avaliação Funcional do Joelho}

O escore de Lysholm foi aplicado para avaliar o quadro clínico do paciente no que diz respeito ao aspecto funcional do joelho (ANEXO V). Este escore consiste de perguntas que são respondidas pelo próprio paciente de acordo com sua análise e são direcionadas aos sintomas da lesão e funcionalidade do joelho. Cada item de escolha das respostas possui uma pontuação, que ao final do questionário gera um escore que varia de zero a cem. $\mathrm{O}$ valor do escore final permite avaliar o quadro clínico do paciente, quanto maior o escore mais próximo do normal encontra-se o joelho.

\subsubsection{Avaliação dinâmica, cinemática e eletromiográfica da marcha}

A marcha foi avaliada segundo parâmetros biomecânicos dinâmicos, cinemáticos e eletromiográficos em uma esteira rolante. A aquisição das respostas dinâmicas e cinemáticas da marcha foi realizada por meio de duas plataformas de forças acopladas à esteira rolante e um eletrogoniômetro, onde as variáveis relativas à FRS, aos parâmetros temporais e espaciais e à variação angular foram registradas. A aquisição das respostas eletromiográficas foram realizadas por meio de um eletromiógrafo, onde a atividade muscular durante a marcha foi registrada. Estas aquisições foram simultâneas e sincronizadas através do sistema Gaitway Kistler e administradas pelo software Gaitway (FIGURA 24). 

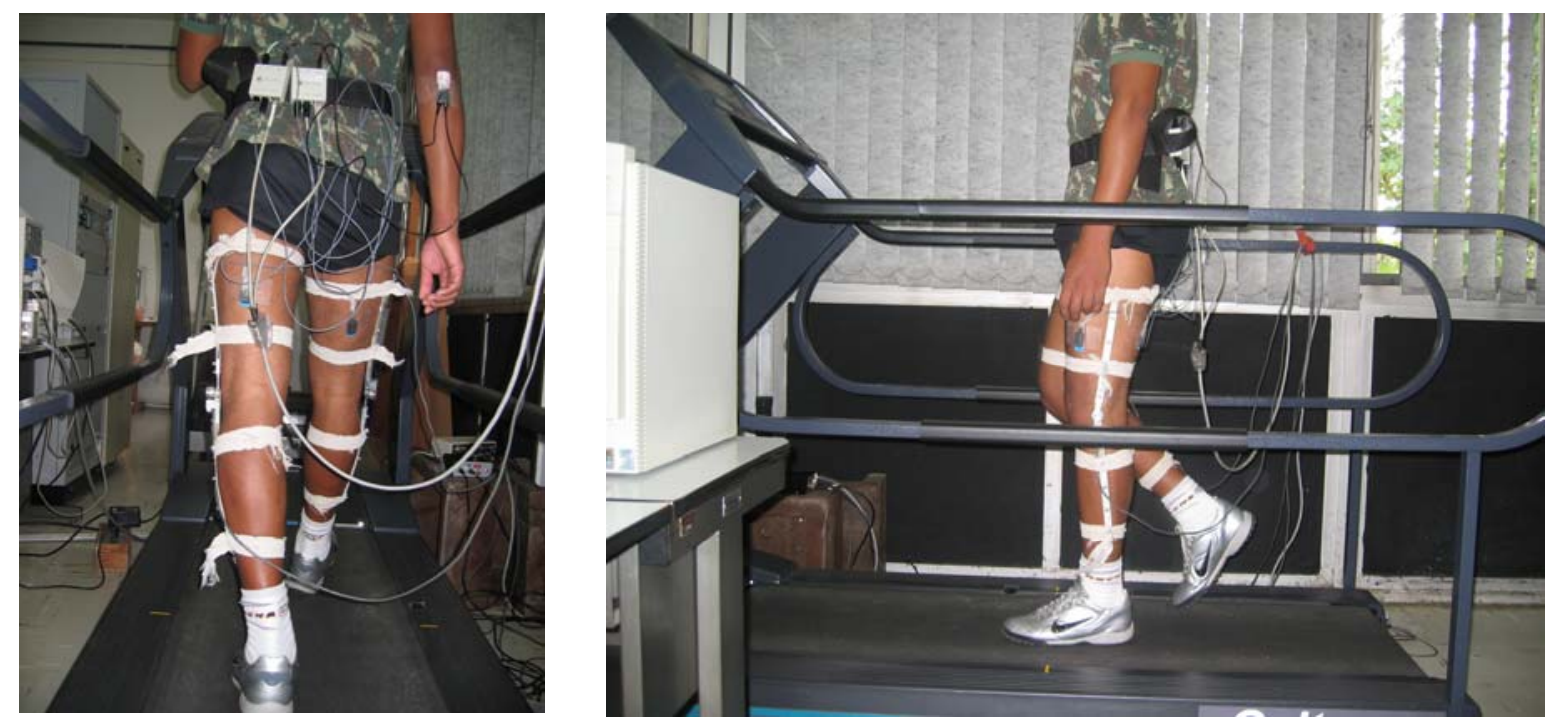

FIGURA 24 - Fotos ilustrativas dos equipamentos utilizados para avaliação da marcha: esteira rolante com plataformas de força acopladas, eletrogoniômetro e eletromiógrafo.

\subsubsection{Determinação das variáveis dinâmicas e cinemáticas: força reação do solo, parâmetros temporais e espaciais do ciclo da marcha}

A determinação das variáveis dinâmicas foi realizada através do Sistema Gaitway Instrumented - Kistler Type 9810S1x \& Software Version 1.0x. Este sistema consiste de uma esteira rolante (Trotter Treadmill Type N01-06560201) com duas plataformas de força montadas na sua superfície (FIGURA 25), gerenciadas por um conversor Analógico/Digital (A/D) e um programa de funções Gaitway responsável pela aquisição, análise parcial e armazenamento dos dados. 

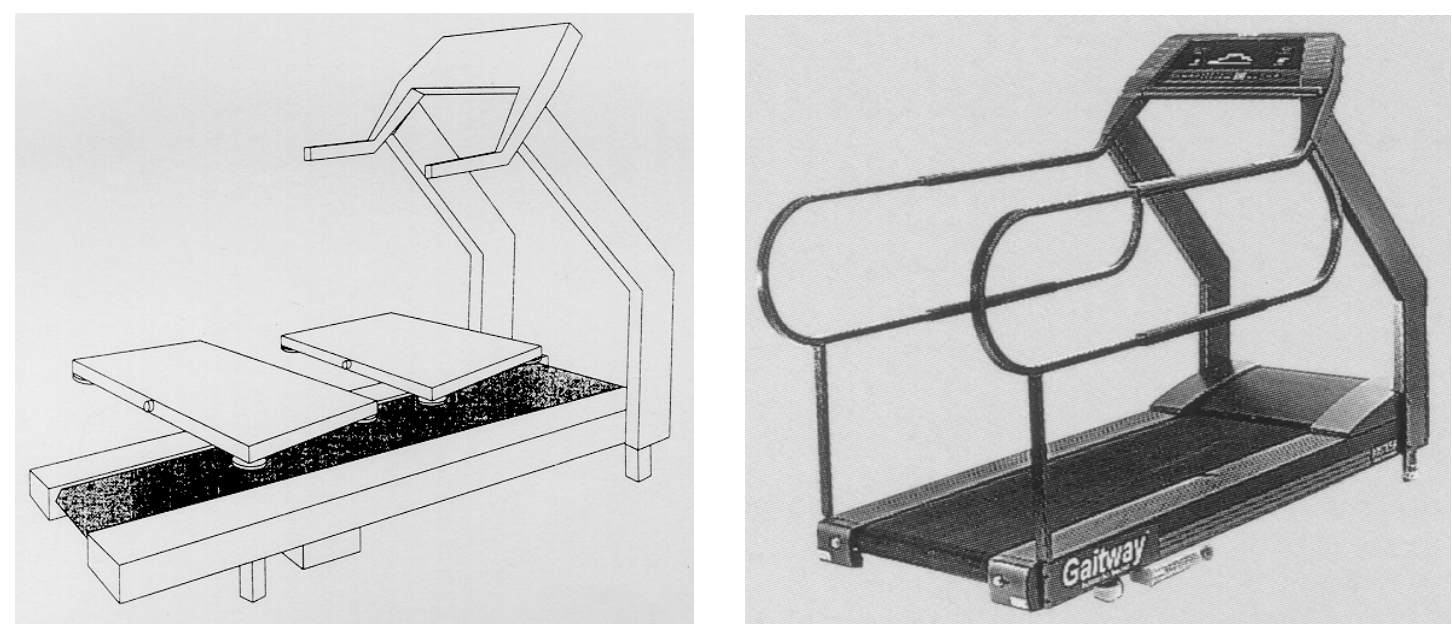

FIGURA 25 - Sistema Gaitway da Kistler: esteira rolante com duas plataformas de força embutidas. (adaptado de GAITWAY, 1996).

As duas plataformas de força Kistler são montadas em série na base da esteira rolante, cujo posicionamento permite a discriminação dos passos em função dos apoios nas plataformas. O software detecta, separa e distingui o pé esquerdo do direto com a ajuda de um dispositivo auxiliar denominado gaitway foot discriminator, este dispositivo é constituído de um sinal infravermelho retro-reflexivo localizado na lateral direita da esteira que identifica a passagem do pé direito.

O sistema necessita de calibração e para realização da mesma, dois procedimentos são utilizados: (1) inicialmente, o ajuste do nível da plataforma em relação a horizontal controlado por um teste específico do software, que informa a necessidade ou não do ajuste do nível, e (2) registro da força peso adquirido a partir da massa do próprio sujeito a ser avaliado, posicionado-o sobre uma das plataformas de força da esteira. A calibragem nominal do sistema (Gaitway System Calibration) envolve a resposta de sensibilidade das células de carga piezoelétricas, faixas de variação do sinal, sensores de velocidade e sensibilidade do sensor que discrimina o pé.

O conversor A/D que foi utilizado para gerenciar os dados da esteira é o DAS 1600/1400 Series Keithlez Instruments Inc. Entre as suas características e especificações técnicas estão: (1) 16 canais, (2) resolução de 12 Bits, (3) acurácia absoluta 0,01\%, (4) tempo

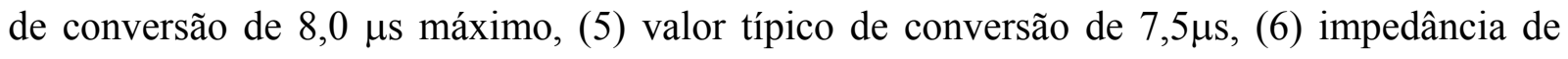
entrada $>25 \mathrm{M}$ ohms, (7) valor mínimo do modo de rejeição comum de $100 \mathrm{~dB}$ para ganho de 
500, (8) presença do direct memory acess (DMA), (9) ganho de 500 (0 a $+20 \mathrm{mV}$ para unipolar) e $500( \pm 20 \mathrm{mV}$ para bipolar).

Por ser um ambiente provavelmente novo para muitos sujeitos, foi realizado um processo de familiarização na esteira antes da realização do teste e este foi composto de algumas etapas a serem descritas a seguir. Os sujeitos caminharam em piso fixo, numa passarela de cerca de $20 \mathrm{~m}$, por aproximadamente cinco minutos de forma a estabelecer a cadência natural mais confortável para cada sujeito quando realizam a marcha em piso fixo. Esta cadência, denominada como cadência auto-selecionada, foi quantificada por meio de um metrônomo. Após esta etapa, os sujeitos passaram para a marcha na esteira. O início do processo na esteira foi reproduzir a cadência auto-selecionada do piso fixo para a esteira. Para isto, a velocidade inicial foi baixa e gradualmente ela foi aumentada até que a cadência da marcha na esteira entrasse em sincronia com o sinal do metrônomo que estava reproduzindo a cadência do piso fixo. A partir da definição da velocidade, os sujeitos tiveram um período de familiarização na esteira de dez minutos aproximadamente, com o objetivo de atingir estabilidade no novo ambiente.

Após a familiarização com a esteira rolante, foi realizada a coleta propriamente dita com duração de cinco minutos, durante este período três coletas foram feitas com duração de doze segundos cada uma, com freqüência de amostragem de $1000 \mathrm{~Hz}$.

As variáveis dinâmicas, temporais e espaciais que foram analisadas durante o ciclo da marcha na esteira rolante, foram as seguintes:

1) pico da força vertical máxima 1 (Fy1);

2) pico da força vertical máxima $2(\mathrm{Fy} 2)$;

3) força vertical mínima (Fymin);

4) taxa de crescimento do $1^{\circ}$ pico da força vertical (txcFy1): definida como a razão entre o $1^{\circ}$ da força vertical e o tempo até este pico de força $(\mathrm{Fy} 1 / \Delta \mathrm{t} 1)$

5) taxa de crescimento do $2^{\circ}$ pico (txcFy2): definidas como a razão entre o $2^{\circ}$ pico da

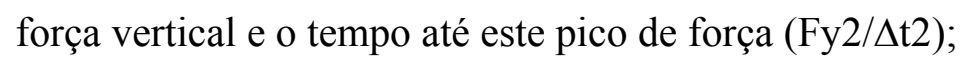

6) deflexão da força vertical: definida como sendo a taxa de decréscimo da Fyl até a força mínima (Fy1 - Fymin/ $\Delta \mathrm{t} 3)$;

7) tempo do primeiro pico de força vertical;

8) tempo do segundo pico de força vertical; 
9) tempo de apoio simples para cada pé;

10) tempo de apoio duplo;

11) tempo da passada direita e esquerda;

12) tempo do passo direito e esquerdo;

13) comprimento do passo direito e esquerdo;

14) comprimento da passada direita e esquerda, que é definida como o espaço percorrido pelo sujeito entre o início do contato de um pé até o início do próximo contato com o mesmo pé;

15) simetria dos itens relacionados (exceto itens $\underline{4}, \underline{5}$ e $\underline{6}$ ), calculada conforme fórmula proposta por HERZOG, NIGG e ULSSON (1989):

$$
A S I=\left|\frac{2(\text { Xesq }- \text { X dir) }}{\text { Xesq }+ \text { Xdir }}\right| \quad x 100 \%
$$

onde,

- Xesq: valor da variável do lado esquerdo ou não-operado

- Xdir: valor da variável do lado direito ou operado

As FIGURAS 26 e 27 apresentam algumas representações necessárias para melhor entendimento das variáveis analisadas. 


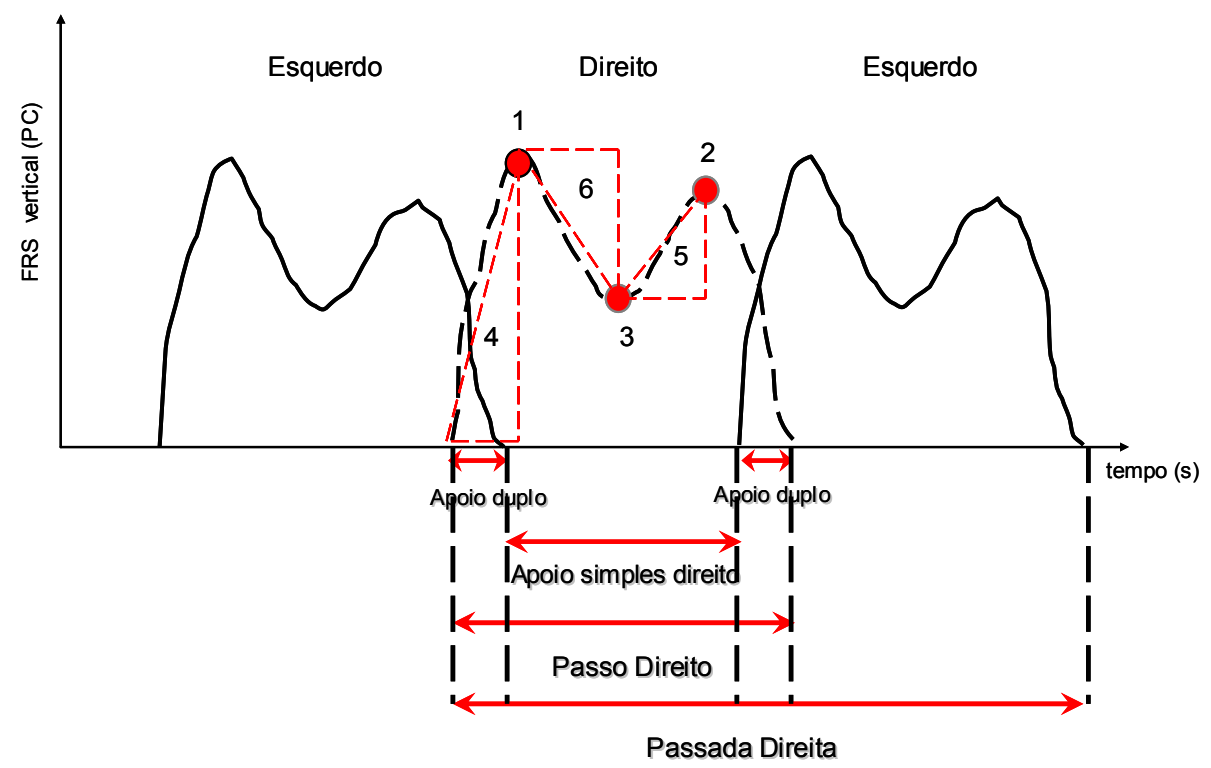

FIGURA 26 - Curva esquemática da força reação do solo representando algumas variáveis estudadas: (1) pico de força vertical máxima 1, (2) pico de força vertical máxima 2, (3) força vertical mínima, (4) taxa de crescimento 1, (5) taxa de crescimento 2, (6) deflexão da força. E representação esquemática do que corresponde a passada, o passo, o apoio duplo e o apoio simples. (Adaptado de $\underline{\text { SACCO, 2001). }}$ 


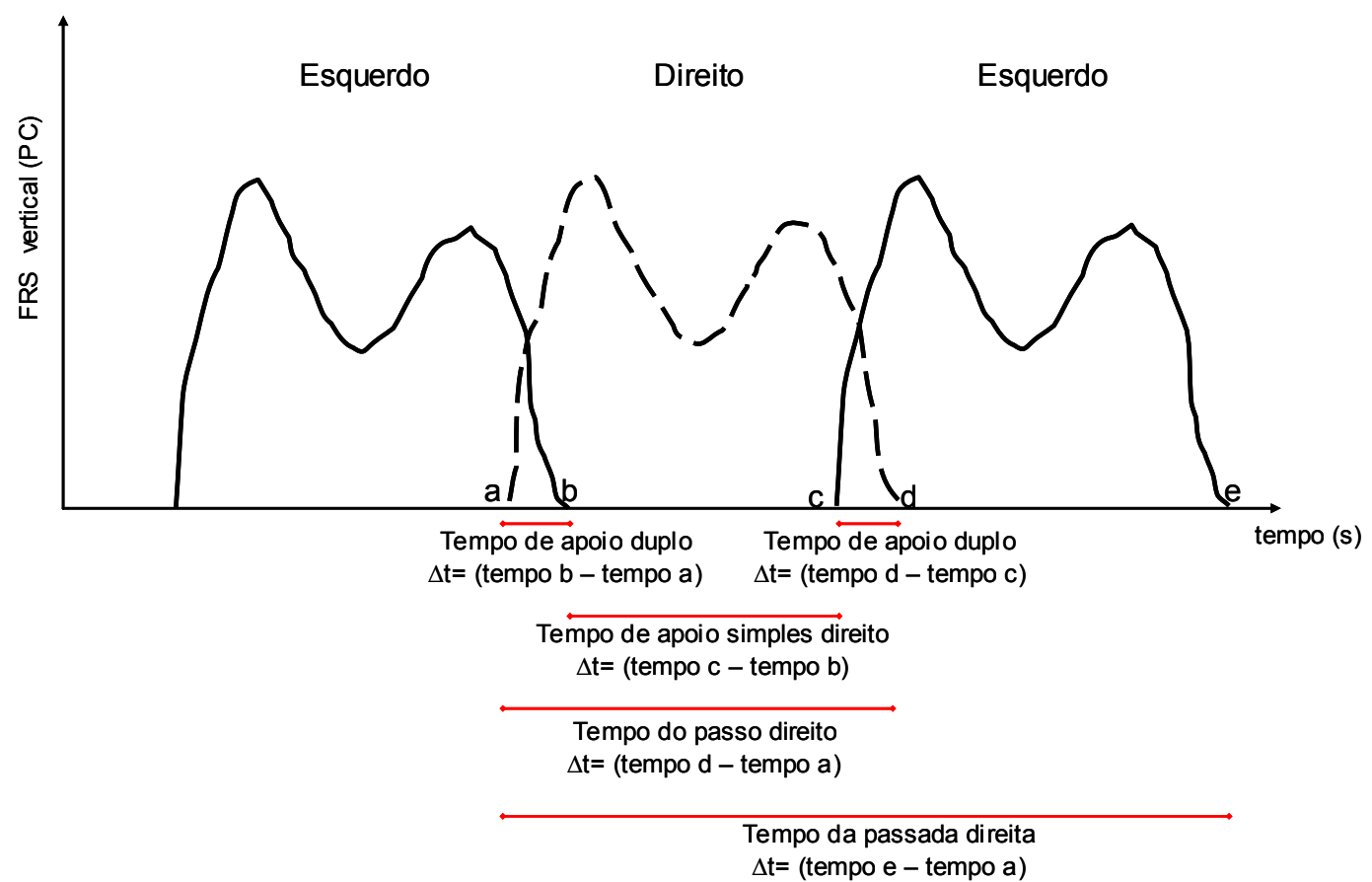

FIGURA 27 - Curva esquemática da força reação do solo com representação esquemática do intervalo de tempo que corresponde o tempo de apoio duplo, tempo de apoio simples, tempo do passo e tempo da passada.

\subsubsection{Determinação de variáveis cinemáticas: Variações angulares do joelho}

As variações angulares da articulação do joelho durante o ciclo da marcha foram monitoradas através de um eletrogoniômetro planar que tem como transdutor um potenciômetro de rotação.

O eletrogoniômetro utilizado (FIGURA 28) é constituído de duas hastes flexíveis, articuladas por um potenciômetro Bourns (tipo 65345-001-502). O potenciômetro apresenta uma linearidade nominal de $\pm 0,5 \%$ e resistência de $5 \mathrm{~K} \Omega \pm 10 \%$, e opera com um amplificador linear de sinais de duas entradas $(+5 \mathrm{~V}$ e $-5 \mathrm{~V} ;+10 \mathrm{~V}$ e $-10 \mathrm{~V})$ e com duas saídas que permitem a conexão com o conversor analógico/digital.

Um eletrogoniômetro foi posicionado no joelho direito e outro no joelho esquerdo. O posicionamento do eletrogoniômetro seguiu alguns parâmetros. As hastes foram fixadas à coxa e à perna dos sujeitos com bandagens elásticas, tendo como referência para seu 
posicionamento na coxa o trocânter maior do fêmur, e na perna o maléolo fibular. Para que o potenciômetro ficasse o mais próximo possível do centro de rotação do joelho ele foi posicionado na altura do côndilo lateral do fêmur. A partir da movimentação da articulação, e conseqüentemente das hastes, o potenciômetro altera sua tensão elétrica, que, a partir de uma rotina de calibração, permite a determinação da variação angular naquela articulação.

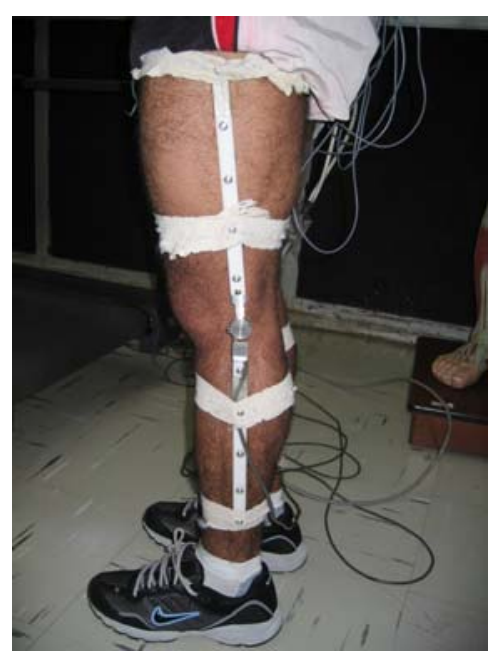

FIGURA 28 - Ilustração do posicionamento do eletrogoniômetro.

\subsubsection{Determinação das variáveis eletromiográficas no ciclo da marcha}

Para o registro da atividade elétrica muscular foi utilizado o eletromiógrafo Bagnoli 8 EMG System - Delsys (FIGURA 29), que possibilitou a análise da ativação dos músculos selecionados durante o ciclo da marcha

O sistema Bagnoli-8 da Delsys possui um amplificador de oito canais analógicos cujas faixas de amplificação são de 100 a 10000 vezes por canal. Cada canal analógico tem uma freqüência de resposta de $20 \pm 5 \mathrm{~Hz}$ a $450 \pm 50 \mathrm{~Hz}$. A amplitude da voltagem máxima de saída do amplificador é de \pm 5 Volts. O amplificador do sistema Bagnoli-8 apresenta um modo comum de rejeição (CMRR) de $92 \mathrm{~dB}$ (valor típico) e usa uma fonte de alimentação de 12 VDC, 120 mA (FIGURA 29).

Além das especificações do amplificador dos sinais eletromiográficos, faz-se necessário a descrição das características dos eletrodos do sistema Bagnoli-8. Os eletrodos são 
de superfície bipolares diferenciais ativos. Eles são constituídos de duas barras de prata das seguintes dimensões: 10 X $1 \mathrm{~mm}$ (FIGURA 29) e sua estrutura tem as seguintes dimensões: 19,8 X 5,4 X 35 mm, sendo a distância entre os eletrodos fixa em 10mm. Os eletrodos já são pré-amplificados com fator 10 .

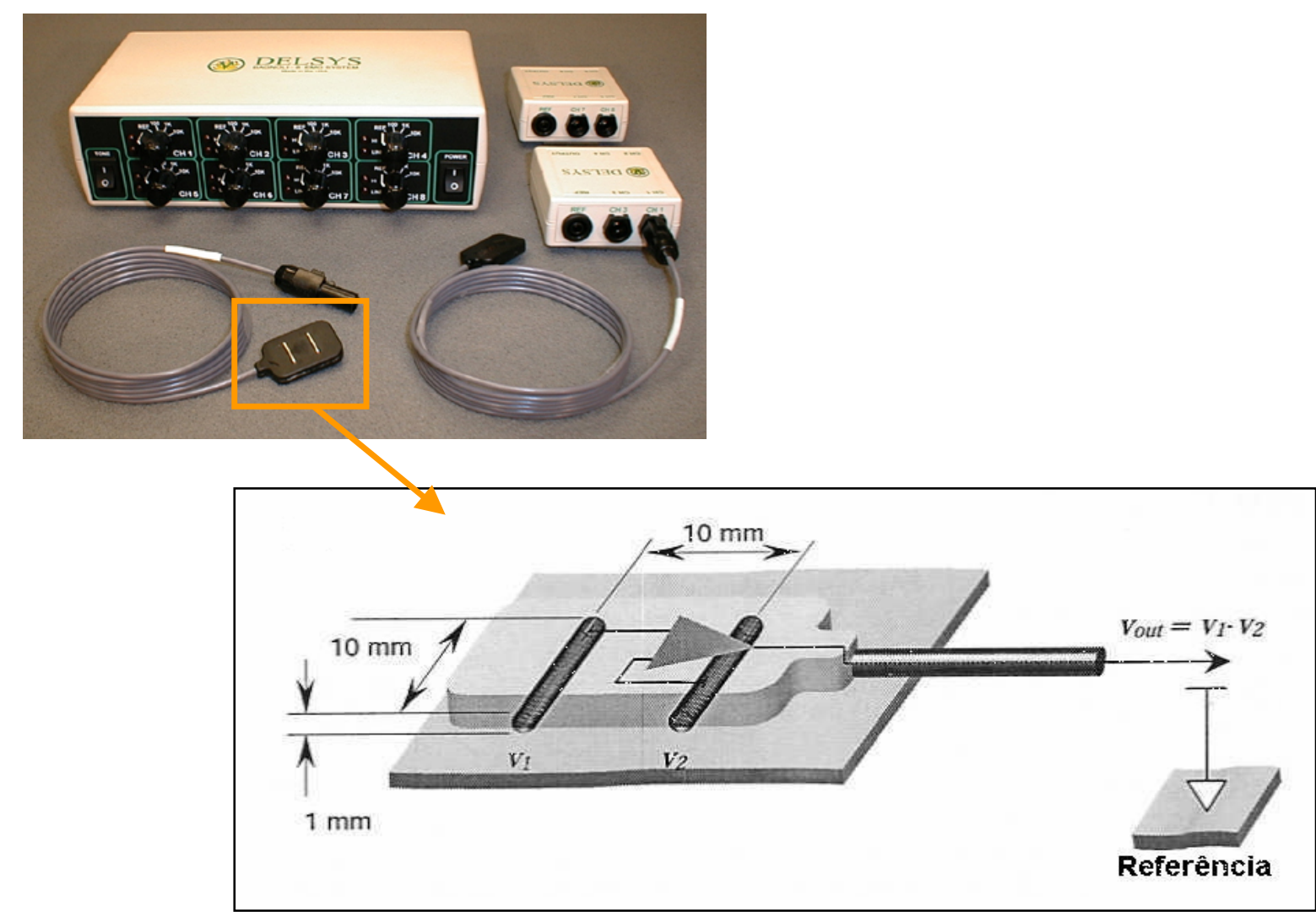

FIGURA 29 - Sistema Bagnoli-8 com oito canais da Delsys (adaptado de WINTER, 1979).

A freqüência de amostragem de sinais foi de $1000 \mathrm{~Hz}$ e o tempo de aquisição dos sinais de $12 \mathrm{~s}$ para cada uma das três coletas no decorrer dos cinco minutos.

A intensidade da atividade elétrica dos músculos investigados foi representada, através de envoltórios lineares, que fornecem o padrão de atividade muscular em função da duração da passada em diferentes tentativas e indicam qualitativamente a coordenação temporal da atividade muscular durante o movimento (FIGURA 30). Além da seqüência de etapas ilustrada na FIGURA 30, para a construção dos envoltórios lineares, o sinal do EMG ainda foi normalizado na base do tempo de apoio ( 0 a $100 \%$ do tempo de apoio). 

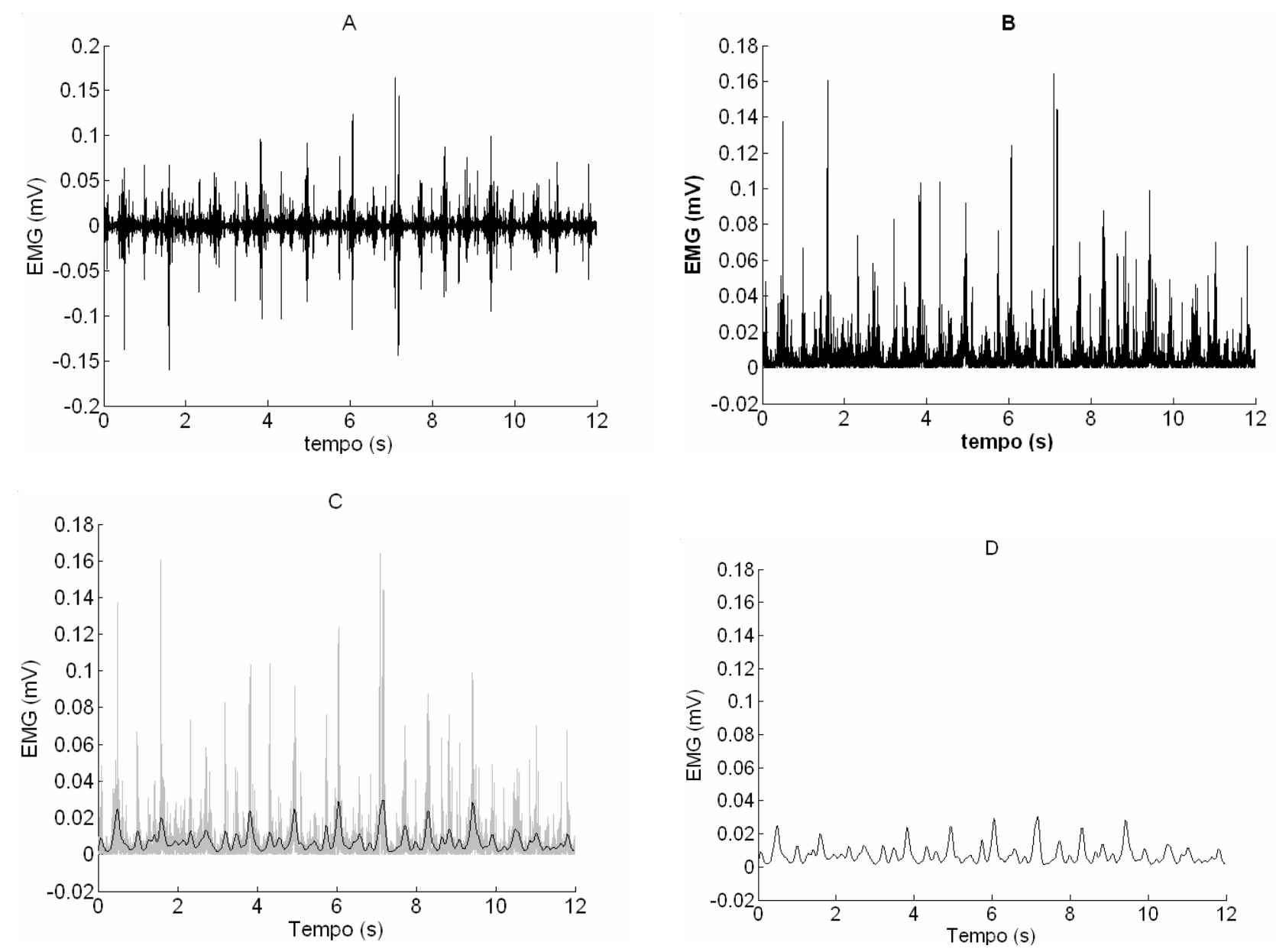

FIGURA 30 - Etapas do tratamento matemático do sinal eletromiográfico do músculo vasto lateral direito para a elaboração dos envoltórios lineares. (A) Sinal EMG bruto. (B) Sinal EMG retificado e retirado o off-set. (C) Sinal EMG retificado (cinza) e sinal filtrado com freqüência de corte de $5 \mathrm{~Hz}$ (preto). (D) Envoltórios lineares.

A distribuição da atividade muscular durante as diferentes fases do andar foram analisadas a fim de se identificar a reorganização das sinergias musculares que podem ocorrer após uma cirurgia de reconstrução do LCA. Estas variáveis foram descritas temporalmente em termos da porcentagem do ciclo do andar.

Os músculos selecionados para serem analisados foram, o M.vasto lateral e o M.bíceps femoral; representando, respectivamente, o grupo extensor e o grupo flexor do joelho (FIGURA 31). Portanto, foram registradas as atividades elétricas de quatro músculos, dois no membro inferior direito e dois no membro inferior esquerdo. 
(a)

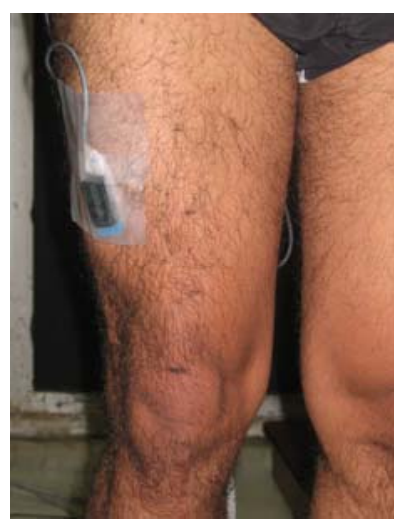

(b)

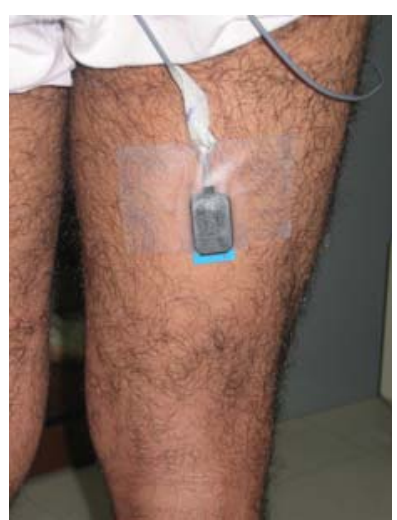

FIGURA 31 - Ilustração do posicionamento dos eletrodos nos músculos avaliados: (a) vasto lateral e (b) bíceps femoral (cabeça longa).

O eletrodo ativo de superfície foi colocado sobre o ventre muscular de cada músculo e o eletrodo referência em uma proeminência óssea que no presente trabalho foi no olécrano da ulna, seguindo as recomendações do SENIAM (HERMENS, FRERIKS, MERLETTI, STEGEMAN, BLOK, RAU, DISSELHORST-KLUG \& HÄGG, 1999). Estes eletrodos foram fixados na pele previamente preparada com a remoção de células mortas e oleosidade. A fixação foi feita com uma fita adesiva de dupla face entre a pele e o eletrodo e uma fita adesiva do tipo transpore por cima do eletrodo, que devido sua composição plástica, evita que o eletrodo se descole em função da provável sudorese provocada pela caminhada na esteira.

Para a aquisição das variáveis eletromiográficas e dinâmicas, foi necessário um equipamento que permitisse a sincronia durante a coleta dos canais provenientes do Sistema Bagnoli, do Sistema Elgon-Bourns, assim como dos canais do Sistema Gaitway. Para atender esta necessidade o mesmo conversor $\mathrm{A} / \mathrm{D}$, já descrito para os dados referentes às plataformas de força, foi utilizado com o eletrogoniômetro e o eletromiógrafo e este estava associado a um computador digital. A função do conversor foi transformar os sinais analógicos, provenientes das plataformas e do eletromiógrafo, em digital, para que se pudesse armazenar e analisar os dados com maior segurança, considerando que as fontes de erro foram controladas. 


\subsubsection{Tratamento Clínico}

O tratamento clínico, dividido em dois grupos distintos de acordo com o tipo de protocolo, teve início na quinta semana pós-cirúrgica. Durante o primeiro mês pós-cirúrgico os pacientes receberam uma orientação de exercícios para serem realizados uma vez ao dia, todos os dias, em casa (QUADRO 1). Além da aplicação de bolsa de gelo três vezes ao dia.

QUADRO 1 - Descrição dos exercícios realizados no primeiro mês pós-cirúrgico, conforme orientação que foi entregue aos pacientes.

\begin{tabular}{|c|c|}
\hline & Exercícios para o $1^{0}$ mês de Pós-Operatório LCA (1x por dia) \\
\hline 1) & $\begin{array}{l}\text { Deitado de barriga para cima. Levantar e abaixar a perna com o joelho esticado. (Repetir } \\
\text { 10x cada perna) }\end{array}$ \\
\hline 2) & $\begin{array}{l}\text { Deitado de lado. Levantar e abaixar a perna que está por cima mantendo o joelho } \\
\text { esticado. (Repetir 10x cada perna) }\end{array}$ \\
\hline 3) & $\begin{array}{l}\text { Deitado de lado. Levantar e abaixar a perna que está por baixo mantendo o joelho } \\
\text { esticado. (Repetir 10x cada perna) }\end{array}$ \\
\hline 4) & $\begin{array}{l}\text { Deitado de barriga para baixo. Levantar e abaixar a perna com o joelho esticado. (Repetir } \\
\text { 10x cada perna) }\end{array}$ \\
\hline 5) & $\begin{array}{l}\text { Deitado de barriga para cima, colocar uma toalha pequena (enrolada) embaixo do joelho. } \\
\text { Pressionar o joelho contra a toalha, fazendo com que o joelho fique mais esticado. Manter } \\
\text { pressionado enquanto conta até } 10 \text { e depois relaxa. (Repetir 10x só com a perna operada) }\end{array}$ \\
\hline & $R 2=$ \\
\hline 6) & $\begin{array}{l}\text { Deitado de barriga para cima. Dobrar e esticar o joelho, respeitando o limite da dor. } \\
\text { (Repetir 10x só com a perna operada). Após manter o joelho dobrado por } 1 \text { minuto. }\end{array}$ \\
\hline 7) & $\begin{array}{l}\text { Deitado de barriga para cima, segurando uma faixa ou corda em volta do pé. Levantar a } \\
\text { perna mantendo o joelho esticado, pela força dos braços. Vai sentir que o músculo atrás da } \\
\text { perna vai esticar (alongar). Manter a posição por } 30 \text { segundos. (Repetir } 4 x \text { cada perna) }\end{array}$ \\
\hline 8) & GELO 20 MINUTOS (3x por dia) \\
\hline
\end{tabular}


O tratamento propriamente dito consistiu de três sessões semanais e se estendeu pelo período de doze semanas (FIGURA 22 - diagrama de blocos que define o protocolo experimental), portanto à partir da $5^{\text {a }}$ semana de pós-operatório. Cada grupo de pacientes teve o seu protocolo específico de tratamento, um dos grupos realizou exercícios em CCA e o outro em CCF, no entanto procedimentos como alongamentos, exercícios proprioceptivos, treino de marcha, corrida, crioterapia e massagem cicatricial foram realizados pelos dois grupos e a forma de execução foi a mesma (QUADRO 2). Os protocolos de reabilitação foram elaborados a partir da experiência profissional da autora e com base nos estudos de DEVITA et al. (1997), HOOPER et al. (2001), KEAYS et al. (2000), LIMA e GUIMARÃES (1999), LIMA e GUIMARÃES (2001), SNYDER-MACKLER, DELITTO e STRALKA (1995).

QUADRO 2 - Descrição dos exercícios realizados nos protocolos de reabilitação do ligamento cruzado anterior entre a quinta e a décima sexta semana de pós-operatório (PO).

\begin{tabular}{|c|c|}
\hline $5^{\mathrm{a}}$ semana $\mathrm{PO}$ & $\begin{array}{l}\text { 1- Em decúbito dorsal. Extensão de } \\
\text { joelho pressionando uma toalha: } \\
\text { isométrico e isotônico } \\
\text { 2- Em decúbito dorsal. Flexão de joelho } \\
\text { até no máximo } 90^{0} \text {. } \\
\text { Alongamento de isquios-tibiais com } \\
\text { auxílio de uma faixa. } \\
\text { Alongamento de quadríceps. Em } \\
\text { 4- decúbito lateral, com auxílio do } \\
\text { fisioterapeuta para não ultrapassar os } 90^{0} \\
\text { de flexão do joelho. } \\
\text { Alongamento de tríceps sural em um } \\
\text { degrau. } \\
\text { Agachamento OU extensão do joelho } \\
\text { 6- extensão do quadril: 40\% } \mathbf{1 R M ,} \\
\text { mantendo um ângulo limite de } 60^{0} \text { de } \\
\text { flexão dos joelhos. } 2 \text { séries de } 15 \\
\text { repetições. } \\
\text { 7- Repete os exercícios } 3,4 \text { e } 5 \text {; } \\
\text { 8- Repete os exercícios } 1 \text { e } 2 . \\
\text { 9- Crioterapia } 20 \text { minutos, em elevação e } \\
\text { com joelho apoiado }\end{array}$ \\
\hline
\end{tabular}


QUADRO 2 - Descrição dos exercícios realizados nos protocolos de reabilitação do ligamento cruzado anterior entre a quinta e a décima sexta semana de pós-operatório (PO) (continuação).

\begin{tabular}{|c|c|}
\hline $6^{\mathrm{a}}$ semana $\mathrm{PO}$ & $\begin{array}{l}\text { Repete os mesmos exercícios da } 5^{\text {a }} \text { semana, com } \\
\text { as seguintes alterações: } \\
\text { A flexão do joelho nos exercícios em que era } \\
\text { limitada em } 90^{0} \text { graus passa a ser livre, forçando o } \\
\text { ganho de ADM. } \\
\text { Agachamento OU extensão do joelho e extensão } \\
\text { do quadril: } 40 \% 1 \mathrm{RM} \text {, mantendo um ângulo limite } \\
\text { de } 60^{0} \text { de flexão dos joelhos. } 3 \text { séries de } 15 \\
\text { repetições. } \\
\text { * Caminhada flexionando joelho }\end{array}$ \\
\hline $7^{\mathrm{a}}$ semana $\mathrm{PO}$ & $\begin{array}{l}7^{\text {a }} \text { semana: Repete os mesmos exercícios da } 6^{\mathrm{a}} \\
\text { semana, alterando o agachamento OU extensão do } \\
\text { joelho e extensão do quadril: } 40 \% \text { 1RM, para } 3 \\
\text { séries de } 20 \text { repetições. } \\
\text { * Caminhada costas }\end{array}$ \\
\hline $8^{\text {a }}$ semana $P O$ & $\begin{array}{l}\text { Repete os mesmos exercícios da } 7^{\mathrm{a}} \text { semana, } \\
\text { alterando: } \\
\text { Agachamento OU extensão do joelho e extensão } \\
\text { do quadril: } 55 \% \text { 1RM, } 2 \text { séries de } 15 \text { repetições. } \\
\text { Durante a crioterapia o joelho fica sem apoio, o } \\
\text { apoio é apenas até o tornozelo. (mínimo } 2 \text { minutos } \\
\text { e evolui até atingir } 10 \text { minutos do tempo total de } \\
20 \text { minutos). } \\
\text { * Caminhada ponta dos pés }\end{array}$ \\
\hline $9^{\mathrm{a}}$ semana $\mathrm{PO}$ & $\begin{array}{l}\text { Repete os mesmos exercícios da } 8^{\mathrm{a}} \text { semana, } \\
\text { alterando o agachamento OU extensão do joelho e } \\
\text { extensão do quadril: } 55 \% \text { 1RM, para } 3 \text { séries de } \\
15 \text { repetições. } \\
\quad \text { * Circuito para trabalhar propriocepção } \\
\quad \text { * Treino de escada }\end{array}$ \\
\hline $10^{\mathrm{a}}$ semana $\mathrm{PO}$ & $\begin{array}{l}\text { Repete os mesmos exercícios da } 9^{\mathrm{a}} \text { semana, } \\
\text { alterando: } \\
\text { Agachamento OU extensão do joelho e } \\
\text { extensão do quadril: } 55 \% \text { 1RM, para } 3 \text { séries de } \\
20 \text { repetições. } \\
\text { Alongamento de isquios-tibiais passa a ser } \\
\text { realizado sentado, sem a faixa. } \\
\text { Alongamento de quadríceps passa a ser } \\
\text { realizado pelo próprio paciente. }\end{array}$ \\
\hline
\end{tabular}


QUADRO 2 - Descrição dos exercícios realizados nos protocolos de reabilitação do ligamento cruzado anterior entre a quinta e a décima sexta semana de pós-operatório (PO) (continuação).

\begin{tabular}{|c|c|}
\hline $11^{\mathrm{a}}$ semana $\mathrm{PO}$ & $\begin{array}{l}\text { Repete os mesmos exercícios da } 10^{\mathrm{a}} \text { semana, } \\
\text { alterando: } \\
\text { Agachamento OU extensão do joelho e } \\
\text { extensão do quadril: } \mathbf{7 0 \%} \text { 1RM, } 2 \text { séries de } 15 \\
\text { repetições } \\
\text { * Caminhada em zigue-zague } \\
\text { * Corrida } 3 \text { minutos }\end{array}$ \\
\hline $12^{\mathrm{a}}$ semana $\mathrm{PO}$ & $\begin{array}{l}\text { Repete os mesmos exercícios da } 11^{\text {a }} \text { semana, } \\
\text { alterando: } \\
\text { Agachamento OU extensão do joelho e } \\
\text { extensão do quadril: } 70 \% \text { RM, } 3 \text { séries de } 15 \\
\text { repetições. } \\
\text { Durante a crioterapia, se necessário, amplia-se } \\
\text { o tempo sem apoio no joelho (podendo atingir o } \\
\text { tempo total de aplicação do gelo - } 20 \text { minutos). } \\
\text { * Corrida } 5 \text { minutos }\end{array}$ \\
\hline $13^{a}$ semana $P O$ & $\begin{array}{l}\text { Repete os mesmos exercícios da } 12^{\mathrm{a}} \text { semana, } \\
\text { alterando: } \\
\text { Agachamento OU extensão do joelho e } \\
\text { extensão do quadril: } 70 \% \text { 1RM, } 3 \text { séries de } 20 \\
\text { repetições } \\
\text { * Retirar as caminhadas e acrescentar corrida } \\
\text { de frente, de costas, de lado, em zigue-zague. } \\
\text { * Propriocepção apoio unipodal } \\
\text { * Corrida } 10 \text { minutos }\end{array}$ \\
\hline $14^{\mathrm{a}}$ semana $\mathrm{PO}$ & $\begin{array}{l}\text { Repete os mesmos exercícios da } 13^{\mathrm{a}} \text { semana, } \\
\text { alterando: } \\
\text { Agachamento OU extensão do joelho e } \\
\text { extensão do quadril: } 80 \% \text { 1RM, } 2 \text { séries de } 15 \\
\text { repetições } \\
\quad \text { * Corrida } 15 \text { minutos }\end{array}$ \\
\hline $15^{\mathrm{a}}$ semana $\mathrm{PO}$ & $\begin{array}{l}\text { Repete os mesmos exercícios da } 14^{\mathrm{a}} \text { semana, } \\
\text { alterando: } \\
\text { Agachamento OU extensão do joelho e } \\
\text { extensão do quadril: } 80 \% \text { 1RM, } 3 \text { séries de } 15 \\
\text { repetições } \\
\text { * Propriocepção apoio unipodal de olhos } \\
\text { fechados } \\
\text { * Corrida em rampa leve (subir e descer) } \\
\text { * Corrida } 20 \text { minutos }\end{array}$ \\
\hline
\end{tabular}


QUADRO 2 - Descrição dos exercícios realizados nos protocolos de reabilitação do ligamento cruzado anterior entre a quinta e a décima sexta semana de pós-operatório (PO) (continuação).

\begin{tabular}{|l|l|}
\hline $1^{\text {a }}$ semana PO & $\begin{array}{l}\text { Repete os mesmos exercícios da } 15^{\text {a }} \text { semana, } \\
\text { alterando: } \\
\text { Agachamento OU extensão do joelho e } \\
\text { extensão do quadril: } 80 \% 1 \mathrm{RM}, 3 \text { séries de } 20 \\
\text { repetições. } \\
\text { * Corrida } 25 \text { minutos }\end{array}$ \\
\hline
\end{tabular}

A comparação entre CCA e CCF no que diz respeito à marcha necessitou que se trabalhasse com as cargas normalizadas para os dois tipos de exercícios em relação a cada indivíduo. Neste caso, o critério de normalização foi o percentual da carga máxima. $\mathrm{O}$ indivíduo realizou o teste de 1RM (uma repetição máxima) para cada exercício utilizado durante a reabilitação. Este teste foi realizado no dia do teste pré-cirúrgico e quando começou o período de tratamento a carga inicial utilizada foi de $40 \%$ do valor do 1RM. Este percentual de 1RM, aparentemente baixo, foi utilizado porque no pós-operatório a força máxima dos pacientes diminui devido a uma hipotrofia muscular por desuso, conseqüente do procedimento cirúrgico. Dessa forma, os 40\% do valor do 1RM medidos no período pré-operatório, no pósoperatório é equivalente a um valor percentual maior, porém seguro para os pacientes.

Os pacientes do grupo CCA realizaram os exercícios de extensão do joelho, na mesa extensora (FIGURA 32), e, de extensão de quadril, na mesa extensora (FIGURA 33). Os pacientes do grupo CCF realizaram o exercício de agachamento paralelo (FIGURA 34).
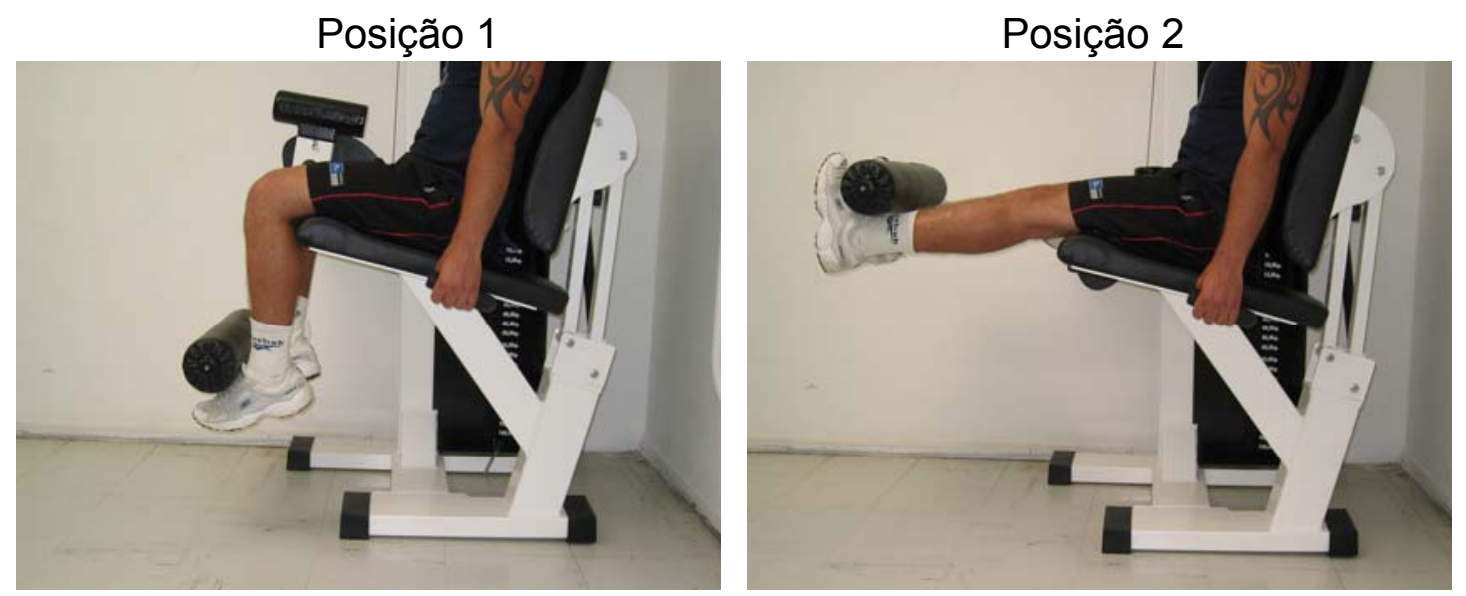

FIGURA 32 - Fotos ilustrativas do exercício de extensão do joelho. Posição 1: posição inicial e final de execução. Posição 2: posição final da fase ascendente do exercício. 
Posição 1

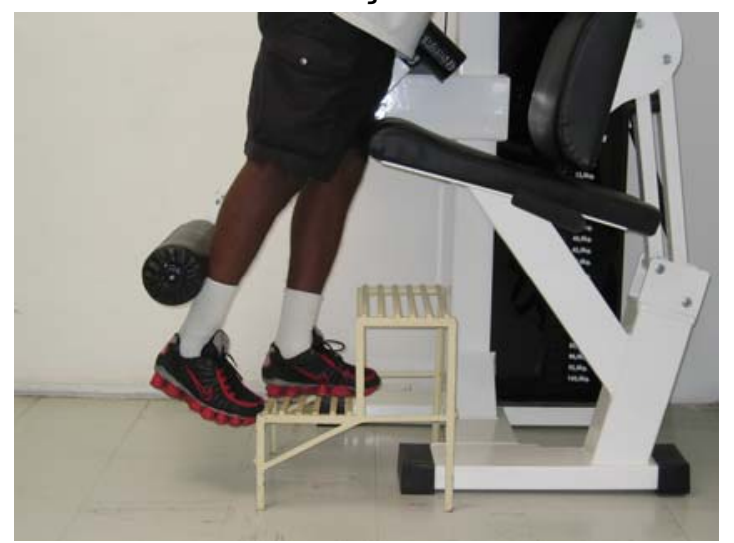

FIGURA 33 - Fotos ilustrativas do exercício de extensão do quadril. Posição 1: posição inicial e final de execução. Posição 2: posição final da fase ascendente do exercício.
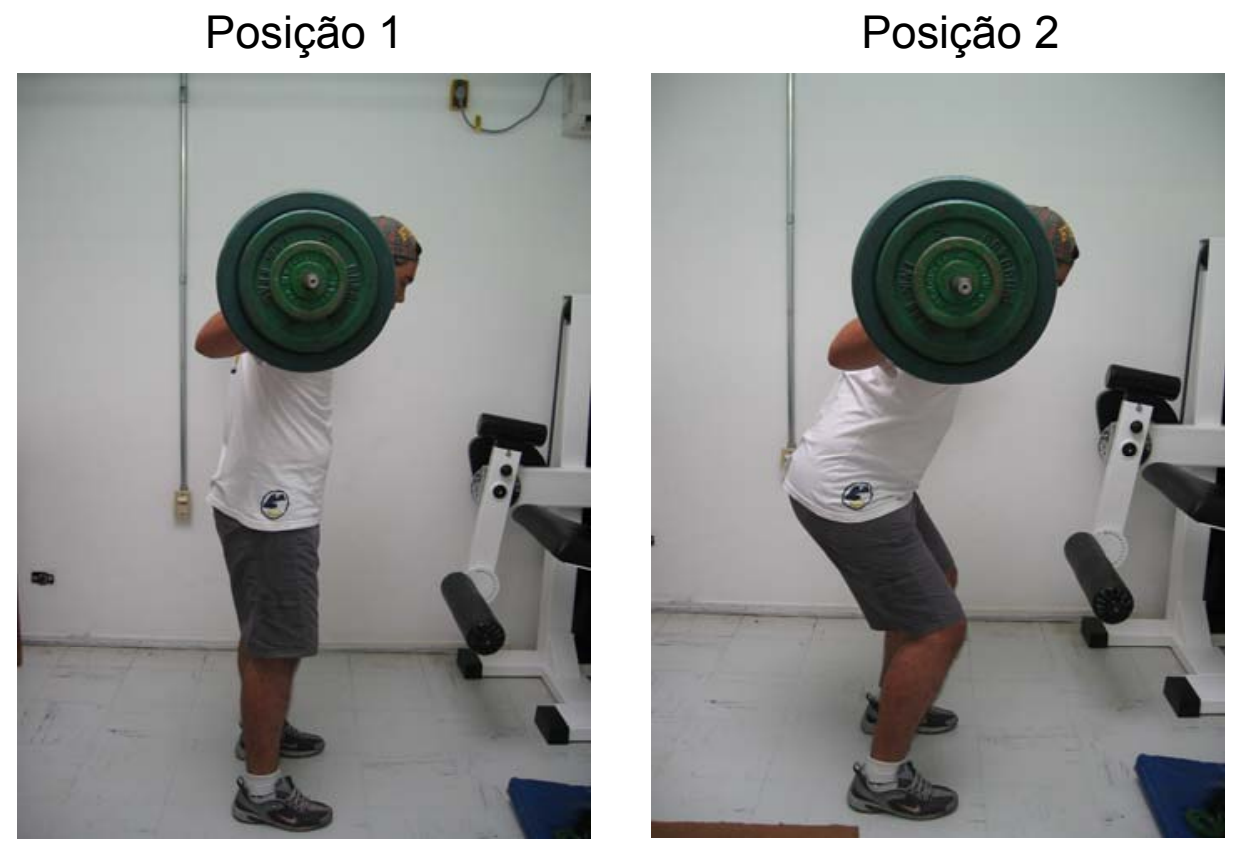

FIGURA 34 - Fotos ilustrativas do exercício de agachamento. Posição 1: posição inicial e final de execução. Posição 2: posição final da fase descendente do exercício. 
O QUADRO 3 demonstra como foi desenvolvido o treinamento de resistência muscular do protocolo de reabilitação durante as doze semanas. O princípio do treinamento segue as orientações de FLECK e KRAEMER (1999).

QUADRO 3 - Programação do treinamento de resistência dos protocolos de exercícios em cadeia cinética aberta e fechada, em relação ao número de séries e repetições, e à carga utilizada no período pós-operatório $(\mathrm{PO})$.

\begin{tabular}{|c|c|c|}
\hline Semana & Repetições & $\begin{array}{c}\text { Carga } \\
\text { (percentual do teste de 1RM } \\
\text { realizado no pré-operatório) }\end{array}$ \\
\hline $5^{\mathrm{a}}$ semana de PO & $2 \times 15$ repetições & $\begin{array}{c}\text { Carga inicial } 40 \% \text { do teste de } \\
1 \mathrm{RM}\end{array}$ \\
\hline $6^{\mathrm{a}}$ semana de PO & $3 \times 15$ repetições & Carga mantida \\
\hline $7^{\mathrm{a}}$ semana de PO & $3 \times 20$ repetições & Carga mantida \\
\hline $8^{\mathrm{a}}$ semana de PO & $2 \times 15$ repetições & Aumento da carga para $55 \%$ \\
& & do teste de 1RM \\
\hline $9^{\mathrm{a}}$ semana de PO & $3 \times 15$ repetições & Carga mantida \\
\hline $10^{\mathrm{a}}$ semana de PO & $3 \times 20$ repetições & Carga mantida \\
\hline $11^{\mathrm{a}}$ semana de PO & $2 \times 15$ repetições & Aumento da carga para $70 \%$ \\
& & do teste de 1RM \\
\hline $12^{\mathrm{a}}$ semana de PO & $3 \times 15$ repetições & Carga mantida \\
\hline $13^{\mathrm{a}}$ semana de PO & $3 \times 20$ repetições & Carga mantida \\
\hline $14^{\mathrm{a}}$ semana de PO & $2 \times 15$ repetições & Aumento da carga para $80 \%$ \\
& & do teste de 1RM \\
\hline $15^{\mathrm{a}}$ semana de PO & $3 \times 15$ repetições & Carga mantida \\
\hline
\end{tabular}

O grupo controle, formado por indivíduos sem lesão, não foi submetido a nenhum tipo de tratamento, apenas realizaram os testes. 
Os dados obtidos através dos equipamentos mencionados e conforme variáveis selecionadas necessitaram passar por alguns procedimentos para só então poder ser aplicada a análise estatística.

O programa MATLAB (versão 6.5.0.180913a Release13, 2002, MathWorks Inc., Natick, MA) foi utilizado para realização destes procedimentos. As rotinas necessárias para análise dos dados foram desenvolvidas pela autora. O sinal EMG foi analisado através da rotina "LCAemg" (ANEXO VI), a FRS e o eletrogoniômetro foram analisados através da rotina "LCAFRS" (ANEXO VII), os parâmetros temporais através da rotina "LCAtempo" (ANEXO VIII), os parâmetros espaciais através da rotina "LCAcomprimento" (ANEXO IX). Além dessas as rotinas "mcycle” (desenvolvida previamente pelo Prof. Marcos Duarte), "inifim", "picos", "vales” e "sime” (desenvolvidas pela autora) foram utilizadas para que as análises pudessem ser concluídas. Estas rotinas incluem determinação do início e fim dos passos, determinação de picos e vales da FRS, variáveis temporais e espaciais dos passos e passadas, realização do envoltório linear do sinal EMG e determinação da variação angular durante as fases da marcha. Todas elas realizam passos básicos necessários como retirar o offset, normalizar os dados e passar filtros adequados aos dados que estão sendo analisados.

Em relação às filtragens utilizadas: (1) nos dados da FRS foi utilizado o filtro passabaixa Butterworth de quarta ordem com freqüência de corte de $10 \mathrm{~Hz}$; (2) para o sinal EMG foram utilizados dois tipos de filtro, o filtro passa-banda Butterworth de segunda ordem com freqüência de corte entre $20 \mathrm{~Hz}$ e $300 \mathrm{~Hz}$ e um filtro rejeita-banda Butterworth de quarta ordem com freqüência de corte entre $59,9 \mathrm{H}$ e $60,1 \mathrm{~Hz}$; (3) para os dados do eletrogoniômetro foi utilizado o filtro passa-baixa Butterworth de segunda ordem com freqüência de corte de $40 \mathrm{~Hz}$.

Os dados foram normalizados na base do tempo e o procedimento utilizado foi a interpolação dos mesmos. Além disso, a FRS foi normalizada pelo peso corporal dos sujeitos, o eletrogoniômetro pela histerese determinada durante o procedimento de calibração (volts/ângulo) do equipamento e as variáveis cinemáticas relativas ao comprimento foram normalizadas pela estatura dos sujeitos.

Após o uso do programa MatLab por meio de suas rotinas, as informações desejadas passaram pela análise estatística descrita a seguir. 
Os dados foram analisados quanto a sua normalidade através dos testes de Kolmogorov-Smirnov e Wilcoxon e não foi aceita a suposição de normalidade dos dados, portanto os testes estatísticos utilizados foram não-paramétricos.

Nos dados relativos a FRS foi utilizada a análise de componentes principais. O valor de corte utilizado para determinação do número de componentes principais foi o percentual acumulado de representatividade das variáveis próximo de $80 \%$. Na comparação entre grupos dois componentes principais foram suficientes e na comparação entre testes três componentes principais foram suficientes para que fosse atingida a representatividade de $80 \%$ das variáveis relativas à FRS.

O Teste de Kruskal-Wallis foi utilizado na comparação das variáveis quantitativas de razão contínua entre três amostras independentes (grupos CON, CCF e CCA), ou seja, comparação entre grupos em cada teste.

Na comparação das variáveis quantitativas de razão contínua de três amostras repetidas (Teste 1, 2 e 3), para cada grupo (CCF e CCA) em separado, o teste utilizado foi o Teste de Friedman. Nas situações onde o Teste de Friedman apresentou diferença significativa foi realizado o procedimento de particionar o Qui-quadrado, para identificar estas diferenças.

Os dados foram processados e analisados estatisticamente levando em consideração o nível de significância de 0,05 .

$\mathrm{Na}$ apresentação de alguns dos resultados serão utilizados asteriscos demonstrando diferenças significativas, nestes casos deve-se seguir a seguinte orientação: * $=p \leq 0,05$; ** $=$ $\mathrm{p} \leq 0,01 \mathrm{e}^{* * *}=\mathrm{p} \leq 0,001$.

\subsection{Controle do Erro Experimental e Limitações Metodológicas}

Entre as limitações metodológicas encontra-se o resultado da análise dos dados no teste inicial, que foi o teste realizado antes da cirurgia. Ao analisar os dados, o componente principal da FRS e simetrias relativas as variáveis da FRS apresentaram diferenças significativas entre os grupos neste teste, o que demonstra que para estes aspectos os grupos eram diferentes antes de serem submetidos ao tratamento proposto. A decisão de fazer por sorteio inicial a seleção dos grupos permitiu que este tipo de problema aparecesse sem que se 
pudesse fazer uma interferência posterior. Portanto, para estas variáveis a análise e discussão dos resultados foram realizadas observando a diferença inicial entre os grupos.

Outro aspecto limitador foi o fato de alguns pacientes terem experiência prévia de andar na esteira. A maior familiarização destes pacientes com o equipamento pode ter influenciado na sua forma de andar durante o teste. Os dez minutos iniciais de familiarização na esteira, proposto no protocolo de pesquisa, tiveram como objetivo minimizar este aspecto.

A impossibilidade de realizar o teste de carga máxima (1RM) com apenas um mês de pós-operatório fez com que este teste fosse realizado antes da cirugia. A carga máxima atingida antes da cirurgia não seria o equivalente à carga máxima com um mês pós-operatório, neste período a força muscular diminui pela hipotrofia muscular que ocorre após o procedimento cirúrgico. A proposta foi começar o tratamento com $40 \%$ do $1 \mathrm{RM}$ alcançado antes da cirurgia porque assim estaria sendo utilizado um percentual maior quando considerada a carga máxima após a cirurgia. Porém, o percentual exato não era possível conhecer.

\subsubsection{Deslocamento Tibial Anterior}

O equipamento KT1000 que foi utilizado para quantificar o DTA é o artrômetro mais utilizado no meio científico por ser considerado de maior precisão nas medidas. Apesar de todos os mecanismos do próprio equipamento para evitar problemas na medida, alguns cuidados são necessários. Os resultados obtidos podem sofrer influência da contração muscular, tendo o sujeito que estar totalmente relaxado para realizar o teste. $\mathrm{O}$ teste deve ser realizado sempre pelo mesmo sujeito e este deve ser experiente na utilização do equipamento para evitar erros sistemáticos observacionais (VUOLO, 1996) que podem ser decorrentes de limitações do próprio observador.

\subsubsection{Força de Reação do Solo}

A escolha da esteira gaitway se deu pela possibilidade de análise da FRS do lado direito e esquerdo em sincronia. Esta escolha teve implicações como a necessidade de realizar o andar na esteira, mesmo diante do fato de muitos trabalhos demonstrarem uma variação do andar no piso fixo em relação ao andar na esteira. Esta questão foi minimizada nessa pesquisa pelo fato de o andar ser comparado em diferentes momentos do processo de reabilitação e as 
comparações foram feitas sempre entre as variáveis obtidas pelo andar na esteira. Apesar do andar na esteira não ter uma reprodução exata do andar em piso fixo, a análise do andar na esteira permitiu observar a evolução obtida pelos pacientes que foi o objetivo principal da pesquisa.

Os erros associados à determinação das grandezas derivadas de força vertical e do ponto de aplicação da força limitam-se a valores de $\pm 1 \%$, considerando-se o necessário controle de calibração (GAITWAY, 1996).

\subsubsection{Variação Angular}

A utilização do eletrogoniômetro tem como uma limitação a obtenção de informações cinemáticas apenas da articulação do joelho, no entanto tem a vantagem de poder ser utilizado nos canais acessórios da esteira e, assim, os dados das plataformas de força, do EMG e do eletrogoniômetro são sincronizados durante a coleta experimental. Isto evita o uso de outros recursos de sincronização que podem apresentar um erro de medida maior. Como o foco desta pesquisa é a articulação do joelho, o entendimento das alterações de movimento do joelho forneceu informações relevantes para o trabalho.

Outro aspecto importante relativo às limitações do eletrogoniômetro é o seu posicionamento. Referenciais anatômicos da articulação do quadril, joelho e tornozelo garantem um posicionamento mais adequado do equipamento, no entanto o erro de medida por diferenças no posicionamento do eletrogoniômetro pode estar presente.

Para a avaliação da variação angular dos joelhos operou-se com erro experimental no registro destas grandezas inferior a $1 \%$ do valor da medida após determinação da histerese destas respostas.

\subsubsection{Análise Eletromiográfica}

A utilização da EMG para análise da atividade muscular, apesar de todas as limitações apresentadas pela alteração do sinal em função do posicionamento dos eletrodos, do tipo de eletrodo utilizado, da presença de ruído e da possível presença do crosstalk, entre outros fatores de discussão, ainda é a melhor forma de identificar o comportamento muscular durante o ciclo do andar. Com o objetivo de minimizar os erros de interpretação do sinal EMG 
devido à presença destes fatores vários cuidados foram tomados, como: a preparação da pele de acordo com o preconizado na literatura, o uso de eletrodos ativos que minimizam a captação de ruído, posicionamento do eletrodo utilizando referenciais anatômicos e fisiológicos como orientação, além de cuidados com a freqüência de amostragem e o tratamento dos dados.

\section{$5 \quad$ RESULTADOS}

\subsection{Caracterização da Amostra}

Um total de trinta sujeitos iniciou e concluiu o protocolo de pesquisa proposto. Desses sujeitos, dez não apresentavam lesão do LCA e pertenceram ao grupo controle e vinte apresentavam lesão do LCA e foram divididos em dois grupos de acordo com o tipo de reabilitação que realizaram (CCF ou CCA). A análise descritiva (média e desvio padrão) e distribuição de freqüência (\%) das características de cada grupo são apresentadas na TABELA 1.

TABELA 1 - Análise descritiva e distribuição de freqüência das características dos grupos amostrais: controle $(\mathrm{CON})$, cadeia cinética aberta $(\mathrm{CCA})$ e cadeia cinética fechada (CCF) separados por teste: testes 1 (Pré), 2 (1PO) e 3 (4PO), quando necessário.

\begin{tabular}{|c|c|c|c|c|c|c|c|c|c|c|c|}
\hline \multirow[t]{2}{*}{ Grupos } & \multirow[t]{2}{*}{$\mathrm{n}$} & \multirow[t]{2}{*}{$\begin{array}{l}\text { Idade } \\
\text { (anos) }\end{array}$} & \multirow[t]{2}{*}{$\begin{array}{l}\text { Estatura } \\
\text { (m) }\end{array}$} & \multicolumn{3}{|c|}{ Massa $(\mathrm{kg})$} & \multicolumn{3}{|c|}{$\begin{array}{l}\text { Velocidade da } \\
\text { marcha }(\mathrm{km} / \mathrm{h})\end{array}$} & \multirow[t]{2}{*}{$\begin{array}{c}\text { Perna } \\
\text { acometida }\end{array}$} & \multirow{2}{*}{$\begin{array}{c}\text { Tempo de } \\
\text { lesão } \\
\text { (meses) }\end{array}$} \\
\hline & & & & T1 & $\mathbf{T} 2$ & T3 & T1 & $\mathrm{T} 2$ & T3 & & \\
\hline Controle & 10 & $\begin{array}{l}28,80 \\
\pm 7,51\end{array}$ & $\begin{array}{c}1,74 \\
\pm 0,08\end{array}$ & $\begin{array}{r}74,43 \\
\pm 10,41\end{array}$ & - & - & $\begin{array}{r}4,17 \\
\pm 1,04\end{array}$ & - & - & - & - \\
\hline $\mathrm{CCF}$ & 10 & $\begin{array}{c}28,6 \\
\pm 10,13\end{array}$ & $\begin{array}{c}1,73 \\
\pm 0,06\end{array}$ & $\begin{array}{c}80,27 \\
\pm 12,38\end{array}$ & $\begin{array}{c}79,92 \\
\pm 12,39\end{array}$ & $\begin{array}{c}81,26 \\
\pm 12,53\end{array}$ & $\begin{array}{l}3,67 \\
\pm 0,47\end{array}$ & $\begin{array}{c}3,20 \\
\pm 0,60\end{array}$ & $\begin{array}{l}3,67 \\
\pm 0,47\end{array}$ & $\begin{array}{l}60 \% \mathrm{E} \\
40 \% \mathrm{D}\end{array}$ & $\begin{array}{c}19 \\
\pm 13\end{array}$ \\
\hline $\mathrm{CCA}$ & 10 & $\begin{array}{l}29,20 \\
\pm 6,18\end{array}$ & $\begin{array}{c}1,71 \\
\pm 0,06\end{array}$ & $\begin{array}{l}71,18 \\
\pm 8,80\end{array}$ & $\begin{array}{l}71,03 \\
\pm 8,81\end{array}$ & $\begin{array}{l}71,29 \\
\pm 8,64\end{array}$ & $\begin{array}{c}4,15 \\
\pm 0,53\end{array}$ & $\begin{array}{c}3,90 \\
\pm 0,68\end{array}$ & $\begin{array}{c}4,15 \\
\pm 0,53\end{array}$ & $\begin{array}{l}80 \% \mathrm{D} \\
20 \% \mathrm{E}\end{array}$ & $\begin{array}{c}26 \\
\pm 16\end{array}$ \\
\hline
\end{tabular}


O deslocamento tibial anterior possui apenas duas medidas para os grupos CCA e CCF. Esta variável não foi avaliada no teste realizado com um mês pós-cirúrgico por motivos de segurança ao enxerto ligamentar, conforme recomendação e cuidados prescritos pelo médico.

\section{Análise entre Grupos}

No Teste 1 (Pré), o deslocamento tibial anterior do grupo CCF e do grupo CCA foi significativamente maior do que do grupo $\operatorname{CON}(p=0,00$ e $p=0,00$; respectivamente). Os grupos CCF e CCA não apresentaram diferença estatística entre eles (FIGURA 35).

O Teste 3 (4PO) não apresentou diferença significativa entre os três grupos (FIGURA 35).

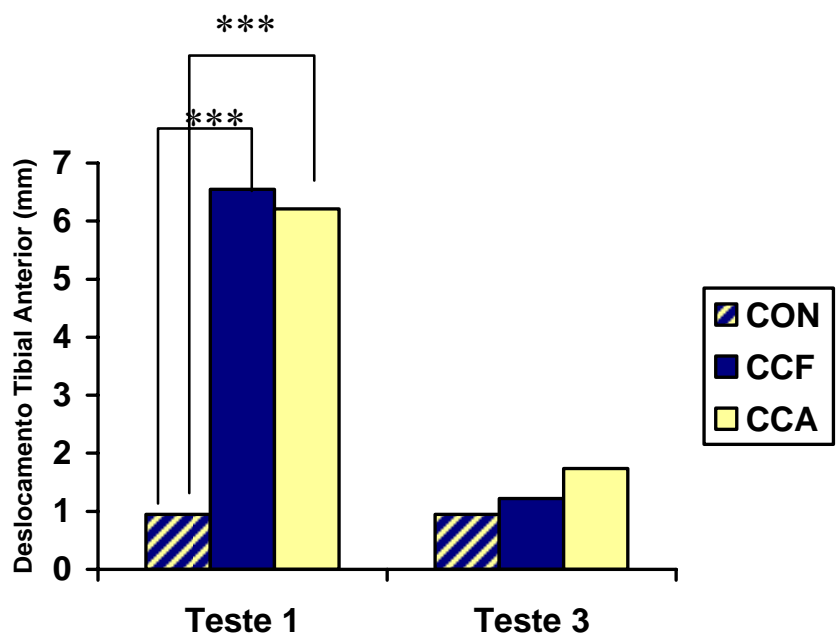

FIGURA 35 - Gráfico do deslocamento tibial anterior na comparação entre os grupos controle $\underline{(C O N), \text { cadeia cinética aberta }(C C A) \text { e cadeia cinética fechada }(C C F)(n=10 \mathrm{em}}$ cada grupo) nos testes 1 (Pré) e 3 (4PO).

\section{Análise entre Testes}

Os valores do deslocamento tibial anterior dos grupos CCF e CCA no Teste 1 (Pré) foram significativamente maiores do que no Teste 3 (4PO) $(p=0,00$ e $p=0,00$; respectivamente) (FIGURA 36). 


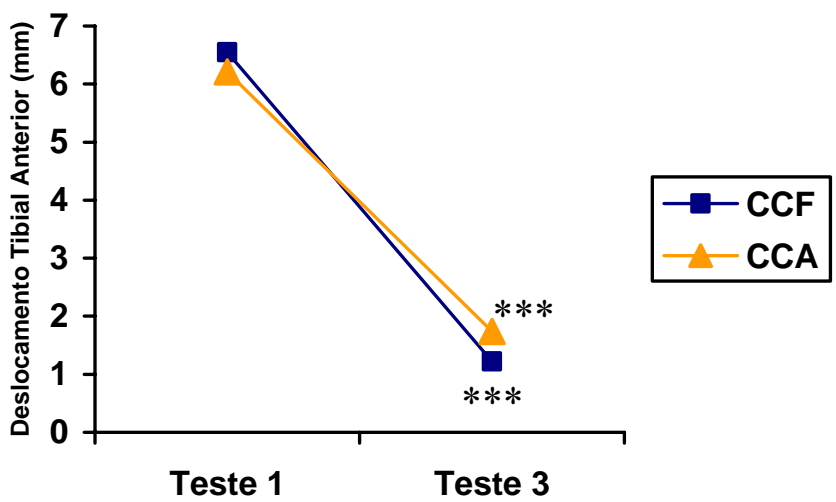

FIGURA 36 - Gráfico do deslocamento tibial anterior na comparação entre testes: testes 1 (Pré) e $3(4 \mathrm{PO})$ por grupo: controle $(\mathrm{CON})$, cadeia cinética aberta (CCA) e cadeia cinética fechada (CCF) $(\mathrm{n}=10$ em cada grupo).

\subsection{Escore de Lysholm - Escala de Avaliação Funcional do Joelho}

\section{Análise entre Grupos}

O escore de Lysholm foi aplicado apenas nos grupos que apresentavam lesão do ligamento cruzado anterior, grupos CCF e CCA. O escore de Lysholm não foi aplicado no Teste 2 (1PO) da mesma forma que o DTA.

Na comparação entre os grupos no Teste 1 (Pré) e no Teste 3 (4PO) não foi encontrada diferença significativa entre eles (FIGURA 37). 


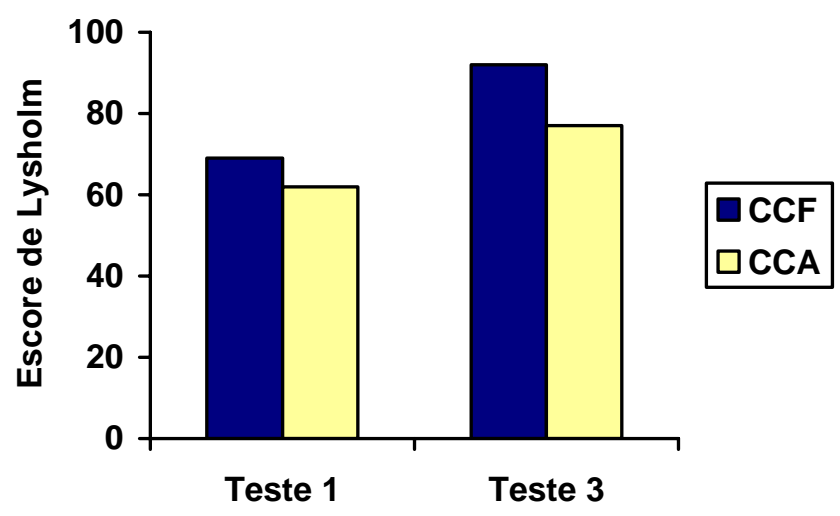

FIGURA 37 - Gráfico do valor do escore de Lysholm na comparação entre os grupos controle $(\mathrm{CON})$, cadeia cinética aberta (CCA) e cadeia cinética fechada $(\mathrm{CCF})(\mathrm{n}=10 \mathrm{em}$ cada grupo) nos testes 1 (Pré) e 3 (4PO).

\section{Análise entre Testes}

O grupo CCF e o grupo CCA apresentaram os valores do Teste 1 (Pré) significativamente menores do que os valores do Teste 3 (4PO) $(\mathrm{p}=0,00$ e $\mathrm{p}=0,02$; respectivamente) (FIGURA 38).

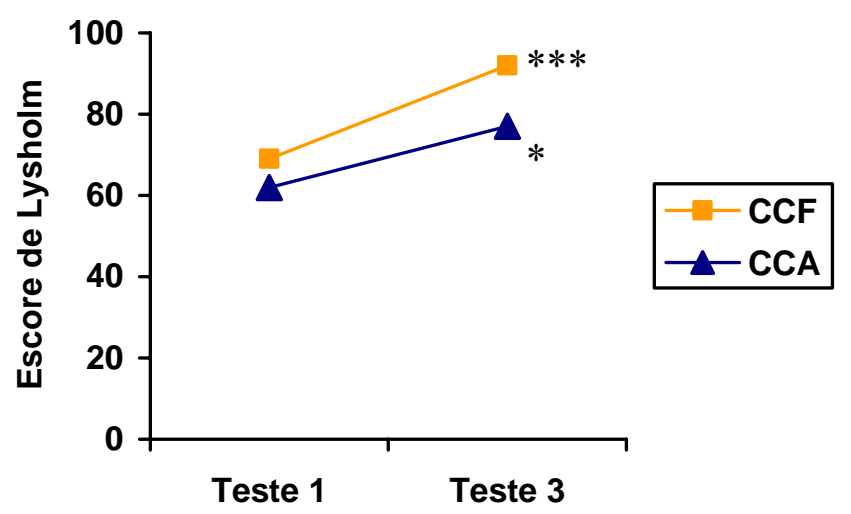

FIGURA 38 - Gráfico do valor do escore de Lysholm na comparação entre os testes 1 (Pré) e 3 (4PO)em cada grupo: controle (CON), cadeia cinética aberta (CCA) e cadeia cinética fechada (CCF) ( $\mathrm{n}=10$ em cada grupo). 


\subsection{Força de Reação do Solo}

\section{Análise Descritiva}

No Teste 1 (Pré) o grupo CCF apresentou o primeiro pico da força vertical maior que os grupos CON e CCA e no restante da curva os seus valores foram semelhantes ao grupo CON tanto na perna operada quanto na não-operada (FIGURA 39). O grupo CCA foi o que apresentou maiores diferenças nas curvas de ambas as pernas quando comparado ao grupo CON. O valor da força mínima foi superior a atingida pelos grupos CON e CCF e ela ocorreu antes no grupo CCA ( $45 \%$ da fase do apoio) do que nos grupos CON e CCF (50\% da fase de apoio). O primeiro pico da força vertical do grupo CCA foi semelhante ao do grupo CON, no entanto o segundo pico da força vertical foi menor que o do grupo CON e, da mesma forma que a força mínima o pico aconteceu antes (70\% da fase do apoio) do que aconteceu o do grupo CON e CCF (78\% da fase de apoio) (FIGURA 39).
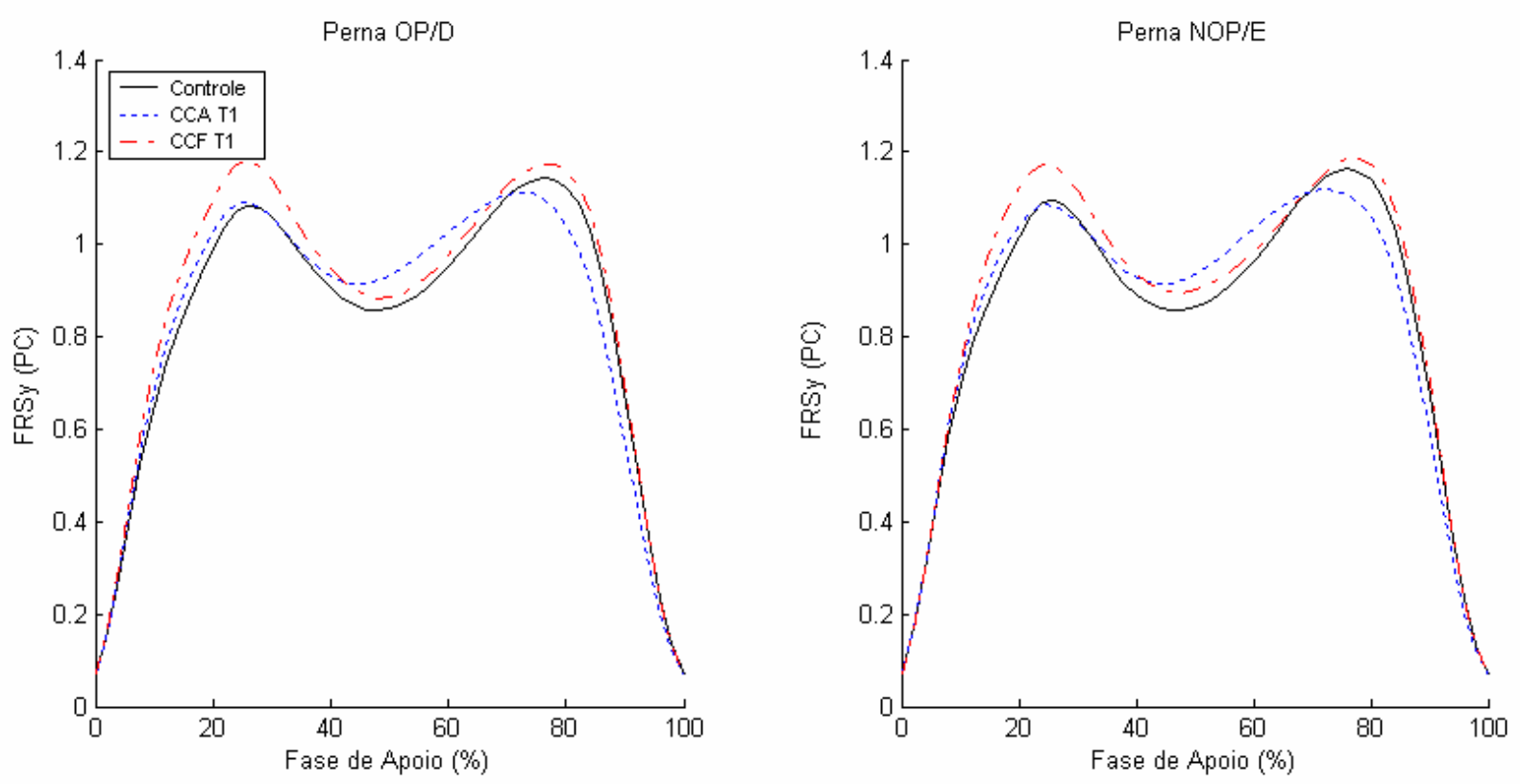

FIGURA 39 - Gráficos da componente vertical da força de reação do solo da perna operada ou direita (OP/D) e da perna não-operada ou esquerda (NOP/E) durante a fase de apoio da marcha na comparação entre grupos: controle $(\mathrm{CON})$, cadeia cinética aberta $(\mathrm{CCA})$ e cadeia cinética fechada $(\mathrm{CCF})(\mathrm{n}=10 \mathrm{em}$ cada grupo) no Teste 1 (Pré). 
No Teste 2 (1PO) a perna operada do grupo CCF foi a que mais se assemelhou ao grupo CON tendo apenas um valor mais alto de força mínima. A perna não-operada manteve um valor de primeiro pico da componente vertical da FRS mais alto que o grupo CON (FIGURA 40). O grupo CCA apresentou os dois picos de força menores que do grupo CON em ambas as pernas. Na análise temporal o primeiro pico da perna operada ocorreu depois (30\% da fase de apoio) e o segundo pico de ambas as pernas ocorreu um pouco antes $(75 \%$ da fase de apoio) do grupo $\operatorname{CON}(25 \%$ e $80 \%$ da fase de apoio, respectivamente). A força mínima de ambas as pernas do grupo CCA teve seu valor maior que do grupo CON e esta foi atingida antecipadamente, principalmente na perna não-operada ( $40 \%$ da fase de apoio) em relação aos grupos CON e CCF (46\% da fase de apoio) (FIGURA 40).
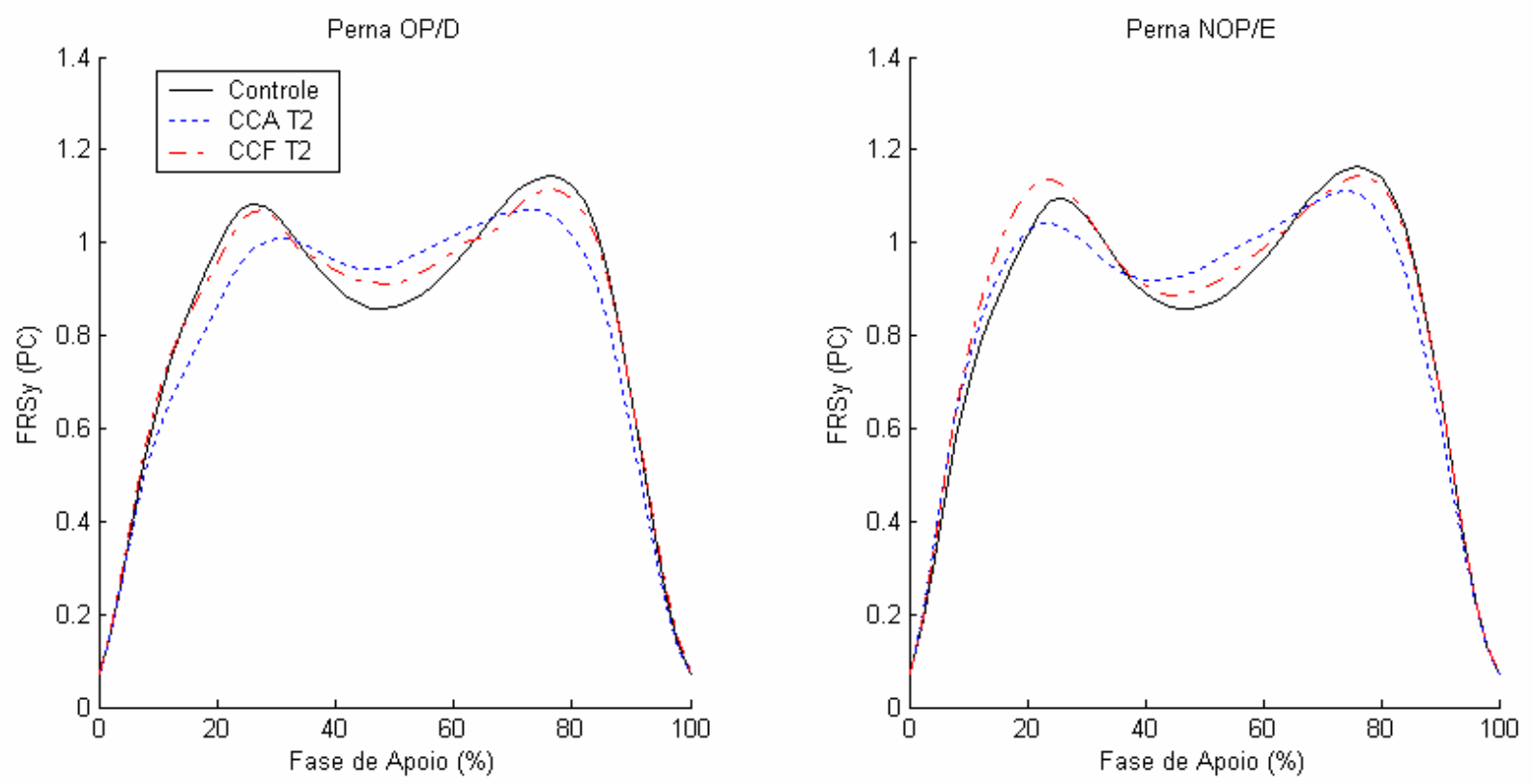

FIGURA 40 - Gráficos da componente vertical da força de reação do solo da perna operada ou direita (OP/D) e da perna não-operada ou esquerda (NOP/E) durante a fase de apoio da marcha na comparação entre grupos: controle $(\mathrm{CON})$, cadeia cinética aberta (CCA) e cadeia cinética fechada (CCF) $(n=10$ em cada grupo) no Teste $\underline{2(1 \mathrm{PO})}$. 
As curvas da componente vertical da FRS de ambas as pernas dos grupos CCF e CCA praticamente se igualaram a curva do grupo CON no Teste 3 (4PO). Apenas o grupo CCA ainda teve um valor maior da força mínima do que os demais grupos em ambas as pernas (FIGURA 41).
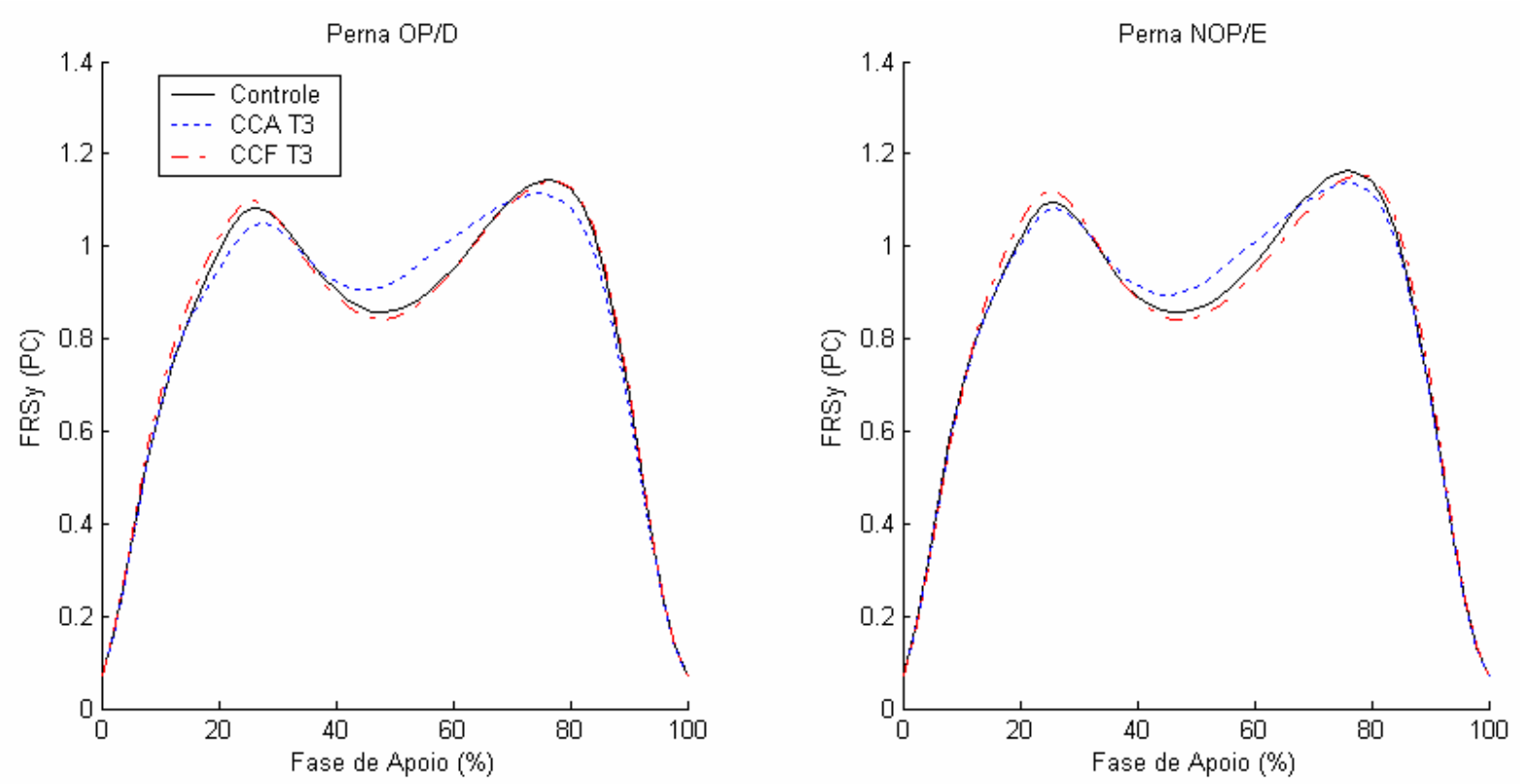

FIGURA 41 - Gráficos da componente vertical da força de reação do solo da perna operada ou direita $(\mathrm{OP} / \mathrm{D})$ e da perna não-operada ou esquerda (NOP/E) durante a fase de apoio da marcha na comparação entre grupos: controle $(\mathrm{CON})$, cadeia cinética aberta $(\mathrm{CCA})$ e cadeia cinética fechada $(\mathrm{CCF})(\mathrm{n}=10 \mathrm{em}$ cada grupo) no Teste $\underline{3(4 \mathrm{PO}) .}$

Ao analisar os grupos ao longo do tratamento pode-se observar que no Teste 1 (Pré) o primeiro pico da componente vertical da FRS de ambas as pernas do grupo CCF foi superior aos valores dos demais momentos da reabilitação. Nos Testes 2 (1PO) e 3 (4PO) as curvas praticamente se normalizaram, apenas no Teste 2 (1PO) a força mínima da perna operada foi um pouco maior do que nos demais testes (FIGURA 42). 

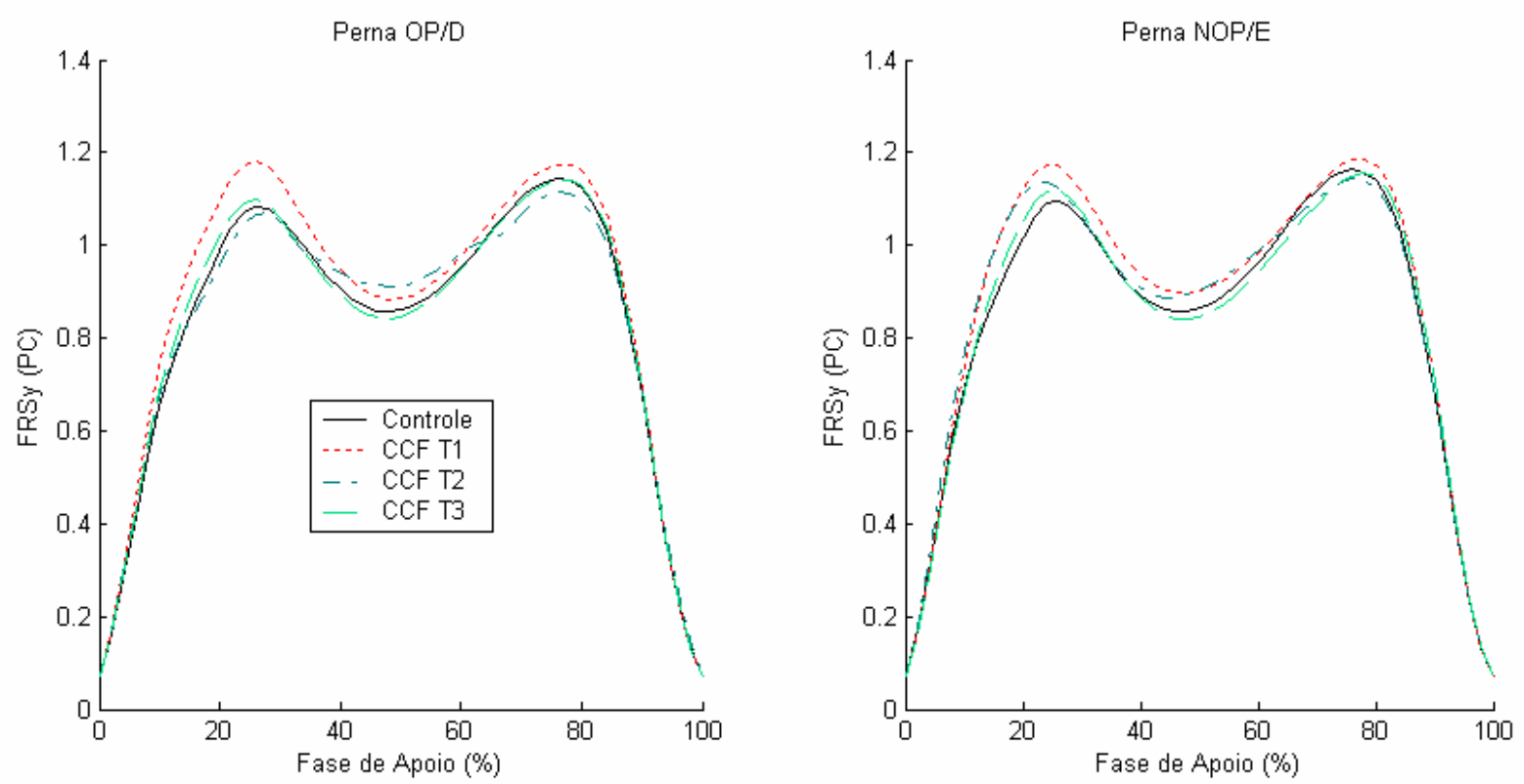

FIGURA 42 - Gráficos da componente vertical da força de reação do solo da perna operada ou direita (OP/D) e da perna não-operada ou esquerda (NOP/E) durante a fase de apoio da marcha na comparação entre os testes 1 (Pré), 2 (1PO) e 3 (4PO), do grupo cadeia cinética fechada $(\mathrm{CCF})(\mathrm{n}=10)$. A curva do grupo controle aparece como referência.

No grupo CCA a curva do Teste 2 (1PO) foi a que apresentou maiores alterações, principalmente da perna operada. O primeiro e o segundo pico com valores menores e a força mínima com valor maior que nos demais testes. A força mínima de ambas as pernas foi a variável que apresentou menos alteração ao longo dos testes, ela se manteve com valor alto em todos eles (FIGURA 43). 

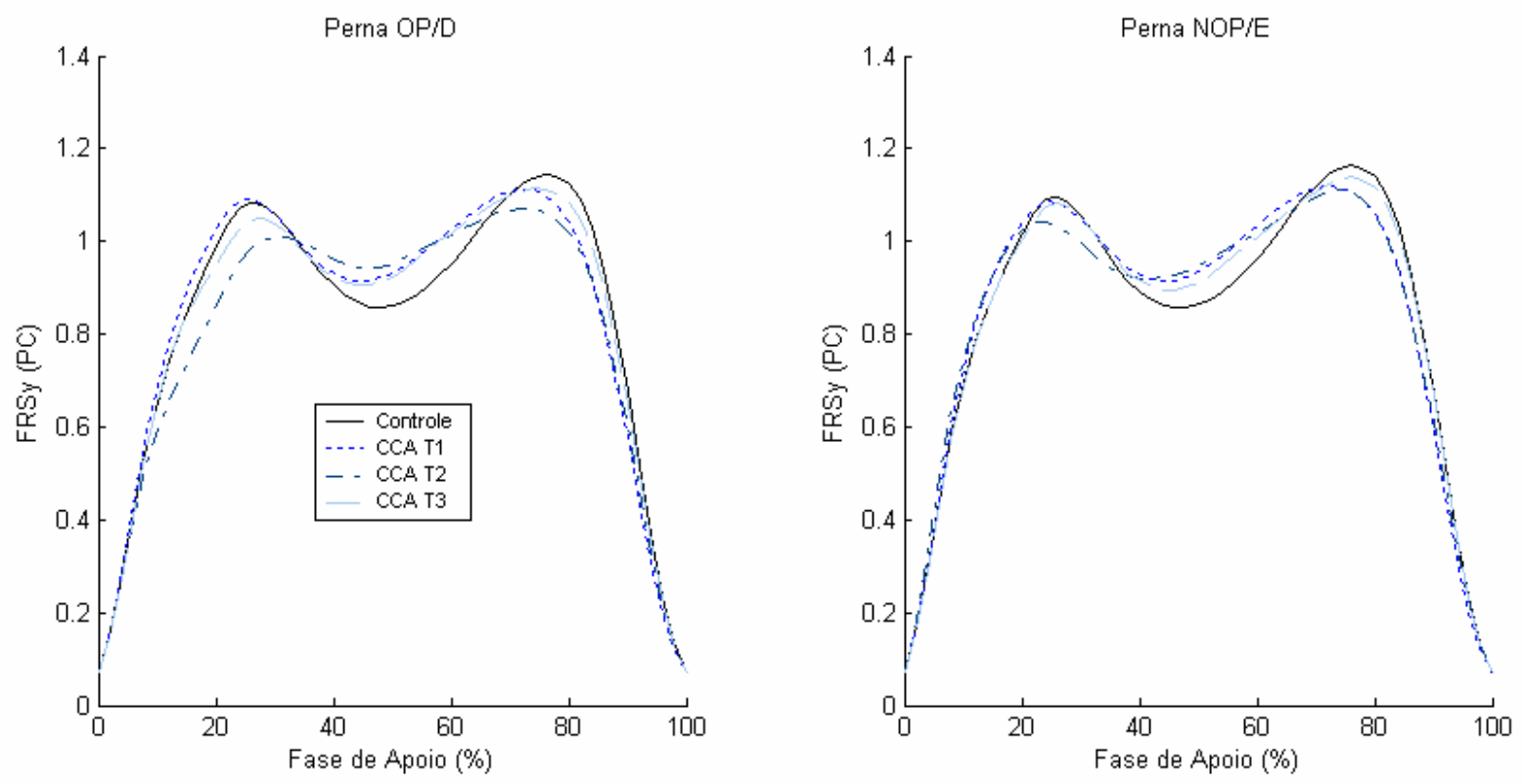

FIGURA 43 - Gráficos da componente vertical da força de reação do solo da perna operada ou direita (OP/D) e da perna não-operada ou esquerda (NOP/E) durante a fase de apoio da marcha na comparação entre os testes 1 (Pré), 2 (1PO) e 3 (4PO), do grupo cadeia cinética aberta $(\mathrm{CCA})(\mathrm{n}=10)$. A curva do grupo controle aparece como referência.

\section{Análise entre Grupos}

As variáveis relativas à força de reação do solo foram analisadas através da determinação de componentes principais para cada um dos membros inferiores, porém para propiciar um adequado acompanhamento dos resultados os valores médios e o desvio padrão de cada variável são apresentados na TABELA 2. 
TABELA 2 - Média e desvio padrão das variáveis da força de reação do solo, apresentadas por teste: testes 1 (Pré), 2 (1PO) e 3 (4PO) em cada grupo: controle (CON), cadeia cinética aberta (CCA) e cadeia cinética fechada (CCF) $(\mathrm{n}=10$ em cada grupo).

\begin{tabular}{|c|c|c|c|c|c|c|c|c|}
\hline & Perna & $\mathrm{CON}$ & & $\mathrm{CCF}$ & & & CCA & \\
\hline & & $\mathrm{T} 1$ & T1 & $\mathrm{T} 2$ & T3 & $\mathrm{T} 1$ & $\mathrm{~T} 2$ & T3 \\
\hline \multirow[t]{4}{*}{ Fy1 (PC) } & $\mathrm{OP}$ & 1,10 & 1,16 & 1,09 & 1,12 & 1,11 & 1,03 & 1,07 \\
\hline & & $\pm 0,06$ & $\pm 0,09$ & $\pm 0,08$ & $\pm 0,07$ & $\pm 0,05$ & $\pm 0,05$ & $\pm 0,05$ \\
\hline & NOP & 1,11 & 1,15 & 1,14 & 1,14 & 1,12 & 1,08 & 1,11 \\
\hline & & $\pm 0,07$ & $\pm 0,11$ & $\pm 0,07$ & $\pm 0,08$ & $\pm 0,06$ & $\pm 0,06$ & $\pm 0,07$ \\
\hline \multirow{4}{*}{ Fy2 (PC) } & OP & 1,17 & 1,15 & 1,13 & 1,16 & 1,12 & 1,08 & 1,12 \\
\hline & & $\pm 0,09$ & $\pm 0,07$ & $\pm 0,06$ & $\pm 0,05$ & $\pm 0,05$ & $\pm 0,05$ & $\pm 0,05$ \\
\hline & NOP & 1,18 & 1,16 & 1,17 & 1,17 & 1,13 & 1,13 & 1,15 \\
\hline & & $\pm 0,08$ & $\pm 0,06$ & $\pm 0,04$ & $\pm 0,04$ & $\pm 0,05$ & $\pm 0,04$ & $\pm 0,05$ \\
\hline \multirow{4}{*}{ Fymin (PC) } & $\mathrm{OP}$ & 0,84 & 0,84 & 0,90 & 0,83 & 0,90 & 0,93 & 0,906 \\
\hline & & $\pm 0,10$ & $\pm 0,06$ & $\pm 0,07$ & $\pm 0,07$ & $\pm 0,06$ & $\pm 0,05$ & $\pm 0,06$ \\
\hline & NOP & 0,84 & 0,84 & 0,86 & 0,83 & 0,90 & 0,89 & 0,88 \\
\hline & & $\pm 0,09$ & $\pm 0,08$ & $\pm 0,07$ & $\pm 0,08$ & $\pm 0,06$ & $\pm 0,05$ & $\pm 0,07$ \\
\hline \multirow{4}{*}{ tFy1 (s) } & $\mathrm{OP}$ & 0,19 & 0,17 & 0,21 & 0,18 & 0,19 & 0,22 & 0,20 \\
\hline & & $\pm 0,04$ & $\pm 0,03$ & $\pm 0,06$ & $\pm 0,04$ & $\pm 0,04$ & $\pm 0,03$ & $\pm 0,03$ \\
\hline & NOP & 0,18 & 0,17 & 0,17 & 0,18 & 0,18 & 0,18 & 0,19 \\
\hline & & $\pm 0,03$ & $\pm 0,03$ & $\pm 0,04$ & $\pm 0,03$ & $\pm 0,04$ & $\pm 0,04$ & $\pm 0,03$ \\
\hline \multirow{4}{*}{ tFy2 (s) } & OP & 0,53 & 0,53 & 0,54 & 0,53 & 0,53 & 0,54 & 0,54 \\
\hline & & $\pm 0,03$ & $\pm 0,03$ & $\pm 0,05$ & $\pm 0,03$ & $\pm 0,04$ & $\pm 0,04$ & $\pm 0,04$ \\
\hline & NOP & 0,53 & 0,54 & 0,56 & 0,54 & 0,54 & 0,57 & 0,55 \\
\hline & & $\pm 0,04$ & $\pm 0,03$ & $\pm 0,04$ & $\pm 0,04$ & $\pm 0,04$ & $\pm 0,04$ & $\pm 0,04$ \\
\hline \multirow{4}{*}{ tFymin (s) } & $\mathrm{OP}$ & 0,34 & 0,34 & 0,34 & 0,33 & 0,33 & 0,34 & 0,33 \\
\hline & & $\pm 0,03$ & $\pm 0,03$ & $\pm 0,05$ & $\pm 0,03$ & $\pm 0,03$ & $\pm 0,04$ & $\pm 0,03$ \\
\hline & NOP & 0,33 & 0,33 & 0,33 & 0,33 & 0,33 & 0,33 & 0,33 \\
\hline & & $\pm 0,03$ & $\pm 0,03$ & $\pm 0,04$ & $\pm 0,03$ & $\pm 0,03$ & $\pm 0,04$ & $\pm 0,03$ \\
\hline \multirow[t]{4}{*}{ txcFy1 (PC/s) } & $\mathrm{OP}$ & 6,09 & 6,87 & 5,57 & 6,62 & 6,25 & 4,89 & 5,63 \\
\hline & & $\pm 1,45$ & $\pm 1,32$ & $\pm 1,31$ & $\pm 1,40$ & $\pm 1,26$ & $\pm 0,77$ & $\pm 1,12$ \\
\hline & NOP & 6,34 & 6,96 & 6,88 & 6,71 & 6,44 & 6,16 & 6,11 \\
\hline & & $\pm 1,27$ & $\pm 1,30$ & $\pm 1,25$ & $\pm 1,19$ & $\pm 1,58$ & $\pm 1,40$ & $\pm 1,26$ \\
\hline \multirow{4}{*}{ txcFy2 (PC/s) } & OP & 1,72 & 1,67 & 1,21 & 1,65 & 1,12 & 0,78 & 1,11 \\
\hline & & $\pm 0,96$ & $\pm 0,43$ & $\pm 0,45$ & $\pm 0,44$ & $\pm 0,33$ & $\pm 0,22$ & $\pm 0,29$ \\
\hline & NOP & 1,78 & 1,60 & 1,38 & 1,68 & 1,15 & 0,98 & 1,21 \\
\hline & & $\pm 0,87$ & $\pm 0,57$ & $\pm 0,41$ & $\pm 0,57$ & $\pm 0,37$ & $\pm 0,27$ & $\pm 0,33$ \\
\hline \multirow{4}{*}{ dFymin (PC/s) } & OP & 1,73 & 1,99 & 1,34 & 1,88 & 1,52 & 0,84 & 1,30 \\
\hline & & $\pm 0,97$ & $\pm 0,69$ & $\pm 0,67$ & $\pm 0,67$ & $\pm 0,70$ & $\pm 0,28$ & $\pm 0,51$ \\
\hline & NOP & 1,83 & 1,95 & 1,68 & 2,03 & 1,56 & 1,30 & 1,65 \\
\hline & & $\pm 0,86$ & $\pm 0,84$ & $\pm 0,72$ & $\pm 0,79$ & $\pm 0,73$ & $\pm 0,64$ & $\pm 0,75$ \\
\hline
\end{tabular}

$\mathrm{Na}$ análise entre grupos dois componentes principais foram suficientes para ter aproximadamente $80 \%$ das variáveis representadas. A composição dos dois componentes principais e os percentuais acumulados em relação à representatividade das variáveis são apresentados na TABELA 3. 
TABELA 3 - Composição dos componentes principais das variáveis relativas à força de reação do solo e seus percentuais acumulados, para os testes 1 (Pré), 2 (1PO) e 3 (4PO).

\begin{tabular}{lcccccccccccc}
\hline & \multicolumn{1}{c}{ Teste 1 } & \multicolumn{3}{c}{ Teste 2 } & & \multicolumn{2}{c}{ Teste 3 } \\
\hline & Comp. 1 & Comp. 2 & Comp. 1 & Comp. 2 & Comp. 1 & Comp. 2 \\
\hline & OP & NOP & OP & NOP & OP & NOP & OP & NOP & OP & NOP & OP & NOP \\
\hline Fy1 (PC) & $-0,325$ & $-0,321$ & 0,143 & 0,259 & $-0,317$ & $-0,318$ & 0,296 & 0,211 & $-0,321$ & $-0,309$ & 0,239 & 0,262 \\
Fy2 (PC) & $-0,160$ & $-0,148$ & 0,491 & 0,401 & $-0,291$ & $-0,230$ & 0,428 & 0,546 & $-0,243$ & $-0,220$ & 0,529 & 0,453 \\
Fymin (PC) & 0,388 & 0,397 & 0,456 & $-0,187$ & 0,369 & 0,384 & - & - & 0,355 & 0,357 & - & $-0,135$ \\
tFy1 (s) & 0,361 & 0,357 & 0,316 & 0,320 & 0,336 & 0,335 & 0,344 & 0,353 & 0,349 & 0,359 & 0,326 & 0,339 \\
tFy2 (s) & 0,306 & 0,312 & 0,363 & 0,348 & 0,238 & 0,315 & 0,454 & 0,150 & 0,313 & 0,330 & 0,323 & 0,255 \\
tFymin (s) & 0,246 & 0,212 & $-0,214$ & 0,587 & 0,227 & 0,220 & 0,556 & 0,559 & 0,282 & 0,258 & 0,515 & 0,601 \\
tXCFy1 (PC/s) & $-0,390$ & $-0,397$ & $-0,208$ & $-0,150$ & $-0,399$ & $-0,382$ & - & $-0,208$ & $-0,374$ & $-0,392$ & $-0,149$ & $-0,114$ \\
tXCFy2 (PC/s) & $-0,349$ & $-0,366$ & 0,434 & 0,349 & $-0,377$ & $-0,360$ & 0,263 & 0,388 & $-0,357$ & $-0,356$ & 0,379 & 0,374 \\
dFymin (PC/s) & $-0,400$ & $-0,396$ & 0,147 & 0,159 & $-0,396$ & $-0,404$ & 0,134 & - & $-0,381$ & 0,380 & 0,111 & 0,115 \\
\hline \% acumulado & 56,8 & 58,1 & 74,0 & 74,7 & 62,3 & 58,5 & 81,6 & 74,6 & 64,5 & 63,5 & 79,2 & 77,4 \\
\hline
\end{tabular}

No Teste 1 (Pré), a componente principal um da perna operada apresentou diferença significativa entre os grupos CCF e CCA. A componente principal dois da mesma perna apresentou diferença significativa entre os grupos CON e CCA e entre os grupos CCF e CCA. A perna não-operada não apresentou diferenças significativas para a componente principal 1 . A componente principal dois da perna não-operada apresentou diferença significativa entre o grupos CON e CCA (TABELA 4).

No Teste 2 (1PO) da perna operada, a componente principal um e dois apresentaram diferenças significativas para todas as comparações entre grupos, ou seja, entre os grupos CON e CCA, CON e CCF e os grupos CCF e CCA. Na perna não-operada a componente principal 1 apresentou diferença significativa entre os grupos CON e o CCA e entre o grupo CCF e CCA. Na componente principal dois foi encontrado diferença significativa entre os grupos CON e CCF e os grupos CON e CCA (TABELA 4).

A análise relativa ao componente principal 1 no Teste 3 (4PO) da perna operada apresentou diferença significativa para todas as comparações entre grupos, ou seja, entre os grupos $\mathrm{CON}$ e $\mathrm{CCA}, \mathrm{CON}$ e $\mathrm{CCF}$ e entre os grupos $\mathrm{CCF}$ e CCA. O componente principal dois 
da perna operada apresentou diferença significativa apenas entre os grupos CON e o CCA. Na perna não-operada apenas o componente principal 1 apresentou diferença significativa e esta diferença foi entre os grupos CCF e CCA (TABELA 4).

TABELA 4 - Comparação entre os grupos controle (CON), cadeia cinética aberta (CCA) e cadeia cinética fechada (CCF) $(\mathrm{n}=10$ em cada grupo) dos componentes principais das variáveis da força de reação do solo nos testes 1 (Pré), 2 (1PO) e $\underline{3(4 \mathrm{PO})}$.

\begin{tabular}{|c|c|c|c|c|c|c|c|}
\hline & Pernas & Teste 1 & $\begin{array}{c}\text { Valor } \\
\text { de } p\end{array}$ & Teste 2 & $\begin{array}{c}\text { Valor } \\
\text { de } p\end{array}$ & Teste 3 & $\begin{array}{c}\text { Valor } \\
\text { de } p\end{array}$ \\
\hline \multirow[t]{6}{*}{ Componente 1} & $\overline{\mathbf{O P}}$ & $\mathrm{CON}=\mathrm{CCF}$ & NS & $\mathrm{CON} \neq \mathrm{CCF}$ & $\overline{0,01}$ & $\mathrm{CON} \neq \mathrm{CCF}$ & 0,02 \\
\hline & & $\mathrm{CON}=\mathrm{CCA}$ & NS & $\mathrm{CON} \neq \mathrm{CCA}$ & 0,00 & $\mathrm{CON} \neq \mathrm{CCA}$ & 0,00 \\
\hline & & $\mathrm{CCF} \neq \mathrm{CCA}$ & 0,04 & $\mathrm{CCF} \neq \mathrm{CCA}$ & 0,00 & $\mathrm{CCF} \neq \mathrm{CCA}$ & 0,00 \\
\hline & NOP & $\mathrm{CON}=\mathrm{CCF}$ & NS & $\mathrm{CON}=\mathrm{CCF}$ & NS & $\mathrm{CON}=\mathrm{CCF}$ & NS \\
\hline & & $\mathrm{CON}=\mathrm{CCA}$ & NS & $\mathrm{CON} \neq \mathrm{CCA}$ & 0,00 & $\mathrm{CON}=\mathrm{CCA}$ & NS \\
\hline & & $\mathrm{CCF}=\mathrm{CCA}$ & NS & $\mathrm{CCF} \neq \mathrm{CCA}$ & 0,00 & $\mathrm{CCF} \neq \mathrm{CCA}$ & 0,00 \\
\hline \multirow[t]{6}{*}{ Componente 2} & OP & $\mathrm{CON}=\mathrm{CCF}$ & NS & $\mathrm{CON} \neq \mathrm{CCF}$ & 0,05 & $\mathrm{CON}=\mathrm{CCF}$ & NS \\
\hline & & $\mathrm{CON} \neq \mathrm{CCA}$ & 0,01 & $\mathrm{CON} \neq \mathrm{CCA}$ & 0,00 & $\mathrm{CON} \neq \mathrm{CCA}$ & 0,02 \\
\hline & & $\mathrm{CCF} \neq \mathrm{CCA}$ & 0,05 & $\mathrm{CCF} \neq \mathrm{CCA}$ & 0,01 & $\mathrm{CCF}=\mathrm{CCA}$ & NS \\
\hline & NOP & $\mathrm{CON}=\mathrm{CCF}$ & NS & $\mathrm{CON} \neq \mathrm{CCF}$ & 0,01 & $\mathrm{CON}=\mathrm{CCF}$ & NS \\
\hline & & $\mathrm{CON} \neq \mathrm{CCA}$ & 0,01 & $\mathrm{CON} \neq \mathrm{CCA}$ & 0,00 & $\mathrm{CON}=\mathrm{CCA}$ & NS \\
\hline & & $\mathrm{CCF}=\mathrm{CCA}$ & NS & $\mathrm{CCF}=\mathrm{CCA}$ & NS & $\mathrm{CCF}=\mathrm{CCA}$ & NS \\
\hline
\end{tabular}

$\mathrm{OP}=$ operada; $\mathrm{NOP}=$ não-operada; $\mathrm{NS}$ = não significativo.

\section{Análise entre Testes}

$\mathrm{Na}$ análise entre testes três componentes principais foram suficientes para ter aproximadamente $80 \%$ das variáveis representadas. A composição dos três componentes principais e os percentuais acumulados em relação à representatividade das variáveis são apresentados na TABELA 5. 
TABELA 5 - Composição dos componentes principais das variáveis relativas à força de reação do solo e os percentuais acumulados, para os grupos cadeia cinética fechada (CCF) e aberta (CCA) $(\mathrm{n}=10$ em cada grupo).

\begin{tabular}{lcccccccccccc}
\hline & \multicolumn{3}{c}{ Grupo CCF } & & & & \multicolumn{3}{c}{ Grupo CCA } \\
\hline & Comp. 1 & Comp. 2 & Comp. 3 & Comp. 1 & Comp. 2 & Comp. 3 \\
\hline & OP & NOP & OP & NOP & OP & NOP & OP & NOP & OP & NOP & OP & NOP \\
\hline Fy1 (PC) & $-0,308$ & $-0,354$ & 0,352 & 0,349 & 0,323 & 0,148 & $-0,274$ & $-0,314$ & $-0,461$ & $-0,416$ & 0,131 & 0,317 \\
Fy2 (PC) & - & - & - & $-0,236$ & $-0,815$ & $-0,837$ & - & - & $-0,663$ & $-0,737$ & 0,154 & 0,108 \\
Fymin (PC) & 0,370 & 0,402 & $-0,263$ & $-0,180$ & - & 0,128 & 0,349 & 0,341 & $-0,236$ & $-0,290$ & 0,632 & 0,293 \\
tFy1 (s) & 0,399 & 0,324 & 0,295 & 0,446 & - & - & 0,406 & 0,378 & $-0,199$ & $-0,165$ & - & $-0,183$ \\
tFy2 (s) & 0,333 & 0,363 & 0,393 & 0,256 & - & - & 0,304 & 0,322 & $-0,136$ & - & $-0,571$ & 0,459 \\
tFymin (s) & 0,270 & 0,114 & 0,573 & 0,644 & 0,108 & $-0,160$ & 0,327 & 0,351 & $-0,261$ & $-0,252$ & $-0,290$ & $-0,338$ \\
txcFy1 (PC/s) & $-0,414$ & $-0,404$ & - & $-0,153$ & - & 0,151 & $-0,408$ & $-0,398$ & - & - & 0,137 & 0,272 \\
txcFy2 (PC/s) & $-0,320$ & $-0,365$ & 0,366 & 0,212 & $-0,420$ & $-0,458$ & $-0,328$ & 0,316 & $-0,374$ & $-0,313$ & $-0,252$ & $-0,600$ \\
dFymin (PC/s) & $-0,388$ & $-0,403$ & 0,299 & 0,205 & 0,163 & - & $-0,406$ & $-0,394$ & $-0,145$ & - & $-0,241$ & - \\
\hline \% acumulado & 51,1 & 52,9 & 69,5 & 72,4 & 84,1 & 85,2 & 50,3 & 57,8 & 69,8 & 75,9 & 79,0 & 84,9 \\
\hline
\end{tabular}

No grupo CCF, a perna operada apresentou diferença significativa na componente principal 1 entre os Testes 1 (Pré) e 2 (1PO) e os Teste 1 (Pré) e 3 (4PO). Na perna nãooperada a componente principal 1 apresentou diferença significativa somente entre os Testes 1 (Pré) e 3 (4PO). As componentes principais dois e três não apresentaram diferença significativa para nenhuma das comparações entre os testes, tanto para perna operada quanto para não-operada (TABELA 6).

No grupo CCA, a perna operada apresentou diferença significativa na componente principal 1 entre os Teste 1 (Pré) e 2 (1PO). A componente principal dois não apresentou diferença significativa entre os testes e a componente principal três apresentou diferença estatística entre os Testes 1 (Pré) e 2 (1PO) e entre os Teste 2 (1PO) e 3 (4PO). Em relação à perna não-operada apenas a componente principal três apresentou diferença significativa entre os Testes 1 (Pré) e 2 (1PO) (TABELA 6). 
TABELA 6 - Comparação dos componentes principais das variáveis relativas à força de reação do solo entre testes: 1 (Pré), 2 (1PO) e 3 (4PO) nos grupos controle $(\mathrm{CON})$, cadeia cinética aberta $(\mathrm{CCA})$ e cadeia cinética fechada(CCF) $(\mathrm{n}=10$ em cada grupo).

\begin{tabular}{|c|c|c|c|c|c|}
\hline & Pernas & Grupo CCF & Valor de p & Grupo CCA & Valor de $p$ \\
\hline \multirow[t]{6}{*}{ Componente 1} & $\overline{\mathbf{O P}}$ & $\mathrm{T} 1 \neq \mathrm{T} 2$ & $\overline{0,00}$ & $\mathrm{~T} 1 \neq \mathrm{T} 2$ & 0,00 \\
\hline & & $\mathrm{T} 1 \neq \mathrm{T} 3$ & 0,00 & $\mathrm{~T} 1=\mathrm{T} 3$ & NS \\
\hline & & $\mathrm{T} 2=\mathrm{T} 3$ & NS & $\mathrm{T} 2=\mathrm{T} 3$ & NS \\
\hline & NOP & $\mathrm{T} 1=\mathrm{T} 2$ & NS & $\mathrm{T} 1=\mathrm{T} 2$ & NS \\
\hline & & $\mathrm{T} 1 \neq \mathrm{T} 3$ & 0,01 & $\mathrm{~T} 1=\mathrm{T} 3$ & NS \\
\hline & & $\mathrm{T} 2=\mathrm{T} 3$ & NS & $\mathrm{T} 2=\mathrm{T} 3$ & NS \\
\hline \multirow[t]{6}{*}{ Componente 2} & OP & $\mathrm{T} 1=\mathrm{T} 2$ & NS & $\mathrm{T} 1=\mathrm{T} 2$ & NS \\
\hline & & $\mathrm{T} 1=\mathrm{T} 3$ & NS & $\mathrm{T} 1=\mathrm{T} 3$ & NS \\
\hline & & $\mathrm{T} 2=\mathrm{T} 3$ & NS & $\mathrm{T} 2=\mathrm{T} 3$ & NS \\
\hline & NOP & $\mathrm{T} 1=\mathrm{T} 2$ & NS & $\mathrm{T} 1=\mathrm{T} 2$ & NS \\
\hline & & $\mathrm{T} 1=\mathrm{T} 3$ & NS & $\mathrm{T} 1=\mathrm{T} 3$ & NS \\
\hline & & $\mathrm{T} 2=\mathrm{T} 3$ & NS & $\mathrm{T} 2=\mathrm{T} 3$ & NS \\
\hline \multirow[t]{6}{*}{ Componente 3} & OP & $\mathrm{T} 1=\mathrm{T} 2$ & NS & $\mathrm{T} 1 \neq \mathrm{T} 2$ & 0,01 \\
\hline & & $\mathrm{T} 1=\mathrm{T} 3$ & NS & $\mathrm{T} 1=\mathrm{T} 3$ & NS \\
\hline & & $\mathrm{T} 2=\mathrm{T} 3$ & NS & $\mathrm{T} 2 \neq \mathrm{T} 3$ & 0,04 \\
\hline & NOP & $\mathrm{T} 1=\mathrm{T} 2$ & NS & $\mathrm{T} 1 \neq \mathrm{T} 2$ & 0,05 \\
\hline & & $\mathrm{T} 1=\mathrm{T} 3$ & NS & $\mathrm{T} 1=\mathrm{T} 3$ & NS \\
\hline & & $\mathrm{T} 2=\mathrm{T} 3$ & NS & $\mathrm{T} 2=\mathrm{T} 3$ & NS \\
\hline
\end{tabular}




\subsection{Parâmetros Cinemáticos}

\subsubsection{Parâmetros Temporais}

\section{Análise entre Grupos}

As variáveis analisadas, tempo de apoio simples, tempo para execução do passo, tempo para execução da passada, de ambos os membros inferiores, e o tempo de apoio duplo, não apresentaram diferenças significativas entre os grupos no Teste 1 (Pré) e nem no Teste 3 (4PO) (TABELA 7).

No Teste 2 (1PO), o tempo de apoio simples e o tempo do passo da perna nãooperada do grupo CCA foram significativamente maiores que do grupo $\operatorname{CON}(p=0,00$ e $p=$ 0,04 ; respectivamente). As demais variáveis não apresentaram diferenças significativas entre os grupos (TABELA 7).

\section{Análise entre Testes}

O grupo CCF e o grupo CCA apresentaram o tempo de apoio simples da perna nãooperada significativamente maior no Teste 2 (1PO) do que no Teste 3 (4PO) $(\mathrm{p}=0,01$ e $\mathrm{p}=$ 0,00; respectivamente) e o grupo CCF também apresentou valores desta variável significativamente maiores no Teste 2 (1PO) do que no Teste 1 (Pré) $(\mathrm{p}=0,01)$. Para ambos os grupos também o tempo da passada da perna operada (CCF: $p=0,05$ e CCA: $p=0,01)$ e da não-operada (CCF: $p=0,05$ e CCA: $p=0,01$ ), assim como o tempo do passo da perna nãooperada (CCF: $p=0,05$ e CCA: $p=0,00)$ foram significativamente maiores no Teste $2(1 \mathrm{PO})$ quando comparado ao Teste 3 (4PO). No entanto, somente no grupo CCA, o tempo do passo da perna operada foi maior no Teste 2 (1PO) do que no Teste 3 (4PO) $(\mathrm{p}=0,01)$ (TABELA 7). 
TABELA 7 - Média e desvio padrão dos parâmetros temporais da marcha da perna operada (OP) e não-operada (NOP), apresentados por grupo: controle (CON), cadeia cinética aberta (CCA) e cadeia cinética fechada (CCF) $(\mathrm{n}=10$ em cada grupo) nos testes 1 (Pré), 2 (1PO) e 3 (4PO).

\begin{tabular}{|c|c|c|c|c|c|c|c|c|c|c|}
\hline & \multirow[t]{2}{*}{ Perna } & \multicolumn{3}{|c|}{ Teste 1} & \multicolumn{3}{|c|}{ Teste 2} & \multicolumn{3}{|c|}{ Teste 3} \\
\hline & & $\mathrm{CON}$ & $\mathrm{CCF}$ & CCA & $\mathrm{CON}$ & $\mathrm{CCF}$ & CCA & $\mathrm{CON}$ & $\mathrm{CCF}$ & $\mathrm{CCA}$ \\
\hline \multirow{4}{*}{$\begin{array}{l}\text { Tempo de apoio } \\
\text { simples (s) }\end{array}$} & $\mathrm{OP}$ & 0,426 & 0,425 & 0,429 & 0,426 & 0,435 & 0,451 & 0,426 & 0,421 & 0,436 \\
\hline & & $\pm 0,02$ & $\pm 0,02$ & $\pm 0,03$ & $\pm 0,02$ & $\pm 0,02$ & $\pm 0,04$ & $\pm 0,02$ & $\pm 0,02$ & $\pm 0,03$ \\
\hline & NOP & 0,427 & $0,433^{\mathrm{d}}$ & $0,433^{\mathrm{d}}$ & $0,427^{\mathrm{b}}$ & $0,464^{\mathrm{f}}$ & $0,477^{\mathrm{f}}$ & 0,427 & 0,428 & 0,436 \\
\hline & & $\pm 0,03$ & $\pm 0,03$ & $\pm 0,03$ & $\pm 0,03$ & $\pm 0,05$ & $\pm 0,05$ & $\pm 0,03$ & $\pm 0,03$ & $\pm 0,03$ \\
\hline \multirow{4}{*}{ Tempo do passo (s) } & OP & 0,704 & 0,695 & 0,728 & 0,705 & 0,723 & $0,766^{\mathrm{f}}$ & 0,705 & 0,689 & 0,721 \\
\hline & & $\pm 0,06$ & $\pm 0,05$ & $\pm 0,06$ & $\pm 0,06$ & $\pm 0,07$ & $\pm 0,10$ & $\pm 0,06$ & $\pm 0,06$ & $\pm 0,05$ \\
\hline & NOP & 0,705 & 0,703 & 0,732 & $0,705^{\mathrm{b}}$ & $0,753^{\mathrm{f}}$ & $0,791^{\mathrm{f}}$ & 0,705 & 0,695 & 0,722 \\
\hline & & $\pm 0,06$ & $\pm 0,07$ & $\pm 0,07$ & $\pm 0,06$ & $\pm 0,11$ & $\pm 0,11$ & $\pm 0,06$ & $\pm 0,07$ & $\pm 0,05$ \\
\hline \multirow{4}{*}{$\begin{array}{l}\text { Tempo da passada } \\
\text { (s) }\end{array}$} & $\mathrm{OP}$ & 1,272 & 1,260 & 1,311 & 1,273 & $1,336^{\mathrm{f}}$ & $1,408^{\mathrm{f}}$ & 1,273 & 1,250 & 1,303 \\
\hline & & $\pm 0,09$ & $\pm 0,10$ & $\pm 0,09$ & $\pm 0,09$ & $\pm 0,15$ & $\pm 0,17$ & $\pm 0,09$ & $\pm 0,11$ & $\pm 0,08$ \\
\hline & NOP & 1,268 & 1,264 & 1,307 & 1,268 & $1,325^{\mathrm{f}}$ & $1,389^{\mathrm{f}}$ & 1,268 & 1,249 & 1,298 \\
\hline & & $\pm 0,09$ & $\pm 0,10$ & $\pm 0,10$ & $\pm 0,09$ & $\pm 0,13$ & $\pm 0,17$ & $\pm 0,09$ & $\pm 0,11$ & $\pm 0,08$ \\
\hline \multirow{2}{*}{$\begin{array}{l}\text { Tempo de apoio } \\
\text { duplo (s) }\end{array}$} & & 0,139 & 0,135 & 0,149 & 0,139 & 0,144 & 0,157 & 0,139 & 0,134 & 0,143 \\
\hline & & $\pm 0,03$ & $\pm 0,02$ & $\pm 0,03$ & $\pm 0,03$ & $\pm 0,04$ & $\pm 0,04$ & $\pm 0,03$ & $\pm 0,02$ & $\pm 0,02$ \\
\hline
\end{tabular}

$\mathrm{b}=$ diferença significativa entre CON e CCA

$\mathrm{d}=$ diferença significativa entre $\mathrm{T} 1$ e $\mathrm{T} 2$

$\mathrm{f}=$ diferença significativa entre $\mathrm{T} 2$ e $\mathrm{T} 3$

\subsubsection{Parâmetros Espaciais}

\section{Análise entre Grupos}

No Teste 1 (Pré) e no Teste 3 (4PO) o comprimento da passada e do passo da perna operada e da perna não-operada não apresentaram diferença estatística entre os grupos (TABELA 8).

No Teste 2 (1PO), o comprimento da passada da perna operada foi significativamente menor no grupo CCA quando comparado ao grupo CCF $(p=0,05)$, nas demais comparações entre os grupos em relação a passada da perna operada não foram encontradas diferenças estatísticas. Na perna não-operada o comprimento da passada do grupo 
CCA foi significativamente menor do que dos grupos $\operatorname{CON}$ e $\operatorname{CCF}(p=0,05$ e $p=0,04$; respectivamente). Entre os grupos $\mathrm{CON}$ e $\mathrm{CCF}$ não ocorreram diferenças estatísticas (TABELA 8).

Em relação ao comprimento do passo no Teste 2 (1PO), a perna operada do grupo CCA apresentou valores significativamente menores do que o grupo CON e CCF ( $p=0,03$ e $p$ $=0,05$; respectivamente). Entre os grupos $\mathrm{CON}$ e $\mathrm{CCF}$ não foram encontradas diferenças estatísticas. O comprimento do passo da perna não-operada do grupo CCA foi significativamente menor do que o grupo $\mathrm{CCF}(\mathrm{p}=0,04)$. As comparações entre os grupos CON e CCF e os grupos CON e CCA não apresentaram diferença estatística (TABELA 8).

TABELA 8 - Média e desvio padrão dos parâmetros espaciais da marcha da perna operada (OP) e não-operada (NOP), apresentados por grupo: controle (CON), cadeia cinética aberta (CCA) e cadeia cinética fechada (CCF) $(\mathrm{n}=10$ em cada grupo) nos testes 1 (Pré), 2 (1PO) e 3 (4PO).

\begin{tabular}{|c|c|c|c|c|c|c|c|c|c|c|c|}
\hline & & \multirow[t]{2}{*}{ Perna } & \multicolumn{3}{|c|}{ Teste 1} & \multicolumn{3}{|c|}{ Teste 2} & \multicolumn{3}{|c|}{ Teste 3} \\
\hline & & & $\mathrm{CON}$ & $\mathrm{CCF}$ & $\mathrm{CCA}$ & $\mathrm{CON}$ & $\mathrm{CCF}$ & $\mathrm{CCA}$ & $\mathrm{CON}$ & $\mathrm{CCF}$ & CCA \\
\hline \multirow{4}{*}{$\begin{array}{l}\text { Comprimento } \\
\text { passada (m) }\end{array}$} & da & OP & 0,843 & 0,844 & 0,789 & 0,843 & $0,815^{\mathrm{c}}$ & 0,739 & 0,843 & 0,832 & 0,782 \\
\hline & & & $\pm 0,12$ & $\pm 0,07$ & $\pm 0,07$ & $\pm 0,12$ & $\pm 0,07$ & $\pm 0,07$ & $\pm 0,12$ & $\pm 0,06$ & $\pm 0,06$ \\
\hline & & NOP & 0,839 & 0,843 & 0,786 & $0,839^{\mathrm{b}}$ & $0,805^{\mathrm{c}}$ & 0,731 & 0,839 & 0,834 & 0,781 \\
\hline & & & $\pm 0,12$ & $\pm 0,07$ & $\pm 0,07$ & $\pm 0,12$ & $\pm 0,08$ & $\pm 0,07$ & $\pm 0,12$ & $\pm 0,06$ & $\pm 0,05$ \\
\hline \multirow{4}{*}{$\begin{array}{l}\text { Comprimento } \\
\text { passo }(\mathrm{m})\end{array}$} & do & OP & 0,465 & $0,464^{\mathrm{d}}$ & 0,437 & $0,465^{\mathrm{b}}$ & 0,440 & 0,402 & 0,465 & 0,458 & 0,433 \\
\hline & & & $\pm 0,06$ & $\pm 0,04$ & $\pm 0,04$ & $\pm 0,06$ & $\pm 0,04$ & $\pm 0,04$ & $\pm 0,06$ & $\pm 0,03$ & $\pm 0,03$ \\
\hline & & NOP & 0,466 & 0,469 & 0,439 & 0,466 & $0,456^{\mathrm{c}}$ & 0,414 & 0,466 & 0,463 & 0,433 \\
\hline & & & $\pm 0,06$ & $\pm 0,04$ & $\pm 0,04$ & $\pm 0,06$ & $\pm 0,04$ & $\pm 0,04$ & $\pm 0,06$ & $\pm 0,03$ & $\pm 0,03$ \\
\hline
\end{tabular}

\section{Análise entre Testes}

No grupo CCF, os valores do comprimento do passo da perna operada do Teste 1 (Pré) foram significativamente maiores do que no Teste $2(1 \mathrm{PO})(\mathrm{p}=0,04)$. Em relação às outras comparações entre os testes não foram encontradas diferenças significativas (TABELA $8)$.

No grupo CCA não foram encontradas diferenças significativas entre os testes em nenhuma das variáveis analisadas (TABELA 8). 


\subsubsection{Variação Angular do Joelho}

\section{Análise Descritiva}

No Teste 1 (Pré), ao analisar a perna operada dos grupos CCA e CCF em relação a perna direita do grupo CON, o grupo CCF e o grupo CCA apresentaram um menor pico de flexão do joelho no início da fase de apoio, sendo o pico de flexão do grupo CCA ainda menor do que o do grupo CCF. E este pico de flexão também demorou mais para ocorrer nos grupos CCA e CCF (22\% e $24 \%$ da fase de apoio) do que no grupo CON (18\% da fase de apoio). Em relação ao pico de extensão ao final da fase de apoio o grupo CCF apresentou um pico menor do que o grupo CON e o grupo CCA. O momento em que o pico ocorreu foi em torno de $70 \%$ da fase de apoio para os três grupos (FIGURA 44). A perna não-operada do grupo CCF acompanha a curva da perna esquerda do grupo CON. A perna não-operada do grupo CCA acompanhou a curva do grupo CON, porém com o joelho um pouco mais flexionado ao longo de todo o apoio (FIGURA 44). 

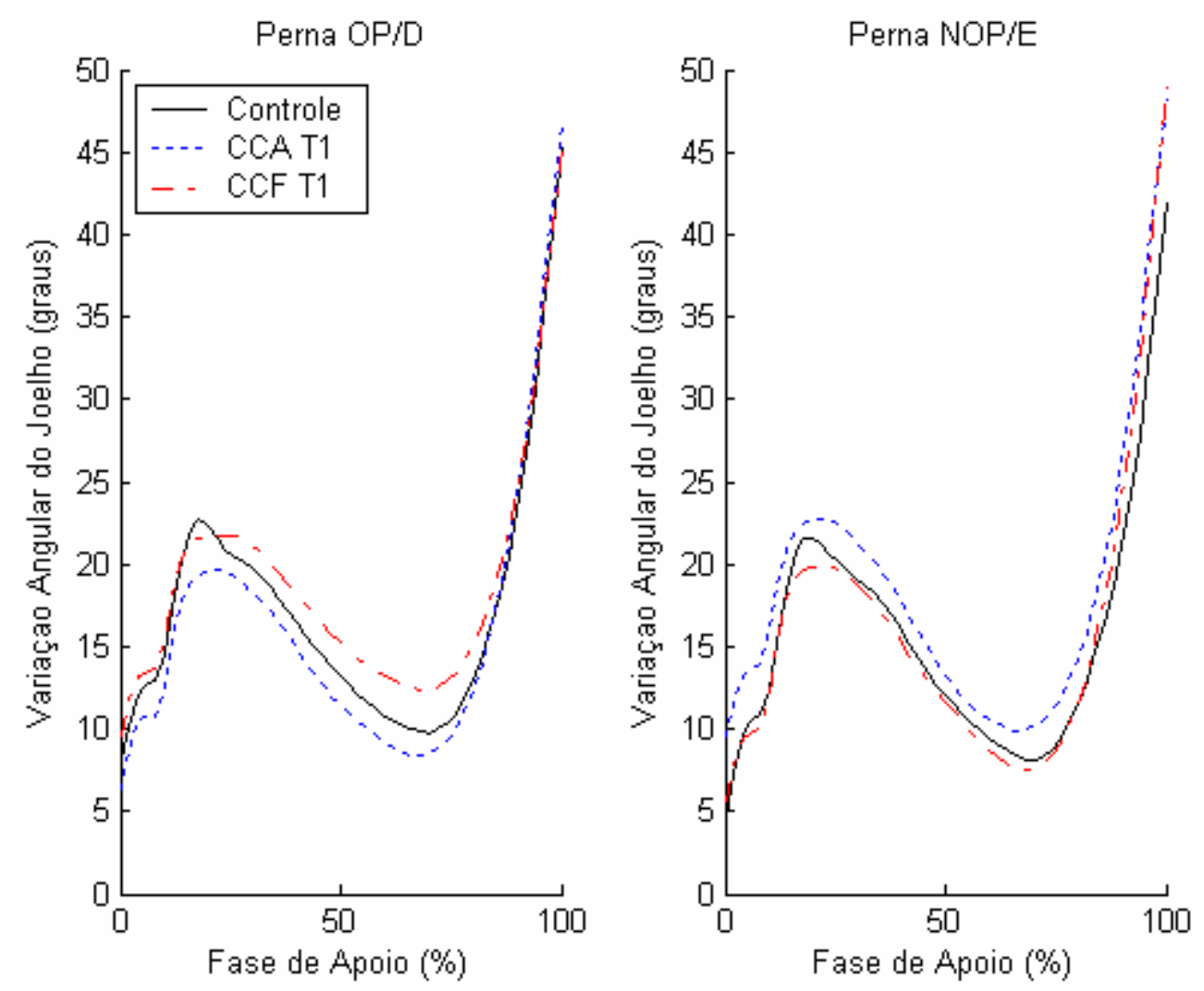

FIGURA 44 - Gráficos da variação angular do joelho da perna operada ou direita (OP/D) e da perna não-operada ou esquerda (NOP/E) durante a fase de apoio da marcha na comparação entre grupos: controle $(\mathrm{CON})$, cadeia cinética aberta $(\mathrm{CCA})$ e cadeia cinética fechada (CCF) $(\mathrm{n}=10$ em cada grupo) no Teste 1 (Pré).

No Teste 2 (1PO) o pico de flexão do início da fase de apoio foi expressivamente menor nos grupos CCA e CCF do que no grupo CON. E o momento em que o pico ocorreu para os grupos com lesão do LCA manteve-se mais tardiamente do que o grupo CON. O pico de extensão do final da fase de apoio dos grupos CCA e CCF não se diferenciou do grupo CON em relação a sua magnitude e ao momento da fase de apoio em que ele ocorreu (FIGURA 45). A variação angular do joelho da perna não-operada foi semelhante entre os três grupos (FIGURA 45). 

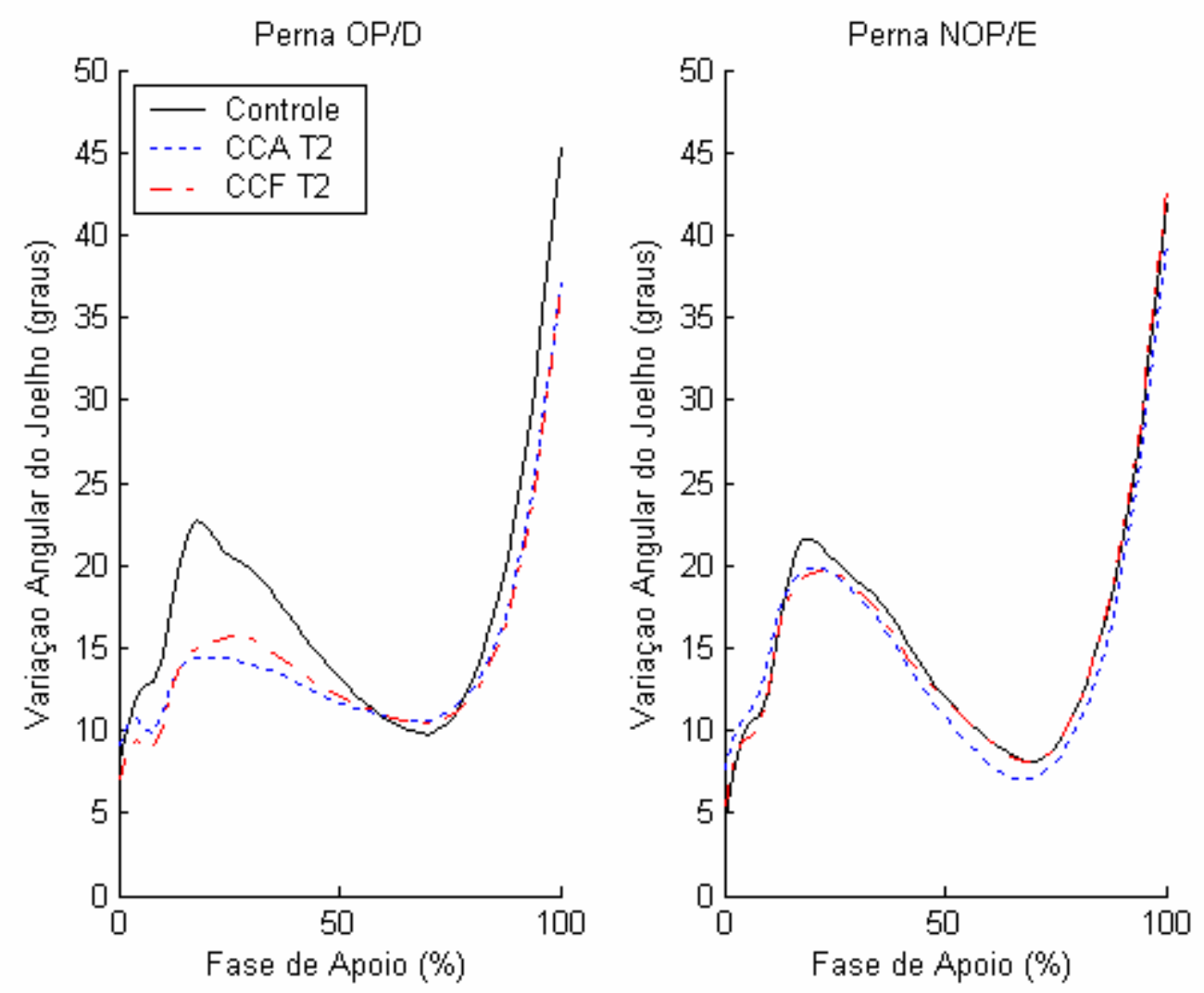

FIGURA 45 - Gráficos da variação angular do joelho da perna operada ou direita (OP/D) e da perna não-operada ou esquerda (NOP/E) durante a fase de apoio da marcha na comparação entre grupos: controle $(\mathrm{CON})$, cadeia cinética aberta $(\mathrm{CCA})$ e cadeia cinética fechada (CCF) $(\mathrm{n}=10$ em cada grupo) no Teste 2 (1PO).

No Teste 3 (4PO) a perna operada do grupo CCF apresentou um aumento do pico de flexão em relação ao grupo CCA, mas ainda abaixo do grupo CON. O grupo CCA foi o que apresentou o menor pico de flexão. O momento em que o pico ocorreu deixou de ser mais tardiamente do que o grupo CON, os três grupos tem o pico de flexão acontecendo em torno de $18 \%$ da fase de apoio. O pico de extensão do final da fase de apoio, da mesma forma que no Teste 2 (1PO), foi semelhante entre os grupos tanto em valor quanto no momento da fase de apoio em que ele ocorreu (FIGURA 46). A variação angular do joelho da perna nãooperada foi semelhante entre os três grupos (FIGURA 46). 

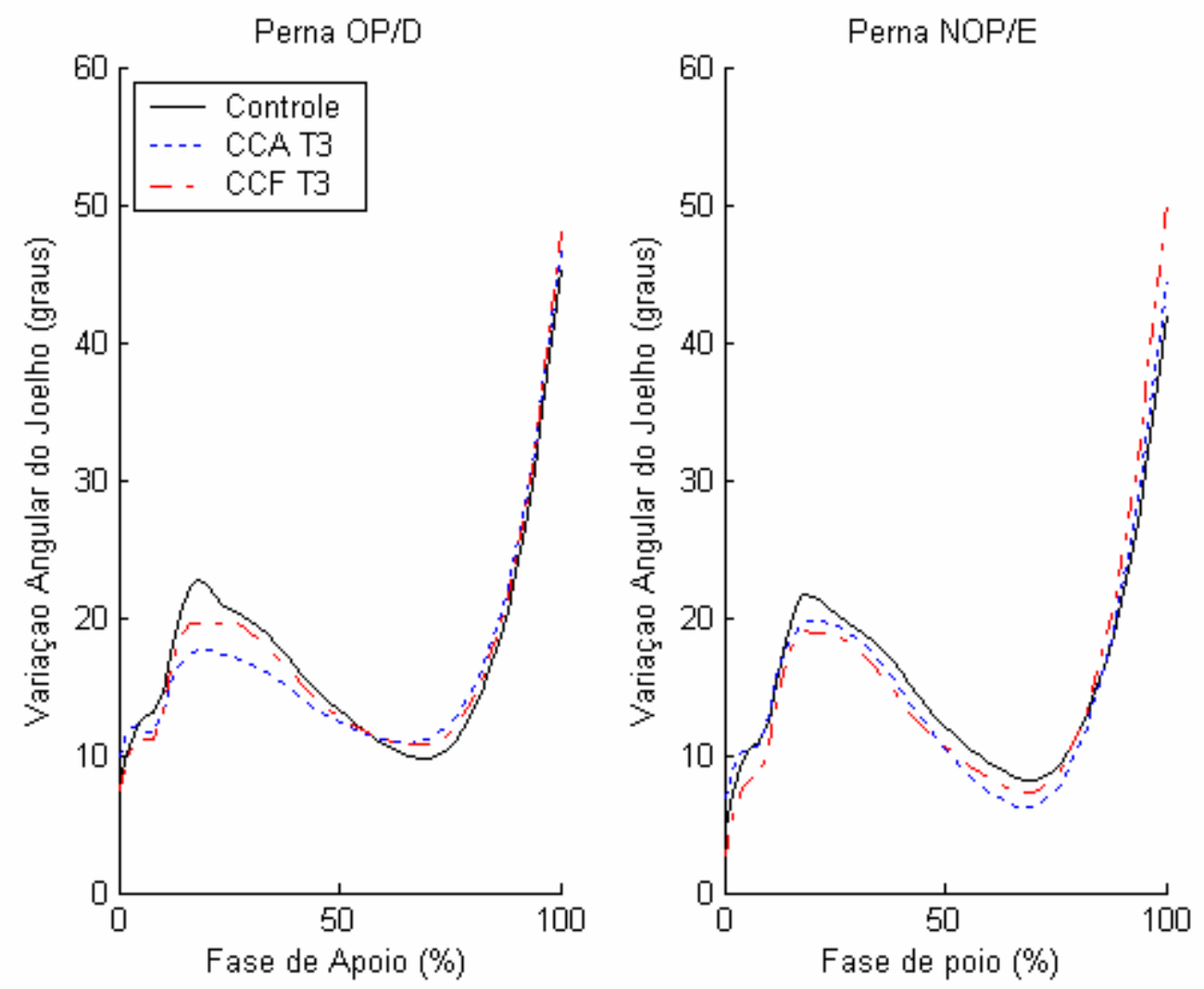

FIGURA 46 - Gráficos da variação angular do joelho da perna operada ou direita (OP/D) e da perna não-operada ou esquerda (NOP/E) durante a fase de apoio da marcha na comparação entre grupos: controle $(\mathrm{CON})$, cadeia cinética aberta $(\mathrm{CCA})$ e cadeia cinética fechada (CCF) $(n=10$ em cada grupo) no Teste 3 (4PO).

A comparação da variação angular do joelho do grupo CCF nos diferentes momentos da reabilitação permite observar que as maiores alterações ocorreram na perna operada no Teste 2 (1PO). Neste teste o joelho permaneceu mais estendido no início da fase de apoio e ao final da mesma. No Teste 2 (1PO) o joelho permaneceu mais flexionado no médio apoio. No Teste 3 (4PO) o joelho ainda permaneceu um pouco estendido no início da fase de apoio, porém o restante da curva ficou bem próximo do normal (FIGURA 47). A perna nãooperada apresentou um pico de flexão levemente menor do que o grupo $\mathrm{CON}$ em todos os testes. No restante da curva elas se assemelham (FIGURA 47). 

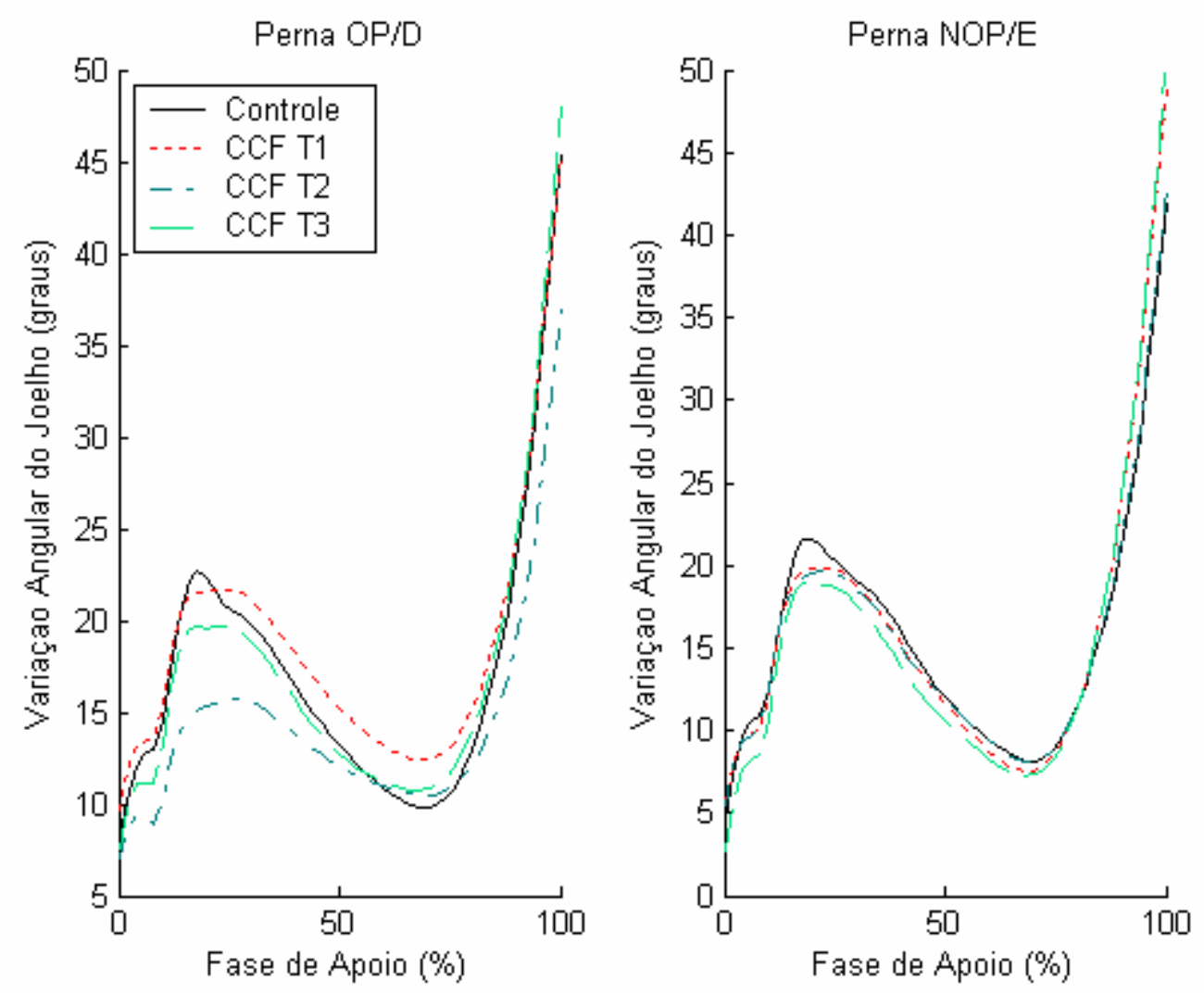

FIGURA 47 - Gráficos da variação angular do joelho da perna operada ou direita (OP/D) e da perna não-operada ou esquerda (NOP/E) durante a fase de apoio da marcha na comparação entre os testes 1 (Pré), 2 (1PO) e 3 (4PO), do grupo cadeia cinética fechada $(\mathrm{CCF})(\mathrm{n}=10)$. A curva do grupo controle aparece como referência.

O grupo CCA também apresentou mais alterações na curva de variação angular da perna operada do joelho no Teste 2 (1PO), permanecendo numa posição mais estendida no início e ao final da fase de apoio como no grupo CCF. O Teste 1 (Pré) e o Teste 3 (4PO) também apresentou uma posição mais entendida no início da fase de apoio (FIGURA 48). A perna não-operada apresentou uma posição mais estendida no Teste 1 (Pré) durante toda a fase de apoio e nos Testes 2 (1PO) e 3 (4PO) o joelho passou para uma posição levemente mais flexionada (FIGURA 48). 

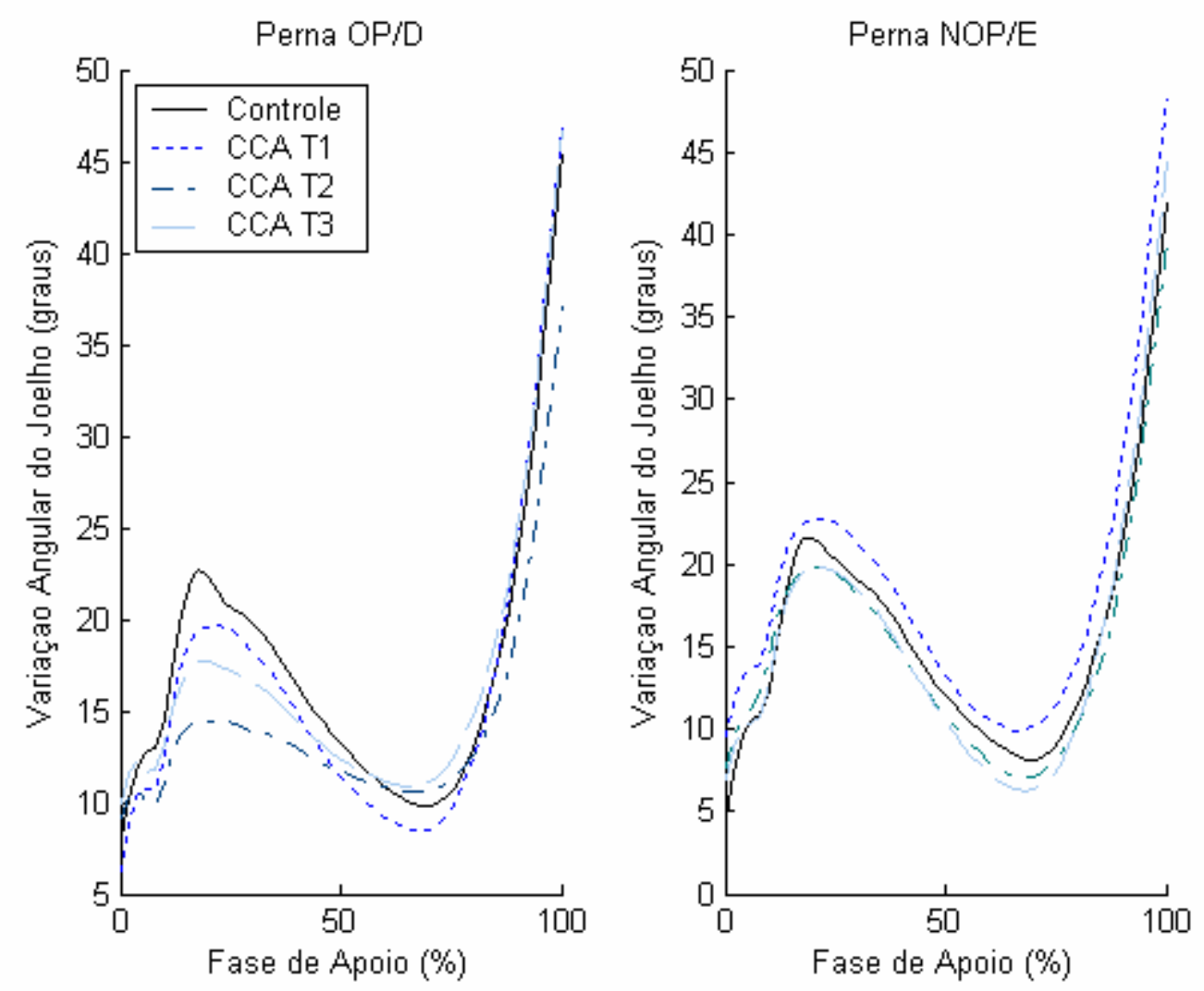

FIGURA 48 - Gráficos da variação angular do joelho da perna operada ou direita (OP/D) e da perna não-operada ou esquerda (NOP/E) durante a fase de apoio da marcha na comparação entre os testes 1 (Pré), 2 (1PO) e 3 (4PO), do grupo cadeia cinética aberta $(\mathrm{CCA})(\mathrm{n}=10)$. A curva do grupo controle aparece como referência.

\section{Análise entre Grupos}

As amplitudes articulares do joelho operado e do não-operado alcançadas durante a fase de apoio e do joelho operado durante a fase de balanço não apresentaram diferença significativa entre os grupos no Teste 1 (Pré). Na fase de balanço da perna não-operada a amplitude articular do joelho foi maior para o grupo CCF do que para o grupo CCA $(p=0,04)$ (FIGURA 49). 


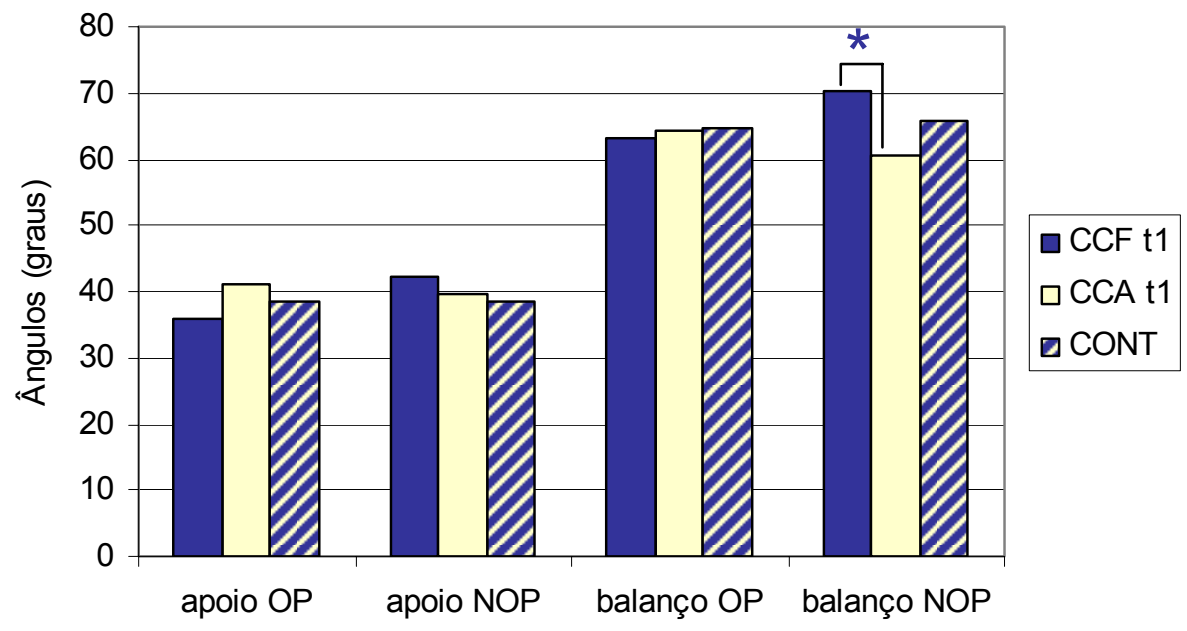

FIGURA 49 - Gráfico da diferença pico a pico do movimento articular do joelho da perna operada (OP) e não-operada (NOP) durante as fases de apoio e balanço da marcha nos grupos controle (CON), cadeia cinética aberta (CCA) e cadeia cinética fechada(CCF) $(\mathrm{n}=10$ em cada grupo) no Teste 1 (Pré).

No Teste 2 (1PO), o grupo CCF e o grupo CCA, apresentaram valores significativamente menores de amplitude de movimento do joelho operado na fase de apoio quando comparados com o grupo $\operatorname{CON}(\mathrm{p}=0,02$ e $\mathrm{p}=0,02$; respectivamente) na fase de balanço o grupo CCF foi significativamente menor do que o CON $(p=0,00)$. A amplitude de movimento do joelho não-operado não apresentou diferença significativa entre os grupos nem na fase de apoio e nem na fase de balanço (FIGURA 50). 


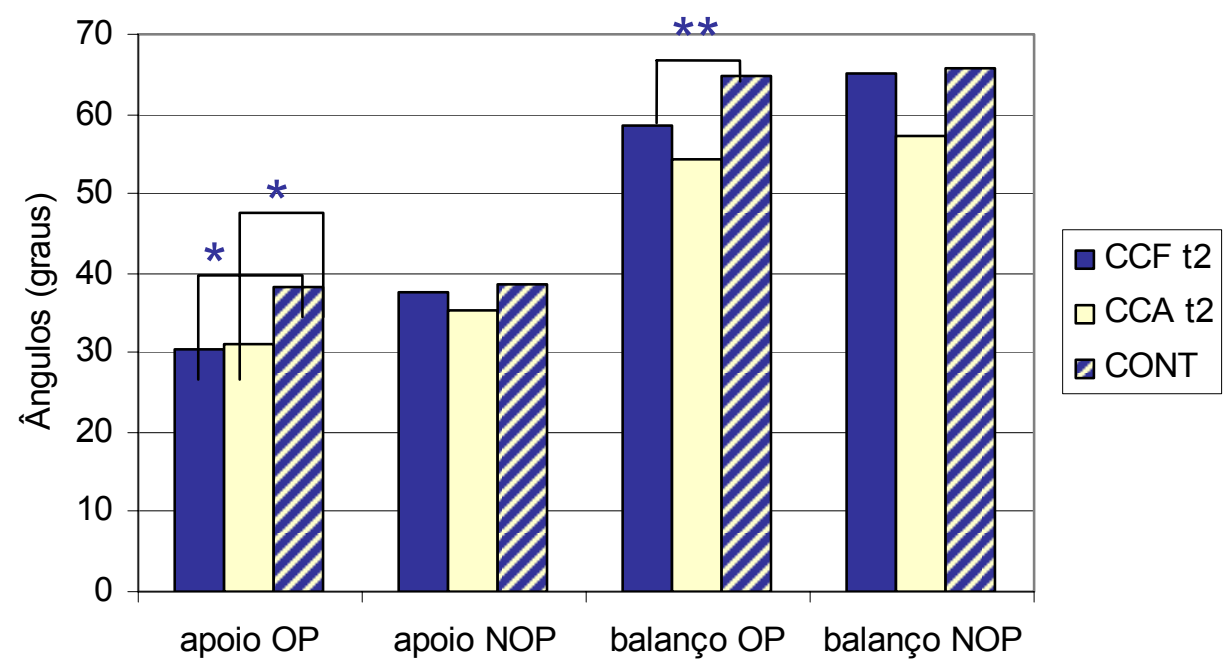

FIGURA 50 - Gráfico da diferença pico a pico do movimento articular do joelho da perna operada (OP) e não-operada (NOP) durante as fases de apoio e balanço da marcha nos grupos controle (CON), cadeia cinética aberta (CCA) e cadeia cinética fechada(CCF) $(\mathrm{n}=10$ em cada grupo)no Teste 2 (1PO).

Ao final do tratamento (Teste 3 (4PO)) nenhuma das variáveis analisadas relativas a amplitude articular do joelho apresentou diferença significativa entre os grupos (FIGURA 51).

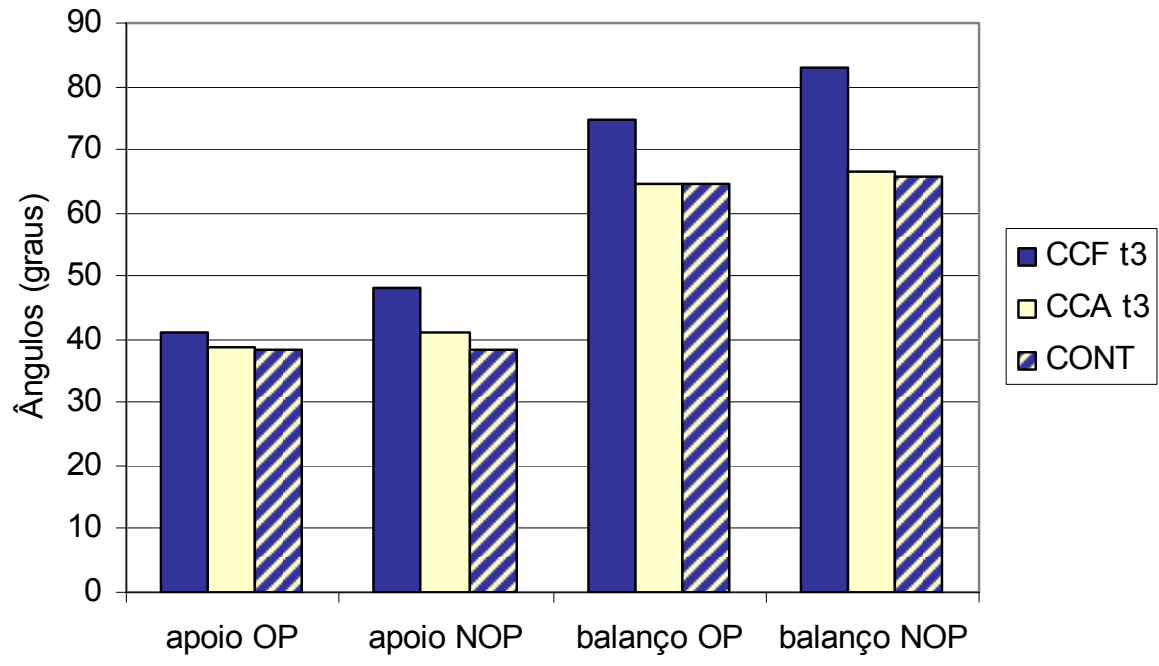

FIGURA 51 - Gráfico da diferença pico a pico do movimento articular do joelho da perna operada (OP) e não-operada (NOP) durante as fases de apoio e balanço da marcha nos grupos controle (CON), cadeia cinética aberta (CCA) e cadeia cinética fechada(CCF) ( $\mathrm{n}=10$ em cada grupo) no Teste 3 (4PO). 


\section{Análise entre Testes}

O grupo CCF (FIGURA 52) e o grupo CCA (FIGURA 53) apresentaram amplitudes de movimento do joelho operado durante a fase de apoio significativamente menores no Teste 2 (1PO) quando comparado ao Teste 1 (Pré) $(\mathrm{p}=0,00$ e $\mathrm{p}=0,00$; respectivamente). As demais variáveis, nos dois grupos, não apresentaram diferenças estatísticas nas comparações entre testes.

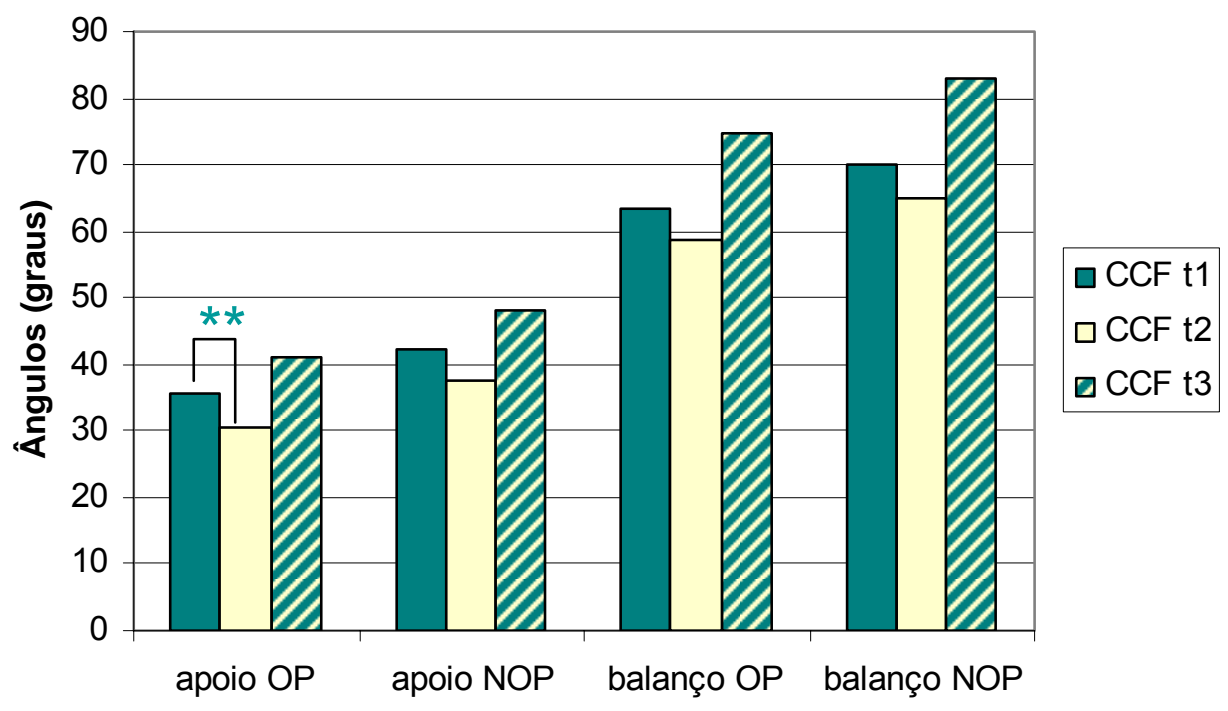

FIGURA 52 - Gráfico da diferença pico a pico do movimento articular do joelho da perna operada (OP) e não-operada (NOP) durante as fases de apoio e balanço da marcha na comparação entre os testes 1 (Pré), 2 (1PO) e 3 (4PO), do grupo cadeia cinética fechada $(\mathrm{CCF})(\mathrm{n}=10)$. 


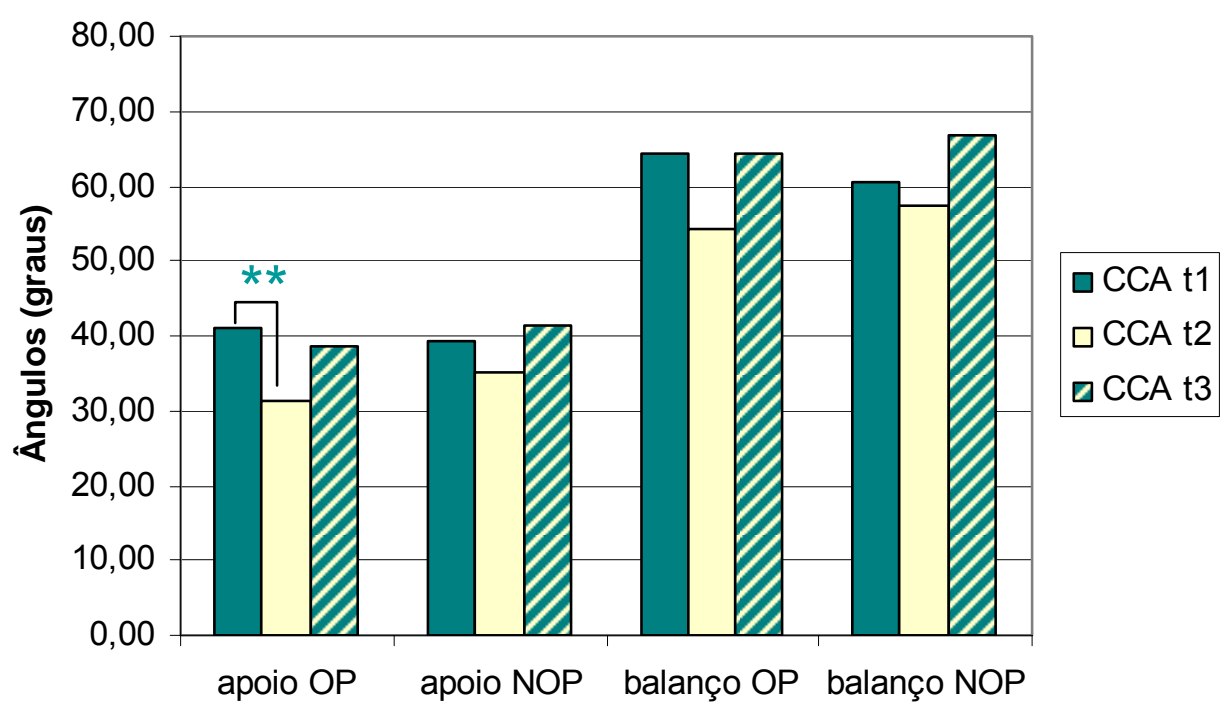

FIGURA 53 - Gráfico da diferença pico a pico do movimento articular do joelho da perna operada (OP) e não-operada (NOP) durante as fases de apoio e balanço da marcha na comparação entre os testes 1 (Pré), 2 (1PO) e 3 (4PO), do grupo cadeia cinética aberta $(\mathrm{CCA})(\mathrm{n}=10)$.

\subsection{Análise Eletromiográfica}

\section{Análise Descritiva}

O envoltório linear extraído do sinal eletromiográfico demonstrou diferenças no padrão de ativação do M.vasto lateral e M.bíceps femoral na comparação entre os grupos experimentais e o grupo controle.

O grupo CON apresentou padrões diferenciados de ativação da perna direita em relação à perna esquerda. A perna direita apresentou dois períodos de ativação do M.vasto lateral na fase de apoio. Estes períodos de ativação ocorreram do início da fase de apoio até aproximadamente $50 \%$ desta fase, com o seu pico de ativação alcançado ao redor de $25 \%$ da passada. No final da fase de apoio este músculo voltou a ser ativado, com seu início em torno de $50 \%$ da passada e com o pico de ativação próximo dos $60 \%$ da passada, ou seja, no final da fase de apoio. Na fase de balanço o M.vasto lateral seguiu ativado até aproximadamente $80 \%$ da passada. E apresentou um novo período de ativação que começou ao redor de $85 \%$ da passada e atingiu o seu pico ao final da fase de balanço. A perna esquerda teve um período de ativação no início da fase de apoio com seu pico ao redor de $10 \%$ da passada. Depois foi 
ativado no final da fase de apoio da mesma forma que na perna direita. Em relação à fase de balanço o padrão de ativação ocorreu da mesma forma que a perna direita. O M.bíceps femoral da perna direita e esquerda foi ativado no início da fase de apoio até aproximadamente $30 \%$ da passada com o seu pico no início da fase. Ao final da fase de apoio apresentou uma pequena ativação que seguiu até o meio da fase de balanço, com seu pico ao redor de $65 \%$ da passada. A fase de balanço ainda teve um período de ativação do M.bíceps femoral que começou ao redor de $80 \%$ da passada e seguiu até o final da mesma, e o pico de ativação foi atingido em torno de $90 \%$ da passada. A diferença maior entre as pernas foi que o M.bíceps femoral da perna direita foi mais ativado no início da fase de balanço e na perna esquerda foi no final da mesma (FIGURA 54).

O grupo CCF, no Teste 1 (Pré), em relação ao M.vasto lateral da perna acometida, apresentou dois períodos de ativação apenas no final da fase de apoio. Um deles entre $35 \%$ e $45 \%$ da passada com seu pico aos $40 \%$ da mesma e outro bem no final da fase de apoio com seu pico ao término da mesma. O M.vasto lateral da perna esquerda apresentou seu padrão de ativação semelhante à perna direita do grupo CON. Em relação ao M.bíceps femoral da perna operada ele apresentou dois períodos de ativação na fase de apoio e dois períodos na fase de balanço como no grupo CON, porém os mesmos ocorreram mais tardiamente na fase de apoio e antecipadamente na fase de balanço do que ocorreu no grupo CON. O padrão de ativação do M.bíceps femoral da perna não-acometida apresentou a mesma tendência de ativação da perna acometida (FIGURA 54).

No grupo CCA o M. vasto lateral teve sua ativação semelhante nas duas pernas, e estas foram equivalentes à ativação da perna esquerda do grupo $\mathrm{CON}$, a diferença maior foi que este músculo começou a fase de apoio mais ativado no grupo CCA, enquanto no grupo CON o pico de ativação foi atingido um pouco depois. Em relação ao M.bíceps femoral ele apresentou um pico de ativação na fase de apoio que na perna acometida foi em torno de $35 \%$ da passada e na perna não-acometida foi em torno de $10 \%$ da passada. $\mathrm{Na}$ fase de balanço este músculo voltou a ser ativado e atingiu o pico aos 70\% da passada em ambas as pernas, porém a perna não-acometida apresentou um período a mais de ativação do M.bíceps femoral ao final da fase de balanço com o pico de ativação aos $90 \%$ da passada (FIGURA 54). 

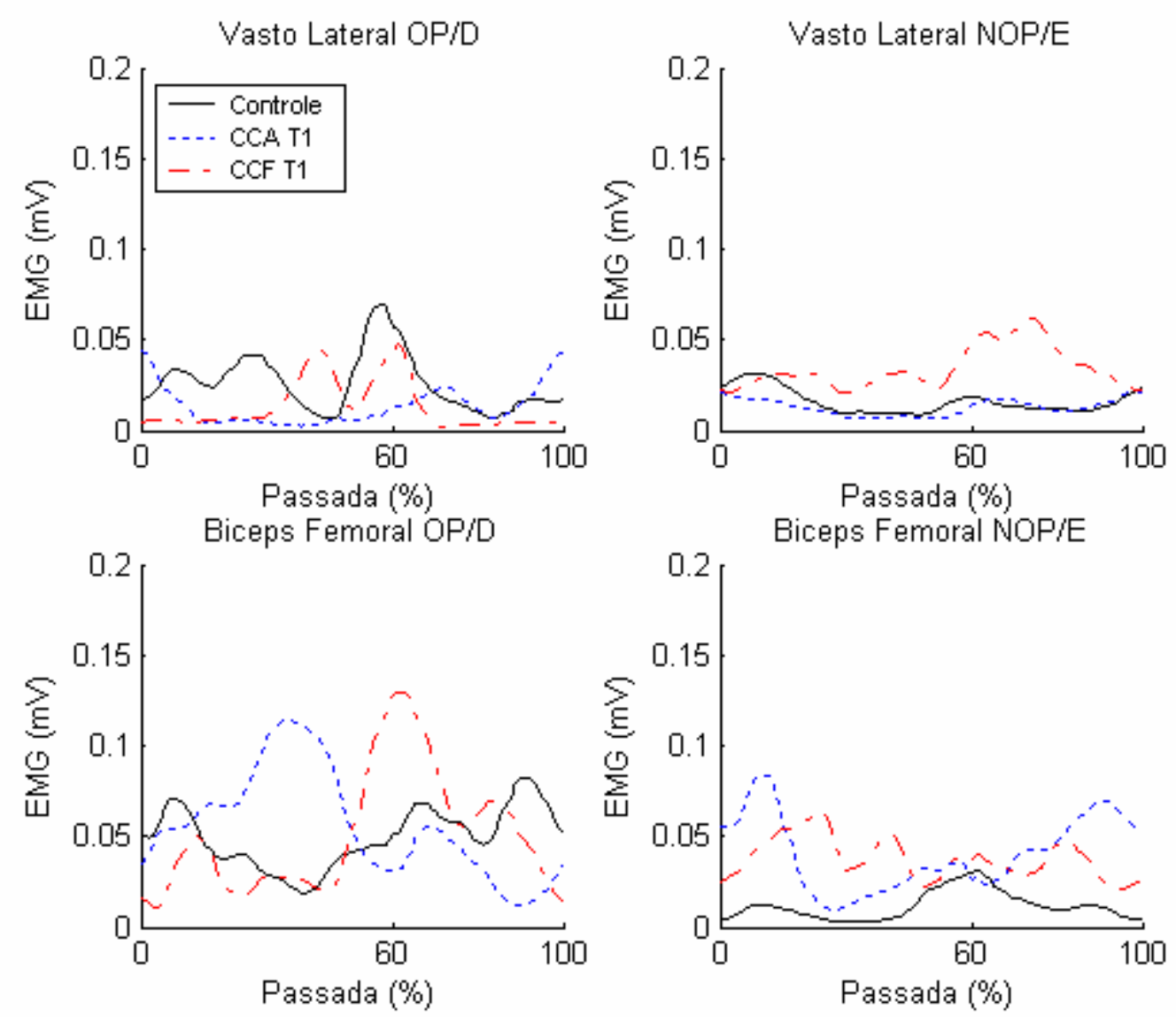

FIGURA 54 - Gráficos dos envoltórios lineares do sinal eletromiográfico dos músculos M.vasto lateral e M.bíceps femoral da perna operada ou direita (OP/D) e da perna não-operada ou esquerda (NOP/E) na comparação entre grupos: controle $(\mathrm{CON})$, cadeia cinética aberta (CCA) e cadeia cinética fechada $\underline{(C C F)(n=10 \text { em cada grupo) no Teste } 1 \text { (Pré), registrada no ciclo da marcha }}$ voluntária. 
No Teste 2 (1PO) o M.vasto lateral da perna operada tanto do grupo CCF quanto do grupo CCA apresentaram um período de ativação no início da fase de apoio da mesma forma que o grupo CON. O grupo CCF teve dois períodos de ativação ao final da fase de apoio, sendo o segundo equivalente ao grupo $\mathrm{CON}$, porém ocorrendo mais tarde. O pico deste período de ativação ocorreu na fase de balanço enquanto no grupo CON ocorreu ainda na fase de apoio. No grupo CCA o M.vasto lateral da perna operada após o período inicial de ativação se manteve praticamente inativo até o final da fase de balanço. A perna não-operada dos grupos CCA e CCF teve sua ativação semelhante à perna esquerda do grupo CON. Três períodos de ativação foram identificados, o primeiro no início da fase de apoio, o segundo entre $40 \%$ e $55 \%$ da passada nos grupos CCF e CCA e no grupo CON entre $50 \%$ e $70 \%$ da passada. Nos três grupos ocorreu um novo período de ativação ao final da fase de balanço (FIGURA 55).

O M.bíceps femoral da perna operada do grupo CCF se manteve ativo praticamente ao longo de toda a passada, tendo uma queda na ativação em torno de $80 \%$ da passada. Neste período seu pico de ativação foi aos $30 \%$ da passada. Este músculo voltou a ser ativado ao final da fase de balanço. No grupo CCA o M.bíceps femoral foi mais ativado na fase de balanço da perna operada, semelhante ao grupo CON. Na perna não-operada este músculo foi ativado no início da fase de apoio da mesma forma que os grupos CON e CCF e voltou a ser ativado ao final desta fase. Ele seguiu ativo na fase de balanço até aproximadamente $65 \%$ da passada e voltou a ser ativado ao final da fase de balanço (FIGURA 55). 

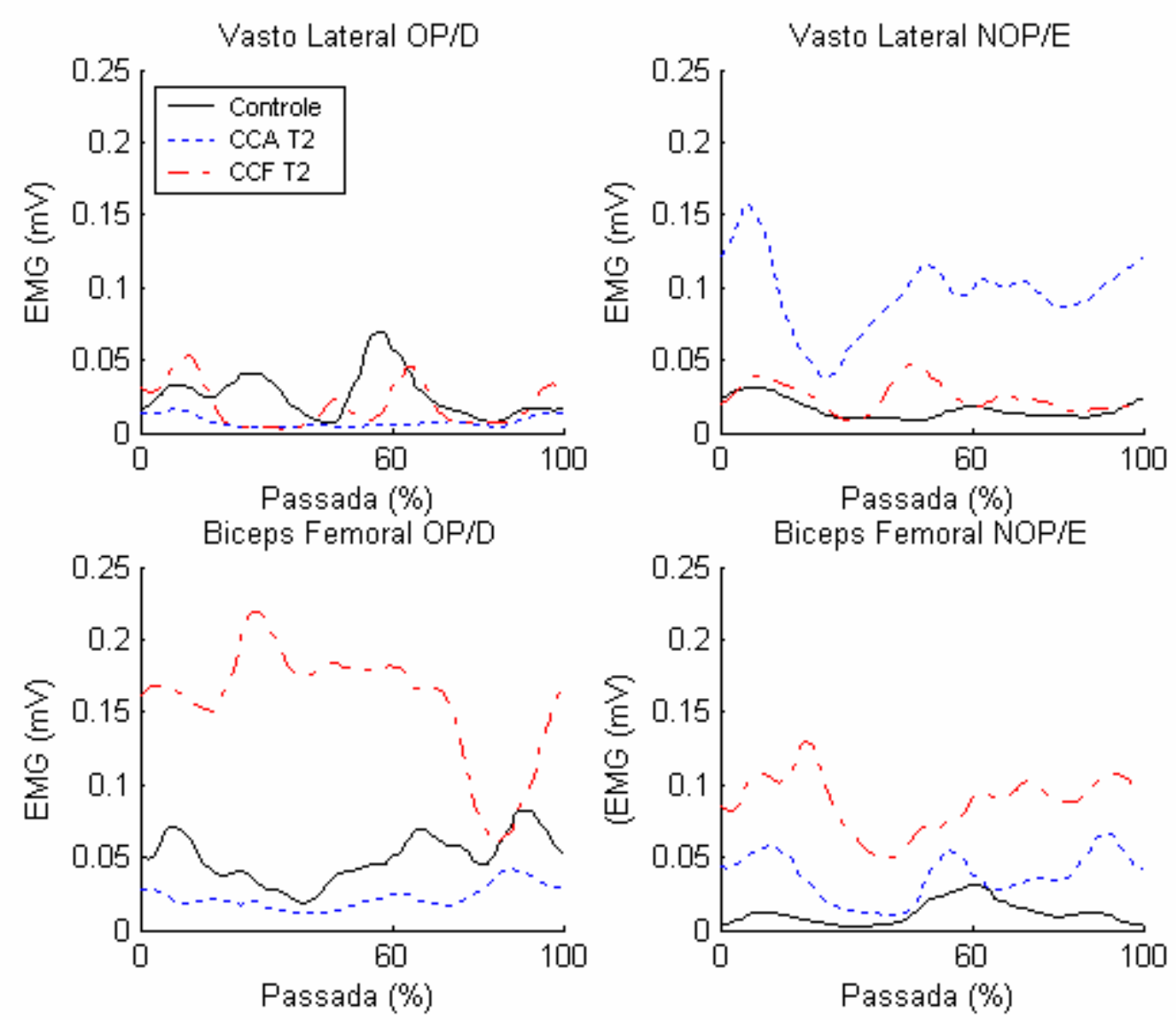

FIGURA 55 - Gráficos dos envoltórios lineares do sinal eletromiográfico dos músculos M.vasto lateral e M.bíceps femoral da perna operada ou direita (OP/D) e da perna não-operada ou esquerda (NOP/E) durante a fase de apoio da marcha na comparação entre grupos: controle $(\mathrm{CON})$, cadeia cinética aberta $(\mathrm{CCA})$ e cadeia cinética fechada (CCF) $(\mathrm{n}=10$ em cada grupo) no Teste 2 (1PO), registrada no ciclo da marcha voluntária

No Teste 3 (4PO), em relação ao M. vasto lateral da perna operada percebeu-se uma tendência de aproximação do padrão de ativação dos grupos CCA e CCF com o grupo CON. Os três grupos apresentaram um período de ativação no início da fase de apoio, que ocorreu um pouco antes nos grupos experimentais. Os outros três períodos de ativação que aconteceram no grupo CON aparecem de forma discreta nos grupos CCF e CCA. O M.vasto lateral da perna não-operada do grupo CCA foi semelhante ao padrão de ativação do grupo 
CON, porém eles ocorreram antes no grupo CCA. No grupo CCF este músculo apresentou um período a mais de ativação na fase de apoio que ocorreu entre $10 \%$ e $30 \%$ da passada, com seu pico em $20 \%$ da passada (FIGURA 56).

O M.bíceps femoral da perna operada apresentou a mesma caracterização de ativação nos três grupos. Três períodos de maior ativação ocorreram na fase de apoio, sendo o pico no início desta fase. $\mathrm{Na}$ fase de balanço dois períodos de ativação ocorreram, no entanto o grupo CCF foi ativado antecipadamente em relação aos demais grupos. Na perna não-operada o grupo CCA apresentou um período a mais de ativação na fase de apoio e o primeiro período ocorreu tardiamente em comparação com o grupo CCF e CON (FIGURA 56).
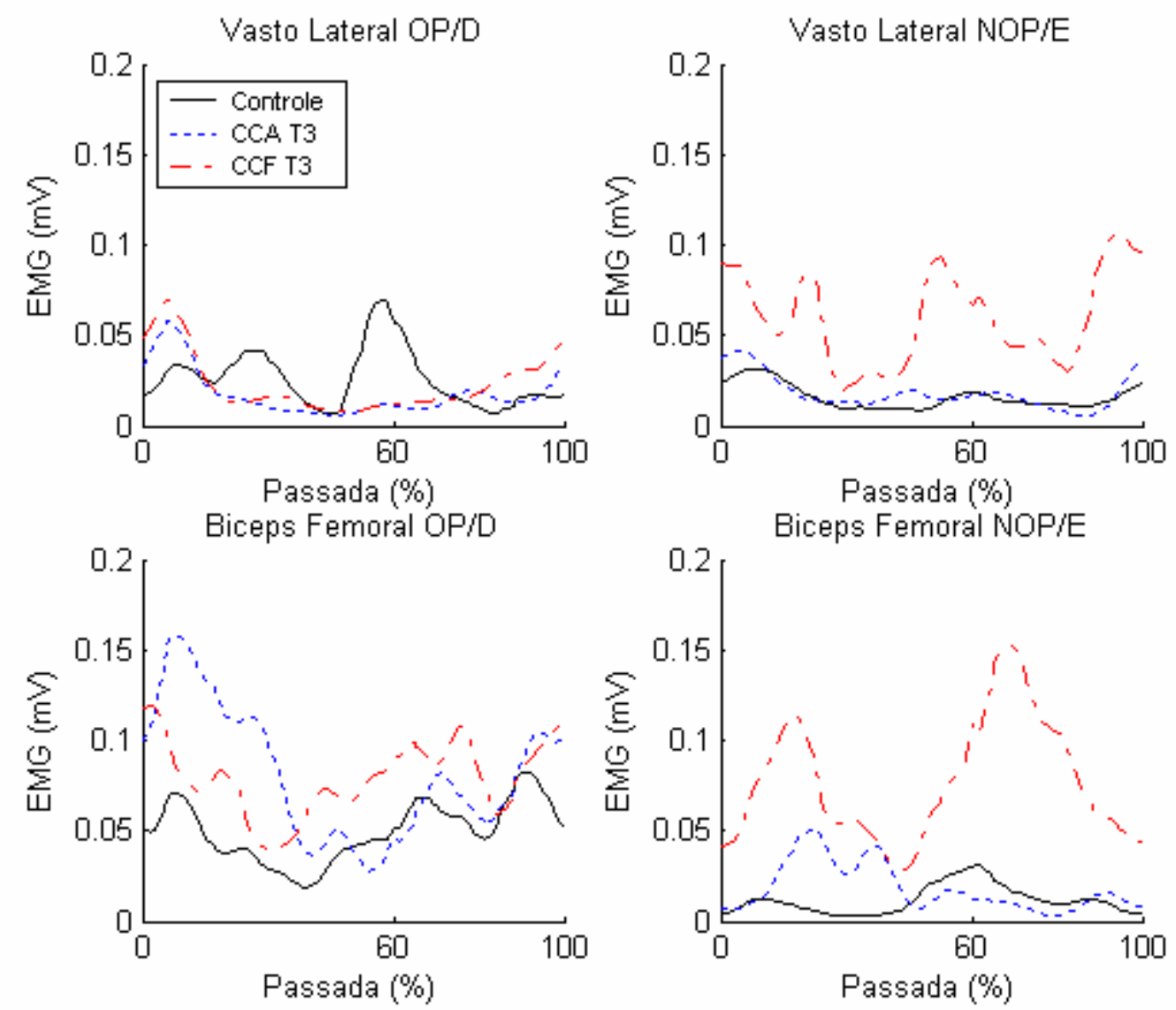

FIGURA 56 - Gráficos dos envoltórios lineares do sinal eletromiográfico dos músculos $\underline{\text { M.vasto lateral e M.bíceps femoral da perna operada ou direita (OP/D) e da }}$ perna não-operada ou esquerda (NOP/E) durante a fase de apoio da marcha na comparação entre grupos: controle (CON), cadeia cinética aberta (CCA) e cadeia cinética fechada (CCF) ( $\mathrm{n}=10$ em cada grupo) no Teste 3 (4PO), registrada no ciclo da marcha voluntária 
Numa comparação do grupo CCF nos diferentes momentos da reabilitação percebeu-se que no Teste 1 (Pré) no M.vasto lateral da perna operada não ocorreu o primeiro período de ativação da fase de apoio e nos testes após a cirurgia este período de ativação passou a ser identificado, porém no Teste 2 (1PO) ele ocorre um pouco mais tarde que no Teste 3 (4PO). No Teste 3 (4PO) a ativação do final da fase de apoio e início da fase de balanço não ocorreu. Na perna não-operada três períodos de ativação puderam ser percebidos no grupo CCF, porém os momentos em que eles aconteceram diferem um pouco. A maior variação ocorreu no período de ativação do final da fase de apoio e início da fase de balanço que no Teste 2 (1PO) ocorreu antes do que ocorreu nos Testes 1 (Pré) e 3 (4PO) (FIGURA 57).

O M.bíceps femoral da perna operada se diferenciou dos demais, principalmente no Teste 2 (1PO), este músculo apresentou um período de ativação entre $20 \%$ e $45 \%$ da passada que não ocorreu nos demais testes e não caracterizou um período de ativação no final da fase de apoio e início da fase de balanço. Nos demais testes a mesma tendência de ativação foi identificada. Na perna não-operada no Teste 1 (Pré) o M.bíceps femoral apresentou um período a mais de ativação entre $30 \%$ e $50 \%$ da passada, com seu pico aos $40 \%$ da passada. Nos demais testes os períodos de ativação tenderam a ser equivalente (FIGURA 57). 

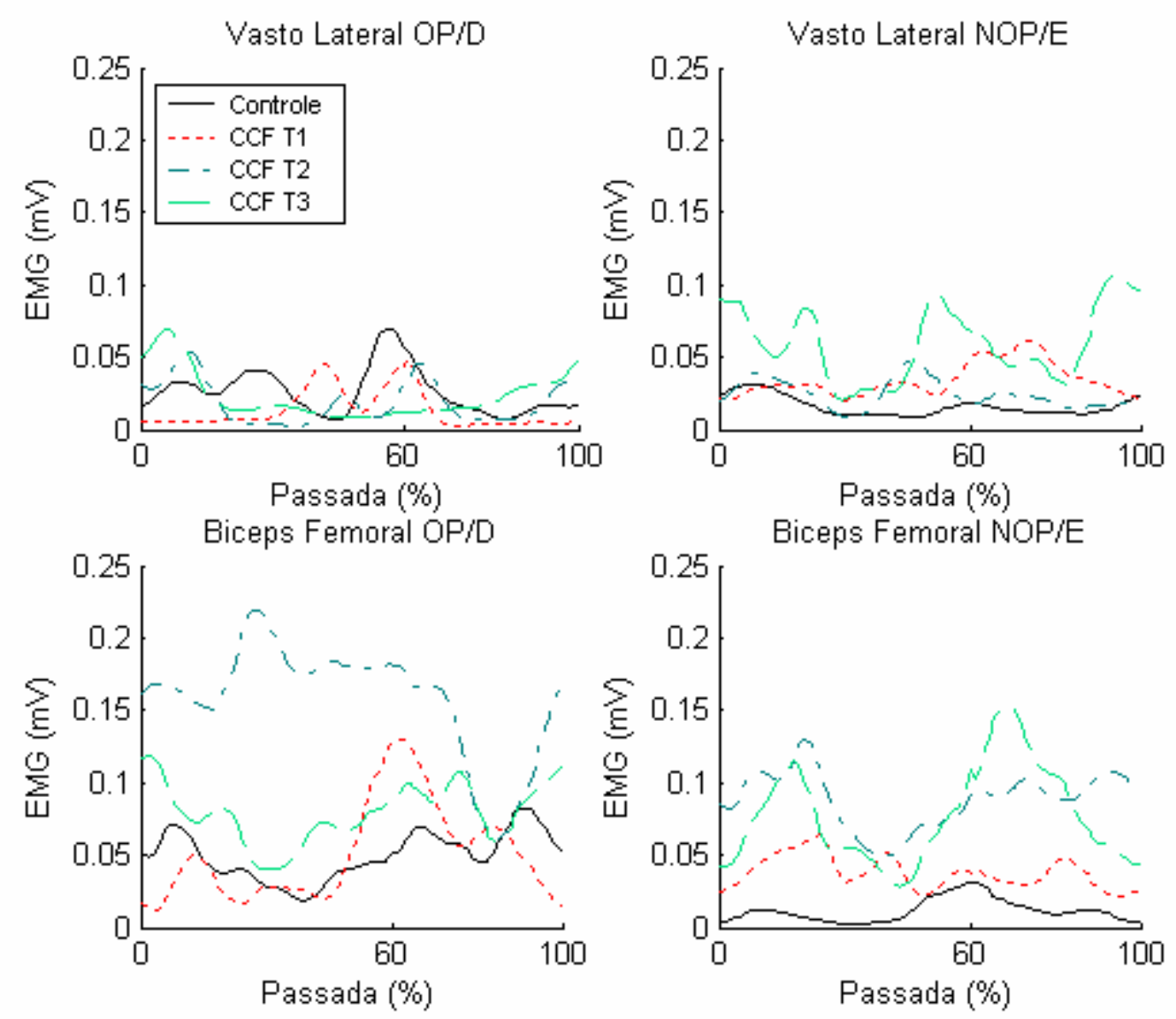

FIGURA 57 - Gráficos dos envoltórios lineares do sinal eletromiográfico dos músculos $\underline{\text { M.vasto lateral e M.bíceps femoral da perna operada ou direita (OP/D) e da }}$ perna não-operada ou esquerda (NOP/E) na comparação entre os testes 1 (Pré), 2 (1PO) e 3 (4PO), do grupo cadeia cinética fechada (CCF) $(\mathrm{n}=10)$, registrada no ciclo da marcha voluntária. A curva do grupo controle aparece como referência.

O grupo CCA na comparação entre os testes do M.vasto lateral da perna operada apresentou praticamente o mesmo padrão de ativação entre eles e em todos eles não se identificou o segundo período de ativação da fase de apoio presente no grupo CON. A perna não-operada seguiu o mesmo padrão de ativação do grupo CON nos Testes 1 (Pré) e 3 (4PO), no Teste 2 (1PO) este músculo apresentou um período de ativação no início da fase de apoio como nos demais testes, mas o segundo período de ativação foi longo começando aos $30 \%$ da passada e diminuindo sua ativação aos $80 \%$ da passada (FIGURA 58). 
Em relação ao M.bíceps femoral o Teste 1 (Pré) apresentou um período a mais de ativação na fase de apoio que ocorreu entre $20 \%$ e $50 \%$ da passada com o pico ocorrendo em torno de $30 \%$ da passada. No Teste 2 (1PO) o M.bíceps femoral foi menos ativo. Na perna não-operada a maior diferença ocorreu no Teste 3 (4PO), neste teste não ocorreu a ativação do M.bíceps femoral logo no início da fase de apoio, a sua ativação só ocorreu entre $15 \%$ e $45 \%$ da passada e apresentou dois picos durante este período (FIGURA 58).
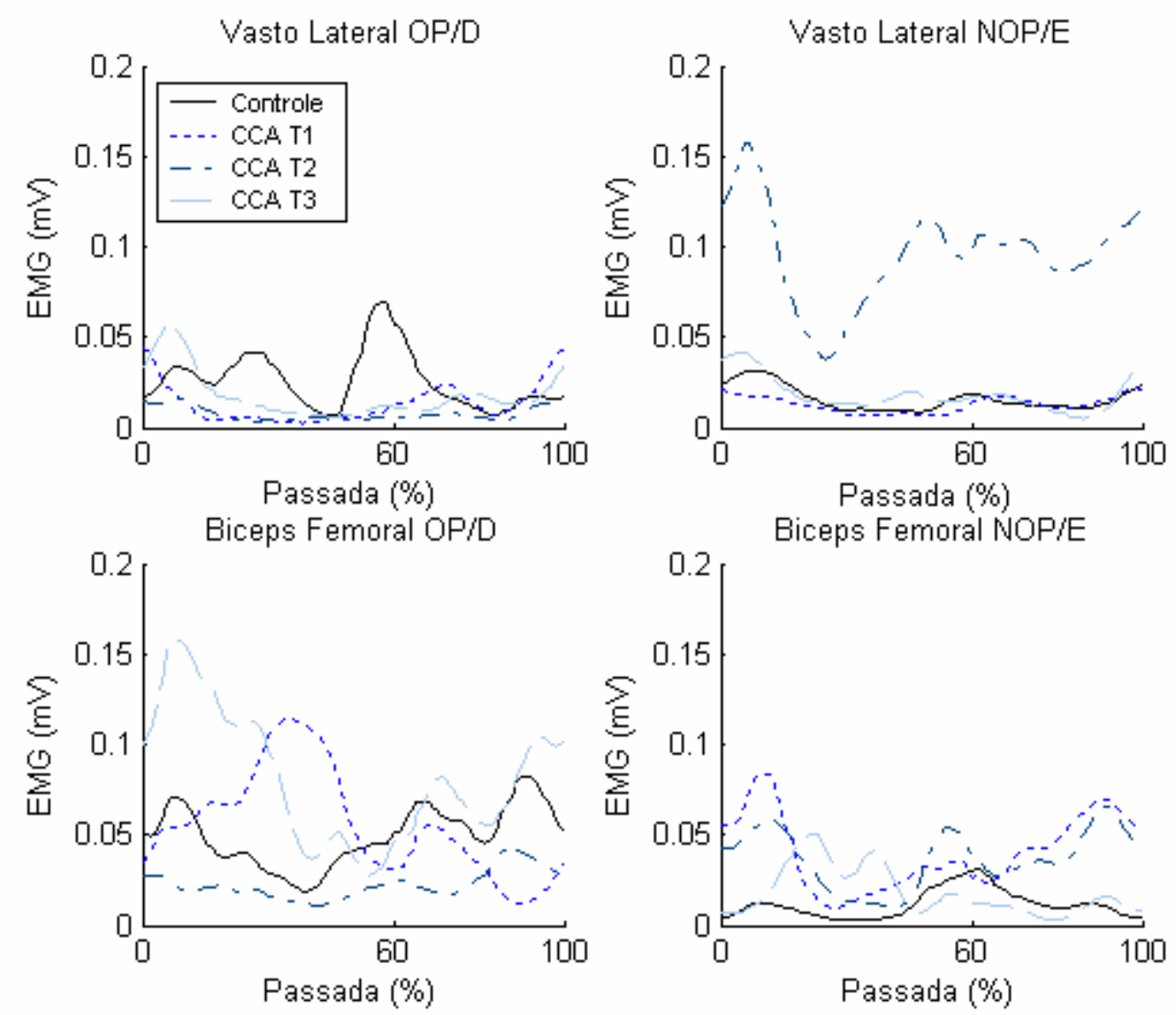

FIGURA 58 - Gráficos dos envoltórios lineares do sinal eletromiográfico dos músculos $\underline{\text { M.vasto lateral e M.bíceps femoral da perna operada ou direita (OP/D) e da }}$ perna não-operada ou esquerda (NOP/E) na comparação entre os testes 1 (Pré), 2 (1PO) e 3 (4PO), do grupo cadeia cinética aberta (CCA) $(\mathrm{n}=10)$, registrada no ciclo da marcha voluntária. A curva do grupo controle aparece como referência. 


\section{Análise entre Grupos}

O coeficiente de variação do M.vasto lateral e M.bíceps femoral de ambas as pernas, na fase de apoio e na fase de balanço, não apresentou diferença significativa entre os grupos no Teste 1 (Pré) e no Teste 2 (1PO). No Teste 3 (4PO), somente o M.bíceps femoral do membro inferior operado, na fase de apoio e de balanço, apresentou diferença significativa na comparação do grupo $\mathrm{CON}$ com o grupo $\mathrm{CCF}(\mathrm{p}=0,03$ e $\mathrm{p}=0,02$; respectivamente). O grupo CCF apresentou coeficientes de variação maiores que do grupo CON (TABELA 9).

\section{Análise entre Testes}

Na comparação entre os Testes 1 (Pré), 2 (1PO) e 3 (4PO) do grupo CCF, nenhum dos coeficientes de variação dos músculos avaliados apresentou diferença significativa. Para a mesma comparação no grupo CCA, somente o coeficiente de variação do M.bíceps femoral da perna operada durante a fase de apoio no Teste 2 (1PO) foi significativamente maior que no Teste 3 (4PO) $(\mathrm{p}=0,02)($ TABELA 9).

TABELA 9 - Média dos coeficientes de variação dos envoltórios lineares do sinal eletromiográfico da perna operada (OP) e não-operada (NOP), apresentados por grupo: controle $(\mathrm{CON})$, cadeia cinética aberta $(\mathrm{CCA})$ e cadeia cinética fechada (CCF) ( $\mathrm{n}=10$ em cada grupo) nos testes 1 (Pré), 2 (1PO) e 3 (4PO).

\begin{tabular}{lllllllllllll}
\hline Coeficiente de Variação (\%) & Perna & \multicolumn{3}{c}{ CON } & \multicolumn{3}{c}{ CCF } & \multicolumn{4}{c}{ CCA } \\
\hline & & T1 & T2 & T3 & T1 & T2 & T3 & T1 & T2 & T3 \\
\hline Vasto lateral - Fase de apoio & OP & 44,5 & 30,4 & 38,1 & 37,7 & 27,8 & 41,4 & 34,9 & 35,0 & 30,6 \\
& NOP & 31,1 & 30,2 & 28,6 & 46,2 & 44,2 & 53,0 & 38,9 & 52,0 & 42,4 \\
& VP & 46,5 & 35,2 & 24,0 & 34,7 & 25,3 & 43,9 & 39,7 & 30,4 & 33,9 \\
Vasto lateral - Fase de balanço & OP & NOP & 32,2 & 34,1 & 35,1 & 48,2 & 40,9 & 42,2 & 30,8 & 54,4 & 41,5 \\
& OP & 38,1 & 33,9 & $35,0^{\mathrm{a}}$ & 50,8 & 29,1 & 68,0 & 38,8 & $63,0^{\mathrm{f}}$ & 50,0 \\
& NOP & 34,0 & 36,3 & 26,4 & 48,1 & 48,5 & 44,3 & 36,3 & 34,5 & 35,0 \\
Bíceps femoral - Fase de balanço femoral - Fase de apoio & OP & 28,7 & 33,0 & $34,6^{\mathrm{a}}$ & 49,3 & 37,7 & 63,3 & 39,8 & 52,4 & 46,8 \\
& NOP & 32,6 & 41,2 & 26,4 & 52,1 & 36,8 & 41,6 & 34,5 & 35,8 & 46,4 \\
\hline
\end{tabular}




\subsection{Simetria em função da lateralidade do acometimento da lesão Análise entre Grupos}

Os primeiros resultados de simetria entre os membros inferiores a serem relatados são relativos a FRS: simetria do primeiro pico (simeFy1), simetria do segundo pico (simeFy2), simetria da força mínima (simeFymin), simetria para o tempo do primeiro pico (simetFy1), simetria para o tempo do segundo pico (simetFy2) e simetria para o tempo da força mínima (simetFymin).

As variáveis simeFy1, simeFy2, simetFy1, simetFymin não apresentaram diferenças estatísticas entre os grupos no Teste 1 (Pré). A simeFymin foi significativamente menor no grupo CCA quando comparado ao grupo CCF $(\mathrm{p}=0,04)$. Os valores da simetFy2 do grupo CON foi significativamente menor do que do grupo CCA $(p=0,03)$. A simeFymin e a simetFy2 não apresentaram diferenças estatísticas nas demais comparações entre os grupos (TABELA 10).

No Teste 2 (1PO) apenas a simeFyl não apresentou diferença estatística entre os grupos. Na comparação entre os grupos CON e CCA, a simeFy2 $(\mathrm{p}=0,03)$, simetFy1 ( $\mathrm{p}=$ $0,01)$, simetFy2 $(p=0,00)$ e simetFymin $(p=0,02)$ foram menores no grupo CON em relação ao grupo CCA. A simetFyl $(\mathrm{p}=0,05)$ e a simeFymin $(\mathrm{p}=0,04)$ foram significativamente menores no grupo CON quando comparado ao grupo CCF. As demais comparações não apresentaram diferenças estatísticas entre elas (TABELA 10).

Em relação ao Teste 3 (4PO), somente a simetFy2 foi significativamente menor no grupo $\mathrm{CON}$ quando comparado ao grupo $\operatorname{CCA}(\mathrm{p}=0,05)$. As demais variáveis não apresentaram diferenças significativas entre os grupos (TABELA 10). 
TABELA 10 - Média e desvio padrão das simetrias relativas à força de reação do solo, apresentados por grupo: controle $(\mathrm{CON})$, cadeia cinética aberta (CCA) e cadeia cinética fechada (CCF) $(\mathrm{n}=10$ em cada grupo) nos testes 1 (Pré), 2 (1PO) e $3(4 \mathrm{PO})$.

\begin{tabular}{|c|c|c|c|c|c|c|c|c|c|}
\hline \multirow[t]{2}{*}{ Simetrias (\%) } & \multicolumn{3}{|c|}{$\mathrm{CON}$} & \multicolumn{3}{|c|}{$\mathrm{CCF}$} & \multicolumn{3}{|c|}{$\mathrm{CCA}$} \\
\hline & $\mathrm{T} 1$ & $\mathrm{~T} 2$ & $\mathrm{~T} 3$ & $\mathrm{~T} 1$ & $\mathrm{~T} 2$ & $\mathrm{~T} 3$ & $\mathrm{~T} 1$ & $\mathrm{~T} 2$ & $\mathrm{~T} 3$ \\
\hline \multirow[t]{2}{*}{ Primeiro Pico } & 3,82 & 3,82 & 3,82 & 4,03 & 6,16 & 5,17 & 3,14 & 5,28 & 4,89 \\
\hline & $\pm 2,81$ & $\pm 2,81$ & $\pm 2,81$ & $\pm 3,13$ & $\pm 4,99$ & $\pm 4,36$ & $\pm 2,42$ & $\pm 4,80$ & $\pm 3,63$ \\
\hline \multirow[t]{2}{*}{ Segundo Pico } & 3,06 & $3,06^{\mathrm{b}}$ & 3,06 & $3,73^{\mathrm{d}}$ & $4,32^{\mathrm{f}}$ & 2,67 & $2,89^{\mathrm{d}}$ & $4,95^{\mathrm{f}}$ & 3,03 \\
\hline & $\pm 1,90$ & $\pm 1,91$ & $\pm 1,91$ & $\pm 3,40$ & $\pm 2,62$ & $\pm 2,11$ & $\pm 2,00$ & $\pm 2,61$ & $\pm 2,15$ \\
\hline \multirow{2}{*}{ Força mínima } & 2,62 & $2,62^{\mathrm{a}}$ & 2,62 & $3,69^{\mathrm{c}}$ & 6,00 & 3,42 & 2,31 & 4,44 & 3,23 \\
\hline & $\pm 2,10$ & $\pm 2,10$ & $\pm 2,10$ & $\pm 3,04$ & $\pm 4,06$ & $\pm 3,02$ & $\pm 1,82$ & $\pm 3,49$ & $\pm 2,54$ \\
\hline \multirow[t]{2}{*}{ Tempo Fy1 } & 8,06 & $8,06^{\mathrm{a}, \mathrm{b}}$ & 8,06 & 8,88 & 19,24 & 8,93 & 10,85 & $20,22^{\mathrm{f}}$ & 10,56 \\
\hline & $\pm 8,80$ & $\pm 8,80$ & $\pm 8,80$ & $\pm 9,49$ & $\pm 13,36$ & $\pm 8,34$ & $\pm 10,89$ & $\pm 13,51$ & $\pm 9,78$ \\
\hline \multirow[t]{2}{*}{ Tempo Fy2 } & $2,71^{\mathrm{b}}$ & $2,71^{\mathrm{b}}$ & $2,71^{\mathrm{b}}$ & $3,21^{\mathrm{d}}$ & $5,36^{\mathrm{f}}$ & 3,00 & 4,61 & 6,96 & 4,21 \\
\hline & $\pm 2,23$ & $\pm 2,23$ & $\pm 2,23$ & $\pm 2,76$ & $\pm 5,28$ & $\pm 2,37$ & $\pm 4,16$ & $\pm 4,93$ & $\pm 3,64$ \\
\hline \multirow[t]{2}{*}{ Tempo Fymin } & 5,27 & $5,27^{\mathrm{b}}$ & 5,27 & 6,19 & 8,33 & 6,18 & 6,52 & $9,21^{\mathrm{f}}$ & 5,57 \\
\hline & $\pm 5,03$ & $\pm 5,03$ & $\pm 5,03$ & $\pm 5,10$ & $\pm 8,76$ & $\pm 4,82$ & $\pm 5,71$ & $\pm 7,18$ & $\pm 4,56$ \\
\hline
\end{tabular}

As simetrias dos parâmetros temporais e espaciais não apresentaram diferenças estatísticas entre os grupos no Teste 1 (Pré) e no Teste 3 (4PO). No Teste 2 (1PO) tanto as simetrias dos parâmetros temporais (tempo de apoio simples: $\mathrm{p}=0,03$; tempo do passo: $\mathrm{p}=$ 0,01; tempo da passada: $p=0,04$ ) como espaciais (comprimento do passo: $p=0,01$; comprimento da passada: $\mathrm{p}=0,04)$ foram significativamente maiores no grupo CCA do que no grupo CON. Para as demais comparações entre grupos não foram encontradas diferenças significativas (TABELA 11).

As simetrias de amplitude de movimento na fase de apoio e de balanço não apresentaram diferenças estatísticas entre os grupos para nenhum dos testes (TABELA 11). 
TABELA 11 - Média e desvio padrão das simetrias relativas as variáveis cinemáticas: parâmetros temporais, parâmetros espaciais e variação angular, apresentados por grupo: controle $(\mathrm{CON})$, cadeia cinética aberta $(\mathrm{CCA})$ e cadeia cinética fechada (CCF) ( $\mathrm{n}=10$ em cada grupo) nos testes 1 (Pré), 2 (1PO) e 3 (4PO).

\begin{tabular}{|c|c|c|c|c|c|c|c|c|c|}
\hline \multirow[t]{2}{*}{ Simetrias (\%) } & \multicolumn{3}{|c|}{$\mathrm{CON}$} & \multicolumn{3}{|c|}{$\mathrm{CCF}$} & \multicolumn{3}{|c|}{$\mathrm{CCA}$} \\
\hline & $\mathrm{T} 1$ & $\mathrm{~T} 2$ & $\mathrm{~T} 3$ & $\mathrm{~T} 1$ & $\mathrm{~T} 2$ & T3 & $\mathrm{T} 1$ & $\mathrm{~T} 2$ & T3 \\
\hline \multirow[t]{2}{*}{ Tempo de apoio } & 3,21 & $3,21^{\mathrm{b}}$ & 3,21 & 3,23 & $6,79^{f}$ & 2,76 & 3,50 & $6,36^{\mathrm{f}}$ & 2,78 \\
\hline & $\pm 2,78$ & $\pm 2,78$ & $\pm 2,78$ & $\pm 3,26$ & $\pm 6,93$ & $\pm 2,51$ & $\pm 2,42$ & $\pm 5,03$ & $\pm 2,06$ \\
\hline \multirow[t]{2}{*}{ Tempo do passo } & 1,85 & $1,85^{\mathrm{b}}$ & 1,85 & 1,93 & $4,07^{\mathrm{f}}$ & 1,72 & 2,02 & $3,90^{\mathrm{f}}$ & 1,67 \\
\hline & $\pm 1,64$ & $\pm 1,64$ & $\pm 1,64$ & $\pm 1,96$ & $\pm 3,84$ & $\pm 1,47$ & $\pm 1,58$ & $\pm 2,83$ & $\pm 1,45$ \\
\hline \multirow[t]{2}{*}{ Tempo da passada } & 0,96 & $0,96^{\mathrm{b}}$ & 0,96 & $0,99^{\mathrm{d}}$ & $1,58^{f}$ & 0,92 & 1,00 & 1,66 & 0,96 \\
\hline & $\pm 0,70$ & $\pm 0,70$ & $\pm 0,70$ & $\pm 0,88$ & $\pm 1,72$ & $\pm 0,69$ & $\pm 0,77$ & $\pm 1,26$ & $\pm 0,66$ \\
\hline Comprimento do & 1,85 & $1,85^{\mathrm{b}}$ & 1,85 & 2,03 & $4,07^{\mathrm{f}}$ & 3,90 & $2,02^{\mathrm{d}}$ & $1,72^{\mathrm{f}}$ & 1,67 \\
\hline passo & $\pm 1,64$ & $\pm 1,64$ & $\pm 1,64$ & $\pm 2,02$ & $\pm 3,84$ & $\pm 2,83$ & $\pm 1,58$ & $\pm 1,47$ & $\pm 1,45$ \\
\hline Comprimento da & 0,92 & $0,92^{\mathrm{b}}$ & 0,92 & 0,98 & 1,54 & 1,63 & $0,97^{\mathrm{d}}$ & $0,89^{f}$ & 0,95 \\
\hline passada & $\pm 0,78$ & $\pm 0,78$ & $\pm 0,78$ & $\pm 0,92$ & $\pm 1,72$ & $\pm 1,27$ & $\pm 0,78$ & $\pm 0,69$ & $\pm 0,66$ \\
\hline Variação angular & 10,40 & 10,40 & 10,40 & 15,86 & 22,81 & 16,23 & 8,21 & 16,39 & 13,27 \\
\hline apoio & $\pm 8,73$ & $\pm 8,73$ & $\pm 8,73$ & $\pm 14,80$ & $\pm 19,04$ & $\pm 9,51$ & $\pm 5,41$ & $\pm 12,88$ & $\pm 13,25$ \\
\hline Variação angular & 8,28 & 8,28 & 8,28 & 9,75 & 10,77 & 10,59 & 9,65 & 9,86 & 8,56 \\
\hline balanço & $\pm 6,11$ & $\pm 6,11$ & $\pm 6,11$ & $\pm 10,27$ & $\pm 7,72$ & $\pm 6,45$ & $\pm 5,71$ & $\pm 8,60$ & $\pm 10,12$ \\
\hline
\end{tabular}

\section{Análise entre Testes}

O grupo CCF apresentou os valores de simetria do segundo pico e simetria do tempo para o segundo pico significativamente maiores no Teste 2 (1PO) do que no Teste 3 (4PO) ( $\mathrm{p}=0,04$ e $\mathrm{p}=0,04$; respectivamente), entre os Testes 1 (Pré) e 2 (1PO) e os Teste 1 (Pré) e 3 (4PO) não foram encontradas diferenças estatísticas para estas variáveis. As demais simetrias relativas a FRS não apresentaram diferenças estatísticas entre os testes. No grupo CCA a simetria do segundo pico, simetria do tempo para o primeiro pico e do tempo para a força mínima foram significativamente maiores no Teste 2 (1PO) do que no Teste 3 (4PO) (p $=0,03, \mathrm{p}=0,05, \mathrm{p}=0,05$; respectivamente), a simetria do segundo pico também foi 
significativamente maior no Teste 2 (1PO) em comparação com o Teste 1 (Pré) $(p=0,01)$. As demais comparações entre testes não foram significativamente diferentes (TABELA 10).

As simetrias dos parâmetros temporais apresentaram diferenças estatísticas entre os testes para o grupo CCF. A simetria do tempo de apoio foi estatisticamente maior no Teste 2 (1PO) do que no Teste 3 (4PO) ( $p=0,05)$, não havendo diferenças estatísticas nas demais comparações entre testes para esta variável. A simetria do tempo da passada e do tempo do passo foram significativamente maiores no Teste 2 (1PO) quando comparado ao Teste 1 (Pré) $(\mathrm{p}=0,03$ e $\mathrm{p}=0,03$; respectivamente) e ao Teste 3 (4PO) $(\mathrm{p}=0,05$ e $\mathrm{p}=0,01$; respectivamente), entre os Testes 1 (Pré) e 3 (4PO) não foi encontrada diferença significativa para estas variáveis. No grupo CCA as simetrias do tempo de apoio e do tempo do passo foram significativamente maiores no Teste 2 (1PO) quando comparado ao Teste 3 (4PO) (p = 0,02 e $\mathrm{p}=0,02$; respectivamente). As demais comparações entre testes não apresentaram diferenças significativas (TABELA 11).

Em relação às simetrias dos parâmetros espaciais, o grupo CCF apresentou diferenças estatísticas somente na simetria do comprimento do passo, onde o Teste 2 (1PO) foi significativamente maior do que o Teste 3 (4PO) $(\mathrm{p}=0,02)$. As variáveis simetria do comprimento do passo e do comprimento da passada do grupo CCA foram significativamente maiores no Teste 2 (1PO) quando comparadas ao Teste 1 (Pré) ( $\mathrm{p}=0,03$ e p = 0,03; respectivamente) e ao Teste 3 (4PO) ( $\mathrm{p}=0,01$ e $\mathrm{p}=0,05$; respectivamente). Na comparação entre o Teste 1 (Pré) e 3 (4PO) não foi encontrada diferença significativa entre eles (TABELA 11).

O grupo CCF e o grupo CCA não apresentaram diferenças estatísticas entre os testes para as simetrias de amplitude de movimento da fase de apoio e da fase de balanço (TABELA 11).

6

\section{DISCUSSÃO DE RESULTADOS}

\subsection{Deslocamento Tibial Anterior}

Os resultados relativos ao deslocamento tibial anterior asseguram a presença da lesão do LCA tanto no grupo CCF quanto no grupo CCA, os valores de ambos os grupos $(6,55 \mathrm{~mm}$ e $6,21 \mathrm{~mm}$; respectivamente) ultrapassam os três milímetros de deslocamento considerado normal (BEYNNON, JOHNSON \& FLEMING, 2002; MAJIMA, YASUDA, 
TAGO, TANABE \& MINAMI, 2002; WOO, DEBSKI, WITHROW \& JANAUSHEK, 1999), enquanto o grupo CON apresentou valores dentro da normalidade $(0,95 \mathrm{~mm})$. O teste realizado após a cirurgia e o período de reabilitação demonstrou que a cirurgia foi efetiva na substituição do LCA e que os programas de reabilitação em CCF e CCA não provocaram deslocamento tibial anterior que pudessem ser prejudiciais ao enxerto ligamentar, os valores do deslocamento tibial anterior estavam em níveis normais $(1,22 \mathrm{~mm}$ e $1,74 \mathrm{~mm}$; respectivamente).

Os resultados da presente pesquisa discordam dos estudos de KVIST e GILLQUIST (2001) e YACK, COLLINS e WHIELDON (1993) onde eles encontraram maior deslocamento tibial anterior nos exercícios de CCA quando comparado aos de CCF.

No entanto, a análise relativa ao deslocamento tibial anterior do presente estudo corrobora com os resultados encontrados no estudo de BEYNNON et al. (1997) e LIMA e GUIMARÃES (1999), que não encontraram diferença significativa no deslocamento tibial anterior gerado por exercícios em CCF e CCA.

Ao avaliar os diferentes estudos percebe-se que são encontradas diferenças significativas na deformação do LCA ou no deslocamento tibial anterior, entre os exercícios em CCF e CCA, nos estudos que utilizaram sujeitos com lesão do LCA que não haviam sido submetidos à cirurgia de reconstrução do ligamento. E nos casos onde não foi encontrada diferença significativa em relação ao deslocamento tibial anterior entre os exercícios de CCF e CCA os sujeitos da pesquisa não apresentavam lesão do LCA ou haviam sido submetidos à cirurgia de reconstrução do mesmo.

A presença de uma estrutura responsável pela limitação do deslocamento tibial anterior, LCA ou enxerto do LCA, parece ser suficiente para bloquear a translação anterior da tíbia tanto nos exercícios de CCF quanto nos de CCA, podendo os dois exercícios serem utilizados sem comprometimento articular. No caso da presença da lesão do LCA, onde a estrutura responsável pela limitação do deslocamento tibial anterior está comprometida, o tipo de exercício utilizado parece ter influência no deslocamento tibial anterior. Nestes casos, de acordo com os estudos citados, o exercício em CCF apresenta menor risco para a articulação do joelho por produzir menor deslocamento tibial anterior.

O estudo de BYNUM, BARRACK e ALEXANDER (1995) poderia colocar em questão as recomendações citadas acima. Neste estudo foi encontrado maior deslocamento tibial anterior em sujeitos que realizaram o protocolo de reabilitação em CCA do que os sujeitos que realizaram o protocolo de reabilitação em CCF. Estes sujeitos se submeteram à 
cirurgia de reconstrução do LCA, ou seja, possuíam uma estrutura responsável pela limitação do deslocamento tibial anterior. Porém, cabe salientar que a diferença entre os programas de CCF e CCA no deslocamento tibial anterior só foi identificada quando realizado o teste no equipamento KT1000 com o máximo de tração que poderia ser aplicada. No teste com tração menor esta diferença não foi detectada. Outro aspecto que deve ser levado em consideração é que mesmo quando foi encontrada a diferença significativa entre os grupos o valor do deslocamento tibial anterior nos exercícios de CCA foi de $3,3 \mathrm{~mm}$, que fica praticamente dentro do limite de normalidade. Ainda, analisando os exercícios utilizados nos protocolos de reabilitação, pode-se questionar que os programas sejam exclusivamente CCA ou CCF, alguns exercícios não se caracterizam especificamente em um tipo de cadeia cinética, o que pode ter influenciado o resultado encontrado.

\subsection{Escore de Lysholm - Escala de Avaliação Funcional do Joelho}

Os resultados obtidos através do escore de Lysholm são importantes porque refletem a forma como os pacientes percebem a sua melhora. Questionários subjetivos, respondidos pelos pacientes, são utilizados na literatura na tentativa de avaliar a condição do joelho para diferentes atividades. O estudo de HOOPER, MORRISEY, DRECHSLER, MCDERMOTT e MCAULIFFE (2001) validou o Hughston Clinic questionare score confrontando os seus dados com dados relativos a análise da marcha. BEYNNON, JOHNSON e FLEMING (2002) citam os escores de Tegner e International Knee Documentation Committee (IKDC) utilizado para avaliar o nível de atividade do paciente. Estes questionários assim como escore de Lysholm buscam fazer uma avaliação funcional do joelho e são freqüentemente utilizados para confrontar com a avaliação clínica ou biomecânica realizada.

Analisando os dados percebe-se que os pacientes tiveram uma melhora com o procedimento cirúrgico. A avaliação funcional do joelho com lesão antes da cirurgia era considerada regular (entre 65 e 83) para o grupo CCF ou ruim $(\leq 64)$ para o grupo CCA de acordo com o escore de Lysholm e após a cirurgia estes valores aumentaram significativamente, o que indica uma melhora no nível de atividade física dos pacientes. Estes dados corroboram com o estudo de BEARD, ANDERSON, DAVIES, PRICE e DODD (2001), BYNUM, BARRACK e ALEXANDER (1995) e HERNANDEZ, REZENDE, GÓIS e GRISENDE (1996) onde eles identificaram, através do escore de Lysholm, que a cirurgia de reconstrução do LCA melhora os níveis de atividade física do paciente. 
A análise dos resultados demonstra que tanto o grupo CCF quanto o grupo CCA apresentaram melhora funcional do joelho após o término do período de tratamento. No entanto, é importante salientar que apesar de não existir diferença significativa entre os grupos após o término do tratamento, corroborando com estudo de BYNUM, BARRACK e ALEXANDER (1995), o escore médio obtido pelo grupo CCF (92) encontra-se dentro dos parâmetros que considera o aspecto funcional do joelho excelente (entre 91 e 100) e o escore médio do grupo CCA (77) encontra-se dentro dos parâmetros que considera o aspecto funcional do joelho regular (entre 65 e 83). Estes resultados, apesar de mostrarem melhora para os dois grupos de pacientes, não coincidem totalmente com os dados de HERNANDEZ et al. (1996) onde a maioria dos pacientes passou de pobre (ruim) ou regular antes da cirurgia para bom ou excelente após a cirurgia. No entanto, é importante salientar que neste estudo o escore de Lysholm foi aplicado após pelo menos sete meses da realização da cirurgia. No presente estudo o escore de Lysholm foi aplicado com quatro meses de pós-operatório, este período de pelo menos três meses de diferença na aplicação do escore de Lysholm pode ter permitido aos pacientes do estudo de HERNANDEZ et al. (1996) recuperarem melhor o aspecto funcional do joelho. O estudo de BEARD et al. (2001) também sugere que o tempo pós-cirúrgico parece interferir na melhora funcional do joelho, os resultados mostram que os valores obtidos no escore de Lysholm com seis meses pós-cirúrgico foram menores do que os obtidos após doze meses da cirurgia de reconstrução. Outra questão que difere entre os trabalhos é que o tipo de reabilitação e o tempo que os pacientes se submeteram a ela não foi controlado nos estudos de BEARD et al. (2001) e HERNANDEZ et al. (1996). No estudo de BYNUM, BARRACK e ALEXANDER (1995) eles controlaram o tipo de exercício utilizado na reabilitação, comparando exercícios em CCA e CCF como no presente estudo e o valor absoluto do escore de Lysholm também foi mais baixo no grupo CCA.

O valor absoluto mais baixo do grupo CCA talvez tenha ocorrido pela maior freqüência de dor patelofemoral neste tipo de exercício (BYNUM, BARRACK \& ALEXANDER, 1995; HOOPER et al., 2001). No entanto, nas revisões realizadas por FITZGERALD (1997) e MsGINTY, IRRGANG e PEZZULLO (2000), eles sugerem que é possível diminuir a dor patelofemoral tanto nos exercícios de CCF quanto de CCA, pela limitação da amplitude de movimento utilizada durante os exercícios. Os exercícios em CCF devem ser realizados em ângulos menores de flexão e os de CCA em ângulos maiores de flexão. Este tipo de limitação não foi utilizado no presente estudo, podendo a dor 
patelofemoral ter influenciado na percepção dos pacientes do grupo CCA na melhora funcional do joelho.

\subsection{Força de Reação do Solo}

As variáveis que possuem maior influência na componente principal 1 da perna operada são as taxas de crescimento para o primeiro pico e segundo pico da força vertical e a deflexão para força mínima, seguidos da força mínima e do tempo para ocorrer o primeiro pico de força. Estas variáveis aparecem quando as duas componentes principais foram determinadas para as comparações entre grupos e quando as três componentes principais foram determinadas para a comparação entre os testes. A perna não-operada, com pequenas variações, segue essa mesma composição da perna operada. Estes dados revelam que a associação dos valores de pico e da força mínima com o tempo que estes levam para ocorrer são variáveis mais sensíveis que cada variável separada.

$\mathrm{Na}$ comparação entre testes de cada grupo foi encontrado diferença significativa da componente principal 1 entre o testes. A taxa de crescimento para o primeiro pico é uma das variáveis mais importantes do componente principal 1 e o valor desta é maior antes da cirurgia, diminui logo após a mesma e volta a aumentar quatro meses após a cirurgia, ao final do período de reabilitação. Segundo o estudo de LOBO DA COSTA e AMADIO (1995) a taxa de crescimento do primeiro pico alta corresponde a um rápido crescimento da força passiva e está presente em sujeitos cuja capacidade de absorção das forças no momento do impacto estão prejudicadas. Isto é possível de ser identificado antes da cirurgia, quando os valores dos grupos CCF e CCA são maiores que os do grupo CON. No entanto, logo após a cirurgia estes valores diminuem e ficam mais baixos que do grupo $\mathrm{CON}$, neste período seria esperado que um valor ainda maior fosse encontrado pela interferência da cirurgia na função do joelho. A provável causa para esta diminuição é que os pacientes neste período estão com o joelho numa posição mais estendida que os sujeitos sem lesão e acabam, por um mecanismo de defesa, diminuindo a força com que eles realizam o impacto com o solo e aumentando o tempo para que isto aconteça, como é possível de verificar nos valores de primeiro pico e tempo para o primeiro pico. Na seqüência do tratamento a taxa de crescimento volta a subir, assim como o ângulo de flexão neste período aumenta, permitindo ao paciente realizar o movimento de forma mais natural. 
A taxa de crescimento do segundo pico de força parece ser a variável de maior influência na análise estatística. Esta variável aparece entre as de maiores índices nos dois componentes principais determinados na comparação entre grupos e nos três componentes principais determinados para a comparação entre testes. A diminuição do valor da taxa de crescimento para o segundo pico, segundo o estudo de LOBO DA COSTA e AMADIO (1995), corresponde a uma diminuição na capacidade de propulsão do sujeito. Os dados revelam que logo após o procedimento cirúrgico ocorre uma diminuição da taxa de crescimento para o segundo pico o que significa que a capacidade de propulsão no final da fase de apoio diminui neste período. Essa hipótese poderia ser reforçada se a componente horizontal (Fx) da força de reação do solo também tivesse sido analisada, porque esta variável é a que melhor avalia a propulsão. Os valores da taxa de crescimento para o segundo pico diminuem no Teste 2 (1PO) para os grupos CCF e CCA e aumentam no Teste 3 (4PO) para os dois grupos. Neste caso, de acordo com os dados o tempo para ocorrer o segundo pico praticamente não altera, o que ocorre é uma diminuição do valor do segundo pico logo após a cirurgia e um aumento do mesmo após o período de reabilitação. Com base nestas informações as mudanças na taxa de crescimento provavelmente estão relacionadas com a capacidade da musculatura de produzir força no momento da propulsão. Logo após a cirurgia as musculaturas sofrem uma hipotrofia e conseqüente perda de força pela diminuição do uso no pós-operatório, já ao final do tratamento deve ter ocorrido um aumento da força muscular por esta ter sido trabalhada durante o período de reabilitação.

A diminuição das taxas de crescimento para o primeiro e segundo pico encontradas um mês após a cirurgia também sofreram influência da diminuição da velocidade de realização do teste na esteira neste período.

A força vertical mínima apesar de aparecer entre as variáveis de maior importância na componente principal 1, ela perde importância nas componentes principais dois e três, muitas vezes nem sendo cotada dentro destas componentes. O segundo pico de força é a variável de menor importância dentro do componente principal um, de modo que na determinação das três componentes principais para comparação entre testes esta variável não aparece entre as variáveis que compõem a componente principal 1. Ela aparece como importante na componente principal dois da comparação entre grupos e da componente principal três da comparação entre testes. 
Os resultados do presente estudo corroboram aos resultados encontrados por MOTA et al. (2002) no que diz respeito ao segundo pico da força vertical e à força mínima. Os autores encontraram um valor maior da força vertical mínima e um menor segundo pico da força vertical no paciente com lesão do LCA quando comparado ao sujeito sem lesão. Ao analisar o presente estudo, o segundo pico da força vertical é uma das variáveis de maior influência do componente dois na comparação entre grupos e este componente do grupo CCA foi estatisticamente diferente do grupo $\mathrm{CON}$ em todos os testes. O segundo pico da força vertical menor no grupo CCA do que no grupo CON é um fator de interferência para a diferença entre os grupos, o que vai ao encontro do estudo de MOTA et al. (2002). Já o componente principal 1 tem como uma das suas variáveis de maior influência a força vertical mínima, e este componente do grupo CCA e do grupo CCF foi estatisticamente diferente do grupo CON no Teste 2 (1PO) e no teste 3 (4PO), portanto a força vertical mínima maior no grupos CCA e $\mathrm{CCF}$ do que no grupo CON é um fator de interferência para a diferença entre os grupos, corroborando ao que foi encontrado no estudo de MOTA et al. (2002). Esta variável também é uma das variáveis que permite ver diferença entre o grupo CCA e CCF, e a força vertical mínima do grupo CCA é maior do que a do grupo CCF.

Segundo AMADIO, LOBO DA COSTA, SACCO, SERRÃO, ARAÚJO, MOCHIZUKI e DUARTE (1999) a força mínima da curva da FRS durante a marcha pode estar relacionado à eficiência do movimento na perna contra-lateral e ao posicionamento do pé durante o médio apoio que permite a distribuição da força em uma área maior do pé. Baseado nestas informações pode-se inferir que o valor maior da força mínima nos grupo CCF e CCA pode estar relacionado ao posicionamento inadequado do pé no solo durante a fase de apoio numa tentativa inconsciente de minimizar a dor ou proteger o joelho.

O estudo de RUDOPLH et al. (1998) encontrou um valor menor de primeiro pico da força vertical em sujeitos com lesão do LCA. No presente estudo, esta variável foi uma das que teve menor influência nos componentes principais. Apesar de os seus valores médios serem menores no grupo CCF do que no grupo CON e ainda menores no grupo CCA no Teste 2 (1PO), no Teste 1 (Pré), onde a situação é semelhante ao estudo de RUDOLPH et al. (1998), ou seja, sujeitos com lesão do LCA antes de realizarem a cirurgia de reconstrução, os valores dos sujeitos com lesão são maiores que os dos sujeitos sem lesão, opondo-se ao estudo de RUDOLPH et al. (1998). No entanto, cabe ressaltar que esta parece não ser a variável de 
maior influência da FRS para detectar diferenças entre os grupos, talvez isto justifique os diferentes resultados entre os estudos.

Os resultados do presente estudo também se contrapõem em parte aos dados encontrados por BULGHERONI et al. (1997). No estudo de BULGHERONI et al. os resultados demonstram um valor menor do primeiro pico e do segundo pico do componente vertical da FRS em sujeitos com lesão do LCA, corroborando com o estudo de RUDOLPH et al. (1998). No presente estudo apenas o grupo CCA antes da cirurgia apresentou um valor de segundo pico menor do que o do grupo $\mathrm{CON}$, os valores do primeiro pico foram até mais altos no grupo CCF antes da cirurgia. A diminuição nos dois picos de força fica evidenciada nos grupos CCF e CCA somente com um mês de pós-operatório. Em relação aos sujeitos com LCA reconstruído após quatro meses de pós-operatório o presente estudo corrobora com BULGHERONI et al. (1998). No estudo BULGHERONI et al. (1998) os sujeitos com LCA reconstruído apresentaram a curva da componente vertical da FRS com valores equivalentes aos sujeitos normais. O mesmo foi encontrado no presente estudo. No estudo de BULGHERONI et al. (1998) os pacientes foram avaliados 17 meses após a cirurgia, no entanto, quatro meses após a cirurgia, tempo da reabilitação do presente estudo, já foi suficiente para perceber uma equivalência entre os pacientes e os sujeitos normais.

O grupo CCA e o grupo CCF apresentavam diferenças nas variáveis relativas à FRS antes da cirurgia, sem influência do tipo de exercício realizado na reabilitação. O grupo CCA parece ser o que apresentava maiores alterações nestas variáveis porque além de ser diferente do grupo CCF também apresentava diferença com o grupo CON.

O procedimento cirúrgico tende a acentuar as alterações da marcha em relação as variáveis da FRS e, além do grupo CCA, o grupo CCF também passa a ser diferente do grupo CON. E o grupo CCA altera inclusive o padrão da marcha da perna não-operada.

Após o período de reabilitação o grupo CCA é o que permanece com as maiores diferenças, porque além do componente principal 1 ser diferente do grupo CON e do grupo $\mathrm{CCF}$, o componente principal dois também se diferencia do grupo CON. Estes resultados sugerem que os exercícios em CCF recuperam melhor as variáveis relativas à FRS do que os exercícios em CCA, porém o tempo de quatro meses de pós-operatório não é suficiente para fazer com que a dinâmica da marcha dos pacientes seja equivalente aos sujeitos do grupo controle. 


\subsection{Parâmetros Cinemáticos}

\subsubsection{Parâmetros Temporais e Espaciais}

As considerações relativas aos parâmetros temporais e espaciais serão apresentadas em conjunto devido a algumas semelhanças nos seus resultados.

$\mathrm{Na}$ análise dos parâmetros temporais na comparação entre grupos observou-se somente na avaliação com um mês de pós-operatório no grupo CCA um aumento do tempo de apoio simples e do tempo do passo da perna não-operada quando comparado com o grupo CON. Este resultado sugere que os pacientes apresentaram comportamento de proteger a perna operada com uma diminuição do tempo de permanência do peso corporal sobre a mesma, alterando a sua dinâmica da marcha. Este aumento nos tempos de apoio não se refletiu no tempo da passada, ou seja, ciclo completo da marcha - fase de apoio e de balanço da mesma perna. Este resultado é esperado porque enquanto o tempo da fase de apoio da perna nãooperada aumenta, o tempo da fase de balanço deve ter diminuído por uma permanência menor de apoio da perna operada.

Os parâmetros espaciais também apresentaram alterações para o grupo CCA no Teste 2 (1PO). Este grupo teve seu comprimento de passo e de passada de ambas as pernas menor que o grupo CCF e, em alguns casos, menor que o grupo CON. A diminuição no comprimento do passo parece ser um mecanismo de proteção ao joelho acometido que aparece somente no pós-operatório mais imediato.

No entanto, o mesmo seria esperado para o grupo CCF, e este não apresentou diferença significativa nos parâmetros temporais e espaciais quando comparado ao grupo CON ou CCA. Estes dados levam a crer que este grupo retomou os parâmetros temporais e espaciais da marcha normal de forma mais rápida que o grupo CCA. No entanto é importante salientar que neste período os dois grupos ainda realizavam o mesmo protocolo de reabilitação, não sendo esta retomada mais rápida aos parâmetros normais da marcha do grupo CCF nos aspectos temporais e espaciais influenciada pelos exercícios específicos de CCF.

O teste realizado ao final do tratamento não apresentou a diferença entre os grupos para os parâmetros temporais e espaciais demonstrando que os quatro meses de pós-operatório foram suficientes para os pacientes do grupo CCA recuperarem os parâmetros temporais normais da marcha, acompanhando o grupo CCF. 
A expectativa que os tempos de apoio da perna operada diminuíssem e os tempos de apoio da perna não-operada aumentassem no teste realizado após um mês de cirurgia nos grupos CCF e CCA não se comprovou. O que foi observado, em ambos os grupos, foi que o teste realizado com um mês de pós-operatório teve o tempo do passo e da passada de ambas as pernas maiores que os encontrados no teste realizado ao término do tratamento. Isto demonstra apenas a diminuição na velocidade de execução da marcha com um mês de pós-operatório, o que era previsto devido ao retorno da marcha sem muletas ter ocorrido a apenas uma semana (terceira semana de pós-operatório).

O estudo de DEVITA et al. (1997) também avaliou parâmetros temporais e espaciais da marcha de pacientes após a cirurgia de reconstrução do LCA. Em relação aos parâmetros temporais os autores utilizaram o termo tempo de apoio para o que o presente estudo considerou o tempo do passo. Os resultados do estudo não apresentaram diferença no tempo de apoio da perna operada de sujeitos com reconstrução do LCA quando comparado ao grupo $\mathrm{CON}$, da mesma forma que no presente estudo não foi encontrada diferença no tempo do passo dos grupos CCF e CCA quando comparado ao grupo CON.

Em relação aos parâmetros espaciais o estudo de DEVITA et al. (1997) avaliou o comprimento do passo e identificou uma diminuição do comprimento do passo dos pacientes com três semanas de pós-operatório. Seus resultados corroboram com os resultados relativos aos parâmetros espaciais do grupo CCA.

A análise dos parâmetros temporais e espaciais da marcha permitem inferir que no período inicial pós-operatório estes parâmetros tendem a apresentar alteração. Uma análise mais específica dos parâmetros temporais permite uma outra consideração. O tempo de apoio simples do grupo CCA foi o único que apresentou um valor maior somente na perna nãooperada no Teste 2 (1PO) em comparação ao teste 3 (4PO), os demais parâmetros temporais quando apresentaram alteração foram em ambas as pernas. Esta alteração somente na perna operada sugere uma compensação utilizada pelo paciente para proteger a perna operada e não apenas uma diminuição de velocidade da marcha. Estes resultados sugerem que o apoio simples talvez seja a melhor variável dos parâmetros temporais para identificar compensações utilizadas pelos pacientes com comprometimento do LCA. 


\subsubsection{Variação Angular do Joelho}

$\mathrm{Na}$ análise descritiva da curva da variação angular do joelho é possível inferir que os sujeitos com lesão do LCA alteram a sua movimentação do joelho antes mesmo de se submeterem à cirurgia, principalmente em relação ao pico de flexão do joelho que é menor e ocorre tardiamente quando comparado ao grupo CON.

Estes resultados são semelhantes aos encontrados por MOTA et al. (2002) e LEWEK et al. (2002) em que eles compararam sujeitos com lesão do LCA que não foram submetidos à cirurgia com sujeitos sem lesão e também encontraram no grupo com lesão do LCA um menor pico de flexão do joelho na fase inicial do apoio. Nesta fase o M.quadríceps femoral atua em contração excêntrica para controlar a flexão do joelho, talvez os pacientes diminuam a flexão do joelho como uma forma de compensação para diminuir a necessidade de atividade do M.quadríceps femoral e desta forma proteger o LCA. Como este grupo muscular tende a deslocar a tíbia anteriormente o LCA deve ser exigido para evitar que o deslocamento excessivo aconteça, a diminuição da atividade deste grupo muscular deve diminuir a exigência do LCA.

Em contrapartida o estudo de DEVITA et al. (1997) não encontrou diferença no pico de flexão na fase inicial do apoio. Porém seus resultados em relação ao final da fase de apoio corroboram com os do grupo CCF antes da cirurgia, ambos apresentaram uma menor extensão na segunda metade do apoio, ou seja, os pacientes mantiveram o joelho mais flexionado que os sujeitos sem lesão.

$\mathrm{O}$ fato de o grupo CCA, antes da cirurgia, apresentar uma diferença maior em relação ao grupo CON do que o grupo CCF no pico de flexão do joelho pode ser justificado com base no trabalho de RUDOLPH et al. (1998). Neste trabalho os autores concluíram que o pico de flexão do joelho é menor nos sujeitos que possuem lesão do LCA e possuem instabilidade da articulação do joelho. Talvez o grupo CCA tivesse mais instabilidade da articulação do joelho do que o grupo CCF antes da cirurgia.

Com um mês de pós-operatório o pico de flexão do grupo CCA e CCF é ainda menor do que o grupo CON, o que demonstra uma dificuldade dos pacientes em realizar a flexão do joelho na fase inicial do apoio. Conforme o trabalho de RUDOLPH et al. (1998) o pico de flexão do joelho coincide com o primeiro pico vertical da FRS e a diminuição da 
flexão do joelho nesta fase do apoio pode dificultar a transferência do impacto sobre o joelho provocado pela FRS.

Em contrapartida, ao final do tratamento ocorre um retorno parcial aos padrões précirúrgico. Demonstrando que a intervenção cirúrgica leva a mudanças mais acentuadas destes aspectos da marcha no período inicial e que os mesmos tendem a serem recuperados num pósoperatório mais tardio, exatamente como foi visto pelo estudo de DEVITA, HORTOBAGYI e BARRIER (1998). O que pode ser acrescentado levando em consideração o presente estudo é que o tipo de reabilitação influencia esta recuperação. O programa de reabilitação em CCF parece recuperar melhor o movimento articular durante a marcha do que o programa em CCA. O estudo de HOOPER et al. (2001) comparou o protocolo de reabilitação em CCA com o programa de reabilitação em CCF e não encontrou diferença para os ângulos articulares do joelho em momentos específicos do apoio (contato do calcanhar, médio apoio e retirada dos dedos), os autores não mencionam o pico de flexão ou de extensão, para efeitos de comparação com o presente estudo. Porém cabe salientar que o período de reabilitação avaliado foi apenas seis semanas de pós-operatório, logo, poderia considerar que este período pode ter sido insuficiente para avaliar o efeito dos diferentes protocolos na recuperação funcional da marcha.

Outro aspecto importante de ressaltar é que o período de quatro meses de pósoperatório para reabilitação não foi suficiente para fazer com que o pico de flexão ficasse semelhante ao grupo CON, principalmente para o grupo CCA. O trabalho de LEWEK et al. (2002) vai ao encontro do presente trabalho, porém, com algumas considerações. No trabalho de LEWEK et al. (2002) o tempo pós-cirúrgico avaliado foi de três meses, e mesmo aumentando o tempo de reabilitação para quatro meses, como foi realizado no presente estudo, julgamos que ainda não foi suficiente para esta variável cinemática ser comparável ao grupo controle. Outra consideração importante em relação ao estudo de LEWEK et al. (2002) é que o menor pico de flexão do joelho foi encontrado apenas no grupo que realizou a cirurgia e encontrava-se com o quadríceps fraco ( $80 \%$ ou menos do valor da força do lado oposto), o grupo que apresentava o quadríceps forte ( $90 \%$ ou mais do valor da força do lado oposto) não apresentou diferença do grupo controle.

Os estudos de LEWEK et al. (2002) e RUDOLPH et al. (1998) sugerem que o reforço do grupo muscular quadríceps e o conseqüente aumento da estabilidade articular do joelho são fatores importantes para o retorno dos padrões normais da marcha dos pacientes 
com comprometimento do LCA. Este fato não pode ser confirmado pelo presente estudo porque não foi realizada avaliação da força muscular do M.quadríceps femoral.

Apesar de serem observadas diferenças nas angulações do joelho ao longo da fase de apoio, a amplitude articular alcançada considerando toda a fase de apoio só é capaz de detectar estas diferenças quando as mesmas são bastante acentuadas. Esta afirmação esta baseada no fato de terem sido encontradas diferenças significativas entre os grupos no que se refere à amplitude articular total da fase de apoio apenas no Teste 2 (1PO). E é nesse teste que na análise descritiva percebe-se maior diferença entre os grupos nos picos de flexão do joelho. Desta forma, a análise apenas da amplitude articular das fases de apoio e balanço não parece ser a melhor forma de avaliar as alterações do movimento articular do joelho dos sujeitos com o LCA rompido ou reconstruído.

\subsection{Análise Eletromiográfica}

A análise dos envoltórios lineares extraídos do sinal eletromiográfico do grupo CON apresentou o padrão de ativação do M.vasto lateral da perna esquerda semelhante ao apresentado por WINTER (1983a) para sujeitos normais. A perna direita apresentou um período a mais de ativação na primeira metade da fase de apoio, que é mencionado no estudo de AMADIO et al. (1999) e FRANKEL e NORDIN (1980). A atividade eletromiográfica do M.bíceps femoral de ambos os membros inferiores se aproxima da apresentada por WINTER (1983a) para sujeitos normais. A diferença maior se encontra no final da fase de balanço da perna esquerda que no presente estudo não fica evidenciado um período de ativação do M.bíceps femoral como ocorreu no estudo de WINTER (1983a).

A ativação do M.vasto lateral no início da fase de apoio, prevista na literatura (AMADIO et al., 1999; ANDERSON \& PANDY, 2003; BEARD et al., 1996; BULGHERONI et al., 1997; WINTER, 1983a) aparece em todos os grupos e em todos os testes, com exceção do grupo CCF no Teste 1 (Pré). Neste grupo o M.vasto lateral é ativado entre 35\% e 45\% da passada, este resultado é próximo ao citado por FRANKEL e NORDIN (1980) ao falar da ativação do grupo dos extensores do joelho durante o ciclo da marcha. Este período de ativação também é demonstrado por AMADIO et al. (1999), no entanto eles também mencionam a ativação do início da fase de apoio que não aparece no estudo de FRANKEL e NORDIN (1980) e nem no grupo CCF do presente estudo. 
ANDERSON e PANDY (2003) inferem que está atividade inicial do M.vasto lateral corresponde a sua necessidade de dar suporte antes da retirada do pé do membro contra-lateral, juntamente com os músculos M.glúteo máximo, M.glúteo médio e M.glúteo mínimo e ainda salientam que estes músculos contribuem pra o primeiro pico da força vertical.

Para FRANKEL e NORDIN (1980) a contração do M.quadríceps femoral está associada à flexão do joelho que ocorre no início da fase de apoio e necessita da contração do M.quadríceps femoral para evitar a flexão total do joelho. Com base nesta informação e ao analisar o gráfico da variação angular do grupo CCF pode-se justificar o aparecimento um pouco mais tardio do primeiro período de ativação do M.vasto lateral no Teste 2 (1PO) porque o pico de flexão do joelho também ocorre mais tarde neste teste.

A contração simultânea do M.vasto lateral e do M. bíceps femoral identificada no início da fase de apoio de praticamente todas as situações analisadas no presente trabalho também é mencionada na literatura (AMADIO et al., 1999; ANDERSON \& PANDY, 2003; BEARD et al., 1996; BULGHERONI et al., 1997; WINTER, 1983a). A justificativa para esta co-ativação, segundo AMADIO et al. (1999) é proporcionar estabilidade no joelho no momento do impacto com o solo.

As atividades mais duradouras dos M.vasto lateral e M.bíceps femoral durante a fase de apoio nos grupos CCF e CCA podem ocorrer pela necessidade de maior estabilidade do joelho dos sujeitos com lesão do LCA (BULGHERONI et al., 1997).

A necessidade de contração dos extensores do joelho no final da fase de apoio para ajudar na propulsão, como mencionado por LOBO DA COSTA e AMADIO (1995), justifica a atividade identificada no presente estudo do M.vasto lateral neste momento do ciclo da marcha. E a continuidade da atividade durante a fase de balanço, que ocorreu em algumas situações, pode ser explicada pela necessidade do controle da flexão do joelho durante a fase de balanço, como menciona PIAZZA e DELP (1996).

O M.bíceps femoral não se caracterizou com um padrão específico de atividade durante o ciclo da marcha nos grupos $\mathrm{CCF}$ e CCA, ele pareceu se manter ativo ao longo de todo o ciclo com períodos de maior e menor atividade. O estudo de BULGHERONI et al. (1997) e BEARD et al. (1996) prevêem uma maior atividade dos isquiostibiais nos sujeito que apresentam lesão do LCA, como mecanismo de proteção ao joelho na tentativa de melhorar a estabilidade do mesmo durante a marcha. 
Ainda em relação ao M.bíceps femoral foi identificado um aumento na sua atividade no final da fase de balanço, corroborando com os estudos de AMADIO et al. (1999), ANDERSON e PANDY (2003), BEARD et al. (1996), BULGHERONI et al. (1997), FRANKEL e NORDIN (1980) e WINTER (1983a). Esta atividade, segundo BULGHERONI et al. (1997), é atribuída a uma estratégia compensatória para aumentar a estabilidade no momento do contato do calcanhar.

\subsection{Simetria em função da lateralidade do acometimento da lesão}

A primeira análise relativa às simetrias diz respeito ao valor absoluto da média do grupo em cada variável. Poucas variáveis tiveram o seu valor absoluto superior aos 10\% considerado normal na comparação entre as pernas (HERZOG, NIGG \& ULSSON, 1989). No Teste 2 (1PO) o grupo CCF e o grupo CCA apresentaram valores superiores aos $10 \%$ para o tempo de Fyl e a perna operada levou um tempo maior para que ocorresse o primeiro pico. A variável amplitude de movimento na fase de apoio teve seu valor superior aos $10 \%$ no grupo CCF e CCA nos Testes 2 (1PO) e 3 (4PO) com a maior amplitude de movimento sendo da perna não-operada, o grupo CCF também apresentou valor superior aos 10\% no Teste 1 (Pré) só que neste caso a amplitude de movimento maior foi da perna com lesão. Estas variáveis podem ser as que mais se alteram na perna que possui o joelho com a lesão do LCA e por isso acabam apresentando maior variação entre as pernas. Os valores de simetrias dessas variáveis são maiores no Teste 2 (1PO) demonstrando que a intervenção cirúrgica tem um efeito maior nas compensações da marcha e que estas melhoram com o período de reabilitação.

Os resultados da comparação entre grupos no Teste 2 (1PO) sugere que o grupo CCA foi o que apresentou maiores diferenças de simetria entre as pernas, enquanto o grupo CCF foi comparável ao grupo CON. Novamente, os resultados indicam que o grupo CCF não alterou de forma acentuada o seu padrão de marcha após a cirurgia, ou que o período de quatro semanas permitiu um retorno mais próximo do normal do que para o grupo CCA.

A maioria das variáveis com seus valores de simetria maiores no Teste 2 (1PO) do que no Teste 3 (4PO) e em alguns casos do que no Teste 1 (Pré), nos grupos CCF e CCA sugere que logo após a cirurgia existe uma maior inconsistência entre as pernas, e que esta diminui após o período de reabilitação de quatro meses. 


\section{CONCLUSÕES}

O procedimento metodológico forneceu importantes contribuições para a discussão das alterações da marcha em função dos protocolos de reabilitação utilizados com os indivíduos submetidos à reconstrução do LCA. Assim temos a destacar as seguintes conclusões, considerando os protocolos utilizados.

Os resultados relativos ao deslocamento tibial anterior reforçam que esta análise antes da cirurgia é eficiente para comprovar a lesão do LCA. Que a diminuição do deslocamento tibial anterior após a cirurgia demonstra que o procedimento cirúrgico foi efetivo na substituição do LCA. E que os protocolos de reabilitação em CCA e CCF não provocam deslocamento tibial anterior que prejudique o enxerto ligamentar.

A percepção dos pacientes na melhora do aspecto funcional do joelho através do escore de Lysholm acompanha a melhora da estabilidade do joelho identificada pelos valores do deslocamento tibial anterior. O procedimento cirúrgico associado à reabilitação, independente do tipo de exercício realizado, melhora a função do joelho e o conseqüente nível de atividade física. Ainda é possível inferir que apesar de não existir diferença significativa entre os grupos no final do tratamento para o escore de Lysholm, os pacientes do grupo CCA parecem sentir maiores limitações nas suas atividades físicas do que o grupo CCF. Esta colocação está baseada no fato de o escore do grupo CCA ser considerado regular enquanto o do grupo CCF é considerado excelente.

Através da análise dos componentes principais, utilizada para as variáveis relativas à força de reação do solo, parece que as taxas de crescimento para os picos da força vertical, a deflexão da força mínima, a força mínima e o segundo pico são mais sensíveis para identificar diferenças na forma de andar. De todas as variáveis analisadas neste estudo apenas as relativas a FRS apresentaram diferença estatística entre os grupos CCA e CCF no teste ao final do tratamento, teste onde o tipo de exercício utilizado na reabilitação influência o resultado. E os dados demonstram que o grupo $\mathrm{CCF}$ foi o que mais se aproximou do grupo $\mathrm{CON}$, sugerindo que o grupo CCA é menos efetivo para recuperar os parâmetros dinâmicos da marcha do que o grupo CCF.

Das variáveis cinemáticas dos parâmetros temporais e espaciais, o tempo de apoio simples parece ser a melhor variável para identificar compensações utilizadas pelos pacientes com comprometimento do LCA. 
A análise descritiva da variação angular sugere que os pacientes com coprometimento do LCA diminuem a flexão do joelho na fase inicial do apoio e no restante desta fase mantém o joelho mais flexionado. Esta análise, após o período de reabilitação, também permite inferir que o grupo CCF tem a movimentação do joelho mais próxima do normal do que o grupo CCA. Ao analisar a amplitude de movimento percebe-se que esta variável é sensível a mudanças expressivas na variação angular, como ocorreram no teste após quatro semanas de pós-operatório. Para diferenças angulares menores, perceptíveis na análise descritiva, avaliar os ângulos em momentos específicos da marcha parece ser mais adequado.

Em relação à atividade muscular os grupos CCF e CCA têm os músculos M.vasto lateral e M.bíceps femoral mais tempo ativos na fase de apoio. O M.bíceps femoral foi o que apresentou maior variação na sua atividade. Provavelmente estes são recursos utilizados pelos pacientes para aumentar a estabilidade no joelho com lesão.

Os valores de simetria demonstram que o grupo cadeia cinética aberta foi o que apresentou maiores diferenças entre as pernas no teste após quatro semanas de cirurgia, o que demonstra maior instabilidade no andar, neste período.

Ao considerar o conjunto dos resultados é possível concluir que as alterações da marcha são mais expressivas um mês após a cirurgia do que no período pré-operatório e após o final do período de reabilitação (quatro meses após a cirurgia). O escore de Lysholm, os componentes principais das variáveis relativas à força de reação do solo e a variação angular do joelho indicam que os exercícios em CCF são mais eficientes para a recuperação da marcha do que os de CCA. No entanto, os dois tipos de exercícios propiciam melhora dos parâmetros da marcha e parecem ser eficientes na recuperação da marcha dos pacientes submetidos à reconstrução do ligamento cruzado anterior. O período de quatro meses de reabilitação assegura uma marcha sem riscos para o paciente, mas ainda distinta da característica da marcha de indivíduos não acometidos pela lesão. 


\section{REFERÊNCIAS}

ACL STUDY GROUP. Lachman Test. Disponível em: $<$ http://www.aclstudygroup.com/ACLFinal/acl02f.htm>. Acesso em: out. 2003.

ALTON, F.; BALDEY, L.; CAPLAN, S.; MORRISSEY, M.C. A kinematic comparison of overground and treadmill walking. Clinical Biomechanics, Bristol, v.13, p.434-40, 1998.

AMADIO, A.C.; LOBO DA COSTA, P.H.; SACCO, I.C.N.; SERRÃO, J.C.; ARAUJO, R.C.; MOCHIZUKI, L.; DUARTE, M. Introdução à análise do movimento humano: descrição e aplicação dos métodos biomecânicos de medição. Revista Brasileira de Fisioterapia, São Carlos, v.3, n.2, p.41-54, 1999.

ANDERSON, F.C.; PANDY, M.G. Individual muscle contributions to support in normal walking. Gait \& Posture, Amsterdam, v.17, p.59-69, 2003.

ARSENAULT, A.B.; WINTER, D.A.; MARTENIUK, R.G. Bilateralism of EMG profiles in human locomotion. The American Journal of Physical Medicine, Baltimore, v.65, n.1, p.1-16, 1986.

ARSENAULT, A.B.; WINTER, D.A., MARTENIUK, R.G.; HAYES, K.C. How many strides are required for the analysis of electromyographic data in gait? Scandinavian Journal of Rehabilitation Medicine, Stockholm, v.18, n.3, p.133-35, 1986.

BEARD, D.J.; ANDERSON, J.L.; DAVIES, S.; PRICE, A.J.; DODD, C.A.F. Hamstrings vs. patella tendon for anterior cruciate ligament reconstruction: a randomized controlled trial. Knee, Oxford, v.8, p.45-50, 2001.

BEARD, D.J.; SOUNDARAPANDIAN, R.S.; O'CONNOR, J.J.; DODD, C.A.F. Gait and electromyographic analysis of anterior cruciate ligament deficient subjects. Gait \& Posture, Amsterdam, v.4, p.83-88, 1996. 
BERCHUCK, M.; ANDRIACCHI, T., BACH, B.; REIDER, B. Gait adaptations by patients who have a deficient anterior cruciate ligament. Journal of Bone and Joint Surgery, Boston, v.72, n.A, p.871-77, 1990.

BEYNNON, B.D.; JOHNSON, R.J.; FLEMING, B.C. The science of anterior cruciate ligament rehabilitation. Clinical Orthopaedics and Related Research, Philadelphia, v.402, p.9-20, 2002.

BEYNNON, B.D.; JOHNSON, R.J.; FLEMING, B.C.; STANKEWICH, C.J.; RENSTROM, P.A; NICHOLS C.E. The strain behavior of the anterior cruciate ligament during squatting and active flexion-extension: a comparison of an open and a closed kinetic chain exercise. The American Journal of Sports Medicine, Columbus, v.25, n.6, p.823-29, 1997.

BEYNNON, B.D.; FLEMING, B. C.; JOHNSON, R.J.; NICHOLS C.E.; RENSTROM, P.A.; POPE, M. H. Anterior cruciate ligament strain behavior during rehabilitation exercise in vivo. The American Journal of Sports Medicine, Columbus, v.23, n.1, p.2434, 1995.

BODOR, M. Quadriceps protects the anterior cruciate ligament. Journal of Orthopaedic Research, New York, v.19, n.4, p.629-33, 2001.

BULGHERONI, P.; BULGHERONI, M.V.; ANDRINI, L.; GUFFANTI, P.; GIUGHELLO, A. Gait patterns after anterior cruciate ligament reconstruction. Knee Surgery, Sports Traumatoloty, Arthroscopy, Heidelberg, v.5, p.14-21, 1997.

BUNTON, E.E.; PITNEY, W.A., KANE, A.W.; CAPPAERT, T.A. The role of limb torque, muscle action and proprioception during closed kinetic chain rehabilitation of the lower extremity. Journal of Athletic Training, Dallas, v.28, n.1, p.10-20, 1993. 
BYNUM, E.B.; BARRACK, R.L.; ALEXANDER, A.H. Open versus closed chain kinetic exercises after anterior cruciate ligament reconstruction. The American Journal of Sports Medicine, Columbus, v.23, n.4, p.401-06, 1995.

CARBON, D.N.; JOHNSON, B.M. The natural history of the anterior cruciate ligament-deficient knee. A review. Clinical Sports Medicine, Bristol, v.12, n.4, p.625$36,1993$.

CARTER, T.R.; EDINGER, S. Isokinetic evaluation of anterior cruciate ligament reconstruction hamstrings versus patellar tendon. Arthroscopy, New York, v.15, n.2, p.169-72, 1999.

DEVITA, P.; HORTOBAGYI, T.; BARRIER, J.; TORRY, M.; GLOVER, K.L.; SPERONI, D.L.; MONEY, J.; MAHAR, M.T. Gait adaptations before and after cruciate ligament reconstruction surgery. Medicine and Science in Sports and Exercise, Madison, v.29, n.7, p.853-59, 1997.

DEVITA, P.; HORTOBAGYI, T.; BARRIER, J. Gait biomechanics are not normal after cruciate ligament reconstruction and accelerated rehabilitation. Medicine and Science in Sports and Exercise, Madison, v.30, n.10, p.1481-88, 1998.

DRAGANICH, L.F.; JAEGER, R.J.; KRALJ, A.R. Coativation of the hamstrings and quadriceps during extension of the knee. The Journal of Bone and Joint Surgery, Boston, v.71, n.7, p.1075-81, 1989.

ESCAMILLA, R.F. Knee biomechanics of the dynamic squat exercise. Medicine Science in Sports and Exercise, Madison, v.33, n.1, p.127-41, 2001.

ESCAMILLA, R.F.; FLEISIG, G.S.; ZHENG, N.; LANDER, J.E.; BARRENTINE S.W.; ANDREWS, J.R.; BERGEMANN, B.W.; MOORMAN, C.T. Effects of thechnique variations on knee biomechanics during the squat and leg press. Medicine Science in Sports and Exercise, Madison, v.33, n.9, p.1552-66, 2001. 
GAITWAY. Operating manual for type 9810s1x \& software version 10x. Winterthur: Kistler, 1996.

FITZGERALD, G.K. Open versus closed kinetic chain exercise: issues in rehabilitation after anterior cruciate ligament reconstructive surgery. Physical Therapy, Chicago, v.77, n.12, p.1747-54, 1997.

FLECK, S.J.; KRAEMER, W.J. Fundamentos do treinamento de força muscular. Porto Alegre: ArtMed, 1999.

FLEMING, B.C.; OKSENDAHL, H.; BEYNNON, B.D. Open or closed kinetic chain exercises after anterior cruciate ligament reconstruction? Exercise Sport Science Review, Baltimore, v.33, n.3, p.134-40, 2005.

FRANKEL, V.H.; NORDIN, M. Basic biomechanics of the skeletal system. Philadelphia: Leo \& Febiger, 1980.

GRAHAM, V.L.; GEHLSEN, G.M.; EDWARDS, J.A. Electromyographic evaluation of closed and open kinetic knee rehabilitation exercises. Journal of Athletic Training, Dallas, v.28, n.1, p.23-30, 1993.

HAMILL, J.; BATES, B.T.; KNUTZEN, K.M. Ground reaction force symmetry during walking and running. Research Quarterly for Exercise and Sport, Washington, v.55, n.3, p.289-93, 1984.

HENNING, C.E.; LYNCH, M.A.; GLICK, K.R. An in vivo strain gage study of elongation of the anterior cruciate ligament. The American Journal of Sports Medicine, Columbus, v.13, n.1, p.22-6, 1985.

HERMENS, H.J.; FRERIKS, B.; MERLETTI, R.; STEGEMAN, D.; BLOK, J.; RAU, G.; DISSELHORST-KLUG, C.; HÄGG, G. SENIAM 8 - European Recommendations for Surface Electromyography. Enschede: Roessingh Research and Development, 1999. 
HERNANDEZ, A.J.; REZENDE, M.U.; GÓIS, S.L.; GRISENDE, S.C. Avaliação funcional e do nível de atividade física nas reconstruções do ligamento cruzado anterior. Revista Brasileira de Ortopedia, São Paulo, v.31, n.12, p.990-94, 1996.

HERZOG, W.; NIGG, R.; ULSSON. Asymmetries in ground reaction force patterns in normal gait. The Medicine and Science in Sports and Exercise, Madison, v.21, p.11014, 1989.

HOOPER, D.M.; MORRISEY, M.C.; DRECHSLER, W.; MCDERMOTT, M.; MCAULIFFE, T.B. Validation of the Hughston Clinic subjective knee questionnaire using gait analysis. The Medicine and Science in Sports and Exercise, Madison, v.33, n.9, p.1456-62, 2001.

HOOPER, D.M.; MORRISEY, M.C.; DRECHSLER, W.; MORRISSEY, D.; KING, J. Open and closed kinetic chain exercises in the early period after anterior cruciate ligament-reconstruction: improvements in level walking, stair ascent, and stair descent. The American Journal of Sports Medicine, Columbus, v.29, n.2, p.167-174, 2001.

HOWELL, S. M. Comparison of closed and open kinetic chain exercise in the anterior cruciate ligament-deficient knee [letter; comment]. The American Journal of Sports Medicine, Columbus, v.21, n.4, p.632-3, 1993.

IMRAN, A.; O'CONNOR, J.J. Control of knee stability after ACL injury or repair: interaction between hamstrings contraction and tibial translation. Clinical Biomechanics, Bristol, v.13, n.3, p.153-62, 1998.

KEAYS, S.L.; BULLOCK-SAXTON, J.; KEAYS, A.C. Strength and function before and after anterior cruciate ligament reconstruction. Clinical Orthopaedics and Related Research, Philadelphia, v.373, p.174-83, 2000. 
KIRKLEY, A.; MOHTADI, N.; OGILVIE, R. The effect of exercise on anteriorposterior translation of the normal knee and knees with deficient or reconstructed anterior cruciate ligaments. The American Journal of Sports Medicine, Columbus, v.29, n.3, p.311-14, 2001.

KNOLL, Z.; KOCSIS, L.; KISS R.M. Gait patterns before and after anterior cruciate ligament reconstruction. Knee Surgery, Sports Traumatolology, Arthroscopy, Heidelberg, v.12, n.1, p.7-14, 2004.

KVIST, J.; GILLQUIST, J. Sagittal plane knee translation and electromyographic activity during closed and open kinetic chain exercises in anterior cruciate ligamentdeficient patients and control subjects. The American Journal of Sports Medicine, Columbus, v.29, n.1, p.72-82, 2001.

LEWEK, M; RUDOLPH, K.; AXE, M.; SNYDER-MACKLER, L. The effect of insufficient quadriceps strength on gait after anterior cruciate ligament reconstruction. Clinical Biomechanics, Bristol, v.17, p.56-63, 2002

LIMA, C.S.; GUIMARÃES, A.C.S. Effects of open and closed kinetic chain exercises on anterior tibial displacement and muscular force after anterior cruciate ligament reconstruction. In: CONGRESS OF THE INTERNATIONAL SOCIETY OF BIOMECHANICS, 17., Calgary, 1999. Book of Abstracts... Calgary: International Society of Biomechanics, 1999.

Analysis of resultant torque during knee rehabilitation. In: CONGRESS OF THE INTERNATIONAL SOCIETY OF BIOMECHANICS, 18., Zurick, 2001. Book of Abstracts... Zurick: International Society of Biomechanics, 2001.

LOBO DA COSTA, P.H.; AMADIO, A.C. Estudo comparativo de três formas de locomoção em crianças: forças de reação do solo no andar no plano, subir e descer escadas. In: CONGRESSO BRASILEIRO DE BIOMECÂNICA, 6., Brasília, 1995. Anais... Brasília: SBB/UnB, 1995. p.91-7. 
MAJIMA, T.; YASUDA, K.; TAGO, H.; TANABE,Y.; MINAMI, A. Rehabilitation after hamstring anterior cruciate ligament reconstruction. Clinical Orthopaedics and Related Research, Philadelphia, v.397, p.370-80, 2002.

MALANGA, G.A.; ANDRUS, S.; NADLER, S.F.; MCLEAN, J. Physical examination of the knee: a review of the original test description and scientific validity of common orthopedic tests. Archives of Physical Medicine and Rehabilitation, Chicago, v.84, p.592-603, 2003.

MATSAS, A.; TAYLOR, N.; McBURNEY, H. Knee joint kinematics from familiarised treadmill walking can be generalised to overground walking in young unimpaired subjects. Gait \& Posture, Amsterdam, v.11, n.1, p.46-53, 2000.

MAUPAS, E.; PAYSANT, J.; DATIE, A.M.; MARTINET, N.; ANDRÉ, J.M. Functional asymmetries of the lower limbs: a comparison between clinical assessment of laterality, isokinetic evaluation and eletrogoniometric monitoring of knees during walking. Gait \& Posture, Amsterdam, v.6, p.304-12, 2002.

McDANIEL JUNIOR, W.J.; DAMERON JUNIOR, T.B. The untreated anterior cruciate ligament rupture. Clin Orthop. v.172, p.158-63, 1983.

McGINITY, G.; IRRGANG, J.J.; PEZZULLO, D. Biomechanical considerations for rehabilitation of the knee. Clinical Biomechanics, Bristol, v.15, p.160-66, 2000.

MOTA, Y.L.; AMADIO, A.C.; HERNANDEZ, A.J.; DUARTE, M. Análise biomecânica da locomoção de indivíduos com e sem lesão no ligamento cruzado anterior: um estudo de caso. Revista Brasileira de Fisioterapia, São Carlos, v.6, n.1, p.9$16,2002$.

NOYES, F.R.; MANGINE, R.E.; BARBER, S. Early knee motion after open and arthroscopic anterior cruciate ligament reconstruction. The American Journal of Sports Medicine, Columbus, v.15, p.149-60, 1987. 
PANARIELLO, R.A. The closed kinetic chain in strength training. Journal of Strength and Conditioning Research, Champaign, v.13, n.1, p.29-33, 1991.

PERRIN, D.H. Open chain isokinetic assessment and exercise of the knee. Journal of Sport Rehabilitation, v.3, p.245-54, 1994.

PIAZZA, S.J.; DELP, S.L. The influence of muscles on knee flexion during the swing phase of gait. Journal of Biomechanics, New York, v.29, n.6, p.723-33, 1996.

RENSTRÖM, P.; ARMS, S.W.; STANWYCK, T.S.; JOHNSON, R.J.; POPE, M.H. Strain within the anterior cruciate ligament during hamstring and quadriceps activity. The American Journal of Sports Medicine, Columbus, v.14, n.1, p.83-87, 1986.

RIVERA, J.E. Open versus closed kinetic chain rehabilitation of the lower extremity: A functional and biomechanical analysis. Journal of Sports Rehabilitation, v.3, p.154-67, 1994.

RUDOLPH, K.S.; EASTLACK, M.E.; AXE, M.J.; SNYDER-MACKLER, L. 1998 Basmajian student award paper movement patterns after anterior cruciate ligament injury: a comparison of patients who compensate well for the injury and those who require operative stabilization. Journal of Eletromiography and Kinesiology, Oxford, v.8, p.349-62, 1998.

SAAD, M.; BATISTELLA, L.R. Análise da marcha: manual do CAMO-SBMFR. São Paulo: Lemos, 1997.

SACCO, I.C.N. Influência da neuropatia diabética no comportamento de respostas biomecânicas e sensoriais no andar em esteira rolante. 2001. Tese (Doutorado) - Escola de Educação Física e Esporte da Universidade de São Paulo, São Paulo, 2001.

SHELBURNE, K.B.; PANDY, M.G. Determinants of cruciate-ligament loading during rehabilitation exercise. Clinical Biomechanics, Bristol, v.13, p.403-13. 1998. 
SHELBURNE, K.B.; TORRY, M.R.; PANDY, M.G. Effect of muscle compensation on knee instability during ACL-deficient gait. The Medicine and Science in Sports and Exercise, Madison, v.37, n.4, p.642-8, 2005.

SHELBOURNE, K.D.; NITZ, P. Accelerated rehabilitation after anterior cruciate ligament reconstruction. The American Journal of Sports Medicine, Columbus, v.18, p.292-99, 1990.

SNYDER-MACKLER, L.; DELITO, A.; STRALKA, S. Strength of the quadríceps femoris muscle and functional recovery after reconstruction of the anterior cruciate ligament. Journal of Bone and Joint Surgery, Boston, v.77A, n.8, p.1166-73, 1995.

SOCIEDADE BRASILEIRA DE ANATOMIA. Terminologia anatômica: Terminologia Anatômica Internacional. Traduçăo da terminologia anatômica estabelecida pela International Federation of Anatomical Associations. São Paulo: Manole, 2001.

STOLZE, H.; KUHTZ-BUSCHBECK, J.P.; MONDWURF, C.; BOCZEK-FUNCKE, A.; JOHN, K.; DEUSCHL, G.; ILLERT, M. Gait analysis during treadmill and overground locomotion in children and adults. Electroencephalography and Clinical Neurophysiology, Amsterdam, v.105, n.6, p.490-7, 1997.

TOUTOUNGI, D.E.; LU, T.W.; LEARDINI, A.; CATANI, F.; O’CONNOR, J.J. Cruciate ligament forces in the human knee during rehabilitation exercises. Clinical Biomechanics, Bristol, v.15, p.176-87, 2000.

VUOLO, J.H. Fundamentos da teoria de erros. 2. ed. São Paulo: Edgard Blücher, 1996.

WHITE, D.M. Comparison of closed and open kinetic chain exercise in the anterior cruciate ligament-deficient knee [letter; comment]. The American Journal of Sports Medicine, Columbus, v.21, n.4, p.633-4, 1993. 
WHITE, S.C.; YACK, H.J.; TUCKER, C.A.; LIN, H.Y. Comparison of vertical ground reaction forces during overground and treadmill walking. The Medicine and Science in Sports and Exercise, Madison, v.30, n.10, p.1537-42. 1998.

WILK, K.E.; ESCAMILLA, R.F.; FLEISIG, G.S.; BARRENTINE, S.W; ANDREWS, J.R.; BOYD, M.L. A comparison of tibiofemoral joint forces and electromyographic activity during open and closed kinetic chain exercises. The American Journal of Sports Medicine, Columbus, v.24, .4, p.518-27. 1996.

WINTER, D.A. Biomechanics of human movement. New York: John Wiley \& Sons, 1979.

. Biomechanical motor patterns in normal walking. Journal of Motor Behavior, Washington, v.15, n.4, p.302-30, $1983 \mathrm{a}$.

. Knee flexion during stance as a determinant of inefficient walking. Physical Therapy, Chicago, v.63, n.3, p.331-33, 1983 b.

WINTER, D.A.; ENG, P. Energy generation and absorption at the ankle and knee during fast, natural, and slow cadences. Clinical Orthopaedics and Related Research, Philadelphia, v.175, p.147-54, 1983.

WINTER, D.A.; YACK, H.J. EMG profiles during normal human walking: stride-tostride and inter-subject variability. Electroencephalography and Clinical Neurophysiology, Amsterdam, v.67, n.5, p.402-11, 1987.

WOJTYS, E.M.; CARPENTER, J.E. Instrumented knee laxity. In: FU, F.H.; HARNER, C.D.; VINCE, K.G. Knee surgery. Baltimore: Williams \& Wilkins, 1994. v.1, cap.13. 
WOO, S.L-Y.; DEBSKI, R.E.; WITHROW, J.D.; JANAUSHEK, M.A. Biomechanics of knee ligaments. The American Journal of Sports Medicine, Columbus, v.27, n.4, p.533-43, 1999.

YACK, H.J.; COLLINS, C.E.; WHIELDON, T.J. Comparison of closed and open kinetic chain exercise in the anterior cruciate ligament-deficient knee. The American Journal of Sports Medicine, Columbus, v.21, n.1, p.49-54, 1993. 
ANEXO I

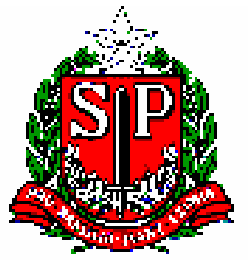

\section{$\underline{\text { Termo de Consentimento Pós-informação }}$}

HOSPITAL DAS CLÍNICAS

DA

FACULDADE DE MEDICINA DA UNIVERSIDADE DE SÃO PAULO

TERMO DE CONSENTIMENTO PÓS -INFORMAÇÃO

\section{I - DADOS DE IDENTIFICAÇÃO DO SUJEITO DA PESQUISA OU RESPONSÁVEL} LEGAL

1. NOME DO PACIENTE .

DOCUMENTO DE IDENTIDADE N: SEXO : .M $\mathrm{F}$

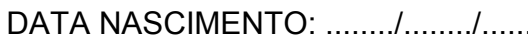

ENDEREÇO $\mathrm{N}^{\circ}$

APTO:

BAIRRO:

CEP:

TELEFONE: DDD

..).

2.RESPONSÁVEL LEGAL

NATUREZA (grau de parentesco, tutor, curador etc.)

DOCUMENTO DE IDENTIDADE : SEXO: $M$

$\mathrm{F}$

DATA NASCIMENTO.: ....................

ENDEREÇO:

$\mathrm{N}^{0}$

APTO:

BAIRRO:

CIDADE:

CEP:

TELEFONE: DDD

).

\section{II - DADOS SOBRE A PESQUISA CIENTÍFICA}

1. TítULO DO PROTOCOLO DE PESQUISA: Aspectos biomecânicos da marcha em seres humanos submetidos a dois protocolos de reabilitação após reconstrução do Ligamento Cruzado Anterior

2. PESQUISADOR: Cláudia Silveira Lima

CARGO/FUNÇÃO: Professora Universitária, Fisioterapeuta INSCRIÇÃO CONSELHO REGIONAL No $11551 \mathrm{~F}$

UNIDADE DO HCFMUSP:

3. AVALIAÇÃO DO RISCO DA PESQUISA:

$\begin{array}{lr}\text { SEM RISCO } & \text { RISCO MÍNIMO } \\ \text { RISCO MÉDIO } & \mathbf{X} \\ \text { RISCO BAIXO } & \text { RISCO MAIOR }\end{array}$

(probabilidade de que o indivíduo sofra algum dano como consequência imediata ou tardia do estudo)

4. DURAÇÃO DA PESQUISA : 1 ano e 6 meses (Coleta de dados) 
ANEXO I Termo de Consentimento Pós-informação (cont.)

\section{III - REGISTRO DAS EXPLICAÇÕES DO PESQUISADOR AO PACIENTE OU SEU REPRESENTANTE LEGAL SOBRE A PESQUISA, CONSIGNANDO:}

1. Existem duas formas distintas de exercícios que podem ser utilizados na fisioterapia para reabilitação após a cirurgia de reconstrução do ligamento cruzado anterior, aqueles onde os exercícios são realizados sem o apoio do pé no solo ou em algum equipamento de ginástica (chamados de exercícios de cadeia cinética aberta) e aqueles onde os exercícios são realizados com o apoio do pé no solo ou em algum equipamento de ginástica (chamados de exercícios de cadeia cinética fechada). Não se sabe qual desses exercícios recupera melhor a maneira normal de andar. Dessa forma, esta pesquisa pretende estudar e comparar como ocorre a recuperação do andar quando os exercícios em cadeia cinética aberta e fechada são usados na reabilitação após a cirurgia do ligamento cruzado anterior.

2. Para isso, o senhor será solicitado a executar alguns testes que estão descritos mais detalhadamente abaixo. Estes testes serão aplicados em laboratório e terão duração de aproximadamente 1h30min.

- Teste 1: análise do deslocamento tibial anterior, que é o movimento que mostra o quanto seu ligamento cruzado anterior lhe faz falta e causa o seu problema no joelho, através de um aparelho que será colocado na perna e será realizada uma força para tracionar a perna para frente.

- Teste 2: deitado alguns músculos do senhor serão localizados. Isto será feito através de um aparelho que causa pequenos choques (gerador de pulsos elétricos), semelhantes a uma vibração e, normalmente, sem dor nenhuma em alguns músculos da perna e coxa.

- Teste 3: Análise do andar. O senhor caminhará em uma esteira elétrica rolante por aproximadamente 10 a 20 minutos, para coleta de dados e posterior análise.

Estes testes serão realizados cinco vezes ao longo da recuperação do senhor, antes da cirurgia e depois com 1 mês, 4 meses, 8 meses e 12 meses após a cirurgia.

Durante três meses (entre o primeiro e o quarto mês de cirurgia) o senhor irá realizar os exercícios de reabilitação, que poderão ser de cadeia cinética aberta (estender e flexionar o joelho) ou fechada (agachamento) conforme o grupo para o qual o senhor for encaminhado de acordo com sorteio prévio. Neste período o senhor terá que ir três vezes na semana na Escola de Educação Física e Esporte da USP para realizar os exercícios indicados para sua reabilitação.

3. O Teste 1 não oferece risco, mas pode causar alguma dor ou apenas desconforto, principalmente no teste realizado com 1 mês após a cirurgia onde o trauma do procedimento cirúrgico ainda é recente. No Teste 2 os pulsos elétricos, necessários para identificar os músculos que serão avaliados, causam um desconforto (como um formigamento) que aumenta quando o músculo é localizado. No Teste 3 durante o andar na esteira pode ocorrer algum desequilíbrio, mas a própria esteira tem um corrimão onde o senhor poderá se apoiar até restabelecer o equilíbrio ou até a esteira parar. Neste teste o senhor pode sentir dor ao realizá-lo com um mês após cirurgia por fazer pouco tempo que estás caminhando sem muletas (dor semelhante a que poderá estar sentindo ao caminhar no chão).

4. A participação na pesquisa proporcionará uma recuperação orientada e adequada, recuperando o movimento do joelho, a força dos músculos e a capacidade de realizar as suas atividades do dia-adia. Os testes irão oferecer informações objetivas de como a sua recuperação está ocorrendo, evitando com isso que se faça mais ou menos do que poderia ser feito em termos de atividade física.

5. O senhor pode ao invés de participar da pesquisa ter a sua recuperação sendo orientada através de serviços de reabilitação, utilizando os procedimentos clássicos para isso. 
ANEXO I Termo de Consentimento Pós-informação (cont.)

\section{IV - ESCLARECIMENTOS DADOS PELO PESQUISADOR SOBRE GARANTIAS DO SUJEITO DA PESQUISA:}

1. O sujeito da pesquisa, terá a qualquer momento livre acesso às informações sobre os procedimentos, riscos e benefícios relacionados à pesquisa, inclusive para retirar eventuais dúvidas.

2. O sujeito da pesquisa tem liberdade de retirar seu consentimento a qualquer momento e deixar de participar do estudo, sem que isso traga prejuízo à continuidade de sua assistência na instituição.

3. Os resultados serão analisados e utilizados única e exclusivamente para fins científicos, não se utilizando dados pessoais capazes de identificar o sujeito, ou seja a uma confidencialidade, sigilo e privacidade desses dados.

4. Caso haja um eventual dano à saúde decorrente da pesquisa, haverá disponibilidade de assistência no HCFMUSP.

5. Não há viabilidade de indenização por eventuais danos à saúde decorrentes da pesquisa.

\section{INFORMAÇÕES DE NOMES, ENDEREÇOS E TELEFONES DOS RESPONSÁVEIS PELO ACOMPANHAMENTO DA PESQUISA, PARA CONTATO EM CASO DE INTERCORRÊNCIAS CLÍNICAS E REAÇÕES ADVERSAS.}

$\begin{array}{llc}\begin{array}{l}\text { Cláudia Silveira Lima } \\ 37266419 \text { ou } 92541871\end{array} & \text { Endereço: Rua Barroso Neto, } 302 \text { apto. } 61 & \text { Telefone: } \\ \begin{array}{l}\text { Alberto Carlos Amadio } \\ 30647881 \text { ou } 95890477\end{array} & \text { Endereço: Av. Oscar Freire, 1961 apto. } 114 & \text { Telefone: } \\ \begin{array}{l}\text { Arnaldo José Hernandez } \\ 99665491\end{array} & \text { Endereço: Rua Maracanã, } 260 \text { apto. } 71 & \text { Telefone: } 30212865 \text { ou }\end{array}$

vI. OBSERVAÇÕES COMPLEMENTARES:

\section{VII - CONSENTIMENTO PÓS-ESCLARECIDO}

Declaro que, após convenientemente esclarecido pelo pesquisador e ter entendido o que me foi explicado, consinto em participar do presente Protocolo de Pesquisa.

São Paulo, de de 200 . 


\section{ANEXO II}

\section{Estudo Piloto 1}

O primeiro problema a ser solucionado estava relacionado ao período de tratamento dos pacientes. Os pacientes serão divididos em dois grupos, que realizarão exercícios distintos, CCA e CCF. Estes exercícios, entre outros fatores, terão por objetivo aumentar a força muscular. E, este ganho de força terá influência sobre a recuperação da marcha (LEWEK et al., 2002; LIU \& MAITLAND, 2000).

Diante disto, é preciso realizar um programa de tratamento onde as cargas utilizadas nos diferentes exercícios sejam equivalentes. A opção selecionada foi seguir o mesmo princípio do treinamento de força e determinar a carga a ser utilizada em cada exercício a partir de um percentual da carga máxima do paciente em cada um deles.

Para confirmar que a utilização de um percentual da carga máxima propiciaria uma atividade muscular semelhante nos exercícios em CCA e CCF optou-se por realizar um estudo comparando a atividade muscular dos exercícios em CCA e CCF em carga máxima.

\section{Objetivo}

O estudo piloto 1 teve, portanto, por objetivo determinar e comparar a atividade muscular do M.quadríceps femoral e dos isquiostibiais nos exercícios de CCA (extensão do joelho e extensão do quadril) e CCF (agachamento) selecionados para serem utilizados durante o período de reabilitação.

\section{Amostra}

A amostra foi constituída de 5 (cinco) sujeitos. Os critérios de inclusão foram serem sujeitos saudáveis sem comprometimento dos ligamentos do joelho, não realizar treinamento de força como atividade física sistemática e estar entre as idades de 21 e 55 anos. A caracterização da amostra é apresentada na TABELA 1. 


\section{ANEXO II $\quad$ Estudo Piloto 1 (Cont.)}

TABELA 1 - Caracterização da amostra em relação à idade, estatura e massa.

\begin{tabular}{cccc}
\hline Sujeito & Idade & Estatura $(\mathrm{m})$ & Massa $(\mathrm{kg})$ \\
\hline 1 & 33 & 1,78 & 75,0 \\
2 & 24 & 1,77 & 61,3 \\
3 & 35 & 1,83 & 86,2 \\
4 & 54 & 1,78 & 77,1 \\
5 & 40 & 1,70 & 80,0 \\
\hline
\end{tabular}

\section{Procedimentos}

Os sujeitos compareceram ao laboratório para realizar o teste de 1 repetição máxima (1RM) para extensão do joelho, extensão do quadril e agachamento em um dia préestabelecido. O tempo para execução do movimento foi controlado em três segundos para cada fase, concêntrica e excêntrica, num total de seis segundos para execução do movimento completo. $\mathrm{O}$ controle do tempo foi realizado por meio de metrônomo e os sujeitos realizaram o movimento sem carga até estarem familiarizados com o tempo de execução dos exercícios. Após a familiarização o teste de 1RM era realizado e a carga máxima registrada.

Os sujeitos retornaram ao laboratório no dia seguinte para realizar o exercício com a carga máxima determinada e ao mesmo tempo fazer o registro do sinal EMG. Os músculos monitorados foram M.vasto lateral e M.reto da coxa, representando o grupo muscular M.quadríceps femoral; e, M.bíceps femoral, representando o grupo muscular isquiostibiais.

O valor RMS de todo o período de execução do exercício foi calculado e normalizado pelo tempo de execução. Os músculos M.vasto lateral e M.reto da coxa foram comparados entre o exercício de extensão do joelho e o agachamento. O músculo M.bíceps femoral foi comparado entre o exercício de extensão do quadril e o agachamento.

A análise estatística foi realizada através do teste $\mathrm{t}$ de student para amostras dependentes. Os dados foram processados e analisados estatisticamente através do pacote estatístico SPSS, levando em consideração o nível de significância de 0,05. 


\section{ANEXO II $\quad$ Estudo Piloto 1 (Cont.)}

\section{Resultados}

Apesar de os músculos apresentarem padrões de ativação diferentes nos exercícios de CCA comparados ao de CCF (FIGURA 1), o valor RMS de nenhum dos músculos estudados apresentou diferença significativa entre os exercícios (TABELA 2).

TABELA 2 - Valor RMS (mV) para os exercícios extensão do joelho, agachamento e extensão do quadril (Média e (desvio padrão)).

\begin{tabular}{llll}
\hline Músculos & Extensão Joelho & Agachamento & Extensão Quadril \\
\hline M.vasto lateral & $0,0196(0,0073)$ & $0,0303(0,0214)$ & \\
M.reto da coxa & $0,0159(0,0096)$ & $0,0144(0,0114)$ & \\
$\begin{array}{l}\text { M.bíceps } \\
\text { femoral }\end{array}$ & $0,0080(0,0046)$ & $0,0208(0,0152)$ \\
\hline$* p<0,05$, na comparação entre extensão do joelho e agachamento. & \\
${ }^{* * p}<0,05$, na comparação entre extensão do quadril e agachamento. &
\end{tabular}


(a)

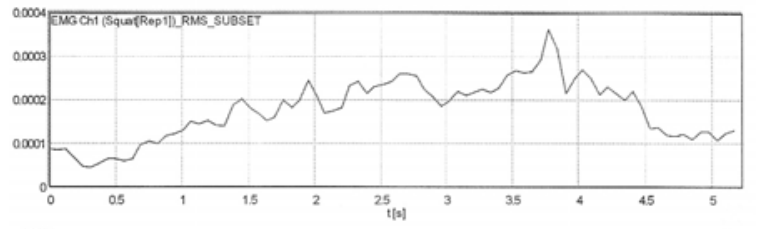

I

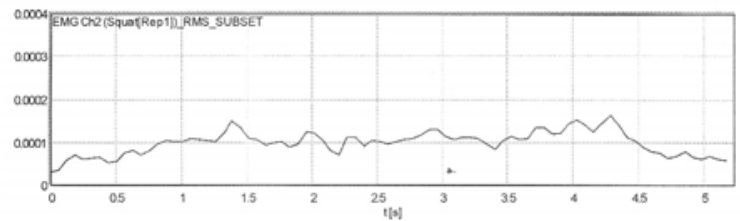

II

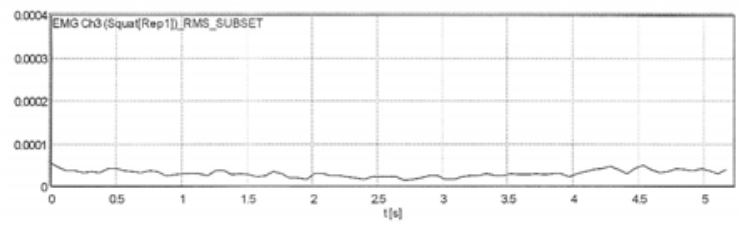

(b)
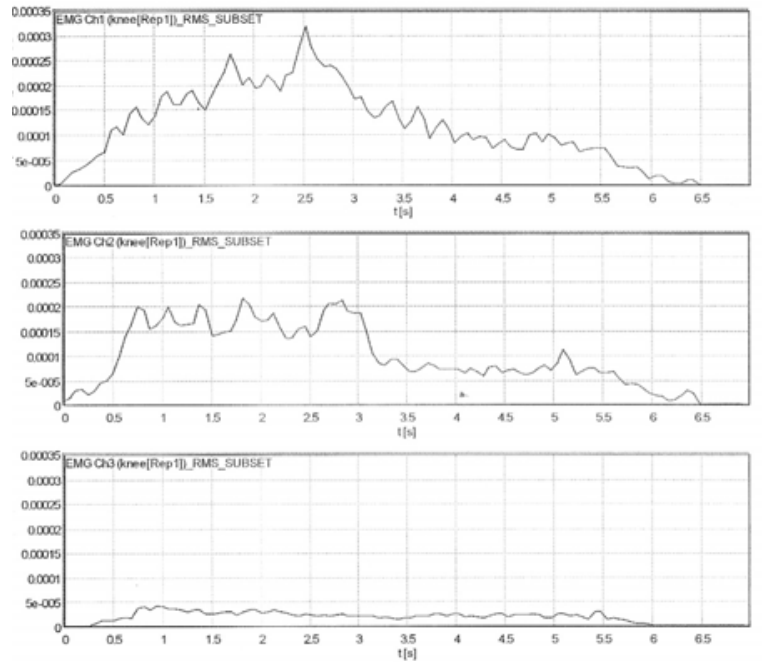

III

(c)
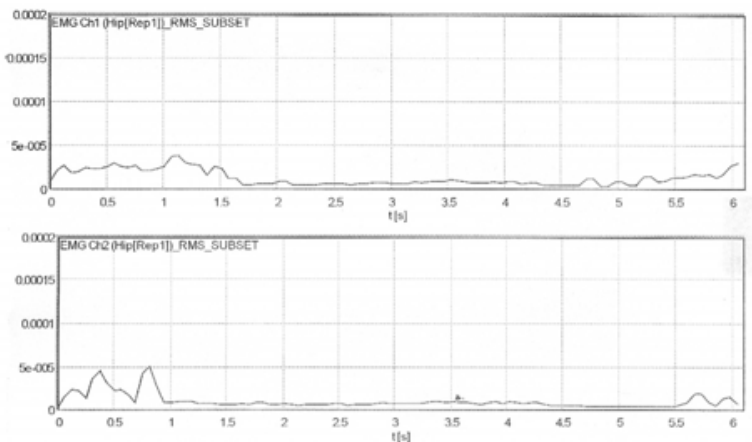

II

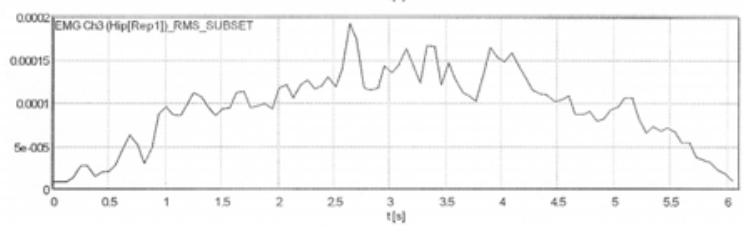

III

FIGURA 1 - Curva dos envoltórios lineares dos valores RMS (sujeito 3, exemplo) do M.reto da coxa (I), M.vasto lateral (II) e M.bíceps femoral (III) nos exercícios (a) agachamento, (b) extensão do joelho e (c) extensão do quadril.

\section{Conclusões}

Com base nestes resultados é possível inferir que a intensidade de ativação muscular do M.quadríceps femoral e dos isquiostibiais não difere entre os exercícios de CCA e CCF quando a carga máxima é utilizada para realização dos mesmos. Desta forma, parece ser 


\section{ANEXO II $\quad$ Estudo Piloto 1 (Cont.)}

adequado comparar os exercícios em CCA e CCF quando o programa de tratamento é baseado na utilização do mesmo percentual da carga máxima nos diferentes exercícios.

\section{Referências}

LEWEK, M; RUDOLPH, K.; AXE, M.; SNYDER-MACKLER, L. Tthe effect of insufficient quadriceps strength on gait after anterior cruciate ligament reconstruction. Clinical Biomechanics v.17, p.56-63, 2002

LIU, W.; MAITLAND, M. E. The effect of hamstring muscle compensation for anterior laxity in the ACL-deficient knee during gait. Journal of Biomechanics v.33, p.871-79, 2000. 


\section{ANEXO III $\quad$ Estudo Piloto 2}

Com o resultado do estudo piloto 1 pode-se confirmar a utilização do percentual de carga máxima para o período de tratamento dos pacientes. Com isto, uma nova questão precisava ser resolvida, se o paciente conseguiria realizar o teste de 1RM na avaliação précirúrgica.

\section{Objetivo}

O objetivo principal do estudo piloto 2 foi avaliar se o paciente no período précirúrgico era capaz de realizar o teste de 1RM para extensão do joelho, extensão do quadril e agachamento.

\section{Amostra}

A amostra foi constituída de um sujeito (idade 42 anos; estatura 1,80m; massa $79 \mathrm{~kg}$ ) com lesão do LCA que seria tratada por meio de reconstrução cirúrgica. O sujeito foi um voluntário recrutado entre os pacientes do grupo de ortopedia adulto do Instituto de Ortopedia e Traumatologia do Hospital das Clínicas da Universidade de São Paulo.

\section{3. $\quad$ Procedimentos}

O paciente realizou um aquecimento inicial em cicloergômetro e alongamento de membros inferiores. Ao término do aquecimento o paciente foi orientado para realização do teste de 1RM. O teste foi realizado para extensão do joelho, extensão do quadril e agachamento.

\section{4. $\quad$ Resultados}

A carga máxima alcançada pelo paciente ao realizar o teste de 1RM para cada exercício são mostradas na TABELA 1. A tabela também inclui estas mesmas cargas relativas aos sujeitos normais do estudo piloto 1 . 
ANEXO III

Estudo Piloto 2 (cont.)

TABELA 1 - Carga máxima do paciente e dos sujeitos normais para cada exercício.

\begin{tabular}{lccc}
\hline & $\begin{array}{c}\text { Extensão Joelho } \\
(\mathrm{kg})\end{array}$ & $\begin{array}{c}\text { Agachamento } \\
(\mathrm{kg})\end{array}$ & $\begin{array}{c}\text { Extensão do Quadril } \\
(\mathrm{kg})\end{array}$ \\
\hline Paciente & 60 & 80,0 & 30 \\
Sujeito 1 & 70 & 82,5 & 35 \\
Sujeito 2 & 70 & 142,5 & 30 \\
Sujeito 3 & 75 & 92,5 & 30 \\
Sujeito 4 & 70 & 92,5 & 30 \\
Sujeito 5 & 85 & 122,0 & 25 \\
\hline
\end{tabular}

5. Inferências

O paciente no período pré-cirúrgico foi capaz de realizar o teste de $1 \mathrm{RM}$, podendo este ser utilizado para estabelecer a carga de trabalho no período de tratamento pós-cirúrgico. E os valores de carga máxima obtidos são muito semelhantes aos valores dos sujeitos normais. 
O estudo piloto 3 foi realizado para testar o protocolo na esteira e ver o período mínimo pós-cirúrgico necessário para que o paciente fosse capaz de realizar o protocolo na esteira sem a necessidade de apoio.

Pela rotina médica do grupo de ortopedia adulto do Instituto de Ortopedia e Traumatologia da Faculdade de Medicina do Hospital das Clínicas da Universidade de São Paulo com três semanas pós-cirúrgica os pacientes retiram as muletas e passam a andar com apoio total sobre o membro inferior operado. Desta forma, o período mínimo considerado para realizar o primeiro teste pós-cirúrgico da marcha foi de 1 mês, com este período o paciente estaria andando há uma semana sem o uso das muletas e provavelmente seria apto a realizar o teste na esteira. Esta hipótese precisava ser confirmada para que o protocolo experimental fosse finalizado.

\section{Objetivos}

Um dos objetivos deste estudo piloto foi testar o protocolo de avaliação da marcha na esteira estabelecido para ser utilizado. E, avaliar se pacientes com 1 mês pós-cirúrgico eram capazes de executar o protocolo de avaliação da marcha na esteira.

Outro aspecto que se fez necessário avaliar neste estudo piloto foi como incluir no protocolo de coleta um equipamento que fornecesse informações a respeito da cinemática específica do joelho. Entre os recursos disponíveis no laboratório a opção para obter este tipo de informação seria a utilização do eletrogoniômetro. No entanto, a esteira Gaitway possui apenas 6 (seis) canais auxiliares que permitem que os dados sejam sincronizados com as informações provenientes das plataformas de força. Inicialmente, a previsão era utilizar estes canais com a aquisição do sinal EMG dos músculos M.vasto lateral, M.bíceps femoral e M.gastrocnêmio (cabeça lateral), e a aquisição seria bilateral para todos os músculos. Para poder incluir o eletrogoniômetro um dos músculos, em ambos os lados, deveria ser abandonado. A opção foi permanecer com o M.vasto lateral e o M.bíceps femoral por serem ambos considerados músculos motores primários dos movimentos de extensão e flexão do joelho, respectivamente e excluir o M.gastrocnêmio (cabeça lateral) por ser considerado motor secundário do movimento de flexão do joelho. 


\section{ANEXO IV Estudo Piloto 3 (cont.)}

Desta forma, outro objetivo foi avaliar se os dados provenientes do eletrogoniômetro trariam informações pertinentes que justificassem a sua inclusão no protocolo de testes.

\section{Amostra}

A amostra foi constituída de um sujeito (idade: 20 anos, estatura: 1,84m, massa: $61,6 \mathrm{~kg}$ ) com três semanas de cirurgia de reconstrução do LCA. O sujeito foi um voluntário recrutado entre os pacientes do grupo de ortopedia adulto do Instituto de Ortopedia e Traumatologia da Faculdade de Medicina do Hospital das Clínicas da Universidade de São Paulo.

\section{Procedimentos}

O paciente inicialmente realizou caminhada em piso fixo para, com o auxílio de um metrônomo, estabelecer a cadência da marcha do paciente neste tipo de piso. Este procedimento foi utilizado com o objetivo de reproduzir a mesma cadência da marcha em piso fixo quando o paciente realiza a caminhada na esteira, evitando assim uma alteração acentuada da marcha quando passa de piso fixo para a esteira.

Após este procedimento foram localizados os pontos de colocação dos eletrodos de superfície nos músculos M.vasto lateral e M.bíceps femoral, sendo estes monitorados do lado direito e esquerdo. Na seqüência a preparação da pele para colocação dos eletrodos foi realizada.

O próximo passo foi o posicionamento dos eletrogoniômetros direito e esquerdo para as informações da cinemática do joelho e, na seqüência, passou-se para a etapa de coleta de dados.

O paciente então realizou o protocolo de coleta de dados referente a marcha na esteira. Nesta etapa, o paciente passou pelo período de ajuste da velocidade, a velocidade foi sendo ajustada até atingir a cadência da marcha em piso fixo (89rpm), o valor correspondente de velocidade na esteira foi de $2,6 \mathrm{~km} / \mathrm{h}(88,6 \mathrm{rpm})$, sendo esta confortável para o paciente. Depois de ajustada a velocidade o paciente caminhou por 10 minutos na esteira como familiarização. Nos 5 minutos seguintes as coletas de dados relativas à marcha foram 


\section{ANEXO IV Estudo Piloto 3 (cont.)}

realizadas. Três coletas de 12 segundos cada foram realizadas no total: uma logo no início dos 5 minutos, outra com 2,5 minutos e a terceira ao final dos 5 minutos.

Nesta coleta os canais auxiliares foram utilizados pelos músculos M.vasto lateral e M.bíceps femoral monitorados do lado direito e esquerdo. Após o término desta coleta, os eletrodos relativos aos gastrocnêmios laterais foram retirados e substituídos pelos eletrogoniômetros direito e esquerdo.

\section{4. $\quad$ Resultados}

O protocolo de avaliação da marcha foi avaliado pela consistência do movimento durante as coletas. Ou seja, analisar se os 10 minutos de familiarização na esteira foram suficientes para produzir um movimento consistente durante a coleta dos dados da marcha. Para isto, foi utilizado o coeficiente de variação do tempo de apoio simples da perna direita e esquerda e do tempo de apoio duplo. Os coeficientes de variação são apresentados na TABELA 1.

TABELA 1 - Coeficiente de variação (CV) do apoio simples direito e esquerdo e apoio duplo.

\begin{tabular}{cccc}
\hline & Apoio Simples Direito & Apoio Simples Esquerdo & Apoio Duplo \\
\hline $\mathrm{CV}(\%)$ & 8,99 & 4,44 & 11,09 \\
\hline
\end{tabular}

O paciente demonstrou uma certa insegurança inicial em soltar as mãos do apoio, mas que foi eliminada com o tempo de permanência na esteira, sendo os 10 minutos suficientes para isso. Nenhuma referência à dor ou desconforto foi mencionada, além do que ele vinha sentindo para realizar a caminhada em piso fixo.

A partir do eletrogoniômetro foi possível obter informações interessantes em relação à cinemática do joelho. Entre elas, diferenças importantes nos ângulos de flexão máxima do joelho da fase de balanço (FIGURA 1). 


\section{ANEXO IV Estudo Piloto 3 (cont.)}

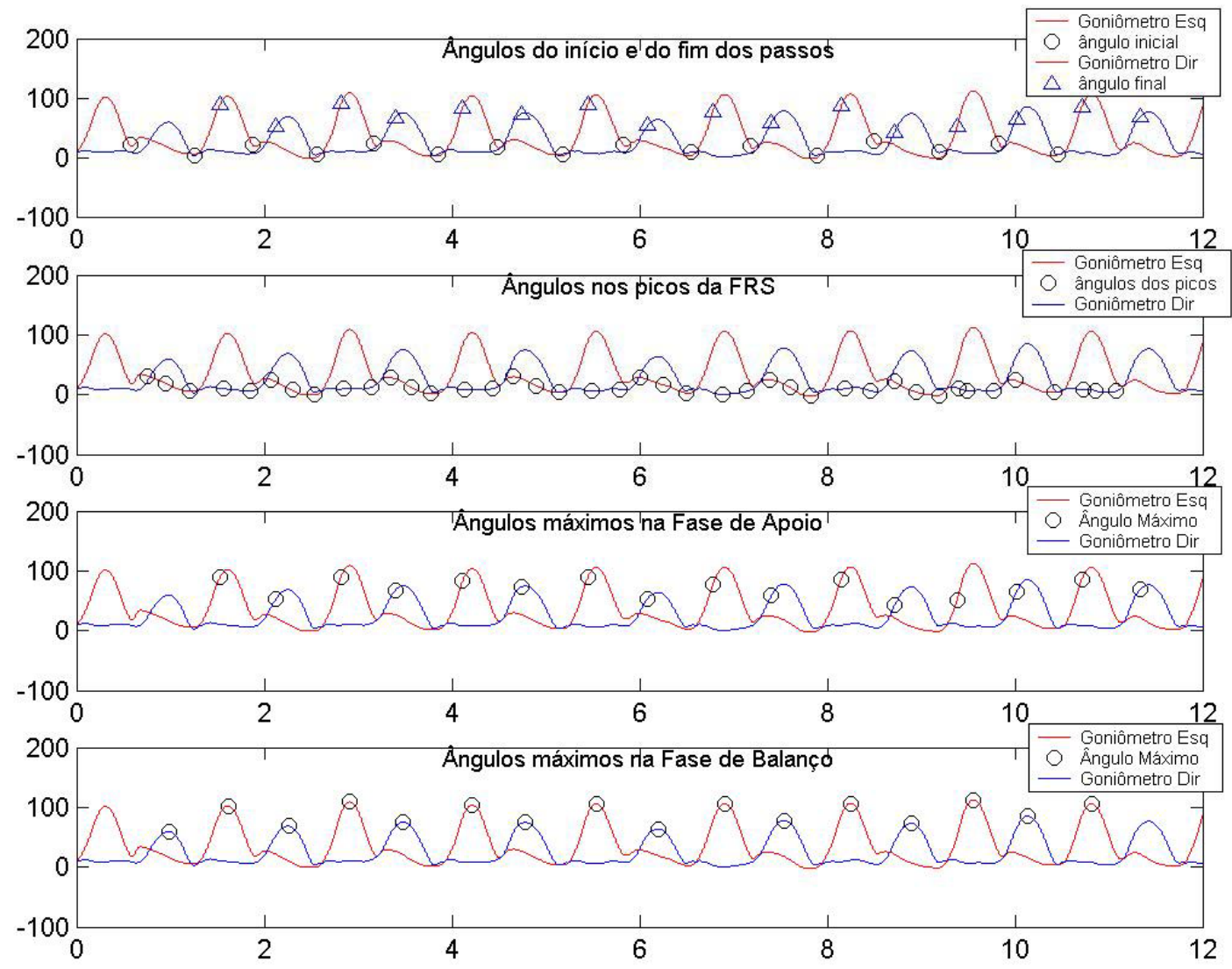

FIGURA 1 - Curvas da variação angular do joelho durante a marcha, com a determinação dos ângulos de início e fim do passo, dos ângulos nos picos da FRS e dos ângulos máximos de flexão na fase de apoio e na fase de balanço.

As informações relativas as forças de reação do solo e aos sinais eletromiográficos serão apresentados com o intuito, apenas, de ilustrar as informaçőes que poderão ser obtidas através deste protocolo de análise de marcha. A FIGURA 2 apresenta os dados relativos ao início e fim dos passos e aos picos da força de reação do solo e a FIGURA 3 apresenta os envoltórios lineares extraídos do sinal eletromiográfico dos músculos da perna operada. 
(a)

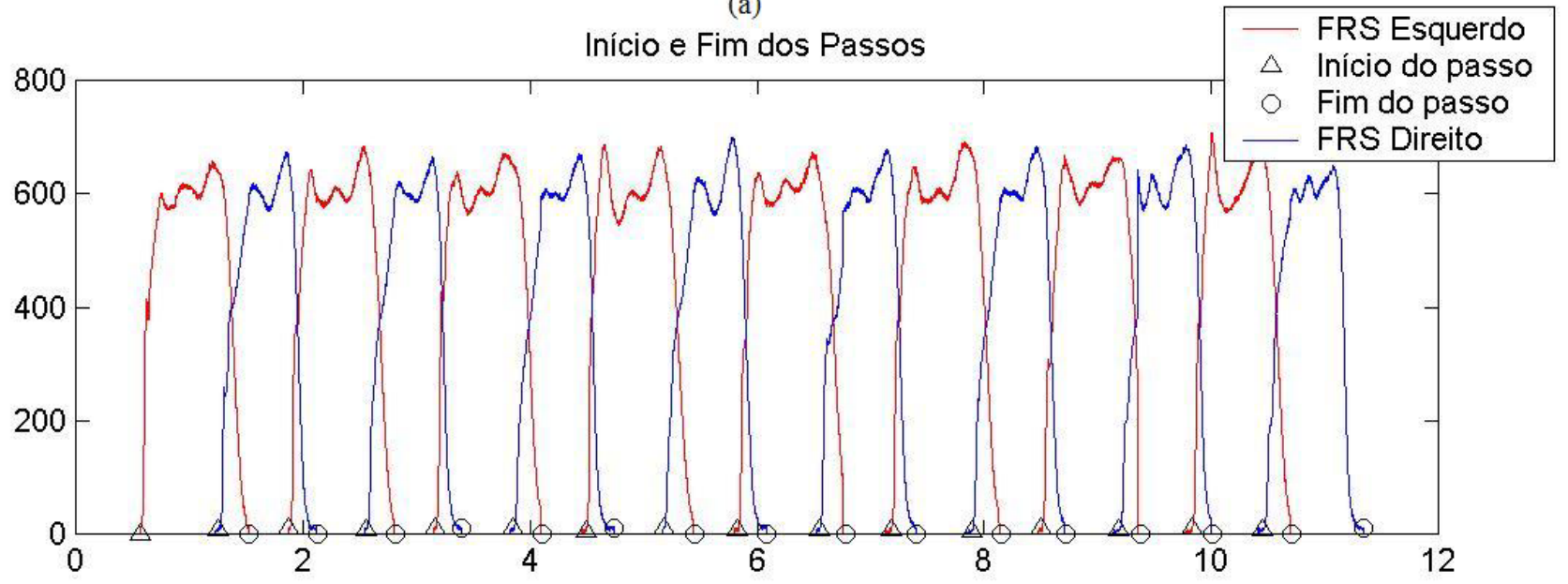

(b)

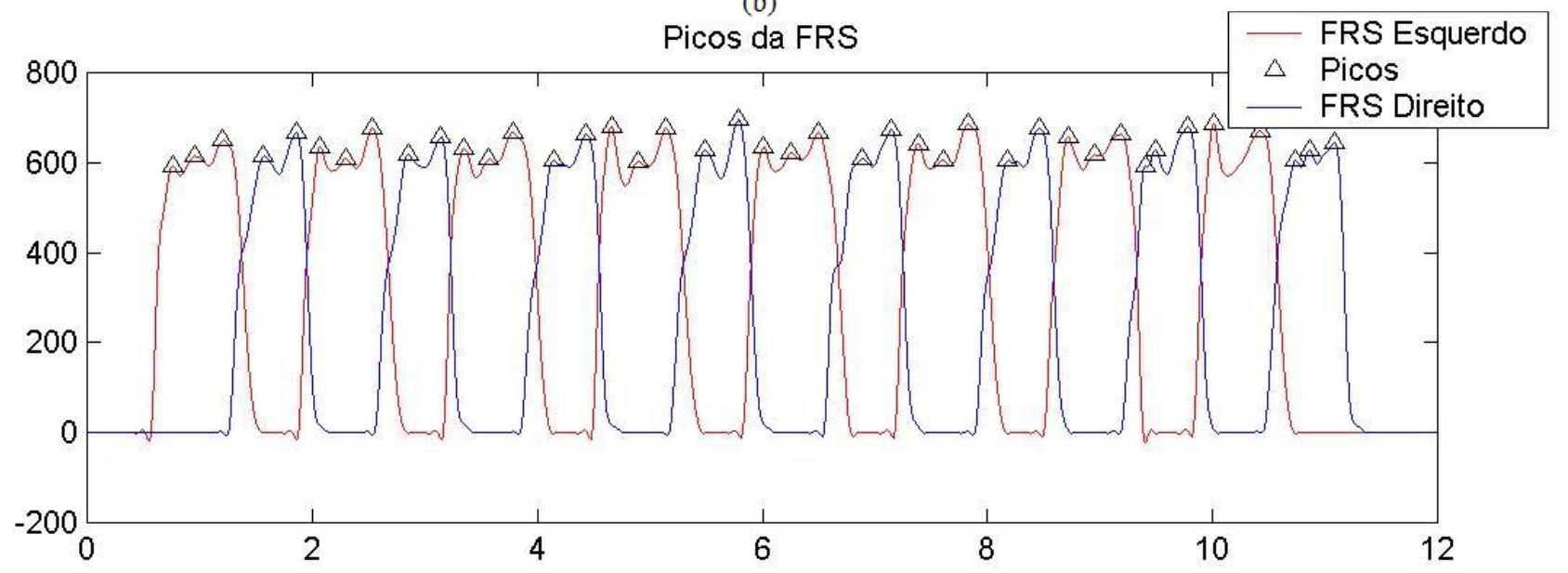

FIGURA 2 - Curvas da força reação do solo relativas às fases de apoio do pé esquerdo e direito. (a) início e fim dos passos e (b) picos da força de reação do solo. 


\section{ANEXO IV Estudo Piloto 3 (cont.)}
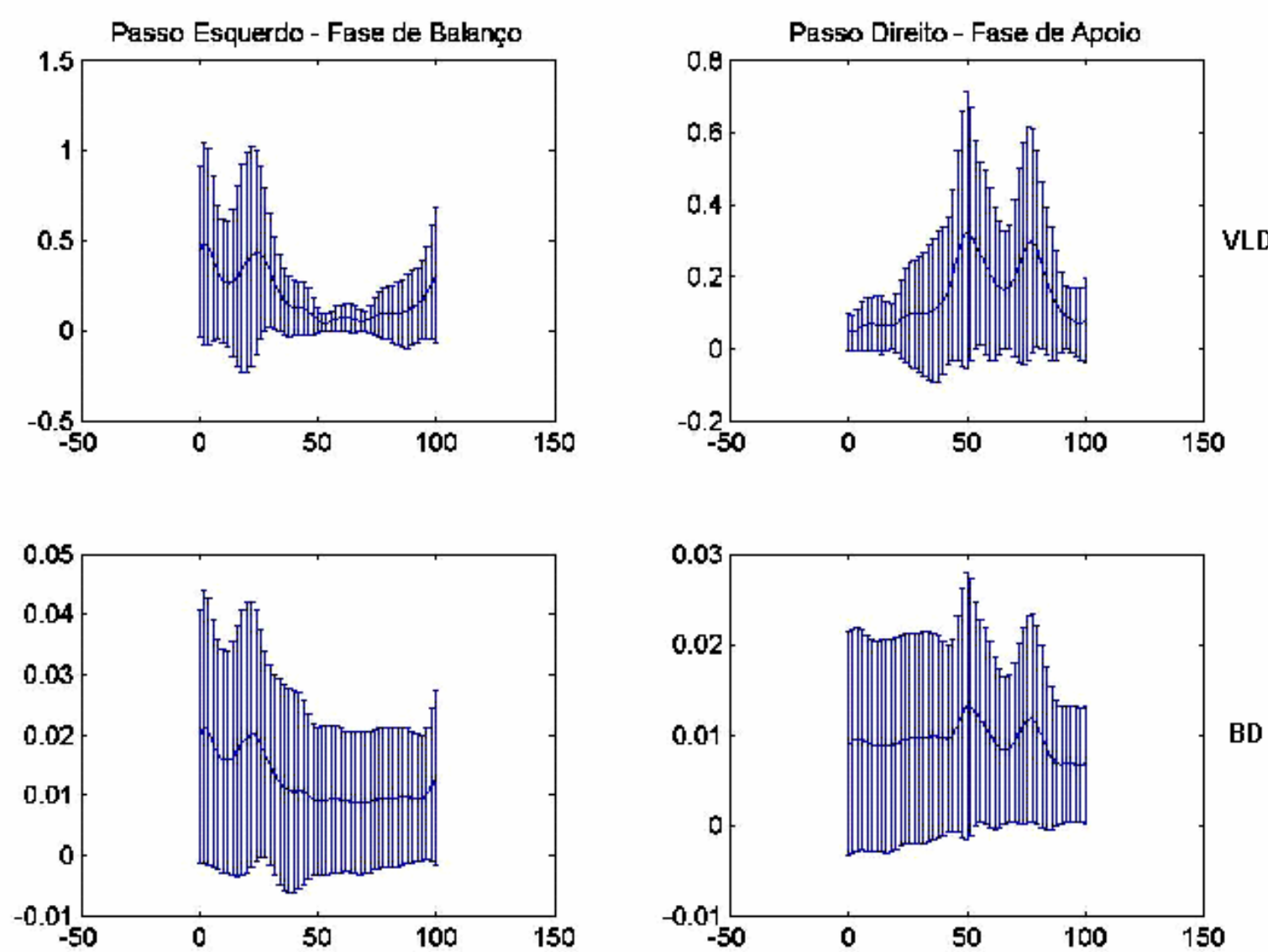

FIGURA 3 - Curvas dos envoltórios lineares do M.vasto lateral direito (VLD) e M.bíceps femoral direito (BD) durante a realização do passo esquerdo e direito.

\section{Inferências}

Em relação à avaliação na esteira, percebeu-se que a reprodução da cadência do piso fixo para esteira permite ao paciente sentir-se confortável na esteira. O período de familiarização de 10 minutos foi suficiente para adaptação do paciente à esteira e os 15 minutos totais permitem uma consistência nas coletas dos últimos 5 minutos, sendo este protocolo adequado para adquirir as informações desejadas.

$\mathrm{O}$ fato de o paciente ter conseguido realizar a marcha na esteira sem necessidade de nenhum tipo de apoio na $3^{\mathrm{a}}$ semana de pós-operatório assegura o fato de que é possível realizar o primeiro teste pós-cirúrgico com os pacientes com um mês pós-cirúrgico. 


\section{ANEXO IV Estudo Piloto 3 (cont.)}

A análise da coleta na esteira realizada com o eletrogoniômetro ofereceu informações importantes em relação às variações angulares do joelho, demonstrando-se de extrema importância esta informação. Estes dados permitiram assegurar a retirada do M.gastrocnêmio (cabeça lateral) para viabilizar a utilização do eletrogoniômetro em sincronia com as demais variáveis. 


\section{ANEXO V Escore de Lysholm}

Nome do Paciente:

Data:

\section{Escala de Avaliação Funcional do Joelho - Escore de Lysholm}

\section{CLAUDICAÇÃO (5 pontos)}

Nenhum $=5$

Levemente ou periodicamente $=3$

Severo e constante $=0$

SUPORTE ( 5 pontos)

Nenhum $=5$

Claudicante $=2$

Impossível descarga de peso $=0$

BLOQUEIO (15 pontos)

Nenhuma sensação de bloqueio ou crepitação = Sensação de "fisgada" mas sem sensação de Bloqueio ocasional $=6$

Freqüentemente $=2$

Bloqueio articular durante o exame $=0$

INSTABILIDADE (25 pontos)

Nunca apresentou falseio $=25$

Raramente durante atividades esportivas ou outros Freqüentemente durante ativ. esportivas ou outros Ocasionalmente nas atividades de vida diária Freqüentemente nas atividades de vida diária A todo passo $=0$

DOR (25 pontos)

Nenhum $=25$

Inconstante e leve durante esforços

Evidente durante esforços severos $=15$

Evidente ao andar $2 \mathrm{Km}$ ou mais (durante ou após)= 10

Evidente ao andar menos que $2 \mathrm{Km}$ (durante

Constante $=0$

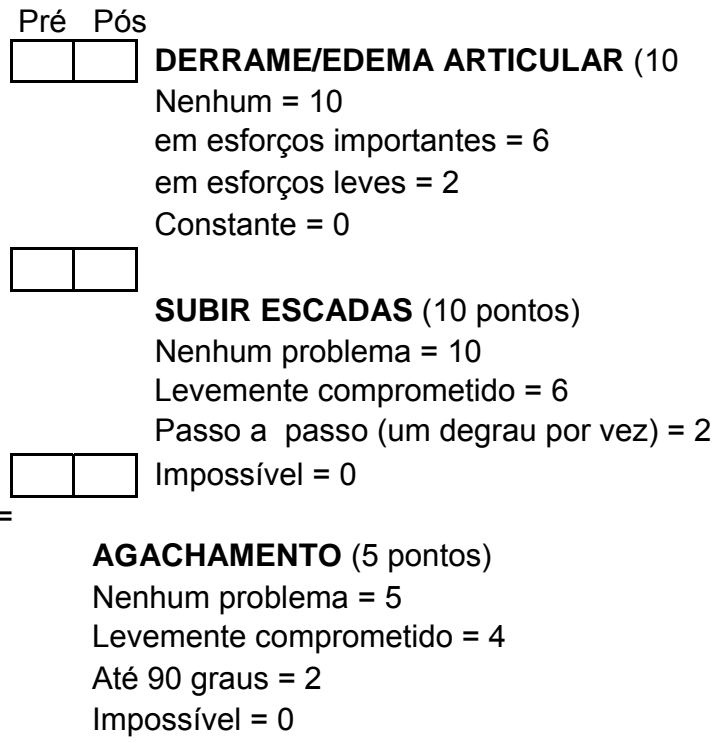

SUBIR ESCADAS (10 pontos)

Nenhum problema $=10$

Levemente comprometido $=6$

Passo a passo (um degrau por vez) $=2$

\begin{tabular}{|l|l|l}
\hline & \\
Impossível & $=0$
\end{tabular}

AGACHAMENTO (5 pontos)

Nenhum problema $=5$

Levemente comprometido $=4$

Até 90 graus $=2$

Impossível $=0$

Pré Pós
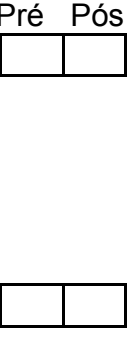

CONTAGEM TOTAL

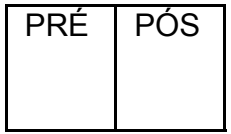

\begin{tabular}{l|l|l|}
\hline RESULTADO & PRÉ & PÓS \\
EXCELENTE: $91-100$ & & \\
BOM: $84-90$ & & \\
REGULAR: $65-83$ & & \\
RUIM: <Ou $=64$ & & \\
\hline
\end{tabular}




\section{ANEXO VI $\quad$ Rotina LCAemg}

function LCAemg

$\%$ Rotina para análise do sinal eletromiográfico durante coleta na esteira Gaitway

$\%$ Filtra os dados da eletromiografia

$\%$ Filtra os dados da FRS

$\%$ Determina o inicio e o fim dos passos

$\%$ Utiliza a funçao inifim

$\%$ Determina o envoltorio linear

\%Cláudia Silveira Lima

$\%$ maio 2005

\%\%\%\%\%\%\%\%\%\%\%\%\%\%\%\%\%\%\%\%\%\%\%\%\%\%\%\%\%\%\%\%\%\%\%\%\%\%\%

$\%$ Abrir os arquivos a serem trabalhados

\%\%\%\%\%\%\%\%\%\%\%\%\%\%\%\%\%\%\%\%\%\%\%\%\%\%\%\%\%\%\%\%\%\%\%\%\%\%\%

[filename, pathname] = uigetfiles('*.txt', 'Selecione os arquivos');

disp(' '), disp(' Abrindo os arquivos...')

nfile $=$ length(filename);

nlado=input('Entre com o joelho acometido: 1 para Dir; 2 para Esq: ');

npeso=input(' Entre com a massa do sujeito: ');

$\% \% \% \% \% \% \% \% \% \% \% \% \% \% \% \% \% \% \% \% \% \% \% \% \% \% \% \% \% \% \% \% \% \% \% \% \% \% \% \% \% \% \%$

\%Indica que a partir daqui todos os comandos devem ser refeitos para cada arquivo do sujeito

\%\% \% \% \% \% \% \% \% \% \% \% \% \% \% \% \% \% \% \% \% \% \% \% \% \% \% \% \% \% \% \% \% \% \% \% \% \% \% \% \% \% \%

for $\mathrm{i}=1:$ nfile

file $=$ char(filename(i));

data $=\operatorname{load}($ file)

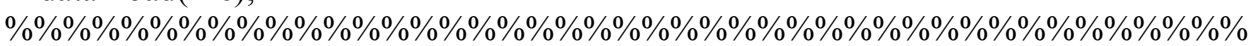

\%informações do que corresponde as colunas do arquivo txt (neste caso coluna $1,2,3,8,9$ )

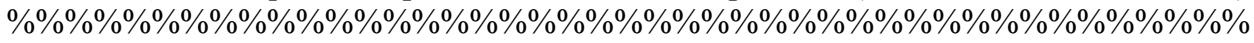

if nlado $==1$

$\mathrm{t}=\operatorname{data}(:, 1) ; \mathrm{Fesq}=\operatorname{data}(:, 2) ; \mathrm{Fdir}=\mathrm{data}(:, 3) ; \operatorname{Vastodir}=\mathrm{data}(:, 4) ; \operatorname{Bicepsdir}=\mathrm{data}(:, 5) ; \operatorname{Vastoesq}=\mathrm{data}(:, 6) ; \ldots$

Bicepsesq= $\operatorname{data}(:, 7) ; \operatorname{Goniodir}=\operatorname{data}(:, 8) ; \operatorname{Gonioesq}=\operatorname{data}(:, 9)$;

end

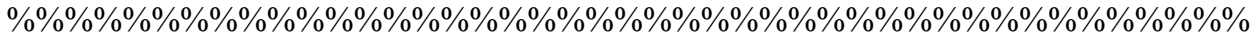

$\%$ Modificar os dados do sujeito que tem o joelho Esquerdo operado

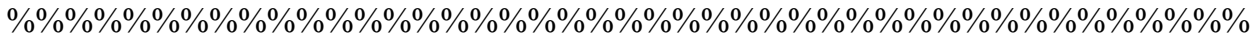

if nlado $==2$

$\mathrm{t}=\operatorname{data}(:, 1) ; \mathrm{Fesq}=\operatorname{data}(:, 3) ; \mathrm{Fdir}=\operatorname{data}(:, 2) ; \operatorname{Vastodir}=\mathrm{data}(:, 6) ; \operatorname{Bicepsdir}=\mathrm{data}(:, 7) ; \operatorname{Vastoesq}=\mathrm{data}(:, 4) ; \ldots$

Bicepsesq $=\operatorname{data}(:, 5) ; \operatorname{Goniodir}=\operatorname{data}(:, 9) ; \operatorname{Gonioesq}=\operatorname{data}(:, 8)$;

end

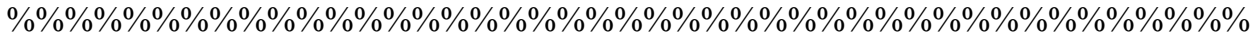

$\%$ passando o filtro de $100 \mathrm{~Hz}(10 \mathrm{~Hz})$ nos dados da FRS pé esquerdo e direito

\% \% \% \% \% \% \% \% \% \% \% \% \% \% \% \% \% \% \% \% \% \% \% \% \% \% \% \% \% \% \% \% \% \% \% \% \% \% \% \% \% \% \%

$[\mathrm{b}, \mathrm{a}]=\operatorname{butter}(4,10 /(1000 / 2))$;

FesqFil=filtfilt(b,a,Fesq);

FdirFil=filtfilt(b,a,Fdir);

\%criando o gráfico com os dados da FRS bruta e filtrado

figure

plot(t,FesqFil,'r',t,FdirFil,'b')

legend('FRS Esquerdo', 'FRS Direito')

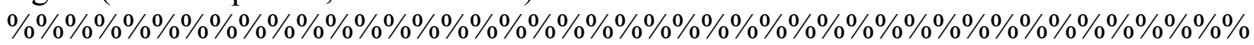

$\%$ Normalizando os dados da FRS pelo peso corporal de cada sujeito

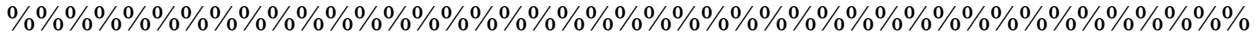

FesqFil $=($ FesqFil/(npeso*10));

FdirFil $=($ FdirFil/(npeso*10) $)$; 
ANEXO VI $\quad \underline{\text { Rotina LCAemg (cont.) }}$

\%\% $\% \% \% \% \% \% \% \% \% \% \% \% \% \% \% \% \% \% \% \% \% \% \% \% \% \% \% \% \% \% \% \% \% \% \% \% \% \% \% \% \%$

$\%$ Determinando o inicio e o fim do passo esquerdo e direito

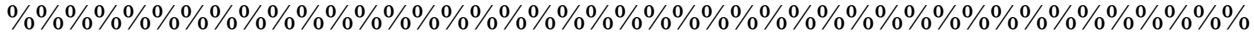

[iniesq,fimesq] $=$ inifim(FesqFil,1,0.07,250);

inifimesq=[iniesq;fimesq].';

[inidir,fimdir] = inifim(FdirFil,1,0.07,250);

inifimdir=[inidir;fimdir].';

figure \%gráfico com os dados da FRS filtrado com inicio e fim lado esquerdo e direito plot(t,FesqFil,'r',t(iniesq),FesqFil(iniesq),'^k',t(fimesq),FesqFil(fimesq),'ok',...

t,FdirFil,'b',t(inidir),FdirFil(inidir),'^k',t(fimdir),FdirFil(fimdir),'ok')

legend('FRS Esquerdo', 'Inicio do passo', 'Fim do passo','FRS Direito')

\%\% \% \% \% \% \% \% \% \% \% \% \% \% \% \% \% \% \% \% \% \% \% \% \% \% \% \% \% \% \% \% \% \% \% \% \% \% \% \% \% \% \% $\%$ passando filtro passa banda entre $20 \mathrm{~Hz}$ e $300 \mathrm{~Hz}$

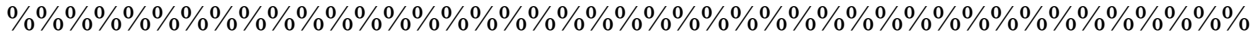
[b,a] $=$ butter $(2,[20300] /(1000 / 2))$;

VastodirFil=filtfilt(b,a,Vastodir);

BicepsdirFil=filtfilt(b,a,Bicepsdir);

VastoesqFil=filtfilt(b,a,Vastoesq);

BicepsesqFil=filtfilt(b,a,Bicepsesq);

\%\% \% \% \% \% \% \% \% \% \% \% \% \% \% \% \% \% \% \% \% \% \% \% \% \% \% \% \% \% \% \% \% \% \% \% \% \% \% \% \% \% \% \% $\%$ passando filtro rejeita banda entre $59.9 \mathrm{~Hz}$ e $60.1 \mathrm{~Hz}$

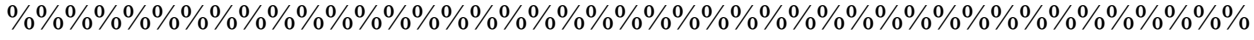
[b,a]=butter(4,[59.9 60.1]/(1000/2),'stop');

VastodirFil=filtfilt $(\mathrm{b}, \mathrm{a}$, VastodirFil);

BicepsdirFil=filtfilt(b,a,BicepsdirFil);

VastoesqFil=filtfilt(b,a,VastoesqFil);

BicepsesqFil=filtfilt(b,a,BicepsesqFil);

\%criando o gráfico com os dados EMG e EMG filtrado

figure

plot(t,Vastodir,'r',t,VastodirFil,'b')

legend('Vasto Direito')

figure

plot(t,Bicepsdir,'g',t,BicepsdirFil,'r')

legend('Biceps Direito')

figure

plot(t,Vastoesq,'r',t,VastoesqFil,'b')

legend('Vasto Esquerdo')

figure

plot(t,Bicepsesq,'g',t,BicepsesqFil,'r')

legend('Biceps Esquerdo')

$\% \% \% \% \% \% \% \% \% \% \% \% \% \% \% \% \% \% \% \% \% \% \%$

$\%$ Retificando o sinal EMG

$\% \% \% \% \% \% \% \% \% \% \% \% \% \% \% \% \% \% \% \% \% \% \% \%$

VastodirRet $=$ abs(VastodirFil);

BicepsdirRet=abs(BicepsdirFil);

VastoesqRet $=$ abs(VastoesqFil);

BicepsesqRet $=$ abs (BicepsesqFil);

\%\% \% \% \% \% \% \% \% \% \% \% \% \% \% \% \% \%

$\%$ Envoltório Linear

$\% \% \% \% \% \% \% \% \% \% \% \% \% \% \% \%$

$[\mathrm{b}, \mathrm{a}]=\operatorname{butter}(2,5 /(1000 / 2))$;

VastodirEl=filtfilt(b,a,VastodirRet);

BicepsdirEl=filtfilt(b,a,BicepsdirRet);

VastoesqEl=filtfilt(b,a,VastoesqRet); 


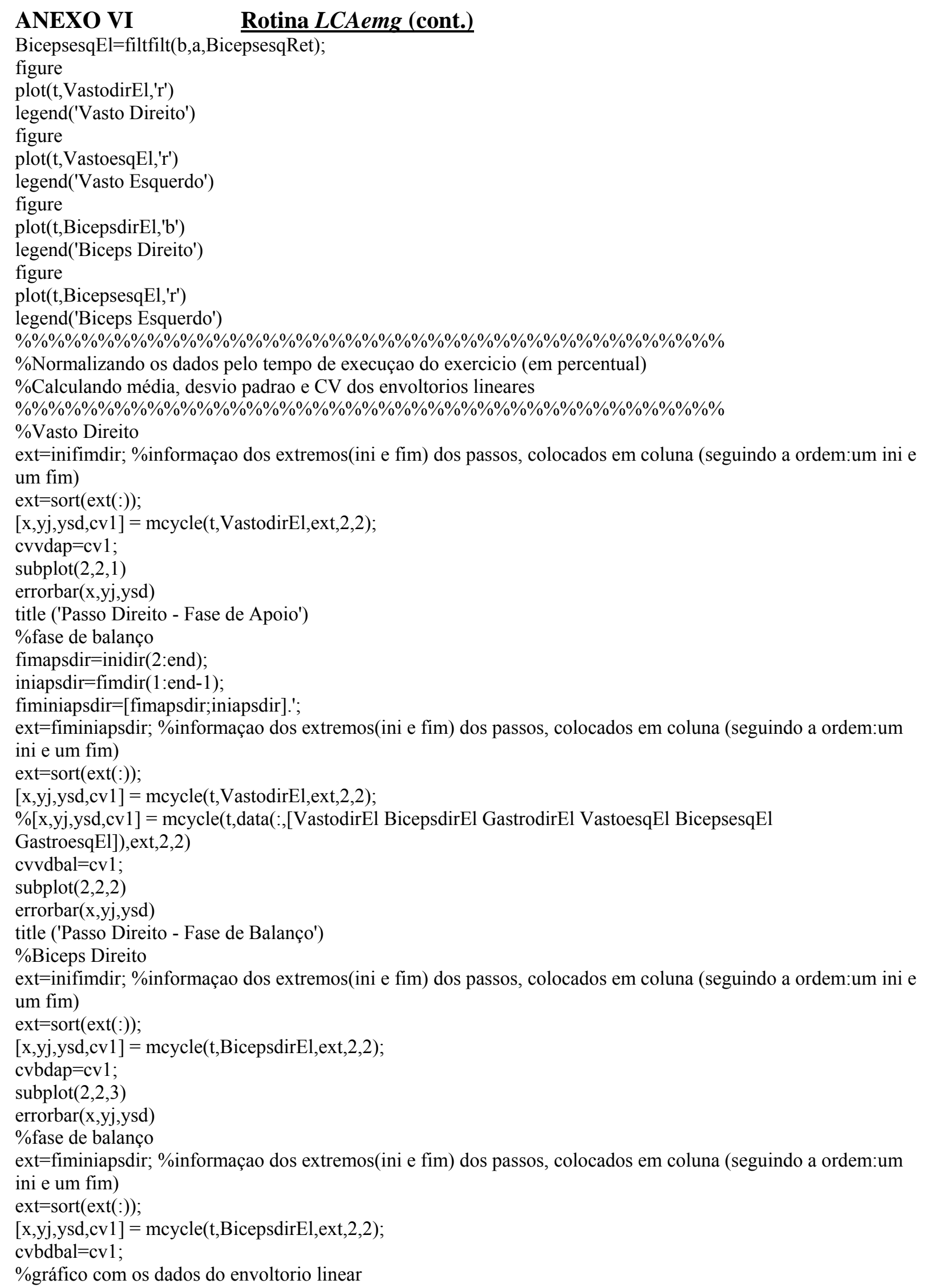




\section{ANEXO VI $\underline{\text { Rotina LCAemq (cont.) }}$}

$\operatorname{subplot}(2,2,4)$

errorbar(x,yj,ysd)

$\%$ Vasto Esquerdo

ext=inifimesq; \%informaçao dos extremos(ini e fim) dos passos, colocados em coluna (seguindo a ordem:um ini e um fim)

$\operatorname{ext}=\operatorname{sort}(\operatorname{ext}(:))$;

$[\mathrm{x}, \mathrm{yj}, \mathrm{ysd}, \mathrm{cv} 1]=\operatorname{mcycle}(\mathrm{t}$, VastoesqEl,ext $, 2,2)$;

$\%[\mathrm{x}, \mathrm{yj}, \mathrm{ysd}, \mathrm{cv} 1]=$ mcycle(t,data $(:,[$ VastodirEl BicepsdirEl GastrodirEl VastoesqEl BicepsesqEl

GastroesqEl]),ext,2,2)

cvveap $=$ cv1;

figure

$\operatorname{subplot}(2,2,1)$

errorbar(x,yj,ysd)

title ('Passo Esquerdo - Fase de Apoio')

$\%$ fase de balanço

fimapsesq=iniesq(2:end);

iniapsesq=fimesq( 1 :end- 1$)$;

fiminiapsesq=[fimapsesq;iniapsesq].';

ext=fiminiapsesq; \%informaçao dos extremos(ini e fim) dos passos, colocados em coluna (seguindo a ordem:um ini e um fim)

$\operatorname{ext}=\operatorname{sort}(\operatorname{ext}(:))$;

$[\mathrm{x}, \mathrm{yj}, \mathrm{ysd}, \mathrm{cv} 1]=\operatorname{mcycle}(\mathrm{t}, \mathrm{VastoesqEl}, \mathrm{ext}, 2,2)$;

cvvebal $=\mathrm{cv} 1$

$\%$ gráfico com os dados do envoltorio linear

$\operatorname{subplot}(2,2,2)$

errorbar(x,yj,ysd)

title ('Passo Esquerdo - Fase de Balanço')

$\%$ Biceps Esquerdo

ext=inifimesq; \%informaçao dos extremos(ini e fim) dos passos, colocados em coluna (seguindo a ordem:um ini e um fim)

$\operatorname{ext}=\operatorname{sort}(\operatorname{ext}(:))$

$[\mathrm{x}, \mathrm{yj}, \mathrm{ysd}, \mathrm{cvl}]=\operatorname{mcycle}(\mathrm{t}, \mathrm{BicepsesqEl}, \mathrm{ext}, 2,2)$;

cvbeap $=\mathrm{cv} 1$;

$\operatorname{subplot}(2,2,3)$

errorbar(x,yj,ysd)

$\%$ fase de balanço

ext=fiminiapsesq; \%informaçao dos extremos(ini e fim) dos passos, colocados em coluna (seguindo a ordem:um ini e um fim)

ext=sort(ext(:));

$[\mathrm{x}, \mathrm{yj}, \mathrm{ysd}, \mathrm{cv1}]=\operatorname{mcycle}(\mathrm{t}, \mathrm{BicepsesqEl}, \mathrm{ext}, 2,2)$;

cvbebal $=\mathrm{cv} 1$;

\%gráfico com os dados do envoltorio linear

subplot $(2,2,4)$

errorbar(x,yj,ysd)

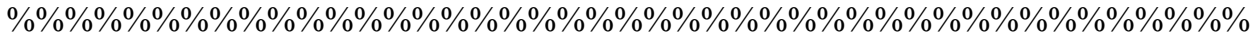

$\%$ Salvando os resultados da rotina no bar - coeficiente de variaçao

\%\%\%\%\%\%\%\%\%\%\%\%\%\%\%\%\%\%\%\%\%\%\%\%\%\%\%\%\%\%\%\%\%\%\%\%\%\%\%\%\%\%\%

file $b=[$ pathname,'resultados $\backslash$ ',char(file),'cvvdap.dat'];

disp(['Salvando ' char(file_b) ' !!'])

save(file_b ,'cvvdap','-ascii');

file $b=$ [pathname,'resultados $\backslash^{\prime}$, char(file),'cvvdbal.dat'];

disp(['Salvando ' char(file_b) ' !!'])

save(file_b ,'cvvdbal','-ascii');

file_b=[pathname,'resultados $\backslash$ ',char(file),'cvbdap.dat']; 
ANEXO VI

Rotina LCAemg (cont.)

disp(['Salvando ' char(file_b) ' !!'])

save(file_b ,'cvbdap','-ascii');

file_b=[pathname,'resultados $\backslash$ ',char(file),'cvbdbal.dat'];

disp(['Salvando ' char(file_b) ' !!'])

save(file_b ,'cvbdbal','-ascii');

file_b=[pathname,'resultados $\backslash$ ',char(file),'cvveap.dat'];

$\operatorname{disp}([$ 'Salvando ' char(file_b) ' !!'])

save(file b ,'cvveap','-ascii');

file_b=[pathname,'resultados $\backslash^{\prime}$, char(file),'cvvebal.dat'];

disp(['Salvando ' char(file_b) ' !!'])

save(file_b ,'cvvebal','-ascii');

file_b=[pathname,'resultados $1^{\prime}$, char(file),'cvbeap.dat'];

disp(['Salvando ' char(file_b) ' !!'])

save(file_b ,'cvbeap','-ascii');

file_b=[pathname,'resultados $\backslash^{\prime}$, char(file),'cvbebal.dat'];

disp(['Salvando ' char(file b) ' !!'])

save(file_b,'cvbebal','-ascii');

end 


\section{ANEXO VII $\quad$ Rotina LCAFRS}

function LCA

\%Rotina para análise do eletrogoniômetro associado a FRS na esteira Gaitway

$\%$ Filtra os dados do eletrogoniômetro

$\%$ Filtra os dados da FRS

$\%$ Determina o início e o fim dos passos

$\%$ Determina os ângulos do joelho no início e no fim dos passos

$\%$ Determina os picos da FRS

\%Determina os ângulos do joelho nos picos da FRS

\%Determina os ângulos máximos e mínimos do joelho na fase de apoio

\%Determina os ângulos máximos e mínimos do joelho na fase de balanço

\%Utiliza as funções inifim, picos e vales

\%Cláudia Silveira Lima

$\%$ maio 2005

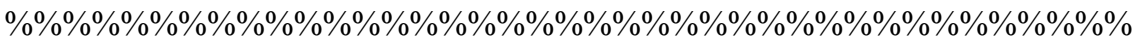

$\%$ Abrir os arquivos a serem trabalhados

\%\%\%\%\%\%\%\%\%\%\%\%\%\%\%\%\%\%\%\%\%\%\%\%\%\%\%\%\%\%\%\%\%\%\%\%\%\%\%

[filename, pathname] = uigetfiles('*.txt', 'Selecione os arquivos');

$\operatorname{disp}($ ' '), disp(' Abrindo os arquivos...')

nfile=length(filename);

nlado=input('Entre com o joelho acometido: 1 para Dir; 2 para Esq: ');

npeso $=$ input(' Entre com a massa do sujeito: ');

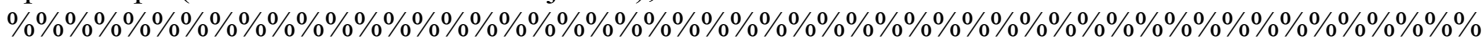

\%Indica que a partir daqui todos os comandos devem ser refeitos para cada arquivo do sujeito

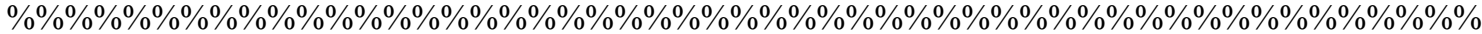

for $\mathrm{i}=1$ :nfile

file $=$ char(filename $(i))$;

data $=$ load(file);

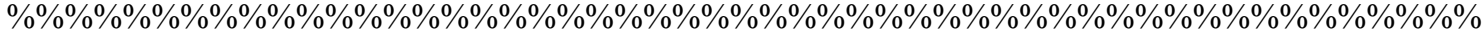

\%informações do que corresponde as colunas do arquivo txt (neste caso coluna $1,2,3,8,9$ )

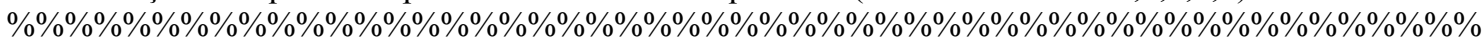

if nlado==1

$\mathrm{t}=\operatorname{data}(:, 1) ; \mathrm{Fesq}=\operatorname{data}(:, 2) ; \mathrm{Fdir}=\operatorname{data}(:, 3) ; \operatorname{Goniodir}=\operatorname{data}(:, 8) ; \operatorname{Gonioesq}=\operatorname{data}(:, 9)$;

end

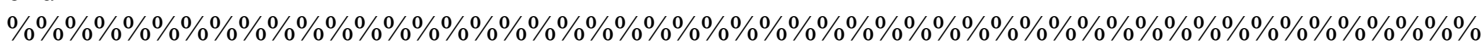

$\%$ Modificar os dados do sujeito que tem o joelho Esquerdo operado

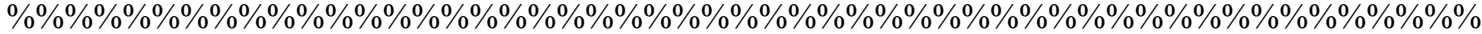

if nlado $==2$

$\mathrm{t}=\operatorname{data}(:, 1) ; \mathrm{Fesq}=\operatorname{data}(:, 3) ; \mathrm{Fdir}=\operatorname{data}(:, 2) ; \operatorname{Goniodir}=\operatorname{data}(:, 9) ; \operatorname{Gonioesq}=\mathrm{data}(:, 8)$;

end

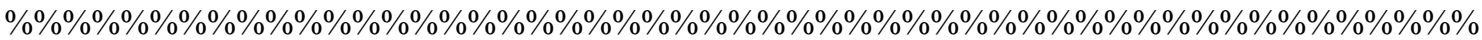
$\%$ passando o filtro de $100 \mathrm{~Hz}(10 \mathrm{~Hz})$ nos dados da FRS pé esquerdo e direito

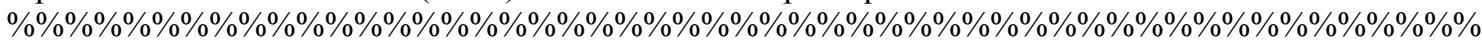
$[\mathrm{b}, \mathrm{a}]=\operatorname{butter}(4,10 /(1000 / 2))$;

FesqFil=filtfilt(b,a,Fesq);

FdirFil=filtfilt(b,a,Fdir);

\%criando o gráfico com os dados da FRS filtrado

figure

plot(t,FesqFil,'r',t,FdirFil,'b')

legend('FRS Esquerdo', 'FRS Direito')

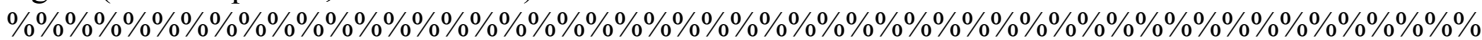
$\%$ Normalizando os dados da FRS pelo peso corporal de cada sujeito

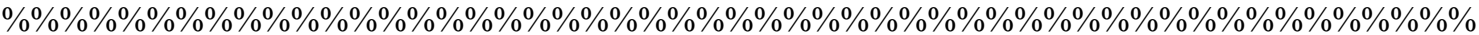




\section{ANEXO VII Rotina LCAFRS (cont.)}

FesqFil $=($ FesqFil $/($ npeso*10) $)$;

FdirFil $=($ FdirFil $/($ npeso*10) $)$;

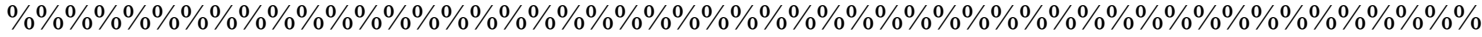

$\%$ Determinando o início e o fim do passo esquerdo e direito

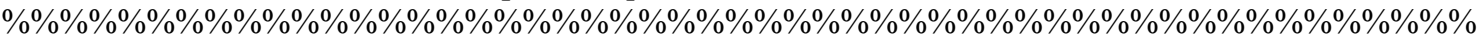

[iniesq,fimesq] = inifim(FesqFil,1,0.07,250);

inifimesq=[iniesq;fimesq].';\%assim os valores de ini e fim aparecem como a primeira coluna os ini e a segunda coluna os fim

$\%$ figure \%gráfico com os dados da FRS filtrado com início e fim lado esquerdo

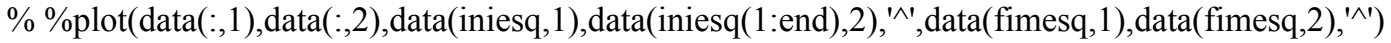

$\%$ plot(t,FesqFil,t(iniesq),FesqFil(iniesq), ${ }^{\prime \wedge}$, ,t(fimesq),FesqFil(fimesq), ${ }^{\prime{ }^{\prime}}$ )

$\%$ legend('FRS Esquerdo', 'Início do passo', 'Fim do passo')

[inidir,fimdir] = inifim(FdirFil, 1,0.07,250);

inifimdir=[inidir;fimdir].';\%assim os valores de ini e fim aparecem como a primeira coluna os ini e a segunda

coluna os fim

figure

plot(t,FesqFil,t(iniesq),FesqFil(iniesq), ${ }^{\prime \wedge}$, ,t(fimesq),FesqFil(fimesq), ${ }^{\prime \wedge}$, ,t,FdirFil,t(inidir),FdirFil(inidir), ${ }^{\prime \wedge \prime}, t($ fimdir)

,FdirFil(fimdir), ${ }^{\wedge}{ }^{\prime}$ )

legend('FRS Esquerdo','Início do passo','Fim do passo','FRS Direito','Início do passo','Fim do passo')

$\% \% \% \% \% \% \% \% \% \% \% \% \% \% \% \% \% \% \% \% \% \% \% \% \% \% \% \% \% \% \% \% \% \% \% \% \% \% \% \% \% \% \% \%$

$\%$ Determinando picos da FRS esquerda e direita

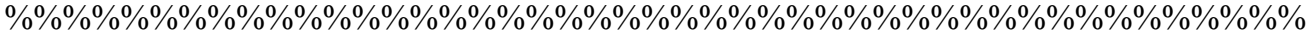

[picosesq] $=$ picos(FesqFil, 1,0.7,200); \%function picos, considerando FRS normalizada pelo peso

$\%[$ picosesq $]=\operatorname{picos}($ FesqFil, 1,560,90); \%function picos, sem normalizar pelo peso

figure \%gráfico com os dados da FRS filtrados e normalizados com os picos lado esquerdo

plot(t,FesqFil,t(picosesq),FesqFil(picosesq), ${ }^{\prime \prime}$ ')

legend('FRS Esq Filt', 'Picos')

[picosdir] $=\operatorname{picos}($ FdirFil, 1,0.7,200);\% function picos, considerando FRS normalizada pelo peso

$\%[$ picosdir] $=$ picos $($ FdirFil $1,560,90) ; \%$ function picos, sem normalizar pelo peso

figure \%gráfico com os dados da FRS filtrados e normalizados com os picos lado esquerdo

plot(t,FdirFil,t(picosdir),FdirFil(picosdir), ${ }^{\wedge}{ }^{\prime}$ )

legend('FRS Dir Filt', 'Picos')

$\mathrm{pd}=$ FdirFil(picosdir); \%cria a variavel pd como os valores dos picos dos passos direitos pe $=$ FesqFil(picosesq); \%cria a variavel pe como os valores dos picos dos passos esquerdos

fyldir $=\operatorname{pd}(1: 2:$ end $)$;

fylesq=pe(1:2:end);

fy 2 dir $=p d(2: 2:$ end $)$

fy 2 esq $=$ pe $(2: 2:$ end $)$;

tfyldir $=\mathrm{t}($ picosdir(1:2:end) $)$ - $\mathrm{t}($ inidir $) ; \%$ determina os tempos para os primeiros picos $\mathrm{D}$ tfy2dir $=t$ (picosdir(2:2:end))-t(inidir);\%determina os tempos para os segundos picos D tfylesq $=\mathrm{t}($ picosesq $(1: 2$ :end $))-\mathrm{t}($ iniesq $) ; \%$ determina os tempos para os primeiros picos $\mathrm{E}$ tfy2esq $=\mathrm{t}($ picosesq $(2: 2:$ end $))$ - $\mathrm{t}($ iniesq $) ; \%$ determina os tempos para os segundos picos $\mathrm{E}$

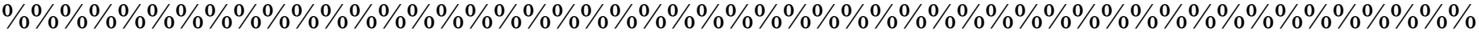
$\%$ Fazendo a media dos picos 1 , media dos picos 2 , media do tempo para pico $1 \mathrm{e}$ $\%$ media tempo para pico 2 para passos D e E de cada tentativa (arquivo)

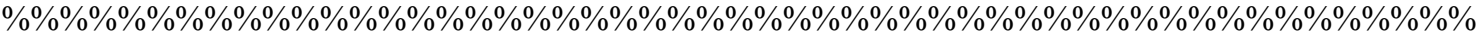
mfyldir $=$ mean(pd(1:2:end $))$; mfy 2 dir $=$ mean $(\operatorname{pd}(2: 2:$ end $))$; mfylesq $=\operatorname{mean}(\operatorname{pe}(1: 2:$ end $)$; mfy2esq=mean $($ pe $(2: 2:$ end $))$; 


\section{ANEXO VII Rotina LCAFRS (cont.)}

mtfyldir=mean(tfyldir);

mtfy2dir=mean(tfy2dir);

mtfylesq=mean $($ tfylesq);

mtfy2esq $=$ mean (tfy2esq);

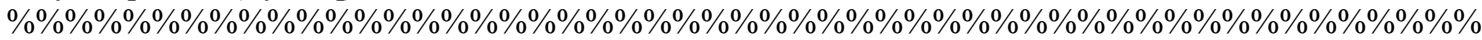

$\%$ Indice de simetria do primeiro e segundo pico da FRS

$\%$ e dos tempos para o primeiro e segundo pico

$\%$ Media dos indices de simetria de todos os passos

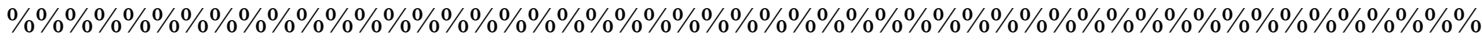

[simefy1] $=\operatorname{sime}($ fy 1 dir, 1, fy 1 esq, 1$)$;

[simefy2] $=\operatorname{sime}($ fy 2 dir, 1, fy2esq, 1$)$;

msimefy $1=$ mean $($ simefy 1$)$;

msimefy $2=$ mean $($ simefy 2$)$;

[simetfy 1$]=\operatorname{sime}($ tfy 1 dir, 1, tfy 1 esq, 1$)$;

[simetfy2] $=$ sime $($ tfy2dir, 1, tfy2esq, 1$)$;

msimetfy $1=$ mean $($ simetfy 1$)$;

msimetfy2 $=$ mean (

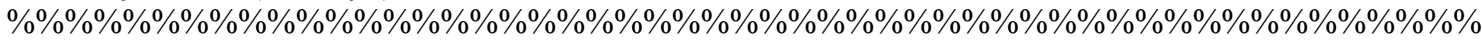

$\%$ Determinando os vales (Fmin) da FRS esquerda e direita

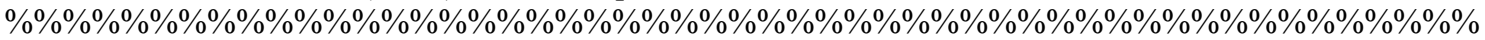

[valesesq] = vales(FesqFil,1,0.2,250);\%funçao vales, considerando FRS normalizada pelo peso

figure \%gráfico com os dados da FRS filtrados e normalizados com os vales lado esquerdo

plot(t,FesqFil,t(valesesq),FesqFil(valesesq), ${ }^{\prime \wedge \prime}$ )

legend('FRS Esq Filt', 'Vales')

[valesdir] = vales(FdirFil,1,0.2,250);\%function vales, considerando FRS normalizada pelo peso

figure \%gráfico com os dados da FRS filtrados e normalizados com os vales lado direito

plot(t,FdirFil,t(valesdir),FdirFil(valesdir), ${ }^{\prime \wedge}$ )

legend('FRS Dir Filt', 'Vales')

$\mathrm{vd}=$ FdirFil(valesdir);\%cria a variavel vd como os valores dos vales dos passos direitos

ve $=$ FesqFil(valesesq);\% cria a variavel ve como os valores dos vales dos passos esquerdos

tvdir $=\mathrm{t}$ (valesdir)-t(inidir);\%determina os tempos para os vales $\mathrm{D}$

tvesq $=\mathrm{t}($ valesesq)-t(iniesq); $\%$ determina os tempos para os vales $\mathrm{E}$

\%\% \% \% \% \% \% \% \% \% \% \% \% \% \% \% \% \% \% \% \% \% \% \% \% \% \% \% \% \% \% \% \% \% \% \% \% \% \% \% \% \% \% \% \% \% \% \% \% \% $\%$

$\%$ Fazendo a media dos vales e a media do tempo para os vales

$\%$ para passos D e E de cada tentativa (arquivo)

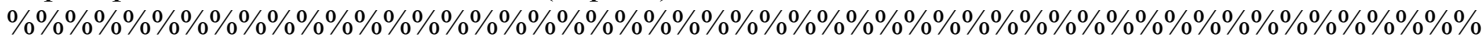
mvdir $=$ mean $(\mathrm{vd})$;

mvesq $=$ mean $(\mathrm{ve})$;

mtvdir=mean(tvdir);

mtvesq $=$ mean(tvesq);

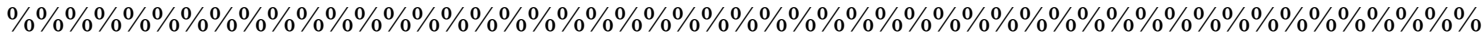

$\%$ Indice de simetria dos vales e do tempo para o vale

$\%$ Media dos indices de simetria de todos os passos

\% $\%$ \% $\% \% \% \% \% \% \% \% \% \% \% \% \% \% \% \% \% \% \% \% \% \% \% \% \% \% \% \% \% \% \% \% \% \% \% \% \% \% \% \% \% \% \% \% \% \% \% \% \% \%$

$[$ simev $]=\operatorname{sime}(\mathrm{vd}, 1, \mathrm{ve}, 1)$

msimev $=$ mean (simev);

$[$ simetv $]=$ sime $($ tvdir, 1, tvesq, 1$)$;

msimetv $=$ mean $($ simetv $)$; 
ANEXO VII $\quad$ Rotina LCAFRS (cont.)

$\% \% \% \% \% \% \% \% \% \% \% \% \% \% \% \% \% \% \% \% \% \% \% \% \% \% \% \% \% \% \% \% \% \% \% \% \% \% \% \% \% \% \% \% \% \% \% \% \% \% \%$

$\%$ Calculando as taxas de crescimento de Fy1 e Fy2 e de deflexao da Fymin

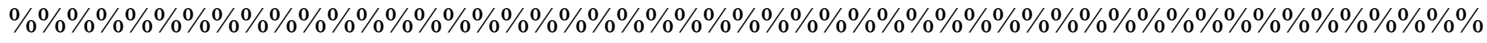

txcfyldir=fyldir./tfyldir;

txcfy 1 esq=fylesq./tfy 1 esq;

txcfy2dir=(fy2dir-vd)./(t(picosdir(2:2:end $))-\mathrm{t}($ valesdir $))$;

txcfy2esq=(fy2esq-ve)./(t(picosesq(2:2:end) $)-\mathrm{t}($ valesesq $))$;

dfydir $=($ fyldir-vd $) . /(t($ valesdir $)-t($ picosdir( $1: 2:$ end $)))$;

dfyesq $=($ fylesq-ve $) . /(t($ valesesq $)-t($ picosesq $(1: 2:$ end $))$;

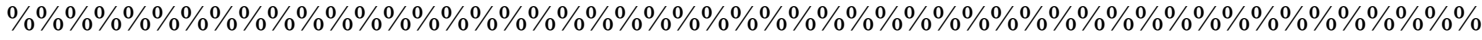

\%Interpolando os dados da Força Vertical: apoio de $0 \%$ a $100 \%$

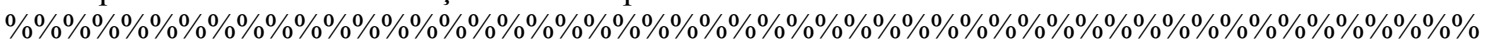

$\%$ Força vertical passo direito

ext=inifimdir; \%informaçao dos extremos(ini e fim) dos passos, colocados em coluna (seguindo a ordem:um ini e um fim)

$\operatorname{ext}=\operatorname{sort}(\operatorname{ext}(:))$;

$[\mathrm{x}, \mathrm{yj}, \mathrm{ysd}, \mathrm{cv} 1]=$ mcycle(t,FdirFil,ext,2,2); \%O x eh a media do tempo e o yj a media da força, o ysd eh o desvio padrao e o cv1 eh o coeficiente de variaçao de todos os passos de 1 tentativa de 1 sujaito.

figure

errorbar(x,yj,ysd)

legend('Força Vertical Passo direito')

mfdir $=[\mathrm{yj}]$;

$\%$ Força vertical passo esquerdo

ext=inifimesq; \%informaçao dos extremos(ini e fim) dos passos, colocados em coluna (seguindo a ordem:um ini e um fim)

$\operatorname{ext}=\operatorname{sort}(\operatorname{ext}(:))$

$[\mathrm{x}, \mathrm{yj}, \mathrm{ysd}, \mathrm{cv} 1]=\operatorname{mcycle}(\mathrm{t}, \mathrm{FesqFil}, \mathrm{ext}, 2,2)$;

figure

errorbar(x,yj,ysd)

legend('Força Vertical Passo Esquerdo')

mfesq $=[\mathrm{yj}]$

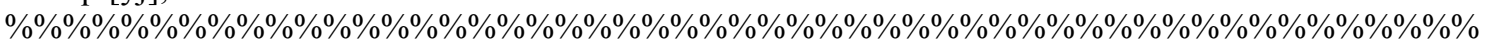

\% Transformando os dados do eletrogoniômetro de volts para graus de acordo com a calibração

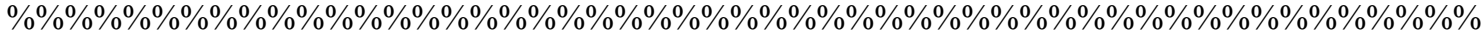

Gonioesq $=(90 *$ Gonioesq $) /(-3.2882)$;

Goniodir $=(90 *$ Goniodir $) /(-3.2882)$;

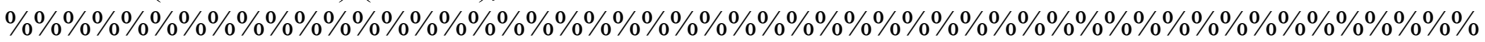

$\%$ passando o filtro passabaixa de $40 \mathrm{~Hz}$ nos dados do eletrogoniômetro do lado esquerdo e direito

\%\% \% \% \% \% \% \% \% \% \% \% \% \% \% \% \% \% \% \% \% \% \% \% \% \% \% \% \% \% \% \% \% \% \% \% \% \% \% \% \% \% \% \% \% \% \% \% \% \%

$[\mathrm{b}, \mathrm{a}]=\operatorname{butter}(2,40 /(1000 / 2))$;

GonioesqFil=filtfilt(b,a,Gonioesq);

GoniodirFil=filtfilt(b,a,Goniodir);

\%criando o gráfico com os dados do eletrogoniômetro filtrado

figure

plot(t,GoniodirFil,'r',t,GonioesqFil,'b')

legend('Goniômetro Direito', 'Goniômetro Esquerdo')

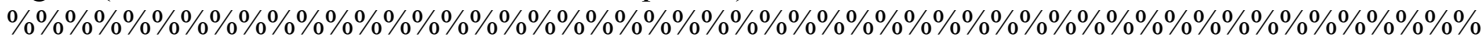

\%Interpolando os dados do Eletrogoniometro: apoio de $0 \%$ a $100 \%$

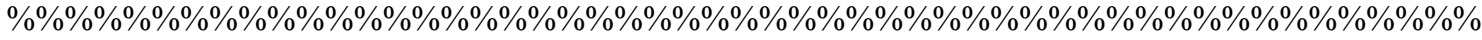

$\%$ Eletrogoniometro passo direito

ext=inifimdir; \%informaçao dos extremos(ini e fim) dos passos, colocados em coluna (seguindo a ordem:um ini e um fim)

$\operatorname{ext}=\operatorname{sort}(\operatorname{ext}(:))$;

$[\mathrm{x}, \mathrm{yj}, \mathrm{ysd}, \mathrm{cv} 1]=\operatorname{mcycle}(\mathrm{t}$, GoniodirFil,ext 2,2$)$; 
ANEXO VII

\section{Rotina LCAFRS (cont.)}

cvgdpd=cv1;

figure

errorbar(x,yj,ysd)

legend('Eletrogoniometro Passo direito')

$\%$ Eletrogoniometro passo esquerdo

ext=inifimesq; \%informaçao dos extremos(ini e fim) dos passos, colocados em coluna (seguindo a ordem:um ini e um fim)

$\operatorname{ext}=\operatorname{sort}(\operatorname{ext}(:))$;

$[\mathrm{x}, \mathrm{yj}, \mathrm{ysd}, \mathrm{cv} 1]=\operatorname{mcycle}(\mathrm{t}$, GonioesqFil,ext,2,2);

cvgepe $=$ cv1;

figure

errorbar(x,yj,ysd)

legend('Eletrogoniometro Passo Esquerdo')

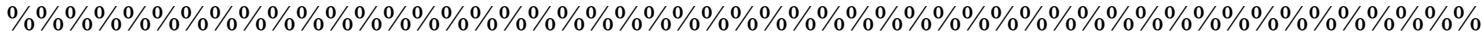

$\%$ Determinando os ângulos máximos (flexão) da fase de apoio dos passos esquerdos

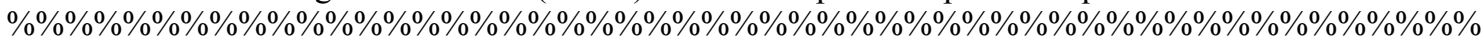

for $\mathrm{i}=1$ :length(iniesq)

[maxi,ind $]=\max ($ GonioesqFil(iniesq(i):fimesq(i)));

goniomaxesq(i) $=$ ind + iniesq(i) -1 ;

end

goniomaxE $=$ GonioesqFil(goniomaxesq);

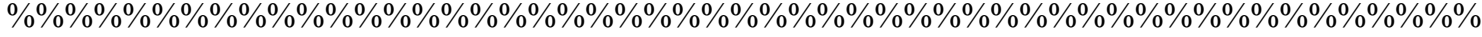

$\%$ Determinando os ângulos máximos (flexão) da fase de apoio dos passos direitos

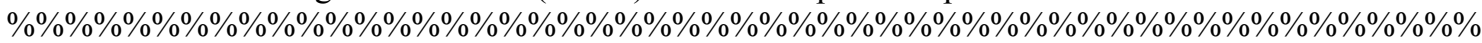

for $\mathrm{i}=1$ :length(inidir)

$[$ maxi,ind $]=\max ($ GoniodirFil(inidir(i):fimdir(i)));

goniomaxdir(i) $=$ ind $+\operatorname{inidir}(i)-1$

end

goniomaxD=GoniodirFil(goniomaxdir);

\%gráfico com os ângulos máximos da fase de apoio dos passos esquerdos e direitos

figure

plot(t,GonioesqFil,'c',t(goniomaxesq), GonioesqFil(goniomaxesq),'ro')

legend('Goniômetro Esq Filt', 'Ângulo Maximo Esq')

title ('Fase de Apoio')

figure

plot(t,GoniodirFil,'g',t(goniomaxdir),GoniodirFil(goniomaxdir),'bo')

legend('Goniômetro Dir Filt', 'Ângulo Máximo Dir')

title ('Fase de Apoio')

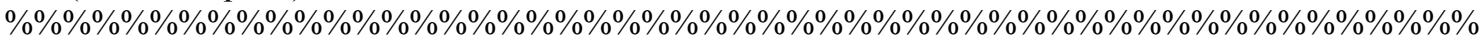

$\%$ Determinando os ângulos mínimos (extensão) da fase de apoio dos passos esquerdos

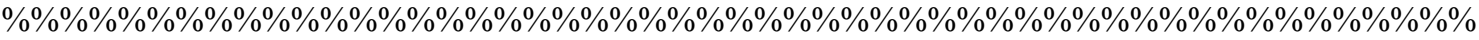

for $\mathrm{i}=1$ :length(iniesq)

$[\min$, ind $]=\min ($ GonioesqFil(iniesq(i):fimesq(i) $))$;

goniominesq(i) $=$ ind + iniesq(i) -1 ;

end

goniominE=GonioesqFil(goniominesq);

$\% \% \% \% \% \% \% \% \% \% \% \% \% \% \% \% \% \% \% \% \% \% \% \% \% \% \% \% \% \% \% \% \% \% \% \% \% \% \% \% \% \% \% \% \% \% \% \% \% \% \%$

$\%$ Determinando os ângulos mínimos (extensão) da fase de apoio dos passos direitos

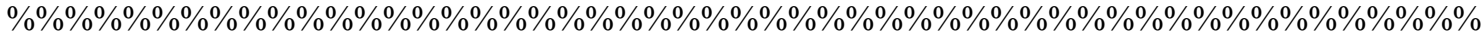

for $\mathrm{i}=1$ :length(inidir)

[min,ind $]=\min ($ GoniodirFil $(\operatorname{inidir}(\mathrm{i}): \operatorname{fimdir}(\mathrm{i})))$;

goniomindir(i) $=$ ind + inidir(i) -1 ;

end

goniomin $\mathrm{D}=$ GoniodirFil(goniomindir); 


\section{ANEXO VII Rotina LCAFRS (cont.)}

\%gráfico com os ângulos mínimos da fase de apoio dos passos esquerdos e direitos figure plot(t,GonioesqFil,'c',t(goniominesq),GonioesqFil(goniominesq),'ro') legend('Goniômetro Esq Filt', 'Ângulo Mínimo Esq') title ('Fase de Apoio')

figure plot(t,GoniodirFil,'g',t(goniomindir), GoniodirFil(goniomindir),'bo') legend('Goniômetro Dir Filt', 'Ângulo Mínimo Dir') title ('Fase de Apoio')

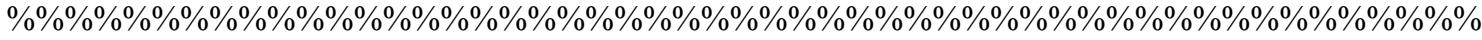
$\%$ Determinando os ângulos máximos (flexão) da fase de balanço da perna esquerda \%\% \% \% \% \% \% \% \% \% \% \% \% \% \% \% \% \% \% \% \% \% \% \% \% \% \% \% \% \% \% \% \% \% \% \% \% \% \% \% \% \% \% \% \% \% \% \% \% \% \% fimbalesq=iniesq(2:end);

inibalesq=fimesq( 1 :end-1);

for $\mathrm{i}=1$ :length(inibalesq)

[max,ind $]=\max ($ GonioesqFil(inibalesq(i):fimbalesq(i)));

goniomaxesqb(i) = ind + inibalesq(i) -1 ;

end

goniomaxEb=GonioesqFil(goniomaxesqb);

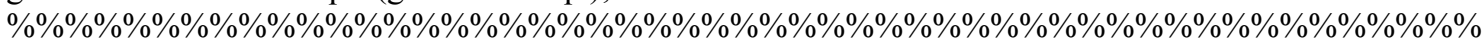

$\%$ Determinando os ângulos máximos (flexão) da fase de balanço da perna direita

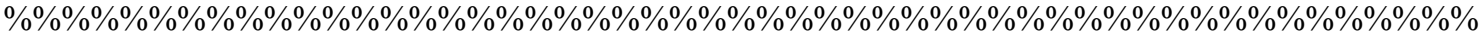
fimbaldir=inidir(2:end);

inibaldir=fimdir( 1 :end-1);

for $\mathrm{i}=1$ :length(inibaldir)

[max,ind $]=\max ($ GoniodirFil(inibaldir(i):fimbaldir(i) $))$;

goniomaxdirb(i) $=$ ind + inibaldir(i) -1 ;

end

goniomax $\mathrm{Db}=$ GoniodirFil(goniomaxdirb);

\%gráfico com os ângulos máximos da fase de balanço da perna esquerda e direita

figure

plot(t,GonioesqFil,'c',t(goniomaxesqb),GonioesqFil(goniomaxesqb),'ro')

legend('Goniômetro Esq Filt', 'Ângulo Máximo Esq')

title ('Fase de Balanço')

figure

plot(t,GoniodirFil,'g',t(goniomaxdirb),GoniodirFil(goniomaxdirb),'bo')

legend('Goniômetro Dir Filt', 'Ângulo Máximo Dir')

title ('Fase de Balanço')

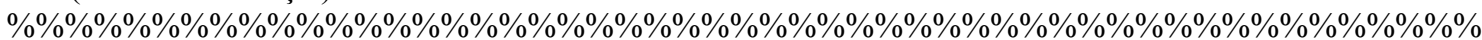

$\%$ Determinando os ângulos mínimos (flexão) da fase de balanço da perna esquerda

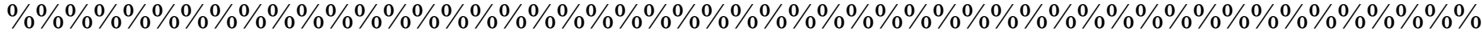
for $\mathrm{i}=1$ :length(inibalesq)

[min,ind $]=\min ($ GonioesqFil(inibalesq(i):fimbalesq(i) $))$;

goniominesqb(i) $=$ ind + inibalesq(i) -1 ;

end

goniominEb=GonioesqFil(goniominesqb);

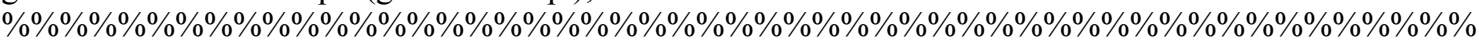

$\%$ Determinando os ângulos mínimos (flexão) da fase de balanço da perna direita

$\% \% \% \% \% \% \% \% \% \% \% \% \% \% \% \% \% \% \% \% \% \% \% \% \% \% \% \% \% \% \% \% \% \% \% \% \% \% \% \% \% \% \% \% \% \% \% \% \% \% \% \%$

for $\mathrm{i}=1$ :length(inibaldir)

$[\min$, ind $]=\min ($ GoniodirFil(inibaldir(i):fimbaldir(i) $))$;

goniomindirb(i) = ind + inibaldir(i) - 1 ;

end 


\section{ANEXO VII Rotina LCAFRS (cont.)}

goniomin $\mathrm{Db}=$ GoniodirFil(goniomindirb);

\%gráfico com os ângulos mínimos da fase de balanço da perna esquerda e direita

figure

plot(t,GonioesqFil,'c',t(goniominesqb),GonioesqFil(goniominesqb),'ro')

legend('Goniômetro Esq Filt', 'Ângulo Mínimo Esq')

title ('Fase de Balanço')

figure

plot(t,GoniodirFil,'g',t(goniomindirb),GoniodirFil(goniomindirb),'bo')

legend('Goniômetro Dir Filt', 'Ângulo Mínimo Dir')

title ('Fase de Balanço')

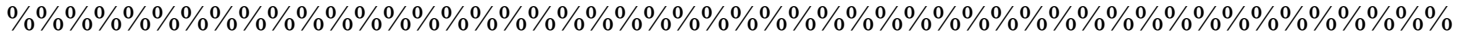

$\%$ Determinando a ADM da fase de apoio e de balanço

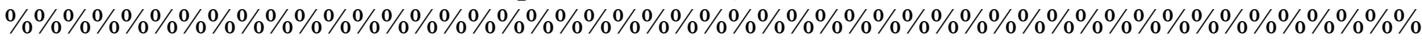

admapoioE=goniomaxE-goniominE;

admapoio $\mathrm{D}=$ goniomaxD-goniominD;

admbalE=goniomaxEb-goniominEb;

admbalD $=$ goniomaxDb-goniominDb;

$\% \% \% \% \% \% \% \% \% \% \% \% \% \% \% \% \% \% \% \% \% \% \% \% \% \% \%$

$\%$ Indice de simetria das ADMs

$\% \% \% \% \% \% \% \% \% \% \% \% \% \% \% \% \% \% \% \% \% \% \% \% \% \% \%$

[simeadmap] $=$ sime(admapoioD, 1,admapoioE,1);

[simeadmbal] $=$ sime (admbalD, 1 ,admbalE, 1$)$;

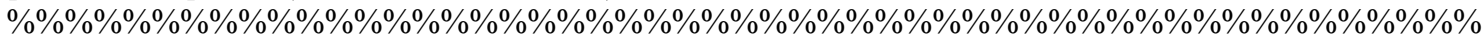

\%Salvando os resultados da rotina no bar - Primeiro e Segundo pico e vale

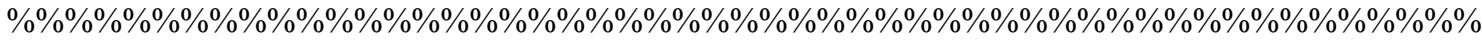

file_b $=$ [pathname,'resultados $\backslash$ ',char(file),'fyldir.dat'];

$\operatorname{disp}([$ 'Salvando ' char(file_b) ' !!'])

save(file b ,'fyldir','-ascii');

file_b=[pathname,'resultados $1^{\prime}$, char(file),'fylesq.dat'];

disp(['Salvando ' char(file_b) ' !!'])

save(file_b ,'fylesq','-ascii');

file $b=$ [pathname,'resultados $l^{\prime}$, char(file),'fy2dir.dat'];

disp(['Salvando ' char(file_b) ' !!'])

save(file_b ,'fy2dir','-ascii');

file_b=[pathname,'resultados $\left.\right|^{\prime}$, char(file),'fy2esq.dat'];

$\operatorname{disp}([$ 'Salvando ' char(file_b) ' !!'])

save(file_b ,'fy2esq','-ascii');

file_b=[pathname,'resultados $\mid$ ',char(file),'vd.dat'];

disp(['Salvando ' char(file_b) ' !!'])

save(file b ,'vd','-ascii');

file_b=[pathname,'resultados $\mid$ ',char(file),'ve.dat'];

disp(['Salvando ' char(file_b) ' !!'])

save(file_b ,'ve','-ascii');

file_b=[pathname,'resultados $\downarrow^{\prime}$, char(file),'simefy1.dat'];

disp(['Salvando ' char(file_b) ' !!'])

save(file_b ,'simefyl','-ascii');

file $b=$ [pathname,'resultados $\downarrow^{\prime}$, char(file),'simefy2.dat'];

disp(['Salvando ' char(file_b) ' !!'])

save(file_b ,'simefy2','-ascii');

file_b $=[$ pathname,'resultados $\backslash$ ',char(file),'simev.dat'];

disp(['Salvando ' char(file_b) ' !!'])

save(file_b,'simev','-ascii'); 


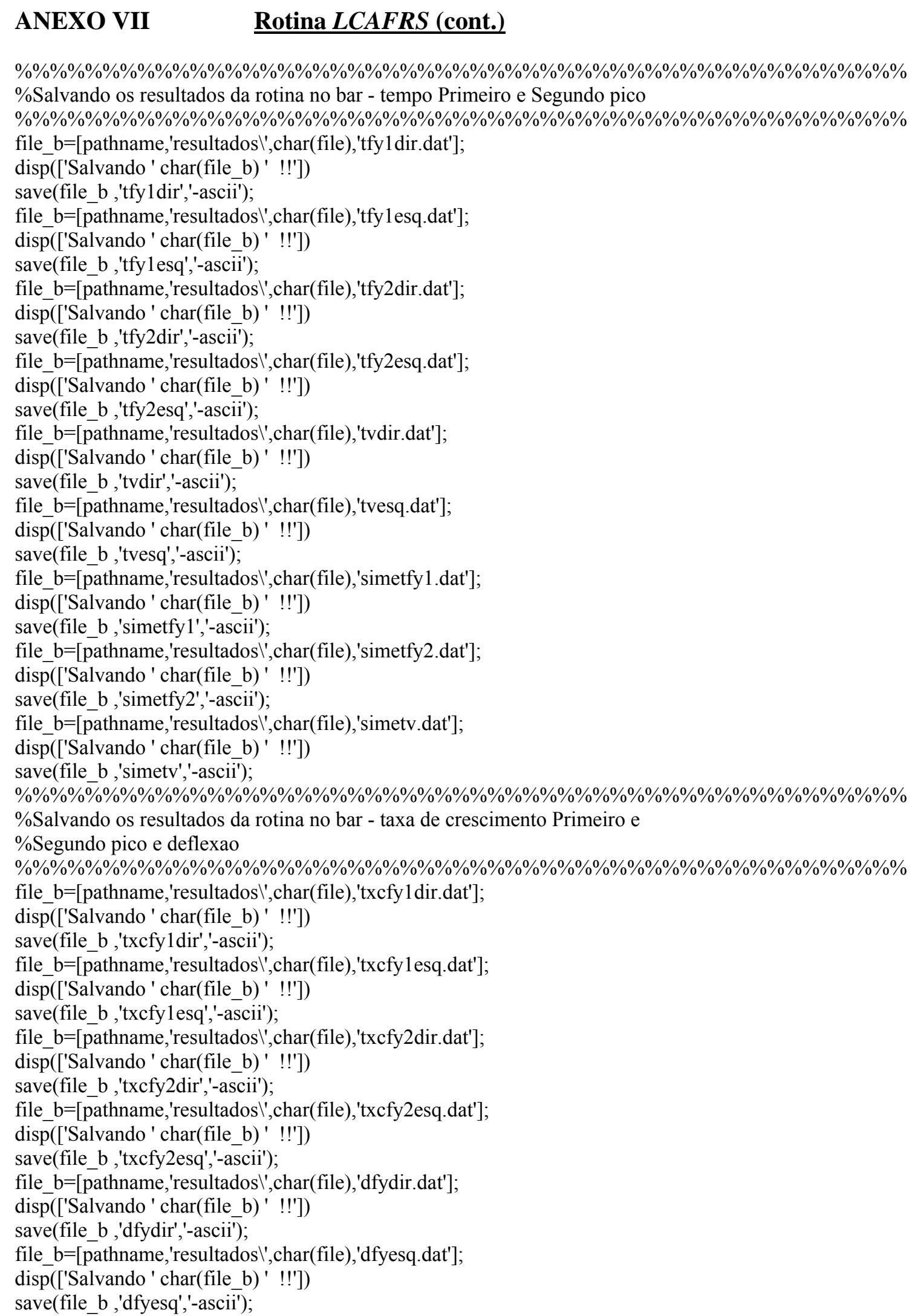




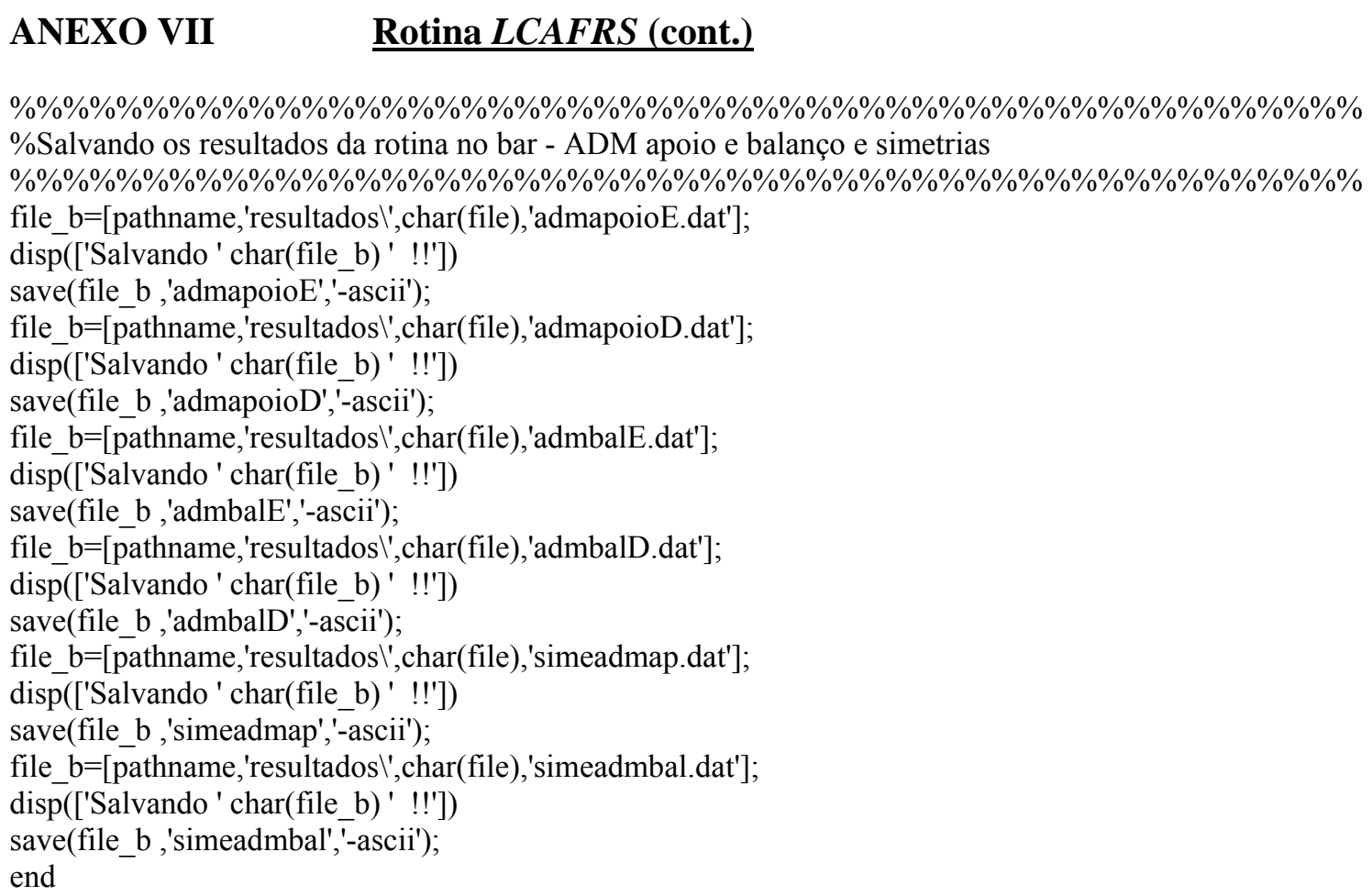




\section{ANEXO VIII $\quad$ Rotina LCAtempo}

function LCAtempo

$\%$ Rotina para análise dos parametros temporais durante coleta na esteira Gaitway

$\%$ Filtra os dados da FRS

$\%$ Determina o inicio e o fim dos passos

$\%$ Determina o tempo de apoio simples direito e esquerdo

$\%$ Determina o tempo de apoio duplo

$\%$ Determina o tempo do passo direito e esquerdo

$\%$ Determina o tempo da passada direita e esquerda

$\%$ Utiliza a funcao inifim

\%Cláudia Silveira Lima

$\%$ maio 2005

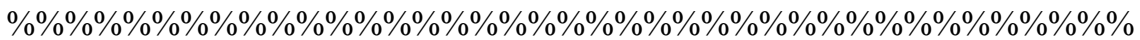

$\%$ Abrir os arquivos a serem trabalhados

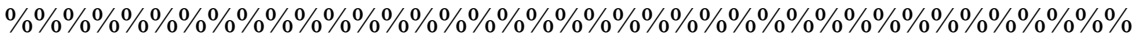

[filename, pathname] = uigetfiles('*.txt', 'Selecione os arquivos');

$\operatorname{disp}($ ' '),disp(' Abrindo os arquivos...')

nfile=length(filename);

nlado=input('Entre com o joelho acometido: 1 para Dir; 2 para Esq: ');

npeso=input(' Entre com a massa do sujeito: ');

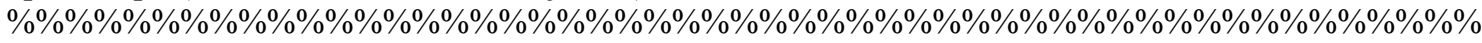

$\%$ Indica que a partir daqui todos os comandos devem ser refeitos para cada arquivo do sujeito

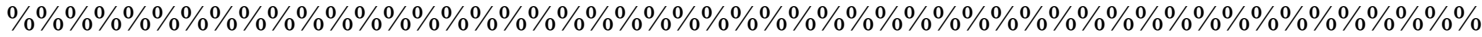

for $\mathrm{i}=1$ :nfile

file $=$ char(filename(i));

data $=\operatorname{load}($ file $)$

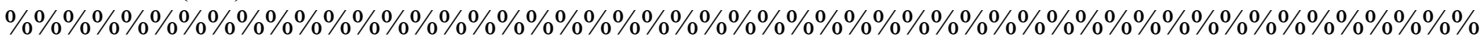

$\%$ informações do que corresponde as colunas do arquivo txt (neste caso coluna $1,2,3$ )

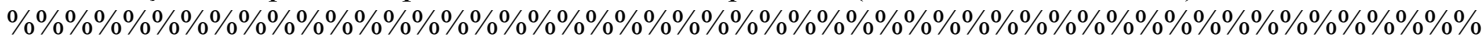

if nlado $==1$

$\mathrm{t}=$ data(:,1);Fesq=data(:,2); Fdir=data(:,3);

end

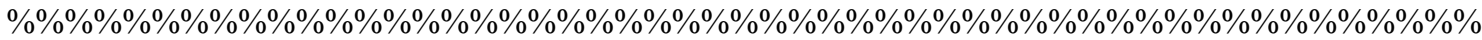

$\%$ Modificar os dados do sujeito que tem o joelho Esquerdo operado

\%\% \% \% \% \% \% \% \% \% \% \% \% \% \% \% \% \% \% \% \% \% \% \% \% \% \% \% \% \% \% \% \% \% \% \% \% \% \% \% \% \% \% \% \% \% \% \%

if nlado $==2$

$\mathrm{t}=\operatorname{data}(:, 1) ; \mathrm{Fesq}=\mathrm{data}(:, 3) ; \mathrm{Fdir}=\operatorname{data}(:, 2)$;

end

\%\%\%\%\%\%\%\%\%\%\%\%\%\%\%\%\%\%\%\%\%\%\%\%\%\%\%\%\%\%\%\%\%\%\%\%\%\%\%\%\%\%\%\%\%\%\%\%\%\%\%\%\% $\%$ passando o filtro de $100 \mathrm{~Hz}(10 \mathrm{~Hz})$ nos dados da FRS pé esquerdo e direito

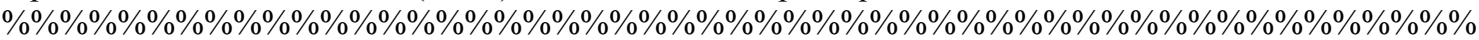
$[\mathrm{b}, \mathrm{a}]=\operatorname{butter}(4,10 /(1000 / 2))$;

FesqFil=filtfilt(b,a,Fesq);

FdirFil=filtfilt(b,a,Fdir);

\%criando o gráfico com os dados da FRS bruta e filtrado

figure

plot(t,FesqFil,'r',t,FdirFil,'b')

legend('FRS Esq Filt', 'FRS Dir Filt')

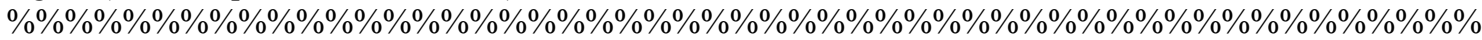

$\%$ Normalizando os dados da FRS pelo peso corporal de cada sujeito

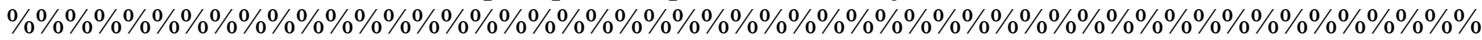

FesqFil $=($ FesqFil $/($ npeso*10) $)$;

FdirFil $=($ FdirFil/(npeso*10) $)$; 
ANEXO VIII

Rotina LCAtempo (cont.)

figure

plot(t,FesqFil,'r',t,FdirFil,'b')

legend('FRS Esq Filt', 'FRS Dir Filt')

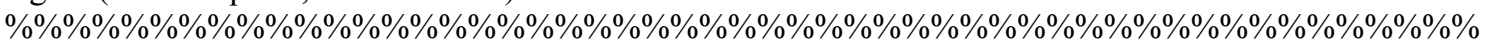

$\%$ Determinando o inicio e o fim do passo esquerdo e direito

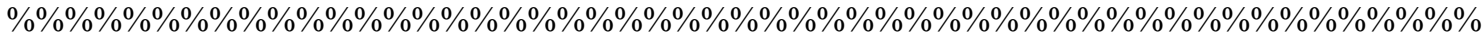

[iniesq,fimesq] = inifim(FesqFil,1,0.07,250);

inifimesq=[iniesq;fimesq].';

figure \%gráfico com os dados da FRS filtrado com inicio e fim lado esquerdo

plot(t,FesqFil,t(iniesq),FesqFil(iniesq), ${ }^{\prime \wedge}$, ,t(fimesq),FesqFil(fimesq), ,^^)

legend('FRS Esquerdo', 'Inicio do passo', 'Fim do passo')

[inidir,fimdir] $=$ inifim $($ FdirFil, 1,0.07,250);

inifimdir=[inidir;fimdir].';

figure \%gráfico com os dados da FRS filtrado com inicio e fim lado direito

plot(t,FdirFil,t(inidir),FdirFil(inidir), ${ }^{\prime \prime \prime}, t\left(\right.$ fimdir),FdirFil(fimdir), ${ }^{\prime \wedge}$ ')

legend('FRS Direito', 'Inicio do passo', 'Fim do passo')

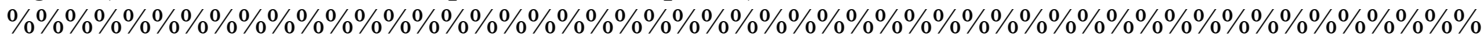

$\%$ Determinando o tempo de apoio simples do passo Direito

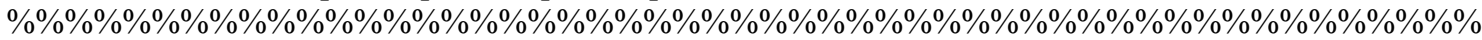
tinidir $=$ data(inidir, 1$)$;

tiniesq $=$ data(iniesq, 1$)$;

tfimdir=data(fimdir, 1$)$;

tfimesq=data(fimesq, 1$)$;

tapoiodir=tiniesq(2:end)-tfimesq(1:end-1);

mtapoiodir $=$ mean(tapoiodir);

std(tapoiodir, 0,2$)$;

cvtapoiodir $=(\operatorname{std}($ tapoiodir $) /$ mean(tapoiodir $))^{*} 100$

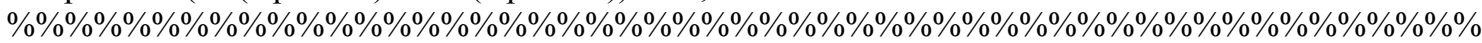

$\%$ Determinando o tempo de apoio simples do passo Esquerdo

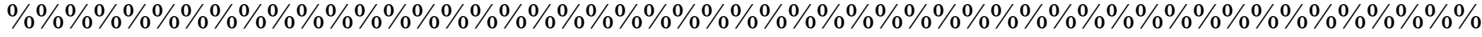
tapoioesq=tinidir(2:end)-tfimdir(1:end-1);

mtapoioesq $=$ mean $(\operatorname{tapoioesq})$;

std(tapoioesq, 0,2$)$;

cvtapoioesq $=(\operatorname{std}(\operatorname{tapoioesq}) /$ mean $($ tapoioesq $)) * 100$;

\%\% \% \% \% \% \% \% \% \% \% \% \% \% \% \% \% \% \% \% \% \% \% \% \% \% \% \% \% \% \% \% \% \% \% \% \% \% \% \% \% \% \% \% \% \% \% \% \%

$\%$ Indice de simetria do tempo de apoio direito

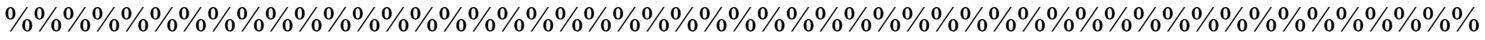

[simetapoio] $=$ sime(tapoiodir, 1 ,tapoioesq, 1 );

$\% \% \% \% \% \% \% \% \% \% \% \% \% \% \% \% \% \% \% \% \% \% \% \% \% \% \% \% \% \% \% \% \% \% \%$

$\%$ Determinando o tempo de apoio duplo

$\% \% \% \% \% \% \% \% \% \% \% \% \% \% \% \% \% \% \% \% \% \% \% \% \% \% \% \% \% \% \% \% \% \% \%$

if tiniesq $(1,1)<\operatorname{tinidir}(1,1) \&$ tfimesq(end, 1$)<$ tfimdir(end, 1$)$

for $\mathrm{i}=$ tfimesq( 1 :end $)$;

$\mathrm{j}=\operatorname{tinidir}(1$ :end $)$;

if $\mathrm{i}>\mathrm{j} \&(\mathrm{i}-\mathrm{j})<0.6$;

tapoioduplo $1=\mathrm{i}-\mathrm{j}$;

tapoioduploa $=[$ tapoioduplo1]

end

end

for $\mathrm{i}=$ tfimdir(1:end-1);

$\mathrm{j}=$ tiniesq $(2$ :end $)$;

if $\mathrm{i}>\mathrm{j} \&(\mathrm{i}-\mathrm{j})<0.6$;

tapoioduplo $2=\mathrm{i}-\mathrm{j}$;

tapoioduplob $=[$ tapoioduplo2 $]$ 
ANEXO VIII

Rotina LCAtempo (cont.)

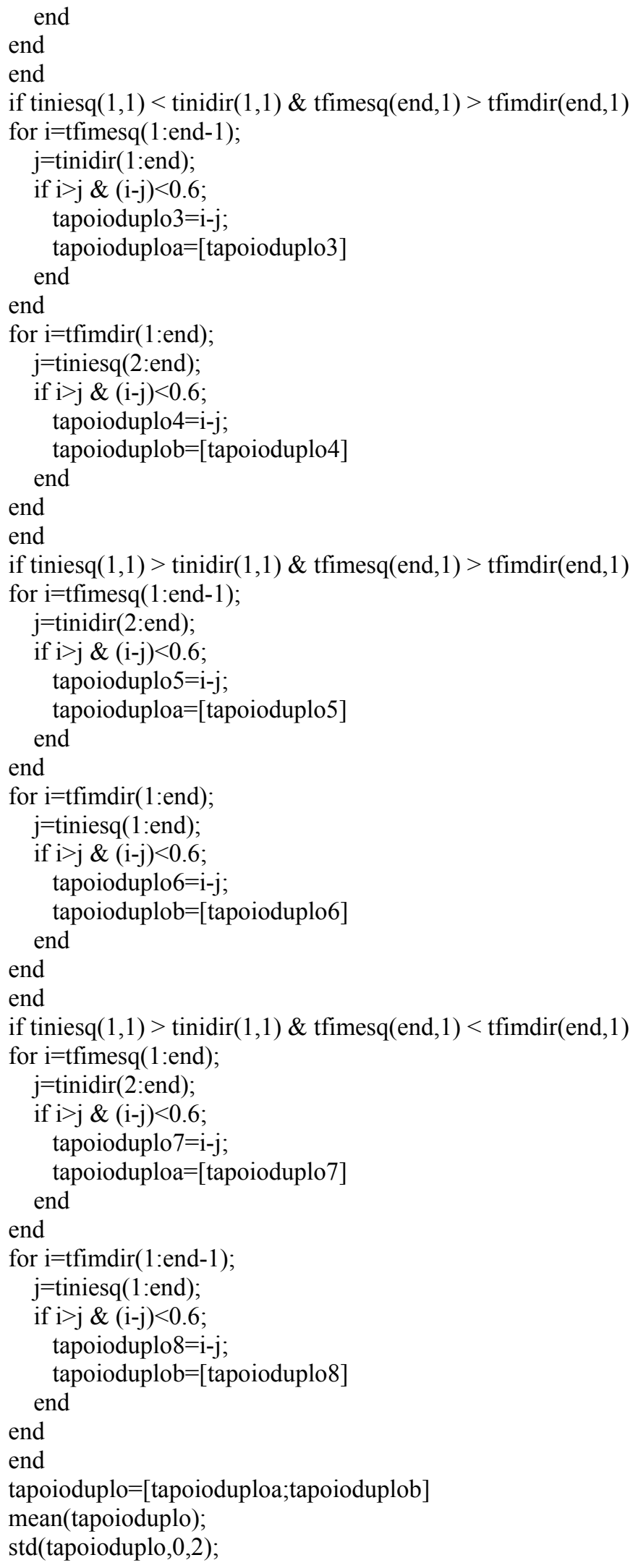


ANEXO VIII Rotina LCAtempo (cont.)

cvtapoioduplo $=(\operatorname{std}($ tapoioduplo $) /$ mean $($ tapoioduplo $)) * 100$;

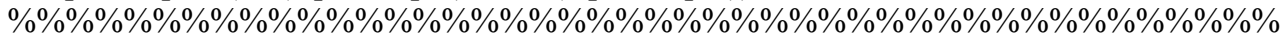

$\%$ Determinando o tempo total de apoio Direito

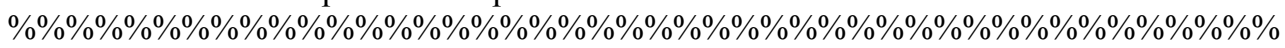
tpassodir=tfimdir(1:end)-tinidir(1:end);

mtpassodir $=$ mean (tpassodir);

std(tpassodir,0,2);

cvtpassodir $=($ std(tpassodir $) /$ mean(tpassodir $)) * 100$;

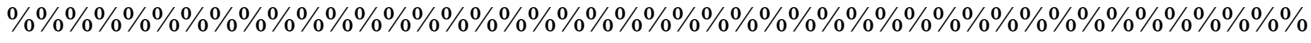

$\%$ Determinando o tempo total de apoio Esquerdo

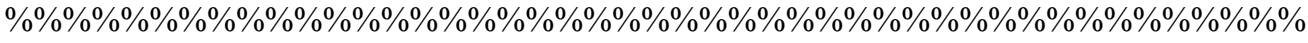

tpassoesq=tfimesq( 1 :end)-tiniesq( $1:$ end $)$;

mtpassoesq=mean(tpassoesq);

$\operatorname{std}($ tpassoesq, 0,2$)$;

cvtpassoesq $=(\operatorname{std}($ tpassoesq $) /$ mean $($ tpassoesq $)) * 100$

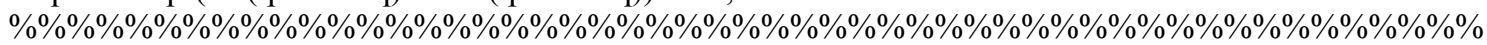

$\%$ Indice de simetria do tempo do passo

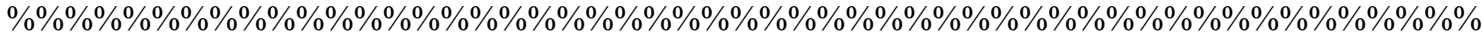

[simetpasso] = sime(tpassodir, 1, tpassoesq,1);

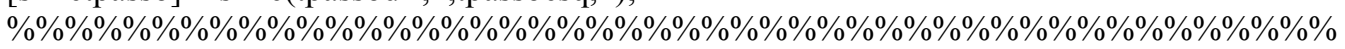

$\%$ Determinando o tempo total da passada Direita

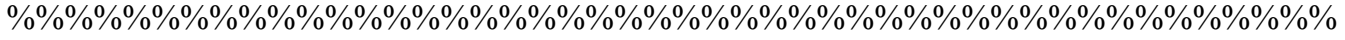

if tiniesq $(1,1)<\operatorname{tinidir}(1,1) \&$ tfimesq(end,1) $<$ tfimdir(end,1)

for $\mathrm{i}=$ tfimesq( 2 :end);

$\mathrm{j}=\operatorname{tinidir}(1$ :end-1);

tpassadadir $=\mathrm{i}-\mathrm{j}$;

tpassadadir $1=[$ tpassadadir $]$

end

end

if tiniesq $(1,1)<\operatorname{tinidir}(1,1) \&$ tfimesq(end,1) $>$ tfimdir(end, 1$)$

for $\mathrm{i}=$ tfimesq(2:end);

$\mathrm{j}=\operatorname{tinidir}(1$ :end);

tpassadadir $=\mathrm{i}-\mathrm{j}$;

tpassadadir $2=[$ tpassadadir $]$

end

end

if tiniesq $(1,1)>\operatorname{tinidir}(1,1) \& \operatorname{tfimesq}(\mathrm{end}, 1)>\operatorname{tfimdir}(\mathrm{end}, 1)$

for $\mathrm{i}=\mathrm{tfimesq}(1$ :end $)$;

$\mathrm{j}=\operatorname{tinidir}(1:$ end $)$;

tpassadadir $=\mathrm{i}-\mathrm{j}$;

tpassadadir $3=[$ tpassadadir $]$

end

end

if tiniesq $(1,1)>\operatorname{tinidir}(1,1) \&$ tfimesq(end, 1$)<$ tfimdir(end, 1$)$

for $\mathrm{i}=\mathrm{tfimesq}(1$ :end $)$;

$\mathrm{j}=\operatorname{tinidir}(1$ :end -1$)$;

tpassadadir $=\mathrm{i}-\mathrm{j}$;

tpassadadir4 $=[$ tpassadadir $]$

end

end

mtpassadadir $=$ mean(tpassadadir);

std(tpassadadir, 0,2);

cvtpassadadir $=(\operatorname{std}($ tpassadadir $) /$ mean $($ tpassadadir $)) * 100$; 


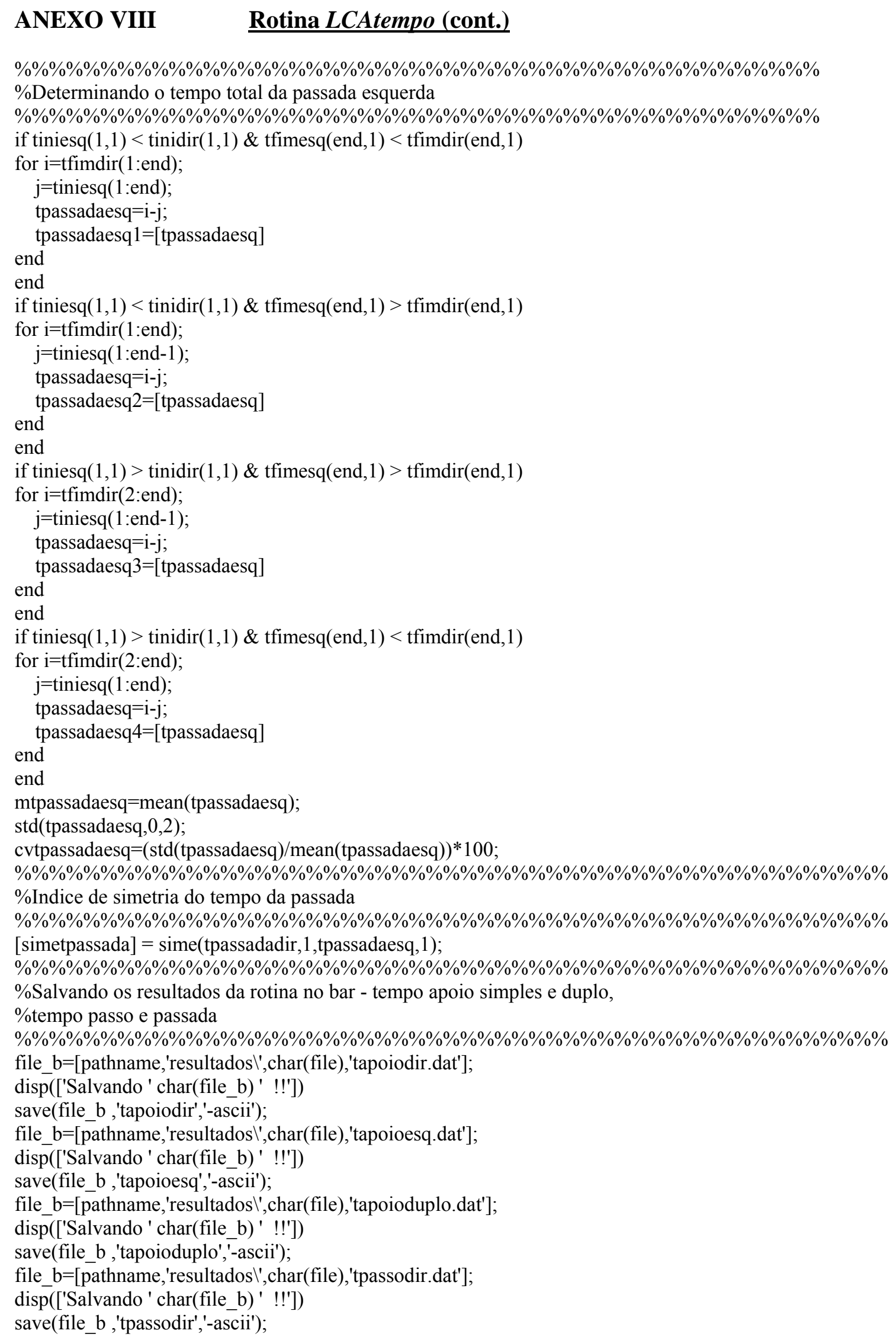


ANEXO VIII

Rotina LCAtempo (cont.)

file_b=[pathname,'resultadosl',char(file),'tpassoesq.dat'];

disp(['Salvando ' char(file_b) ' !!'])

save(file_b ,'tpassoesq','-ascii');

file_b=[pathname,'resultados '',char(file),'tpassadadir.dat'];

disp(['Salvando ' char(file_b) ' !!'])

save(file_b ,'tpassadadir','-ascii');

file_b=[pathname,'resultados $\mid$ ',char(file),'tpassadaesq.dat'];

disp(['Salvando ' char(file_b) ' !!'])

save(file b ,'tpassadaesq','-ascii');

file_b=[pathname,'resultados $\mid$ ',char(file),'simetapoio.dat'];

disp(['Salvando ' char(file_b) ' !!'])

save(file_b ,'simetapoio','-ascii');

file_b=[pathname,'resultados $\mid$ ',char(file),'simetpasso.dat'];

disp(['Salvando ' char(file_b) ' !!'])

save(file_b ,'simetpasso','-ascii');

file_b=[pathname,'resultados' ',char(file),'simetpassada.dat'];

disp(['Salvando ' char(file_b) ' !!'])

save(file_b ,'simetpassada','-ascii');

end 


\section{ANEXO IX $\quad$ Rotina LCAcomprimento}

function LCAcomprimento

$\%$ Rotina para análise dos parametros espaciais durante coleta na esteira Gaitway

$\%$ Filtra os dados da FRS

$\%$ Determina o inicio e o fim dos passos

$\%$ Determina o comprimento do passo direito e esquerdo

$\%$ Determina o comprimento da passada direita e esquerda

$\%$ Utiliza a funcao inifim

\%Cláudia Silveira Lima

$\%$ Maio 2005

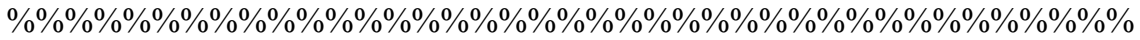

$\%$ Abrir os arquivos a serem trabalhados

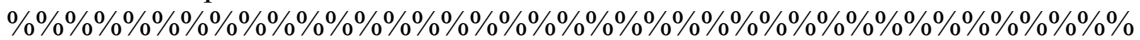

[filename, pathname] = uigetfiles('*.txt', 'Selecione os arquivos');

$\operatorname{disp}($ ' '), disp(' Abrindo os arquivos...')

nfile=length(filename);

nlado=input('Entre com o joelho acometido: 1 para Dir; 2 para Esq: ');

npeso=input(' Entre com a massa do sujeito: ');

nvelocidade=input('Entre com a velocidade do sujeito durante a marcha: ');

naltura $=$ input('Entre com a estatura do sujeito: ');

$\% \% \% \% \% \% \% \% \% \% \% \% \% \% \% \% \% \% \% \% \% \% \% \% \% \% \% \% \% \% \% \% \% \% \% \% \% \% \% \% \% \% \% \% \% \% \% \% \% \% \% \%$

$\%$ Indica que a partir daqui todos os comandos devem ser refeitos para cada arquivo do sujeito

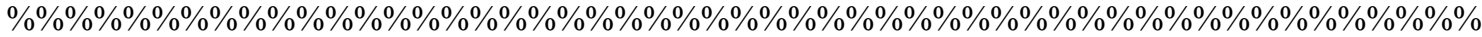

for $\mathrm{i}=1$ :nfile

file $=$ char(filename(i));

data $=\operatorname{load}($ file $)$;

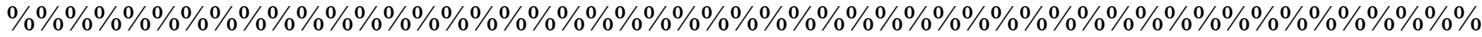

$\%$ informações do que corresponde as colunas do arquivo txt (neste caso coluna $1,2,3$ )

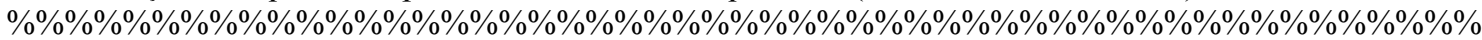

if nlado $==1$

$\mathrm{t}=$ data(:,1);Fesq=data(:,2); Fdir=data(:,3);

end

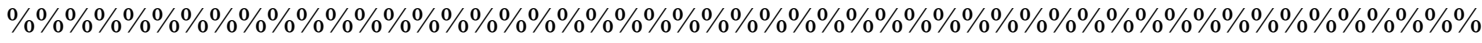

$\%$ Modificar os dados do sujeito que tem o joelho Esquerdo operado

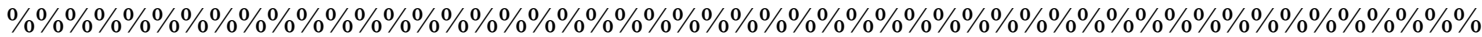

if nlado $==2$

$\mathrm{t}=\operatorname{data}(:, 1) ; \mathrm{Fesq}=\operatorname{data}(:, 3) ; \mathrm{Fdir}=\operatorname{data}(:, 2)$;

end

\%\%\%\%\%\%\%\%\%\%\%\%\%\%\%\%\%\%\%\%\%\%\%\%\%\%\%\%\%\%\%\%\%\%\%\%\%\%\%\%\%\%\%\%\%\%\%\%\%\%\%\%\% $\%$ passando o filtro de $100 \mathrm{~Hz}(10 \mathrm{~Hz})$ nos dados da FRS pé esquerdo e direito

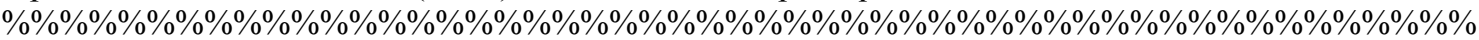
$[\mathrm{b}, \mathrm{a}]=\operatorname{butter}(4,10 /(1000 / 2))$;

FesqFil=filtfilt(b,a,Fesq);

FdirFil=filtfilt(b,a,Fdir);

\%criando o gráfico com os dados da FRS bruta e filtrado

figure

plot(t,FesqFil,'r',t,FdirFil,'b')

legend('FRS Esq Filt', 'FRS Dir Filt')

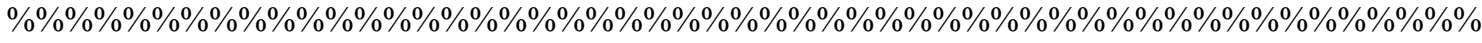

$\%$ Normalizando os dados da FRS pelo peso corporal de cada sujeito

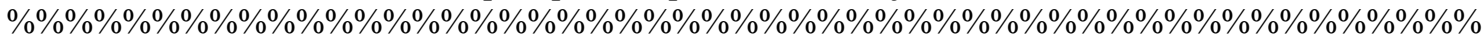

FesqFil $=($ FesqFil/(npeso*10));

FdirFil $=($ FdirFil/(npeso*10)); 
ANEXO IX Rotina LCAcomprimento (cont.)

$\% \% \% \% \% \% \% \% \% \% \% \% \% \% \% \% \% \% \% \% \% \% \% \% \% \% \% \% \% \% \% \% \% \% \% \% \% \% \% \% \% \% \% \% \% \% \% \% \% \% \% \%$ $\%$ Determinando o inicio e o fim do passo esquerdo e direito

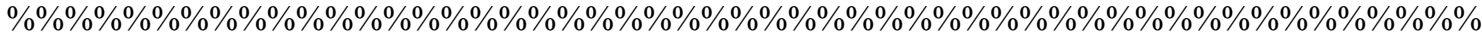
[iniesq,fimesq] $=$ inifim(FesqFil,1,0.07,250);

inifimesq=[iniesq;fimesq].';

figure \%gráfico com os dados da FRS filtrado com inicio e fim lado esquerdo

plot(t,FesqFil,t(iniesq),FesqFil(iniesq), ${ }^{\prime \wedge},, t\left(\right.$ fimesq),FesqFil(fimesq), ${ }^{\prime \wedge}$ ')

legend('FRS Esquerdo', 'Inicio do passo', 'Fim do passo')

[inidir,fimdir] = inifim(FdirFil,1,0.07,250);

inifimdir=[inidir;fimdir].';

figure \%gráfico com os dados da FRS filtrado com inicio e fim lado direito

plot(t,FdirFil,t(inidir),FdirFil(inidir), ${ }^{\prime \wedge \prime}, t\left(\right.$ fimdir),FdirFil(fimdir), ${ }^{\prime \wedge}$ )

legend('FRS Direito', 'Inicio do passo', 'Fim do passo')

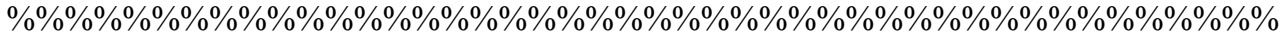

$\%$ Determinando o tempo total de apoio Direito

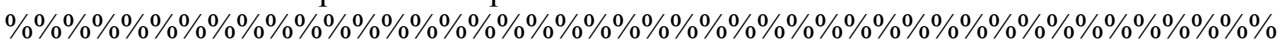

tinidir $=$ data(inidir, 1$)$;

tiniesq $=$ data(iniesq, 1$)$;

tfimdir=data(fimdir,1);

tfimesq=data(fimesq, 1 );

tpassodir=tfimdir(1:end)-tinidir(1:end);

mtpassodir $=$ mean(tpassodir);

std(tpassodir, 0,2$)$;

cvtpassodir $=($ std(tpassodir $) /$ mean $($ tpassodir $)) * 100$;

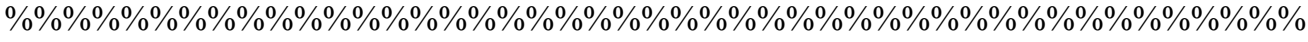

$\%$ Determinando o tempo total de apoio Esquerdo

\%\% \% \% \% \% \% \% \% \% \% \% \% \% \% \% \% \% \% \% \% \% \% \% \% \% \% \% \% \% \% \% \% \% \% \% \% \% \% \% \% \%

tpassoesq=tfimesq( 1 :end)-tiniesq( 1 :end);

mtpassoesq $=$ mean (tpassoesq);

std(tpassoesq, 0,2);

cvtpassoesq $=(\operatorname{std}($ tpassoesq $) /$ mean $($ tpassoesq $)) * 100$;

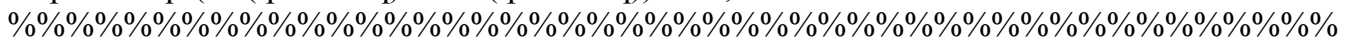

$\%$ Determinando o tempo total da passada Direita

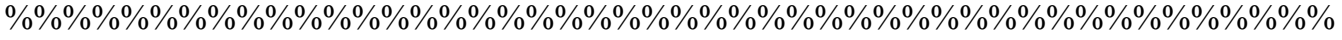

if tiniesq $(1,1)<\operatorname{tinidir}(1,1) \&$ tfimesq(end,1) $<$ tfimdir(end, 1$)$

for $\mathrm{i}=\operatorname{tfimesq}(2$ :end);

$\mathrm{j}=\operatorname{tinidir}(1:$ end -1$)$;

tpassadadir $=\mathrm{i}-\mathrm{j}$;

tpassadadir $1=[$ tpassadadir $]$

end

end

if tiniesq $(1,1)<\operatorname{tinidir}(1,1) \&$ tfimesq(end,1) $>$ tfimdir(end, 1$)$

for $\mathrm{i}=$ tfimesq(2:end);

$\mathrm{j}=\operatorname{tinidir}(1:$ end $)$;

tpassadadir $=\mathrm{i}-\mathrm{j}$;

tpassadadir $2=[$ tpassadadir $]$

end

end

if tiniesq $(1,1)>\operatorname{tinidir}(1,1) \& \operatorname{tfimesq}($ end, 1$)>\operatorname{tfimdir}(\mathrm{end}, 1)$

for $\mathrm{i}=$ tfimesq $(1$ :end $)$;

$\mathrm{j}=\operatorname{tinidir}(1:$ end $)$;

tpassadadir $=\mathrm{i}-\mathrm{j}$;

tpassadadir $3=[$ tpassadadir $]$

end 
ANEXO IX

Rotina LCAcomprimento (cont.)

end

if tiniesq(1,1) > tinidir(1,1) \& tfimesq(end,1) $<$ tfimdir(end,1)

for $\mathrm{i}=$ tfimesq $(1$ :end $)$;

$\mathrm{j}=\operatorname{tinidir}(1:$ end-1);

tpassadadir $=\mathrm{i}-\mathrm{j}$;

tpassadadir4 $=$ [tpassadadir $]$

end

end

mtpassadadir $=$ mean(tpassadadir);

std(tpassadadir,0,2);

cvtpassadadir $=($ std(tpassadadir $) /$ mean(tpassadadir $) * 100$;

\%\% \% \% \% \% \% \% \% \% \% \% \% \% \% \% \% \% \% \% \% \% \% \% \% \% \% \% \% \% \% \% \% \% \% \% \% \% \% \% \% \% \% \% \% \% $\%$

$\%$ Determinando o tempo total da passada esquerda

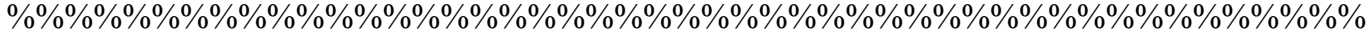

if tiniesq $(1,1)<\operatorname{tinidir}(1,1) \&$ tfimesq(end,1) $<$ tfimdir(end,1)

for $i=$ tfimdir( 1 :end);

$\mathrm{j}=\operatorname{tiniesq}(1$ :end $)$;

tpassadaesq $=\mathrm{i}-\mathrm{j}$;

tpassadaesq $1=[$ tpassadaesq $]$

end

end

if tiniesq $(1,1)<\operatorname{tinidir}(1,1) \&$ tfimesq(end,1) $>$ tfimdir(end, 1$)$

for $\mathrm{i}=$ tfimdir( 1 :end);

$\mathrm{j}=\operatorname{tiniesq}(1$ :end-1);

tpassadaesq $=\mathrm{i}-\mathrm{j}$;

tpassadaesq $2=[$ tpassadaesq $]$

end

end

if tiniesq $(1,1)>\operatorname{tinidir}(1,1) \&$ tfimesq(end, 1$)>\operatorname{tfimdir}(\mathrm{end}, 1)$

for $\mathrm{i}=$ tfimdir(2:end);

$\mathrm{j}=\operatorname{tiniesq}(1$ :end -1$)$;

tpassadaesq $=\mathrm{i}-\mathrm{j}$;

tpassadaesq $3=$ [tpassadaesq $]$

end

end

if tiniesq $(1,1)>\operatorname{tinidir}(1,1) \& \operatorname{tfimesq}(\mathrm{end}, 1)<\operatorname{tfimdir}(\mathrm{end}, 1)$

for $\mathrm{i}=$ tfimdir(2:end);

$\mathrm{j}=\operatorname{tiniesq}(1$ :end $)$;

tpassadaesq $=\mathrm{i}-\mathrm{j}$;

tpassadaesq $4=[$ tpassadaesq $]$

end

end

mtpassadaesq $=$ mean $($ tpassadaesq);

std(tpassadaesq,0,2);

cvtpassadaesq $=(\operatorname{std}($ tpassadaesq $) /$ mean $($ tpassadaesq $) * 100$;

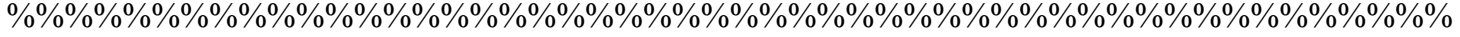

$\%$ Determinando comprimento do passo e passada D e E

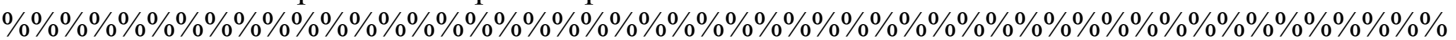

velocidade $=($ nvelocidade $/ 3.6)$

compassoD $=($ velocidade.$*$ tpassodir $)$;

compassoE $=\left(\right.$ velocidade ${ }^{*}$ tpassoesq $)$;

compassada $\mathrm{D}=($ velocidade. $*$ tpassadadir $)$;

compassadaE $=\left(\right.$ velocidade ${ }^{*}$ tpassadaesq $)$; 
ANEXO IX Rotina LCAcomprimento (cont.)

$\% \% \% \% \% \% \% \% \% \% \% \% \% \% \% \% \% \% \% \% \% \% \% \% \% \% \% \% \% \% \% \% \% \% \% \% \% \% \% \% \% \% \% \% \% \% \% \% \% \% \%$ $\%$ Normalizando os dados do comprimento pela estatura de cada sujeito

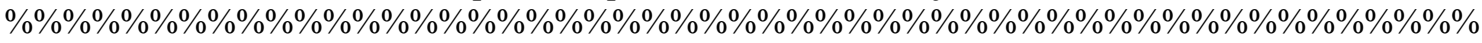
compassoDn $=($ compassoD. $/$ naltura $)$;

compassoEn $=($ compassoE./naltura);

compassadaDn $=($ compassadaD./naltura $)$;

compassadaEn $=($ compassadaE./naltura);

\%\% \% \% \% \% \% \% \% \% \% \% \% \% \% \% \% \% \% \% \% \% \% \% \% \% \% \% \% \% \% \% \% \% \% \% \% \% \% \% \% \% \% \% \% \% \% \% \% \% \% \%

$\%$ Indice de simetria dos comprimentos passo e passada

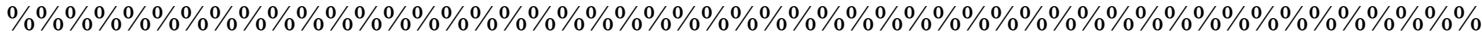

[simecompasso] $=$ sime (compassoD,1,compassoE,1);

[simecompassada] $=$ sime $($ compassadaD, 1, compassadaE, 1$)$;

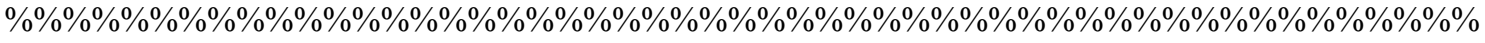

$\%$ Salvando os resultados da rotina no bar - Primeiro e Segundo pico e vale

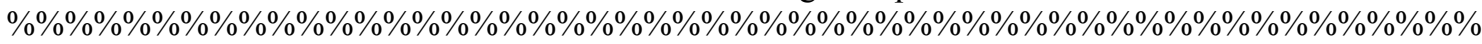

file $\mathrm{b}=$ [pathname,'resultados'',char(file),'compassoDn.dat'];

disp(['Salvando ' char(file b) ' !!'])

save(file_b ,'compassoDn','-ascii');

file_b=[pathname,'resultados $\backslash$ ',char(file),'compassoEn.dat'];

$\operatorname{disp}([$ 'Salvando ' char(file_b) ' !!'])

save(file b ,'compassoEn','-ascii');

file_b $=[$ pathname,'resultados $\backslash$ ',char(file),'compassadaDn.dat'];

disp(['Salvando ' char(file_b) ' !!'])

save(file_b ,'compassadaDn','-ascii');

file_b $=[$ pathname,'resultados $\backslash$ ',char(file),'compassadaEn.dat'];

disp(['Salvando ' char(file_b) ' !!'])

save(file_b ,'compassadaEn','-ascii');

file_b=[pathname,'resultados $\backslash$ ', char(file),'simecompasso.dat'];

disp(['Salvando ' char(file_b) ' !!'])

save(file_b ,'simecompasso','-ascii');

file_ $b=$ [pathname,'resultados $\backslash$ ',char(file),'simecompassada.dat'];

disp(['Salvando ' char(file b) ' !!'])

save(file_b,'simecompassada','-ascii');

end 